\title{
Benin: Poverty Reduction Strategy Paper- Growth Strategy for Poverty Reduction
}

Poverty Reduction Strategy Papers (PRSPs) are prepared by member countries in broad consultation with stakeholders and development partners, including the staffs of the World Bank and the IMF. Updated every three years with annual progress reports, they describe the country's macroeconomic, structural, and social policies in support of growth and poverty reduction, as well as associated external financing needs and major sources of financing. This country document for Benin, dated April 2007, is being made available on the IMF website by agreement with the member country as a service to users of the IMF website.

Copies of this report are available to the public from

International Monetary Fund • Publication Services

$70019^{\text {th }}$ Street, N.W. • Washington, D.C. 20431

Telephone: (202) 623-7430 • Telefax: (202) 623-7201

E-mail: publications@imf.org • Internet: http://www.imf.org

Price: $\$ 18.00$ a copy

\section{International Monetary Fund Washington, D.C.}





\section{REPUBLIC OF BENIN}

\section{GROWTH STRATEGY FOR POVERTY REDUCTION}




\section{ABBREVIATIONS AND ACRONYMS}

AFD

$\mathrm{AfDF}$

ANCB

APRM

ARI

AU

BCEAO

BenInfo

BGE

BOA

BOT

BRVM

BTP

CAA

CCIB

CCS

CDS

CEB

CEBENOR

CNB

CND

$\mathrm{CNE}$

CNDLP

CNPB

$\mathrm{CNS}$

CSA

CSC

CWIQ

DANIDA

DAT

DEPOLIPO

DEPONAT

DOTS

DPP

DPS

DSD

DSO

ECI

ECOWAS

ECVR

EDS

EFA

ELAM

EMICoV

ENOC
French Development Agency

African Development Fund

National Association of Communes of Benin

African Peer Review Mechanism

Acute Respiratory Infections

African Union

Central Bank of West African States

Beninese socioeconomic database

General Government budget

Bank of Africa

Built, Operate and Transfer

Regional Securities Exchange

Construction and Public Works

Autonomous Amortization Fund

Chamber of Commerce and Industry of Benin

Municipal Monitoring Committee

Departmental Monitoring Committees

Beninese Electricity Community

Benin Center for Standardization and Quality Management

National Budget Committee

National Deconcentration Committee

National Debt Committee

National Commission for Development and Combating Poverty

Beninese Employers Federation

National Statistics Council

Arrondissement Health Center

Municipal Health Center

Core Welfare Indicators Questionnaire

Danish International Development Agency

Land Management Delegation

Declaration of Population Policy

Declaration of National Land Management Policy

Directly Observed Therapy Short Course

Planning and Forecasting Directorate

Strategic Planning Directorate

Social Dimension of Development

Operational Strategy Document

Investment Climate Survey

Economic Community of West African States

Survey of Living Conditions of Rural Households

Demographic and Health Survey

Education For All

Short Household Survey

Integrated Modular Survey on Household Living Conditions

Emergency Neonatal Obstetric Care 


\begin{tabular}{|c|c|}
\hline FAO & United Nations Food and Agriculture Organization \\
\hline FDI & Foreign Direct Investment \\
\hline FECECAM & Federation of Credit Unions and Mutual Farm Credit Organizations \\
\hline FIAT & Town and Regional Planning Incentive Fund \\
\hline FRIDC & ECOWAS Regional Investment and Development Fund \\
\hline GDP & Gross Domestic Product \\
\hline GER & Gross Enrollment Ratio \\
\hline HDI & Human Development Indicator \\
\hline HIPC & Heavily Indebted Poor Countries \\
\hline HIPC & Heavily Indebted Poor Countries Initiative \\
\hline HIV/AIDS & Human Immunodeficiency Virus/Acquired Immune Deficiency Syndrome \\
\hline HPI & Human Poverty Index \\
\hline ICAO & International Civil Aviation Organization \\
\hline ICMR & Infant/Child Mortality Rate \\
\hline IDA & International Development Association \\
\hline IFAD & International Fund for Agricultural Development \\
\hline IMF & International Monetary Fund \\
\hline IMR & Infant Mortality Rate \\
\hline INSAE & National Institute for Statistics and Economic Analysis \\
\hline IsDB & Islamic Development Bank \\
\hline ITC & Information and Communications Technologies \\
\hline MAEP & Ministry of Agriculture, Livestock and Fisheries \\
\hline MDCTTP & Ministry Responsible for Public Works and Transport \\
\hline MDEF & Ministry of Development, the Economy, and Finance \\
\hline MDG & Millennium Development Goals \\
\hline MEPS & Ministry of Primary and Secondary Education \\
\hline MMR & Maternal Mortality Rate \\
\hline MS & Ministry of Health \\
\hline MSP & Ministry of Public Health \\
\hline MTEF & Medium-Term Expenditure Framework \\
\hline NAP & National Action Plan \\
\hline NEPAD & New Partnership for Africa's Development \\
\hline $\mathrm{NGO}$ & Nongovernmental Organization \\
\hline NLTPS & National Long-Term Outlook Research \\
\hline OCS & Social Change Observatory \\
\hline ODA & Official Development Assistance \\
\hline PAGEFCOM & Municipal Forest Management and Development Project \\
\hline PAMF & $\begin{array}{l}\text { Project for the Management of the Forest Massifs of Agoua de Mons } \\
\text { Kouffè and Wari-Maro }\end{array}$ \\
\hline PAP & Priority Action Plan \\
\hline PBF & Forest Fire Project \\
\hline PCGPN & National Parks Management and Conservation Project \\
\hline PDC & Municipal Development Plan \\
\hline PEV & Expanded Immunization Program \\
\hline PGDRN & Program for the Sustainable Management of Natural Resources \\
\hline PGFTR & Forest and Shoreline Property Management Program \\
\hline PNGE & National Environmental Management Program \\
\hline PNLS & National Anti-AIDS Program \\
\hline SCRP & Poverty Reduction and Growth Strategy \\
\hline
\end{tabular}




$\begin{array}{ll}\text { ProCGRN } & \text { Natural Resources Management and Conservation Project } \\ \text { PPP } & \text { Purchasing Power Parity } \\ \text { PRS } & \text { Poverty Reduction Strategy } \\ \text { PRSP } & \text { Poverty Reduction Strategy Paper } \\ \text { PTME } & \text { Mother-to-Child Transmission Prevention } \\ \text { PTR } & \text { Pupil-Teacher Ratio } \\ \text { RAT } & \text { Reform of Territorial Administration } \\ \text { RBM } & \text { Results-based management } \\ \text { RESEN } & \text { Report on the National Education System } \\ \text { RGPH } & \text { General Population and Housing Census } \\ \text { SDA } & \text { Strategic Development Approach } \\ \text { SEA } & \text { Strategic Environmental Assessment } \\ \text { SME } & \text { Small and Medium-Sized Enterprises } \\ \text { SNFAR } & \text { National Agricultural and Rural Extension Strategy } \\ \text { SONAPRA } & \text { National Agricultural Promotion Company } \\ \text { SP } & \text { Social Projection } \\ \text { STI } & \text { Sexually Transmitted Infections } \\ \text { TAP } & \text { Primary School Completion Rate } \\ \text { TBS } & \text { Social Scorecard } \\ \text { TFP } & \text { Technical and Financial Partner } \\ \text { UNCTAD } & \text { United Nations Conference on Trade and Development } \\ \text { UVS } & \text { Village Health Unit } \\ \text { WADB } & \text { West African Development Bank } \\ \text { WAEMU } & \text { West African Economic and Monetary Union } \\ \text { WPI } & \text { Women's Participation Indicator } \\ & \end{array}$




\section{LIST OF TABLES AND CHARTS}

\section{List of Tables}

Table 1: Macroeconomic Indicators (\% of GDP unless otherwise indicated) ..................... 8

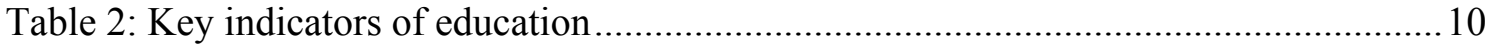

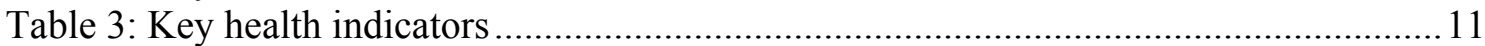

Table 4: MDGs, current situation, and path ahead for Benin ......................................... 15

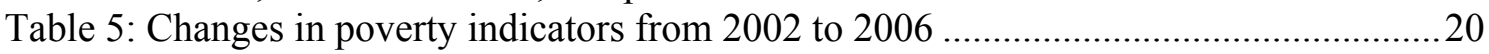

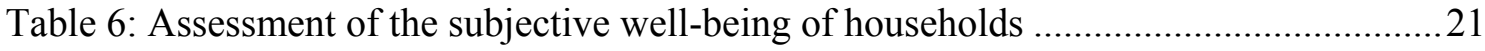

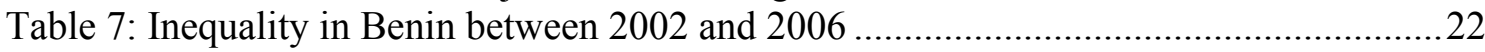

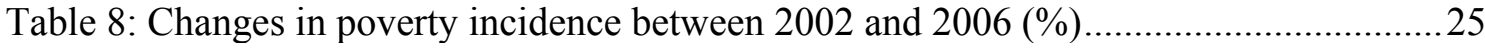

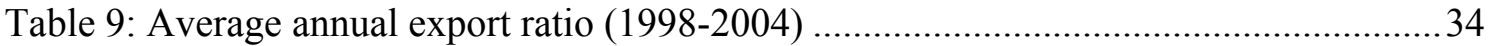

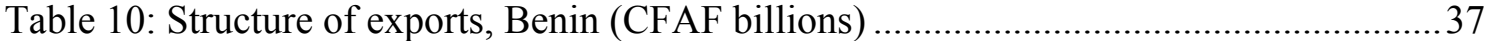

Table 11: Average cost of a three-minute dial-up call to the USA in US\$ ..........................39

Table 12: Comparison of transportation infrastructure in a number of countries ................42

Table 13: Bottlenecks caused by electricity supply problems: an international comparison 46

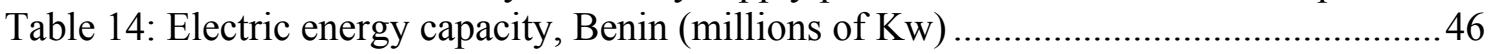

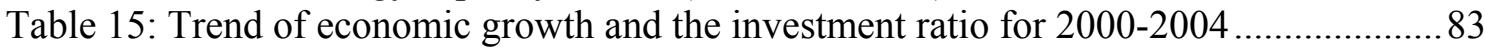

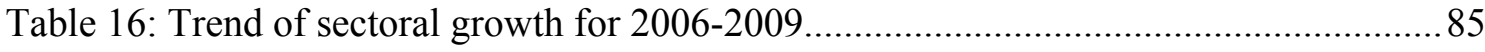

Table 17: Trend of revenue and expenditure as a percentage of GDP ...............................86

Table 18: Budgetary appropriation by sector for the period 2007-2009 (percent of expenditures

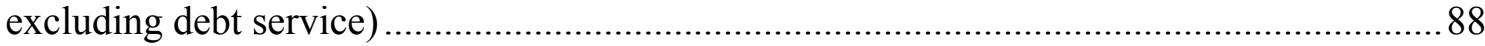

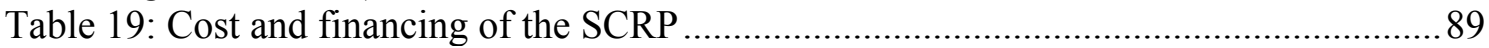

Table 20: Trend of the principal aggregates according to scenario ..................................... 90

\section{List of Boxes}

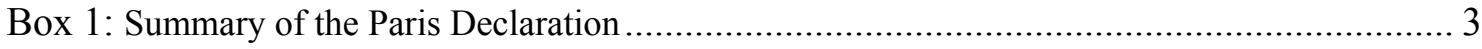

Box 2: Selected human development indicators for Benin .............................................. 9

Box 3: The EMICoV survey and the scope of the data used for poverty analysis ................ 19

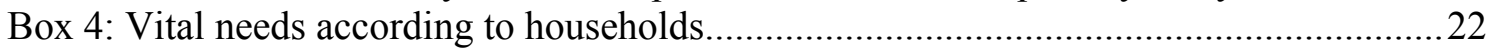

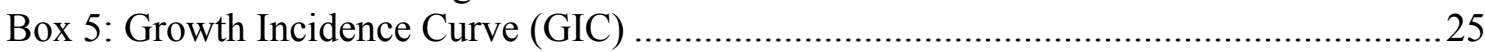

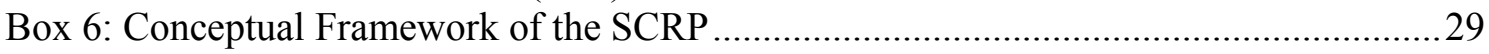

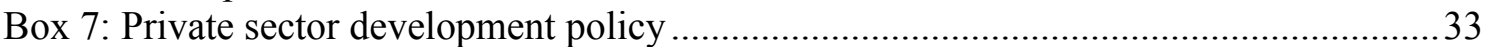

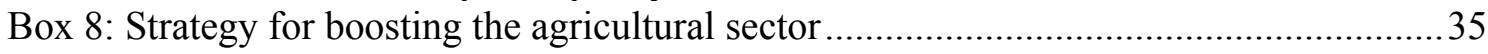

Box 9: National Rural Roads Strategy and Implementation of Pilot Projects......................43

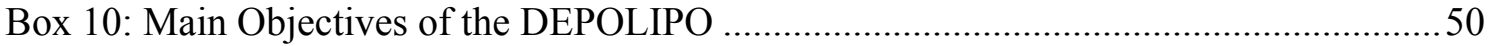

Box 11: Ten-year plan for educational development in Benin .......................................53

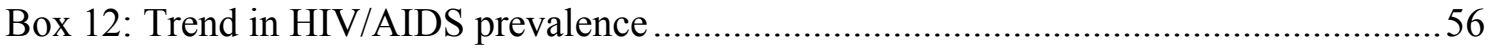

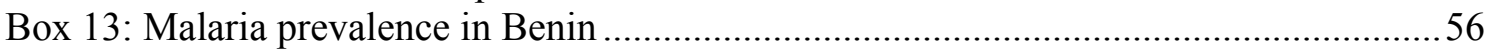

Box 14: Brief overview of the healthcare situation and of the healthcare sector .................57

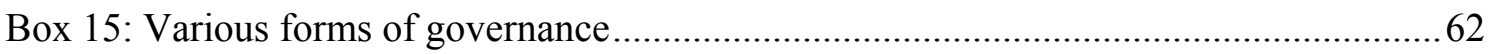

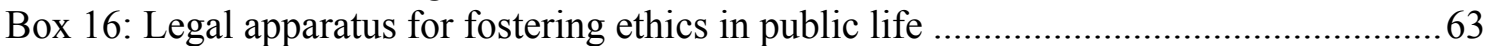

Box 17: Legal and institutional framework of public procurement....................................65

Box 18: Operational Strategy for Implementation of the National Policy Declaration on Town and Regional Planning (DEPONAT) 
Box 19: The 'greening' of the SCRP...

Box 20: Summary description of the macroeconomic and budgetary framework model .....84 Box 21: Some guiding principles 


\section{Table of Contents}

ABBREVIATIONS AND ACRONYMS

LIST OF TABLES AND BOXES

TABLE OF CONTENTS

EXECUTIVE SUMMARY

INTRODUCTION

PART I: CURRENT STATUS

CHAPTER 1: SCRP CONTEXT AND PREPARATION PROCESS

1.1 Context

1.2 Participatory process for SCRP preparation

CHAPTER 2: GAINS UNDER PRS 2003-2005

2.1 Strengthening the macroeconomic framework

2.2 Human capital building

2.3 Promotion of good governance and institutional capacity building

2.4 Promoting jobs and capacity building for the poor

2.5 Status of MDGs in Benin

\section{CHAPTER 3: CHARACTERISTICS AND DYNAMICS OF POVERTY}

3.1 Changes in poverty over the 2002-2006 period

3.2 Inequalities in Benin

3.3 Sociodemographic characteristics of poverty

3.4 Determinants of the various forms of poverty

3.5 Contribution of growth and inequality: a weak growth effect

PART II: STRATEGIC PILLARS OF THE SCRP STRATEGY

\section{CHAPTER 4: ACCELERATION OF GROWTH}

4.1 Stabilization of the macroeconomic framework

4.2 Revitalization of the private sector

4.3 Diversification of the economy

4.4 Promotion of regional integration

CHAPTER 5: DEVELOPMENT OF INFRASTRUCTURE

5.1 Transportation infrastructure

5.2 Energy infrastructure

5.3 Waterworks and sanitation

CHAPTER 6: HUMAN RESOURCE DEVELOPMENT

6.1 Promotion of development-oriented education

6.2 Strengthening of vocational training

6.3 Greater accessibility and quality of health and nutrition services 
6.4 Strengthening of the social safety net

\section{CHAPTER 7: PROMOTION OF GOOD GOVERNANCE}

7.1 Acceleration of administrative reform

7.2 Strengthening of the rule of law and individual liberties

CHAPTER 8: BALANCED AND SUSTAINABLE DEVELOPMENT OF THE NATIONAL TERRITORY

8.1 Sustainable regional and local development

8.2 Emergence of development and growth hubs

8.3 Environment, natural resource management and quality of life

PART III:

CHAPTER 9: MACROECONOMIC AND BUDGETARY FRAMEWORK

9.1 SCRP baseline scenario

9.2 Medium-term expenditure framework (MTEF)

9.3 Alternative scenarios and prospects for the achievement of the MDGs

9.4 Risk analysis

CHAPTER 10: IMPLEMENTATION AND MONITORING/EVALUATION MECHANISMS

10.1 Context

10.2 Major gains and challenges to be faced

10.3 Monitoring and evaluation mechanism for the 2007-2009 SCRP

10.4 Resource allocation for technical monitoring

10.5 Progress report and synchronization of outputs

10.6 Implications for the statistical development strategy

10.7 Implications for capacity-building

10.8 Involvement of the Paris Declaration in SCRP implementation

CONCLUSION

ANNEXES 


\section{EXECUTIVE SUMMARY}

Since 1999, Benin has been implementing a national poverty reduction strategy for sustainable human development. After laying out an Interim Poverty Reduction strategy (PRS, 2000), a three-year strategy (2003-2005) was defined and has subsequently been used as a strategic reference framework, for programming and budgeting of the actions of the Government and for guiding dialogue with the Technical and Financial Partners (TFPs). In this first strategy, the Government of Benin judiciously stressed the development of the social sector and improved governance in order to develop human resources and enhance the effectiveness of its actions so as to lay the foundations for sustainable human development. This "Growth Strategy for Poverty Reduction (Stratégie de Croissance pour la Réduction de la Pauvreté-SCRP)" constitutes a second generation strategy for the three-year period 20072009 , and is aimed at consolidating the gains of the earlier strategy while emphasizing diversification of the economy and the intensification of growth with a view to stepping up the fight against poverty and speeding Benin's achievement of the Millennium Development Goals (MDGs).

This new Growth Strategy for Poverty Reduction for Benin is the fruit of a participatory process which, at each stage, closely involved the public administration, economic agents, and civil society. This strategy features a Priority Action Plan (PAP) covering the period 2007-2009, which is built around the strategic pillars and broken down by sector and ministry.

\section{Participatory process}

The participatory process which culminated in the preparation of the SCRP had several stages, the principal ones being as follows:

- Evaluation of the PRS 2003-2005, which made it possible to draw the main lessons from implementation of PRS 1;

- The national forum on the new Poverty Reduction and Growth Strategy, which brought together all the stakeholders in the process and made it possible to define the guiding principles that steered development of the Strategy;

- Definition of the Strategic Development Orientations (SDOs) 2006-2011, to delineate the broad outlines of the Government's medium-term development vision of which the SCRP is the outgrowth;

- Establishment of ten working groups gathering all the stakeholders, which worked on the major sets of development topics with a view to identifying the major problems, evaluating the policies and programs in place, and proposing revisions for the next three years in order to increase the impact on growth for the sustainable poverty reduction in Benin;

- Organization of pillared workshops on selected topic areas, in particular gender (November 14, 2006), population (November 14, 2006), human rights (November 14 and 15, 2006); the environment (November 5-9, 2006); and HIV/AIDS (February 28March 2, 2007);

- Conduct of an Integrated Modular Survey on Household Living Conditions (EMICoV), organized in four (4) rounds the first of which was carried out from 
August 7 to November 25, 2006, and reached nearly 18,000 households spread throughout the entire national territory. This made it possible to develop the poverty profile and to learn the aspirations of the people at the grass roots level;

- The organization of consultations with various national, departmental, and local structures, which made it possible for all stake holders to assume ownership of the contents of the SCRP.

\section{Gains from implementation of PRS 2003-2005}

The implementation of PRS 2003-2005 made it possible to make notable progress not only on the institutional level, but also with the implementation of reforms and with performance in terms of sustainable development. At the institutional level, important advances were made in the generalization of the participatory approach for developing and implementing multisectoral strategies and for the monitoring and evaluation thereof. In particular, PRS 2003-2005 afforded one of the first opportunities to involve civil society and the private sector in the process of drafting a development orientations paper in Benin. This involvement developed gradually and made it possible for the various stakeholders more readily to assume ownership of the strategy. However, the evaluation of PRS 2003-2005 did find that this participation fell short of taking into account the aspirations of all social groups.

With respect to implementation of the reforms, PRS 2003-2005 constituted the primary frame of reference for structuring and coordinating the interventions of the Technical and Financial Partners (TFPs) in support of the Government's programs, channeling them more effectively toward combating poverty. More than any other strategic document, PRS 2003-2005 served as an instrument for dialogue between the Government and donors. It made it possible to develop the practice of joint missions and budgetary support, to adopt two IMF-supported economic and financial programs, and achieve eligibility for the Heavily Indebted Poor Countries (HIPC) Initiative. Finally, PRS 2003-2005 reflected the Government's resolve to develop an operational national strategy in consultation with the Technical and Financial Partners.

Overall, the evaluation of PRS 2003-2005 shows that while many reforms were undertaken, it must be observed that the results fell short of the goals laid out in terms of growth and poverty reduction. Similarly, at the current pace, achievement of the MDGs by 2015 would appear to be in jeopardy.

This relative shortfall is explained by: (i) insufficient attention devoted to the issues of diversification and growth, in particular the revitalization of the private sector and the development of sectoral and regional growth poles; (ii) underestimation of the role human capital plays in the growth and poverty reduction process; (iii) underestimation of the internal limits of the Public Administration vis-à-vis the changes implied by the principles of performance-based management and good governance; and (iv) the weakness of local government involvement in the development process.

\section{Poverty in Benin}

With a view to devising a new and effective poverty reduction strategy, the Government conducted the Integrated Modular Survey of Household Living Conditions (EMICoV). This aim of this survey is to assess the scope of poverty, and to identify its characteristics and 
determinants, in order to refine poverty reduction policies in Benin. This quantitative survey was supplemented by a qualitative evaluation of poverty and its determinants based on people's perceptions, on the basis of a series of participatory consultations with households carried out throughout the national territory.

The partial and provisional findings of EMICoV revealed in particular that: (i) the incidence of income poverty ${ }^{1}$ in Benin is still high in 2006, and even seems to have increased from the 2002 level (as shown by the CWIQ survey); (ii) poverty in Benin varies considerably by area of residence, with an incidence of 27 percent on average in urban areas as against 40.6 percent in rural areas. However, the analyses would show that nonmonetary poverty ${ }^{2}$ (i.e. nonmonetary material living conditions of the population) appears to have declined slightly in Benin (from 43 percent to 41 percent), in contrast with income poverty, while for their part, Beninese households feel that living is becoming more and more difficult, as shown by the survey results on subjective poverty. ${ }^{3}$

\section{Main strategic pillars of the SCRP}

Analysis of the determinants and evolution of poverty had clearly shown that economic growth is the key factor in poverty reduction. Between 2002 and 2006, economic stagnation appears to have been the main cause behind the deterioration in the incidence of income poverty in Benin. Moreover, national consultation efforts have clearly shown that corruption is a factor that is harmful factor to the business climate, and hence an impediment to investment and diversification, and consequently to growth and poverty reduction.

This explains why, for this new edition of the strategy, the Beninese authorities intend to stress diversification policies in order to accelerate economic growth, promote good governance, and strengthen the social sector in support of poverty reduction efforts and sustainable human development.

Based on the Strategic Development Orientations aimed at making Benin an emerging economy, the SCRP is intended to serve as the framework for the operationalization of the Government's aspirations. It is thus both a "federative" framework aimed at harmoniously bringing together sectoral policies, and an "integrative" framework aimed at enhancing their cohesiveness and complementarity in order to accelerate growth and meet the expectations of the public. Thanks to a detailed PAP that is fully consistent with sectoral program budgets thanks to a strengthened Medium-Term Expenditure Framework (MTEF), the SCRP thus constitutes the programming, budgeting/financing, and monitoring framework for the Government's sectoral programs.

It has been built around five strategic pillars devoted to priority areas of intervention and setting forth the actions and measures to be implemented during the 2007-2009 period.

\footnotetext{
${ }^{1}$ The rate of income poverty is the proportion of the population living below the income poverty line.

${ }^{2}$ Nonmonetary poverty is the level of poverty defined on the basis of the material living conditions of the population.

${ }^{3}$ Subjective poverty measures the people's perception of their own living conditions.
} 


\section{Pillar 1: Acceleration of growth}

The growth rate in recent years has fallen short of the PRS 2003-2005 objectives and is clearly insufficient to give Benin the self-generated resources it needs to support the fight against poverty and achieve the MDGs. These performance shortfalls result mainly from the limited diversification and lack of competitiveness of the economy. This is why the Government is determined to speed up the reforms to diversify the economy and increase the growth rate to 6.5-7 percent by 2009. In addition to the areas with weaknesses that affect growth (governance, social development, infrastructure, etc.), the Government has identified four priority areas for direct intervention to intensify growth, namely: (i) stabilization of the macroeconomic framework; (ii) revitalization of the private sector; (iii) promotion of new branches of activity that show promise in terms of exports; and (iv) promotion of regional integration.

\section{Pillar 2: Development of infrastructure}

Economic infrastructures play a strategic role in the development process. They contribute to linking economic agents to markets, reducing factor costs, and improving the competitiveness of the economy, and also offer essential services to the public (access to roads, water, etc.) which determine the quality of life. Infrastructure thus contributes at one and the same time to growth and to improving the living conditions of the people. This is why the Government has made it a key strategic pillar of the SCRP which will be reflected in the implementation of major works programmed in the PAP. The Government has identified three priority areas in the infrastructure sector, namely: (i) transport infrastructure; (ii) energy; and (iii) water supply and sanitation.

\section{Pillar 3: Human capital building}

Strengthening and making the most of human resources constitutes another pillar of the strategy. This pillar strengthens the social sphere, but also human capital, and thus the foundations of medium- and long-term economic growth. The SCRP programs for developing and enhancing the value of human capital are gathered in four (4) priority areas of intervention, namely: (i) the promotion of a development-oriented education system; (ii) strengthened professional training adapted to the needs of the labor market; (iii) improved accessibility quality of health and nutrition services; and (iv) strengthened social solidarity and protection.

\section{Pillar 4: Promotion of good governance}

Improved governance, including the fight against corruption, constitutes a crucial factor for the success of strategies to promote the private sector and improve the effectiveness of government actions and expenditure, and hence the success of the SCRP. During the participatory consultations, the people quite correctly cited corruption and, more generally, the lack of sound management of public affairs as important determinants of poverty in Benin. This is why, over the next three years, the Government will work to strengthen good governance so as to increase effectiveness and efficiency in the management of public affairs. The priority programs in these areas concern: (i) speeding up administrative reforms; and (ii) strengthening the rule of law and individual freedoms. 


\section{Pillar 5: Balanced and sustainable development of the national space}

Faster growth and poverty reduction imply, on the one hand, devoting increased attention to regional disparities and targeted actions aimed at promoting greater territorial equity in the distribution of social and economic investments, and, on the other hand, a sustained effort to protect the environment and manage natural resources in a sustainable manner. Indeed, each component of the national territory must, in keeping with its potential, take an active role in while reaping the benefits of national economic growth. On the strength of this knowledge, the Government has identified the balanced and sustainable development of the national space as a strategic pillar of the SCRP.

To correct disparities, the Government wants to base all development efforts on a balanced and sustainable spatial distribution of activities and infrastructures. Town and country planning, environmental protection, and decentralization are the principal tools the Government intends to associate with the implementation of sectoral policies and lead Benin toward the emerging country group. The priority programs of this pillar are grouped in three components, namely: (i) sustainable development of regions and localities; (ii) the emergence of development and growth poles; and (iii) the environment, natural resource management, and living standards.

\section{Macroeconomic and budgetary framework}

The macroeconomic and financial framework was developed by taking account of the strategic orientations as well as the macroeconomic and sectoral policies described above. The macroeconomic framing was followed by developing a budgetary framework for the medium term (MTEF) which distributes resources among budget allowances for the various sectors in keeping with the priority sectors of the SCRP. In addition, as part of assessing the costs of the strategy for achieving the MDGs, certain sectors (education, health, infrastructure, water and energy, agriculture, environment, and gender) prepared programs and estimated their cost. These programs were revised in order to bring their costs within the respective sectoral allowances and ensure consistency between the overall macroeconomic framework and the sectoral medium-term expenditure frameworks (MTEFs).

Effective implementation of the SCRP would make it possible to increase the average rate of economic growth from the 3.5 percent recorded for the 2004-2006 period to 6.5 percent for the 2007-2009 period, with population growth projected at 2.9 percent over the period. This would boost the growth of per capita GDP to 2.5 percent on average over the 2007-2009 period. The faster growth stems primarily from the anticipated dynamism of trade and transport activities, as well as from diversification and a greater contribution from exportoriented primary sector production (agriculture for export). Growth is also induced by an increase of approximately 3 points in the investment ratio, rising from 22 percent of GDP in 2006 to 25 percent in 2009, thanks to a significant increase in public investment and to the anticipated effects of an improved business climate on savings and private investment.

Thanks to the implementation of measures to intensify resource mobilization, in particular broadening of the tax base and improved yields from the financial authorities, the ratio of tax receipts to GDP will progress favorably, increasing from 15.1 percent of GDP in 2006 to the Community goal of 17 percent by 2009. During the program period, these resources will be devoted to current expenditure, representing on average 15 percent of GDP, and capital 
expenditure, representing on average 9 percent of GDP. The volume of expenditure as a proportion of GDP would stabilize at around 24 percent between 2007 and 2009, as compared with 21 percent over the three years of PRS 2003-2005, owing to the additional spending required to implement the priority programs of the strategy. As a consequence of the improvement in revenue and the prudent growth of expenditure, the budget deficit will continue to be contained, rising from 5 percent of GDP in 2006 to approximately 7 percent of GDP between 2007 and 2009.

\section{The Medium-Term Expenditure Framework (MTEF)}

The MTEF provides an indication of the projected allocation of resources resulting from the macroeconomic framework, based on SCRP priorities and the financing requirements of the priority programs. Accordingly, the resources allocated to the priority sectors remain in line with the objectives of the strategy; the expenditures allocated to the social sectors (education, health, other social sectors), the manufacturing and trade sectors, and infrastructure respectively account on average for 31 percent, 11 percent, and 19 percent of total expenditure over the 2007-2009 period, as compared to 28 percent, 8 percent, and 12 percent over the period of PRS 2003-2005.

\section{Cost of the strategy and financing}

The SCRP is an integrated strategy in that the strategic pillars, priority programs, and projects touch upon all sectors. These priority programs consume a sizable share of the sectoral ministries' resources. Estimates indicate that the total cost of the strategy will rise from CFAF 631.5 billion in 2007 to CFAF 776.5 billion in 2009 , that is, an annual growth rate of about 11 percent. The Government is determined to continue its efforts to mobilize the domestic and external resources needed to finance the SCRP. In practice, the Government intends to continue the ongoing reforms to rehabilitate public finances and improve the tax situation (broadening the tax base, modernization of the tax and customs administrations, and strengthening auditing).

Moreover, the Government intends to mobilize resources on the national and subregional financial markets. Finally, the Government will work with the development partners to mobilize external resources and improve the coordination of the various kinds of support in light of the priorities of the strategy. This partnership will continue within the framework of the consultative process established for preparing the SCRP, and in connection with implementation of the Paris Declaration on Aid Effectiveness.

Furthermore, the Government will endeavor to meet all the requirements for promoting private sector participation in financing the strategy. This will entail promoting foreign direct investment (FDI), introducing new financing instruments, bolstering the presence of banking throughout of the country, mobilizing national savings, and promoting microfinance.

\section{Implementation and monitoring of the strategy}

The new implementation and monitoring mechanism described in paper is based on an approach that emphasizes the accountability of the structures directly tasked with implementing the various projects and programs included in the Priority Action Plan (PAP) of the SCRP. For monitoring, a minimum list of PRSP and MDG monitoring indicators has 
been drafted; these monitoring indicators will be updated by the findings of the EMICoV survey and the EDS (Demographic and Health Survey). 


\section{INTRODUCTION}

1. The Government aspires to transform Benin into an emerging country by 2011. This ambition is reflected in the desire to create the conditions necessary for accelerated economic growth and a noteworthy reduction in poverty in the country.

2. This Growth Strategy for Poverty Reduction (Stratégie de Croissance pour la Réduction de la Pauvreté-SCRP), which covers the period 2007-2009, is the outgrowth of a participatory strategic planning exercise involving the participation of all the components of Beninese society. The strategic pillars and priority areas of intervention identified are in keeping with the vision of "Benin 2025: Alafia [peace and happiness]," the Millennium Development Goals (MDGs), and the Strategic Development Orientations (SDOs).

3. Throughout its preparation, the SCRP benefited from sustained participation by civil society, the private sector, and the Technical and Financial Partners (TFPs). It serves as the frame of reference for the socioeconomic development of Benin for the 2007-2009 period and the reference document for dialogue between the Government and the TFPs. SCRP implementation will require support from the international community in order to consolidate the gains made in the development process in recent years and ensure the economic take-off sought by all in Benin.

4. The document consists of ten (10) chapters grouped in three (3) parts. Part I addresses the context and preparation process of the SCRP (Chapter 1), summarizes the gains made under the first Poverty Reduction Strategy (PRS 2003-2005) (Chapter 2), and describes the living conditions and poverty on the basis of the initial provisional and partial findings of the Integrated Modular Survey of Household Living Conditions (EMICoV) currently being conducted (Chapter 3). Part II describes the five (5) strategic pillars and priority areas of intervention that will guide the Government's actions during the 2007-2009 period (Chapters 4-8). Finally, Part III of the paper discusses macroeconomic and budgetary framework (Chapter 9) and the implementation and monitoring mechanisms of the strategy (Chapter 10).

5. The sectoral strategies and policies growing out of the SCRP will be refined and/or readjusted in order more clearly to delineate the actions planned and thereby facilitate their implementation. 
PART I: CURRENT STATUS 


\title{
CHAPTER 1: SCRP CONTEXT AND PREPARATION PROCESS
}

\subsection{Context}

6. In Benin, the first Poverty Reduction Strategy (PRS) covering the 2003-2005 period was adopted in September 2002. It was the first genuine intersectoral and participatory planning exercise in Benin and was used as the sole framework for dialogue between the Government and all the Technical and Financial Partners (TFPs). During PRS1 implementation, the Government prepared annual reports taking stock of the progress of the priority programs and projects adopted under the PRS and the results achieved. Preparation of these annual reports enabled the Government to conduct annual program reviews with the TFPs.

7. PRS 2003-2005 had placed special emphasis on the social sectors. Cognizant of the fact that faster growth is a necessary condition for poverty reduction; the Government has adopted an ambitious and dynamic development vision embodied in SCRP 2007-2009. The aim of the SCRP is to accelerate economic growth in order sustainably to reduce poverty. SCRP 2007-2009 constitutes the Government's reference framework for dialogue with the TFPs and seeks to be a framework for the operationalization of the Strategic Development Orientations 2006-2011. The SCRP will also contribute to achievement of the Millennium Development Goals (MDGs) and will be a mechanism for resource mobilization and coordination in keeping with the Paris Declaration (see Box 1).

Box 1: Summary of the Paris Declaration

\begin{abstract}
The Paris Declaration was signed in March 2005 by the Technical and Financial Partners (TFPs) and partner countries including Benin. It is based on a principle of mutual commitment to improving aid effectiveness, and includes a practical and concrete framework aimed at improving the quality of aid and its impact on development. The commitments revolve around five (5) major principles.
\end{abstract}

Ownership: Partner countries exercise effective leadership over their development policies and strategies, and coordinate development actions.

Framework: Donors base their overall support on partner countries' national development strategies, institutions, and procedures.

Harmonization: Donors' actions are more harmonized, transparent, and collectively effective.

Managing for results: Managing resources and improving decision-making for results.

Mutual accountability: Donors and partners are accountable for development results.

Source: OECD, Paris Declaration

\subsection{Participatory process for SCRP preparation}

8. Using as a basis the shortcomings of the participatory process noted in the evaluation of PRS 2003-2005 and taking into account the principles of concerted governance, the preparation of SCRP 2007-2009 involved all stakeholders in development. The preparation process involved the following steps: (i) official launch of the process; (ii) evaluation of PRS 2003-2005; (iii) the establishment of theme-based working groups; (iv) the national forum on the new SCRP; (v) preparation of the Strategic Development Orientations 2006- 
2011; (vi) theme-based workshops; (vii) conduct of the Integrated Modular Survey of Household Living Conditions (EMICoV); (viii) organization of consultations with national, departmental, and local structures; (ix) definition of the strategic pillars of SCRP 20072009; (x) establishment of a SCRP drafting committee; and (xi) SCRP validation and adoption efforts.

9. The official launching for SCRP preparation work took place on February 3, 2006. It made it possible to demonstrate the Government's resolve to continue its commitment to combating poverty through accelerated economic growth. All components of Beninese society took part in this ceremony, thus evidencing their commitment to the participatory process.

10. Evaluation of PRS 2003-2005 led to broad consultations which made it possible to gather the assessments of the public administration, local governments, and civil society, including the trade unions, the private sector, and the TFPs. The evaluation report underwent national validation by representatives of all the groups involved in the process of policy and program development and implementation, thereby allowing stakeholders to assume ownership of the lessons from the implementation of PRS 2003-2005.

11. The national forum on SCRP preparation brought together more than a hundred participants representing the ministerial departments and their main technical units, civil society in its broadest sense, the private sector, and the majority of TFPs. The aim of this forum was to identify the various stakeholders in the process and to define guiding principles for the preparation of SCRP 2007-2009. The forum ultimately produced a roadmap.

12. Ten (10) Theme-based Groups were then established on the following topics: (i) social sectors, infrastructure, and baseline equipment; (ii) environment and living conditions; (iii) macroeconomics and sectors with growth potential; (iv) private sector and employment; (v) good governance, decentralization, and capacity building; (vi) agriculture, natural resources, and land tenure issues; (vii) security and peace; (viii) information and communication technologies; (ix) poverty and targeting; and (x) monitoring and evaluation. Each theme-based group was made up of representatives of the administration, civil society, and the private sector. Within the theme-based groups, working subgroups were established to assess the needs for achieving the MDGs. The work of theme-based groups made it possible to perform a strategic diagnosis of the area in question, estimate the cost requirements of achieving the MDGs, and analyze the constraints on development in the sector. It was thus possible to identify the strategic priorities likely to accelerate the growth and reduce poverty sustainably over the next three years.

13. Following the March 2006 presidential elections, the new Government drew up the document setting forth the Strategic Development Orientations (SDOs) of Benin 20062011. This medium-term paper reflects the Government's socioeconomic development orientations and takes account of the grassroots population's aspirations and needs. It also follows the logic of the MDGs and the long-term vision set forth in "Benin 2025: Alafia." It includes six (6) strategic orientations supported by cross-cutting measures relating to the 
conditions for implementing these orientations. The SCRP is the paper for operationalizing the SDOs over the 2007-2009 period.

14. In order to take the cross-cutting issues of the SCRP into account, studies on crosscutting topics and training workshops were organized for all stakeholders concerned with such issues. These include in particular: (i) the ten-year outlook for development; (ii) gender; (iii) the environment; (iv) human rights; and (v) HIV/AIDS. The relationships between the thematic groups and the SCRP were the subject of conformity evaluations to ensure that these cross-cutting issues would be taken into account.

15. The Integrated Modular Survey of Household Living Conditions (EMICoV) was launched in August 2006, and covers a sample of almost 18,000 households throughout the entire national territory (see Box 2). The originality of this survey lies in its representativity at the commune level and the coupling of the first round with the Demographic and Health Survey (EDS). Its originality also stems from the inclusion of two modules on "Governance" and "The Perception of Poverty" in the questionnaire. This approach will make it possible not only to gather quantitative information, but also to learn the aspirations of all social groups and update the poverty profile.

16. To ensure ownership of the process and impart a greater understanding of what is at stake in SCRP 2007-2009, consultations were organized at all levels. This approach made it bring together the civil society stakeholders in each locality to learn their aspirations. This information was compiled as proposals from civil society. Similarly, the National Association of Communes of Benin (ANCB) and the trade union association each made proposals relating to SCRP 2007-2009 in their respective areas of concern. The concerns and aspirations thus gathered were conveyed to the theme-based groups responsible for synthesizing all the information available.

17. At the national and departmental level, the consultations involved providing the draft SCRP paper to the people to garner their support on the pillars, the priority intervention areas, and the corresponding actions. These consultation sessions provided the people with an opportunity to assume ownership of the contents of the SCRP and to take the concerns expressed by certain vulnerable groups into account. In addition, the National Assembly and the Economic and Social Council were consulted to learn their views on the SCRP priorities as regards combating poverty over the next three years.

18. A working group made up of officials from the public administration and resource persons met to finalize the selection of the strategic pillars of SCRP 2007-09 on the basis of reports from the theme-based groups and the Strategic Development Orientations 2006-

2011. In addition, a group responsible for drafting the SCRP was set up. It was made up of senior officials from the administration, university professors, and national experts. Coordination was provided by the Permanent Secretariat of the CNDLP. ${ }^{4}$ The work of this

\footnotetext{
${ }^{4}$ The Permanent Secretariat of the National Commission for Development and Combating Poverty (CNDLP) became the Economic and Structural Reform Program Monitoring Unit pursuant to Decree No. 2006-616 of November 23, 2006 on the Powers, Organization, and Operation of the Ministry of Development, Economy, and Finance.
} 
group was buttressed by the Government's strategic orientation papers, the reports of the theme-based working groups, the sectoral strategies, recommendations from the workshops, and consultations running up the final draft of SCRP 2007-2009.

19. The preliminary draft final SCRP paper was forwarded to the Technical and Financial Partners (TFPs) for assessment. The final SCRP paper was adopted by the Council of Ministers at its meeting of Monday, February 26, 2007. 


\section{CHAPTER 2: GAINS UNDER PRS 2003-2005}

20. The implementation of PRS 2003-2005 made it possible to make noteworthy progress with use of the participatory approach, with ownership of the mechanisms for devising and implementing multisectoral strategies, and in the area of monitoring and evaluation. PRS 2003-2005 was one of the rare occasions on which civil society and the private sector were associated with the process of preparing an orientation paper on development in Benin. This involvement gradually increased and enabled the various stakeholders to assume ownership of the strategy. However, the PRS evaluation emphasized that this participation was not yet sufficient for taking account of the aspirations of all social groups.

21. Moreover, PRS 2003-2005 also constituted the first reference framework to coordinate and channel the interventions of the Technical and Financial Partners (TFPs) in support of combating poverty. This being so, it served as an instrument of dialogue between the Government and donors. It made it possible to develop the practice of joint missions and budgetary support, to adopt two economic and financial programs supported by the IMF, and to reach the eligibility point for the Heavily Indebted Poor Countries (HIPC) Initiative. Lastly, PRS 2003-05 reflected the Government's resolve to develop an operational national strategy in consultation with the TFPs.

22. The implementation of PRS 2003-2005 made it possible to achieve concrete results as regards improving the living conditions of the people. Evaluation of the strategy also made it possible draw lessons which inspired the preparation of SCRP 2007-2009. The gains and the lessons learned are presented in the sections which follow, in accordance with its four strategic pillars.

\subsection{Strengthening the macroeconomic framework}

23. Overall, macroeconomic stability was maintained during the 2003-2005 period. Inflation was contained within the limit envisaged by the WAEMU convergence pact (less than 3 percent) and the current balance of payments improved during the 2004-2005 period because of the positive shift in the services and incomes areas. The Government also began to introduce an Industrial Free Zone to promote investment, the concentration of enterprises, and job creation. This said, however, the growth target set by the Government could not be met, owing in particular to external shocks that dampened economic activity. The average annual real economic growth rate was of 3.3 percent over the 2003-2005 period, as compared to an average annual target of 7 percent projected for the period.

Table 1: Macroeconomic Indicators (percent of GDP unless otherwise indicated)

\begin{tabular}{|c|c|c|c|c|c|c|c|}
\hline & \multicolumn{3}{|c|}{$\begin{array}{l}\text { Period before PRS1 } \\
\text { 1990-94 1995-99 2000-02 }\end{array}$} & \multicolumn{4}{|c|}{$\begin{array}{l}\text { PRS1 period } \\
20042005\end{array}$} \\
\hline Population (in millions) & 4.9 & 5.8 & 6.6 & 7.0 & 7.2 & 7.4 & 7.2 \\
\hline Population growth rate (in \%) & 3.3 & 3.3 & 3.3 & 3.0 & 3.0 & 3.0 & 3.0 \\
\hline GDP (in CFAF billions) & 644 & 1319 & 1823 & 2067 & 2140 & 2299 & 2169 \\
\hline Per capita GDP (in CFAF thousands) & 131 & 228 & 277 & 296 & 298 & 310 & 302 \\
\hline Real GDP growth rate (in \%) & 3.7 & 5.1 & 5.2 & 3.9 & 3.1 & 2.9 & 3.3 \\
\hline Per capita growth rate (in \%) & 0.4 & 1.8 & 1.9 & 0.8 & 0.2 & -0.1 & 0.3 \\
\hline Gross investment & 14.4 & 18.2 & 18.9 & 20.3 & 20.7 & 17.0 & 19.3 \\
\hline Gross public investment & 4.9 & 6.1 & 5.8 & 6.6 & 5.4 & 5.3 & 5.8 \\
\hline
\end{tabular}


CHAPTER 2: GAINS UNDER PRS 2003-2005

\begin{tabular}{|c|c|c|c|c|c|c|c|}
\hline Gross private investment & 9.5 & 12.1 & 13.2 & 13.7 & 15.3 & 11.6 & 13.5 \\
\hline Gross domestic saving & 10.1 & 9.6 & 10.0 & 10.2 & 12.2 & 8.8 & 10.4 \\
\hline Total revenue & 11.2 & 14.3 & 15.8 & 16.6 & 16.4 & 16.7 & 16.6 \\
\hline Tax receipts & 9.2 & 12.2 & 14.0 & 14.9 & 14.6 & 14.5 & 14.7 \\
\hline Total expenditure & 17.7 & 17.7 & 18.6 & 22.0 & 19.8 & 19.8 & 20.6 \\
\hline Wage bill & 6.2 & 4.7 & 4.4 & 5.1 & 5.8 & 5.7 & 5.5 \\
\hline Baseline primary balance & 0.9 & 3.5 & 1.6 & -1.4 & -0.3 & 0.1 & -0.5 \\
\hline Exports & 16.3 & 17.6 & 15.8 & 15.2 & 14.0 & 13.0 & 14.1 \\
\hline Imports & 24.7 & 24.2 & 22.7 & 23.0 & 20.8 & 19.9 & 21.2 \\
\hline Overall balance & 6.9 & -0.1 & 2.8 & -1.2 & -2.9 & 2.1 & -0.7 \\
\hline Net foreign assets (in months of imports) & 4 & 7 & 12 & 11 & 7 & 10 & 9 \\
\hline Outstanding debt & 52.8 & 59.4 & 51.8 & 40.3 & 40.3 & 40.3 & 40.3 \\
\hline Debt service & 1.8 & 2.0 & 1.3 & 0.8 & 0.7 & 0.6 & 0.7 \\
\hline Debt service (in \% of exports) & 11.9 & 8.6 & 5.9 & 3.8 & 3.6 & 3.1 & 3.5 \\
\hline
\end{tabular}

Source: MDEF.

\subsection{Human capital building}

24. Overall, the human development indicators of Benin improved significantly. By comparison with other countries of West Africa, Benin's indicators are better. For example, life expectancy is 55 years as compared to 48 in West Africa on average, and the proportion of the population living on less than a dollar a day is 31 percent as compared to 60 percent in West Africa. On the other hand, the natural rate of increase in the population (2.89 percent) is one of highest in West Africa and requires actions of adequacy with the economic growth. 
Box 2: Selected human development indicators for Benin

Life expectancy at birth (years)

Literacy rate (\% of young people ages $15-24$ )

Malnutrition rate, weight ( $\%$ of children under 5 )

Mortality rate, under age 5 (per 1,000)

Population growth (\%)

Population living on less than $\$ 1 /$ day (\%)

Source: World Bank (WDI 2006)

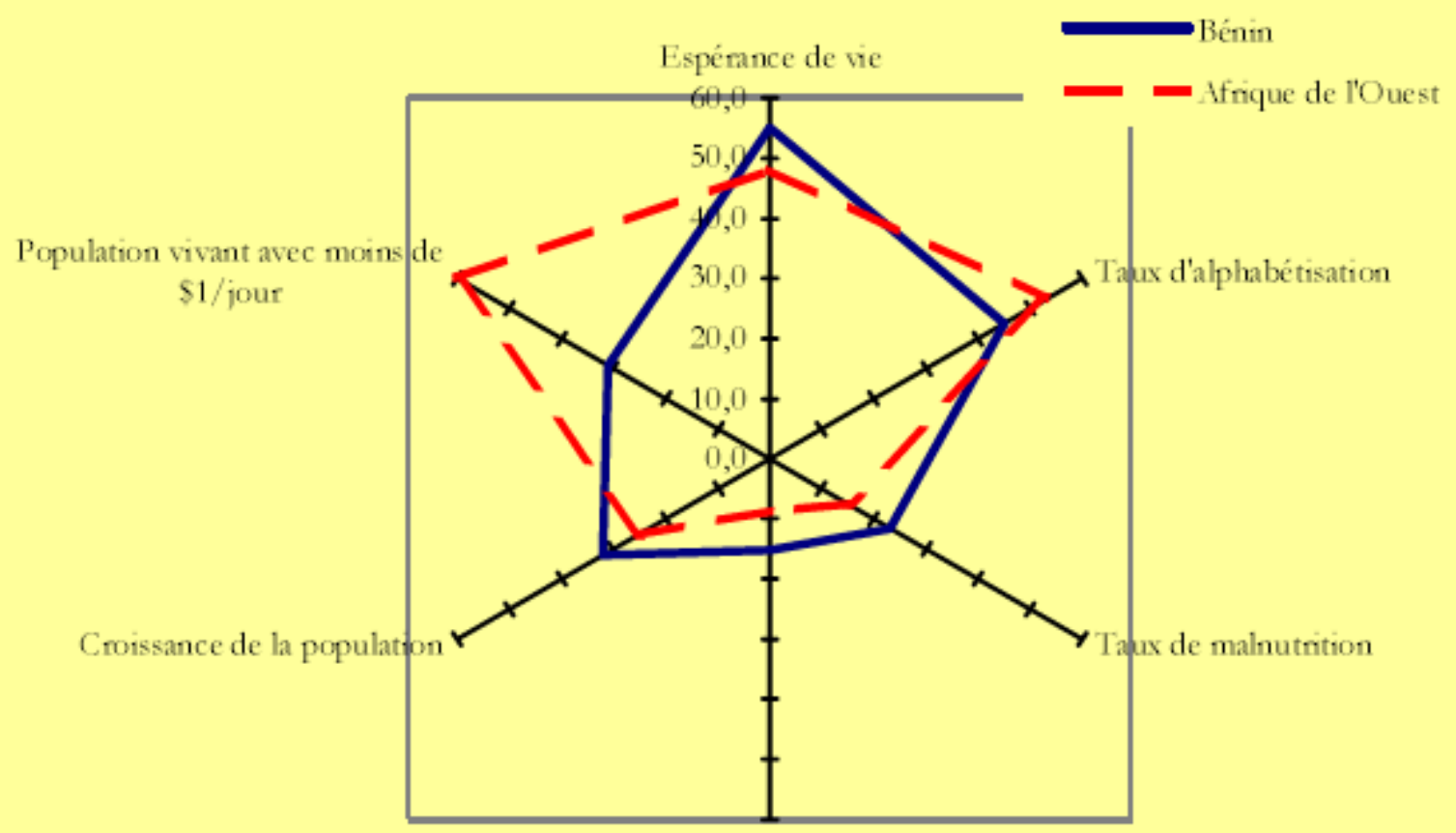

Taux de mortalité

Key:
Life expectancy
Benin
Population living on less than $\$ 1 /$ day
Literacy rate
Population growth
Malnutrition rate

West Africa

Mortality rate 
25. Progress was made in the area of education through improvement in the people's access to education, in particular baseline education. The gross enrollment ratio (GER) was estimated at 94 percent in 2005, with a boy/girl parity index of 80 percent. The Pupil-Teacher Ratio (PTR) was 50 compared to a target of 51.4. In addition, noteworthy improvements were recorded as regards the schooling of girls and addressing gender issues. However, improving the quality of education and reducing disparities of any kind remain important challenges to face.

Table 2: Key indicators of education

\begin{tabular}{lllll}
\hline INDICATORS & 2003 & 2004 & 2005 & PRS1 target value \\
\hline Gross enrollment ratio, primary level & & & & \\
Gross enrollment ratio of girls, primary level & 94 & 96 & 94 & 94 \\
Girl/boy parity Index in \% (*) & 81 & 84 & 83 & $\mathrm{Nd}$ \\
Gross admission rate, primary level & & 75 & 80 & $\mathrm{Nd}$ \\
Primary cycle completion rate & 104 & 106 & 99 & $\mathrm{Nd}$ \\
Pupil-teacher ratio & 49 & 50 & 54 & $\mathrm{Nd}$ \\
\hline
\end{tabular}

Source: PRSP progress report 2005.

Note: $\left({ }^{*}\right)$ gross enrollment ratio of girls as against that of boys.

26. In the area of health, statistics from the National Health Management Information System (NHMIS) indicate a marked improvement in the quality of care during the 2003-2005 period. In particular, efforts were made to reduce infant mortality and maternal mortality and to fight the major endemic diseases, namely malaria, tuberculosis, and HIV/AIDS. The infant mortality rate was 66.8 per mil as compared to an objective of 65 per mil. The incidence of assisted childbirth and the rate of healthcare services access are 75 percent and 37 percent in 2005, respectively, in keeping with the objectives set. The prenatal consultation rate reached 90 percent in 2005 as against the target of 84 percent. In contrast, the continuing high maternal and neonatal mortality rates and death rates from malaria are major concerns given Benin's ambition to achieve the MDGs.

Table 3: Key health indicators

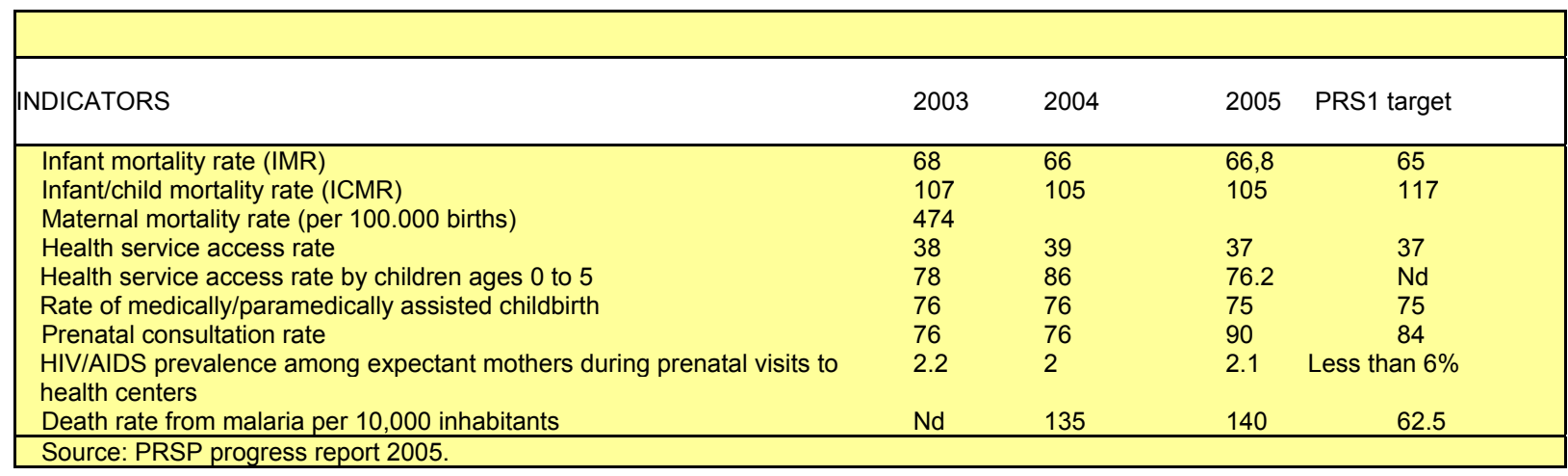

27. The actions taken under PRS 2003-2005 made it possible to improve access to safe drinking water. The access rate in rural areas increased from 35 percent in 2002 to 41 percent in 2005, a six percentage point rise. The sector doubled its capacity to create water supply points. For the first time, in term of creation of water supply points, the performances of 2004 exceeded the threshold of the 
1200 points equivalents of water. Improved planning and budget execution in the sector, coupled with the commitment of several donors, contributed significantly to this good performance.

\subsection{Promotion of good governance and institutional capacity building}

28. In the context of promoting good governance and strengthening the rule of law, in 2005 the Government adopted a strategic plan for combating corruption, with the five following priority pillars: (i) revitalization of the oversight system through the passage of an anti-corruption law; (ii) the promotion of administrative and institutional reforms; (iii) strengthening the capacity for action of civil society and the private sector; (iv) creation of an environment hostile to corruption; and (v) strengthening of reporting requirements and the obligation to combat impunity. Moreover, to build on the gains made in this area, the Government established an Anti-Corruption Observatory (OLC).

29. In addition, the first survey on governance and corruption is in progress and should make it possible to establish a reference base for tracking progress with implementation of the AntiCorruption Strategic Plan (PSAC) and the introduction of the public information mechanism.

30. In the legal sector, the plan for operationalizing the integrated program to strengthen the legal and judiciary systems has been adopted and is currently being implemented. To strengthen the justice sector, the Government is recruiting 40 judges and 30 court clerks a year. To improve the performance of the justice sector, the Government has also engaged in capacity building for the stakeholders in the sector through training and improved compensation of judges.

31. With a view to increasing the efficiency of expenditure in a context of transparent management, the Government undertook a reform of the budgetary system aimed at: (i) generalizing the use of performance-based budgeting in all ministries, using program budgets; (ii) transferring some public expenditure management responsibilities from the Ministry of Finance to the sectoral ministries and decentralized administrative structures; and (iii) streamlining and automating the expenditure circuit.

32. Similarly, the Government introduced various reforms with respect to procurement. These reforms made it possible to introduce a new institutional framework for: (i) increasing transparency and efficiency in government procurement; (ii) modernizing procurement procedures; and (iii) establishing an independent oversight system in order to combat corruption in government procurement.

33. In the area of civil service reform, the Government introduced a Single Reference File that can be used to determine the precise number of paid civil servants, improve the State's personnel management, and curtail the introduction into the system of fraudulent appointment or promotion advices. Moreover, it delegated by decree, to the ministries responsible for education, the management of administrative acts pertaining to their personnel, and set up a technical framework for the integration and coordination of administrative reforms, made up of the Secretaries-General of the ministries.

34. Regarding decentralization and deconcentration, legal provisions on the budgetary and accounting framework for local governments have been adopted. To ensure that the transfer of appropriation management of the ownerships does not jeopardize the quality of public expenditure, 
the Government initiated a program to build local government capacities as regards fiscal management. It created an integrated organizational framework carrying out the reform in respect of deconcentration and established a mechanism for collaboration between the Prefects or the Mayors, as appropriate, and the decentralized agencies.

35. In addition, implementation of PRS 2003-2005 made it possible gradually to introduce a monitoring arrangement. Monitoring and evaluation indicators were defined and used in the preparation of progress reports. The Government recognizes, however, that some of the structures envisaged in the arrangement, such as the Departmental Monitoring Committees, have not functioned the way they should.

\subsection{Promoting jobs and capacity building for the poor}

36. The Government established the National Employment Agency (ANPE) and strengthened employment promotion structures. Significant advances were made in the microfinance area, in particular through capacity building for the stakeholders of the institutions concerned, support for the creation of the Regional Solidarity Bank (BRS) and its local Beninese branch, establishment of the microfinance support fund, and improvement of the legal and regulatory framework for microfinance institutions.

37. With respect to promoting community development, the Government carried out the local master plans for establishing a number of pilot villages in order to make the National Community Development Plan operational. Actions were also taken in connection with the social protection and promotion of women, in particular the exemption from primary school tuition payment for girls, the promotion of access by girls to merit-based academic scholarships, the adoption and implementation of the laws and regulations on the protection of children, and especially of girls, in the schools and apprenticeship centers.

38. Lastly, as regards security in at-risk areas, projects and programs were implemented to: (i) modernize agriculture and to improve the population's access to essential social services; (ii) improve access to development zones by rural access roads; (iii) prevent and resolve the problems associated with transhumance; and (iv) ensure that urbanization and tow management are controlled.

\subsection{Status of MDGs in Benin}

39. In deciding to work toward achieving the Millennium Development Goals (MDGs), the Government of Benin renewed its commitment to implementing the public policies needed to combat poverty and hunger, HIV/AIDS, the other diseases, illiteracy, environmental pollution, discrimination against women. This commitment is all the more necessary in that the progress made to date will probably not make it possible to achieve the MDG targets set for 2015, as indicated in Table 4 . The paragraphs which follow take stock of the progress made toward achieving the major MDG indicators and briefly describe the challenges to be met in order to achieve the goals established. These goals are addressed in detail in the chapters devoted to the strategic pillars of the SCRP.

\section{Eliminate extreme poverty and hunger}

40. Status quo: In Benin, poverty persists. Income poverty remains high, and declined only slightly in recent years. From 29.6 percent in 2000 , the income poverty indicator dropped to 28.5 
percent in 2002. Poverty is more pronounced in rural areas than urban ones. Malnutrition among children under age 5 is on the decline. Less than a fourth of children under age 5 are undernourished. Indeed, the proportion of children under age 5 suffering from malnutrition has evolved erratically since 1996 before stabilizing at 30 percent between 2003 and 2005.

41. Major challenges: The persistence of poverty calls for effective actions. Accordingly, the following challenges must be met: (i) improved credit access by households in the rural world; (ii) diversification of agricultural production; (iii) development of the baseline commune-level infrastructures (roads, water, electricity, telephone); (iv) capacity building in management and the absorption of public resources; (v) effective implementation of the national policy on promoting women; (vi) accelerated growth and improved redistribution; and (viii) accelerated land tenure reform. Moreover, the baseline principles such as the promotion of good governance, social dialogue, and the effective implementation decentralization are likely to play a decisive role in the poverty reduction strategy.

\section{Ensure a primary education for all}

42. Status quo: In the education area, the overall indicators on primary education show a trend which, if maintained, may lead to achieving this goal. There are nevertheless significant disparities between regions and by gender. Moreover, the rate at which children are retained in the system has scarcely improved over the period.

43. Remarkable efforts have been made gradually to move toward achieving the objective of primary education for all. The Gross Enrollment Ratio (GRE) in primary education, which registered 82.8 percent in 2000, is estimated at 94 percent in 2005. Over the same period, the gross enrollment ratios of girls and boys increased, respectively from 67.9 percent to 83 percent and from 97.2 percent to 104 percent. The gap between girls and boys has declined considerably: the number of girl pupils per 100 boy pupils improved markedly, rising from 67 in 2000 to 80 in 2005. If this trend continues, the target (1:1) could be met by 2015 . In contrast, the pupil-teacher ratio has deteriorated considerably, from 39.9 in 1992 to 55.8 in 2000 and then improving to 50 in 2005.

Major challenges: The major challenges to achieving universal access to primary education by 2015 are: (i) enhancing the value of the teaching function; (ii) improving access to schooling on the part of girls and keeping children in the school system; (iii) increasing the number of teachers; (iv) improving the institutional framework; (v) supporting the communes with socio-community infrastructure; (viii) constructing and maintaining training schools; (ix) outfitting the schools and school canteens and facilitating transport; and (x) effectively making primary education free of charge.

Table 4: MDGs, current situation, and path ahead for Benin

\begin{tabular}{|c|c|c|c|c|}
\hline Objectives & Targets & Indicators for Benin & $\begin{array}{l}2004 \text { current } \\
\text { value of } \\
\text { indicator }\end{array}$ & $\begin{array}{l}\text { MDG target } \\
\text { value for } 2015\end{array}$ \\
\hline \multirow{3}{*}{$\begin{array}{l}\text { 1. Eliminate extreme } \\
\text { poverty and hunger }\end{array}$} & \multirow{2}{*}{$\begin{array}{l}1.50 \% \text { reduction of proportion of } \\
\text { Beninese living below poverty line, with } \\
\text { poverty index improving to } 15 \% \text { by } \\
2015\end{array}$} & 1. Income poverty index & $36.3 \%$ & $15 \%$ \\
\hline & & 2. Human poverty index & $48.9 \%$ & $16 \%$ \\
\hline & $\begin{array}{l}\text { 2. By } 2015 \text {, reduce by } 50 \% \text { the number } \\
\text { of persons suffering from malnutrition }\end{array}$ & $\begin{array}{l}\text { 3. Proportion of underweight } \\
\text { children }\end{array}$ & $30 \%$ & $14.6 \%$ \\
\hline 2. Primary education for all & 3. By 2015 , provide primary education & 4. Gross enrollment ratio in & & $100 \%$ \\
\hline
\end{tabular}




\begin{tabular}{|c|c|c|c|c|}
\hline & \multirow{3}{*}{ to all children of school age } & primary school & & \\
\hline & & 5. Primary completion rate & $54 \%$ & $100 \%$ \\
\hline & & 6.Literacy rate & $62 \%$ & $100 \%$ \\
\hline \multirow{3}{*}{$\begin{array}{l}\text { 3. Promote gender equality } \\
\text { and the autonomy of } \\
\text { women }\end{array}$} & \multirow{3}{*}{$\begin{array}{l}\text { 4. Eliminate gender disparities in } \\
\text { primary and secondary education by } \\
2005 \text { and at all education levels by } \\
2015 \text { at the latest }\end{array}$} & $\begin{array}{l}\text { 7. Girl-boy ratio in primary } \\
\text { and secondary }\end{array}$ & 0.75 & 1 \\
\hline & & $\begin{array}{l}\text { 8. Percentage of elected officials } \\
\text { by gender (\% women) }\end{array}$ & $3.2 \%$ & $30 \%$ \\
\hline & & 9. Female participation indicator & 0,356 & 1 \\
\hline \multirow{3}{*}{ 4. Reduce infant mortality } & \multirow{3}{*}{$\begin{array}{l}\text { 5. Reduce infant/child mortality rate } \\
\text { from } 166.5 \text { per mil in } 1996 \text { to } 65 \text { per } \\
\text { mil by } 2015\end{array}$} & 10. Death rate of children under 5 & 146.4 per mil & 65 per mil \\
\hline & & 11. Infant mortality rate & 65.6 per mil & 39 per mil \\
\hline & & $\begin{array}{l}\text { 12. Proportion 1-year-olds } \\
\text { vaccinated against measles }\end{array}$ & $99 \%$ & $100 \%$ \\
\hline \multirow{3}{*}{ 5. Improve maternal health } & \multirow{3}{*}{$\begin{array}{l}\text { 6. Reduce maternal death rate from } 498 \\
\text { per } 100,000 \text { live births in } 1996 \text { to } 390 \text { by } \\
2015\end{array}$} & 13. Maternal mortality rate & $474.4 / 100,000$ & $390 / 100.000$ \\
\hline & & $\begin{array}{l}\text { 14. Proportion of assisted } \\
\text { childbirths }\end{array}$ & $75 \%$ & $100 \%$ \\
\hline & & 15. Prenatal care coverage rate & $90 \%$ & $100 \%$ \\
\hline \multirow{7}{*}{$\begin{array}{l}\text { 6. Fight HIVIAIDS, } \\
\text { malaria, and other } \\
\text { diseases }\end{array}$} & \multirow{3}{*}{$\begin{array}{l}\text { 7. Reduce the prevalence of STIs and } \\
\text { HIVIAIDS }\end{array}$} & $\begin{array}{l}\text { 16. Prevalence of HIVIAIDS } \\
\text { among expectant mothers ages } \\
15 \text { to } 24\end{array}$ & $2 \%$ & $1.9 \%$ \\
\hline & & 17. Contraception usage rate & $10.1 \%$ & $40.9 \%$ \\
\hline & & $\begin{array}{l}\text { 18. Number of children orphaned } \\
\text { by AIDS }\end{array}$ & 32,810 & Stabilized \\
\hline & \multirow{4}{*}{$\begin{array}{l}\text { 8. By } 2015 \text {, bring malaria and other } \\
\text { major diseases under control and } \\
\text { begin to reverse the current trend }\end{array}$} & 19. Malaria incidence rate & 116 per mil & ND \\
\hline & & 20. Death rate from malaria & 140 per mil & ND \\
\hline & & 21. Prevalence of tuberculosis & $4.5 \%$ & Stabilized \\
\hline & & $\begin{array}{l}\text { 22. Rate of use of health services } \\
\text { of health (curative care) }\end{array}$ & $37 \%$ & $100 \%$ \\
\hline \multirow{7}{*}{$\begin{array}{l}\text { 7. Ensure a sustainable } \\
\text { environment }\end{array}$} & \multirow{4}{*}{$\begin{array}{l}\text { 9. Incorporate the principles of } \\
\text { sustainable development into national } \\
\text { policies and reverse the current trend } \\
\text { of dwindling environmental resources }\end{array}$} & $\begin{array}{l}\text { 23. Area of protected spaces (in } \\
\% \text { ) }\end{array}$ & $0.18 \%$ & $1 \%$ \\
\hline & & $\begin{array}{l}\text { 24. Household waste removal } \\
\text { method (waste collection } \\
\text { percentage) }\end{array}$ & $10.1 \%$ & $34 \%$ \\
\hline & & $\begin{array}{l}\text { 24. GDP per energy unit } \\
\text { consumed (energy yield) }\end{array}$ & $3.2 \%$ & ND \\
\hline & & $\begin{array}{l}\text { 25. Carbon dioxide emissions (per } \\
\text { capita) }\end{array}$ & 300 & ND \\
\hline & $\begin{array}{l}\text { 10. By } 2015 \text {, reduce by half the } \\
\text { share of the population without } \\
\text { sustainable access of way to a } \\
\text { source of safe drinking water }\end{array}$ & $\begin{array}{l}\text { 26. Proportion of population with } \\
\text { access to a source of safe } \\
\text { drinking water }\end{array}$ & $76 \%$ & $100 \%$ \\
\hline & \multirow{2}{*}{$\begin{array}{l}\text { 11. By } 2015, \text {, appreciably } \\
\text { improve living conditions of at } \\
\text { least } 2 / 3 \text { of Beninese slum } \\
\text { dwellers }\end{array}$} & $\begin{array}{l}\text { 27. Proportion of households } \\
\text { with no latrine or toilet }\end{array}$ & $67.3 \%$ & $42 \%$ \\
\hline & & $\begin{array}{l}\text { 29. Proportion of substandard } \\
\text { housing units }\end{array}$ & ND & ND \\
\hline
\end{tabular}

Source: Excerpt from the departmental Report on the MDGs in Benin, MDG-PRSP and OCS/MDEF.

\section{Promote gender equity and the autonomy of women}

44. Status quo: The literacy rate of females age 15 and above improved by more than 5.9 percentage points from 1992 (16 percent) to 2002 (21.9 percent). In 2002, the literacy rate of women ages 15-24 is estimated at 31.4 percent as compared to 56.2 percent for men.

45. As regards the participation of women in the development process, the composite "Women's Participation Indicator" (WPI) registered an increase of 13 percent from 2001 (0.315) to 2004 (0.356). Notwithstanding this change, women still hold only 7.2 percent of the seats in Parliament, reflecting the weak degree of participation by Beninese woman in the political and decision-making processes.

46. Major challenges: The challenges facing Benin in respect of achieving this objective are: (i) attenuating the effect of socioeconomic and cultural obstacles; (ii) ensuring that the localities have adequate school infrastructures; and (iii) effective implementation of the Individual and Family Code. 


\section{Improve primary health care}

47. Status quo: With regard to maternal and child health, appreciable efforts have been made in respect of prenatal care, but the extent to which childbirth is medically assisted is still low. Stabilization and reversal of the AIDS pandemic continues to pose problems. The frequency of visits to health services (for curative care) is improving, but the access rate remains low, at 35 percent in 2002, 38 percent in 2003, and 37 percent in 2005.

48. Major challenges: One of the major constraints to achieving the goals relating to primary health care continues to be the shortfall in the financial resources required for investment in baseline infrastructure, so as to ensure the coverage of primary health care costs and make such care available to the people. So long as households continue to bear over half $f^{5}$ of health care costs, it will be difficult to achieve the objectives relating to the frequency of access to health services and bringing the major diseases under control.

49. The challenges that will have to be met in order to achieve the MDGs by 2015 are: (i) information, education, and communications in support of behavioral changes; (ii) combating cultural practices that are harmful to health; (iii) strengthening the efforts to combat unhealthy behaviors; (iv) facilitating access to essential social services (education, health, safe drinking water, sanitation, and other baseline infrastructure), especially in rural areas; and (v) educating the public about the causes of infant/child mortality and about the public's access to relevant kinds of care.

\section{Protecting the environment and mobilizing resources for sustainable development}

50. The major challenges ahead continue to be the constraints on mobilizing the resources needed to modify behaviors that are inconsistent with safeguarding the environment on the one hand, and, on the other, meeting the commitments between the international community and the Beninese State to ensure that all partners contribute to reaching the MDGs, namely: (i) the consistent easing in the conditionality associated with grants and lines of credit; (ii) good governance and the optimal absorption of the funds mobilized; and (iii) framework of the interventions of development partners in the various priority sectors and departments.

51. On the whole, it appears that the progress recorded is such that, at the current pace, it will not be possible to achieve the major Millennium Development Goals. There are many reasons for this, mostly relating to the ineffectiveness of public expenditure, insufficient access to developed country markets, and a number of structural problems such as (i) poor governance and corruption; (ii) low productivity, the lack of competitiveness, and the vulnerability of the Beninese economy; and (iii) poverty.

\footnotetext{
${ }^{5}$ According to the economic accounts for public health published in 2006 , households contribute as much as 52.3 percent of health care financing in Benin.
} 
Figure 1: Evolution of the principal indicators of MDGs

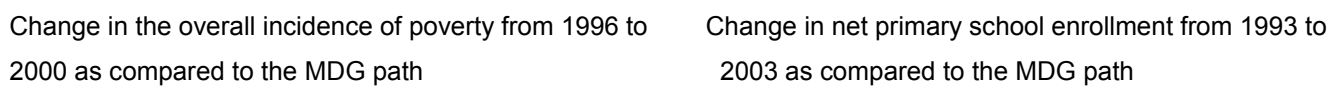

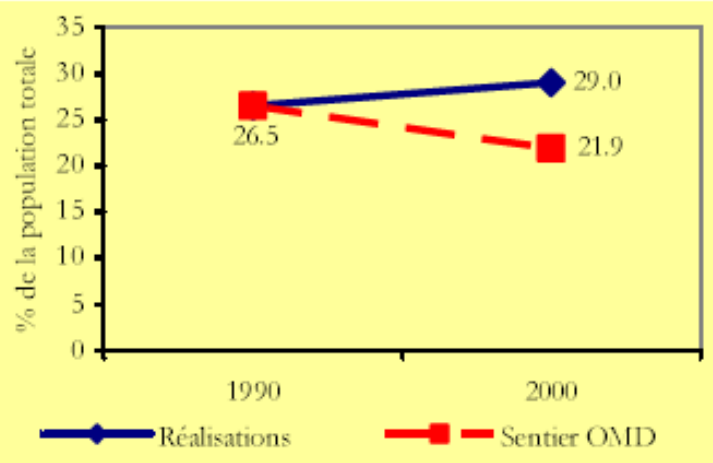

$\%$ of total population

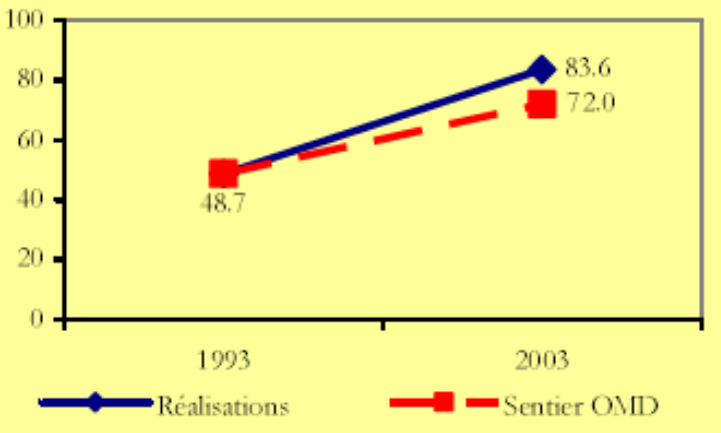

Actuals

MGD path
Change in the infant/child mortality rate from 1996 to 2002 as compared to the MDG path to 2004 as compared to the MDG path

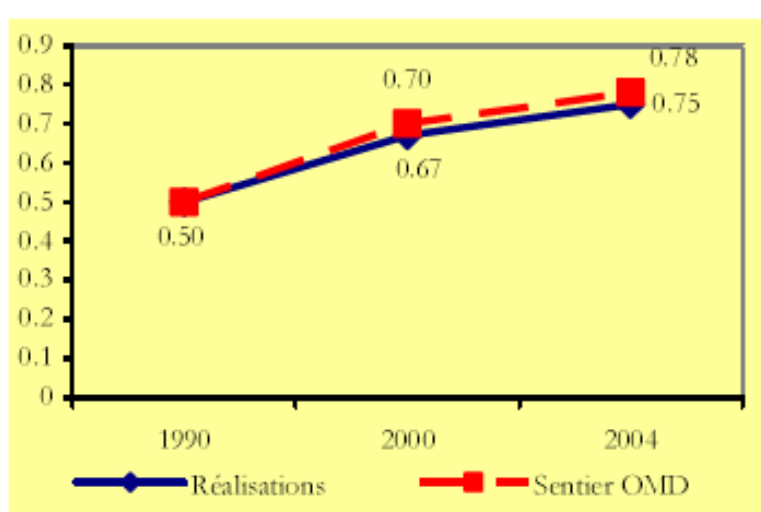

Actuals
MGD path

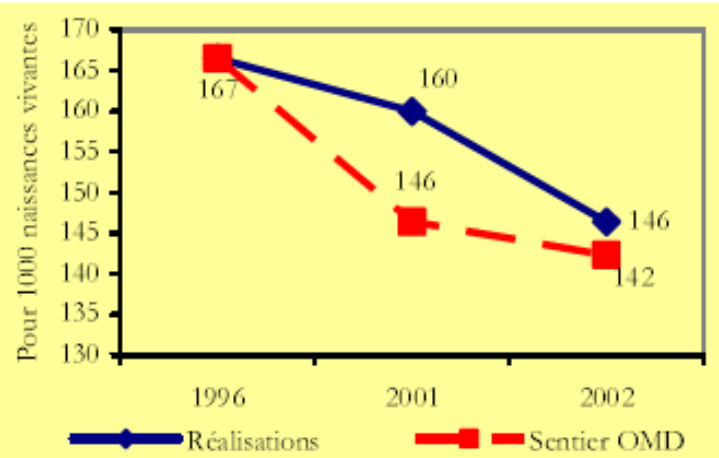

Per 1,000 live births

Actuals

MGD path 
Change in maternal mortality rate from 1996 to 2002
As compared to the MDG path

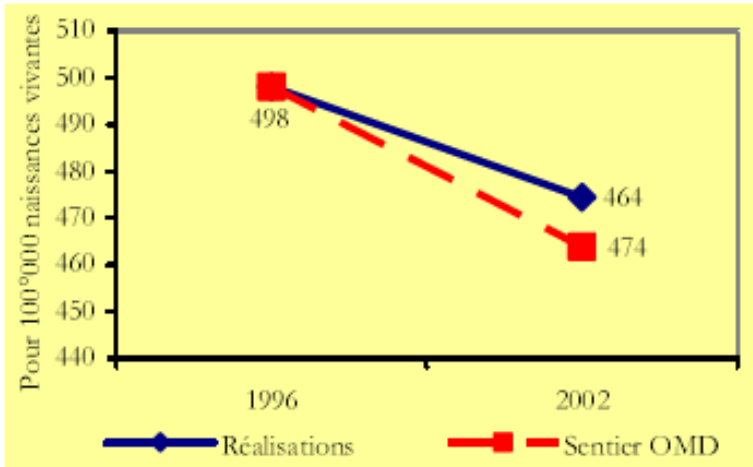

Per 100,000 live births
Change in proportion of official assistance devoted to social sectors from 1999 to 2004

Source: Excerpted from the Departmental report on the MDGs in Benin, MDGs-PRSP and OCS/MDEF.

52. All in all, the evaluation of PRS 2003-2005 showed that while many reforms were initiated, it must be acknowledged that the results fell short of the objectives set. Moreover, progression toward the MDGs could also be jeopardized. This poorer than expected performance is explained by: (i) insufficient attention being devoted to growth issues, in particular the revitalization of the private sector and the development of sectoral and regional growth poles; (ii) underestimation of the role played by human capital in the growth and poverty reduction process; (iii) underestimation of the internal resistance within the public administration to the changes implied by the principles of performance-based management and good governance; and (iv) the limited involvement of local communities in the development process. 


\section{CHAPTER 3: CHARACTERISTICS AND DYNAMICS OF POVERTY}

53. Poverty is multidimensional. It can be analyzed using a monetary approach, treating per capita income or expenditure as a standard-of-living indicator, or using a nonmonetary approach, based on a composite standard-of-living index based on household living conditions and property.

54. The data published here are drawn from the provisional and partial results of the EMICoV survey of 2006 and th4e CWIQ survey of 2002 for the evaluation of income poverty, and the Demographic and Health Survey (EDS) of 2006 for nonmonetary poverty. The initial comparative analyses of income poverty between 2002 and 2006 would appear to indicate a significant increase in poverty in Benin. However, this finding merits explanation (see Box 3)/

Box 3: The EMICoV survey and the scope of the data used for poverty analysis

The Integrated Modular Survey of Household Living Conditions (EMICoV) 2006 is one of the regular survey instruments in Benin. It combines baseline surveys spread over time and light surveys incorporated on a more regular basis, which allows SCRP monitoring and evaluation over time. Operationally, the EMICoV is carried out in four 3-month rounds a one-month break between rounds.

The survey covers a sample of 18,000 households distributed throughout the 77 communes. The sample includes 7,440 urban households and 10,560 rural households.

In practice, the survey began in August 2006. The poverty diagnosis presented in this paper is therefore based on the data from the first round (August-November 2006), which do, however, include retrospective information covering the preceding twelve months. In addition, the analyses carried out covered a sample of 5,231 households that are representative only as regards the area of residence (urban and rural).

These constraints are likely to have an impact on the effective comparability of the data and the robustness of the assessment of the way poverty and inequalities evolved between 2002 and 2006. The results must thus be interpreted with caution pending the full completion of the EMICoV survey and the processing thereof, so as to ensure a rigorous diagnosis of Beninese poverty over time and space, in particular at the commune level.

\subsection{Changes in poverty over the 2002-2006 period}

55. Income poverty: a significant increase. Income poverty analyzed in accordance with the customary indicators of incidence (P0), depth (P1) and severity (P2) was evaluated with reference to annual poverty thresholds ${ }^{6}$ established respectively at CFAF 74,886 per capita in 2002 and CFAF 82,224 CFAF in 2006. The initial provisional and partial results of the EMICoV survey show an increase in poverty since 2002. The incidence of poverty increased from the 2002 level, rising from 28.5 percent to 36.8 percent. Similarly, the depth of poverty (P1) increased appreciably during the period, from 11 percent in 2002 to nearly 14 percent in 2006, with a more pronounced change in rural areas.

\footnotetext{
${ }^{6}$ The measurement of income poverty was carried out using a standard-of-living indicator, namely total household expenditure per capita, including the value of self-consumption. The overall poverty line is that of 2002 , updated by using the GDP deflator.
} 
Table 5: Changes in poverty indicators from 2002 to 2006

\begin{tabular}{|c|c|c|c|c|c|c|}
\hline \multirow[b]{2}{*}{ Area of residence } & \multicolumn{3}{|c|}{2002} & \multicolumn{3}{|c|}{2006} \\
\hline & P0 & $\mathrm{P} 1$ & $\mathrm{P} 2$ & $\mathrm{P} 0$ & $\mathrm{P} 1$ & $\mathrm{P} 2$ \\
\hline Urban & 23.6 & 0.107 & 0.069 & 27.2 & 0.110 & 0.060 \\
\hline Rural & 31.6 & 0.110 & 0.058 & 40.6 & 0.149 & 0.075 \\
\hline Together & 28.5 & 0.109 & 0.062 & 36.8 & 0.138 & 0.071 \\
\hline
\end{tabular}

56. Nonmonetary poverty: $:^{7}$ a decline contrasting with income poverty. When nonmonetary poverty is examined by means of a composite standard-of-living indicator, the data from the third general population and housing census (RGPH3) show that the phenomenon affected nearly 43 percent of the population in 2002, at a rate three times higher for individuals in rural areas than in urban areas (59.1 percent as compared to 17.7 percent).

57. In 2006, nonmonetary poverty declined overall: 41.1 percent of the population are poor as compared to 43 percent in 2002. However, the phenomenon appears to have worsened in urban areas. The number of urban poor increased by a factor of 1.2: the incidence of urban poverty increased from 17.7 percent in 2002 to 22.1 percent in 2006. In rural areas, the incidence of poverty fell by 12.9 percent, dropping from 59.1 percent in 2002 to 50.8 percent in 2006 (see Annex 28).

58. The correlation between the per capita expenditure and the composite is not very high (0.58), but is significant. Furthermore, this correlation is even lower for rural households, for which the coefficient of correlation is 0.29 as compared to 0.63 in urban areas. This indicates that the multidimensional analysis based on the composite index fails to yield a classification of households identical to that from the income poverty approach. However, both indicators show the extent of poverty to Benin.

59. Subjective poverty: households state that living is becoming more and more difficult. Basing analysis on the people's perceptions of poverty makes it possible to escape the "normative" nature of defining the concept of poverty. The imposition of a single style of living is thus avoided. The determination of needs and of the reference poverty threshold is left up to the assessment of those surveyed.

60. The overall assessment by households of their own well-being is rather negative. In 2006, those deeming their lives to be difficult are estimated at 38.7 percent in 2006 as compared to 37.2 percent in 2001. Even if the analysis is limited to Cotonou, for which reference values (from the 1-2-3 household survey conducted in 2001) are available, there is a worsening perception of poverty in 2006. Those quite happy with their situation increased from 3.1 percent of the population in 2001 to 4.3 percent in 2006 . On the whole, slightly over a third of the

\footnotetext{
${ }^{7}$ The "living conditions" approach consists in defining the level of poverty on the basis of material housing conditions. The subjective poverty approach, in turn, is pillared on indicators based on the perceptions of the population. This makes it possible to gather individuals' assessments of their own living conditions.
} 
Beninese feel them more or less satisfied in terms of well-being. One can add to this group the 22 percent of households expressing relative satisfaction while emphasizing that their households are not altogether free of problems. Overall, nearly two households out of five which state that their lives are difficult, and thus should be classified in the poor category. The incidence of subjective poverty is thus relatively high ( 38.7 percent).

Table 6: Assessment of the subjective well-being of households

\begin{tabular}{|lcc|}
\hline Percentage of households stating that: & 2001 & 2006 \\
\hline & & 3.1 \\
Things are going well & 33.3 & 4.3 \\
Things are pretty much okay & 26.4 & 35.0 \\
We have to be careful & 37.2 & 22.0 \\
Living is difficult & 100 & 38.7 \\
\hline & 100 \\
\hline Sources: 1-2-3 Survey, Multiple Dimensions of Poverty module, INSAE, 2001; partial and preliminary results from the first round of \\
the EMICoV survey, 2006.
\end{tabular}

61. The primary needs deemed to be essential by Beninese households broadly parallel those usually identified in studies on the perceptions of poor population groups. They relate in particular to food, healthcare, education, access to baseline services, and housing.

Box 4: Vital needs according to households

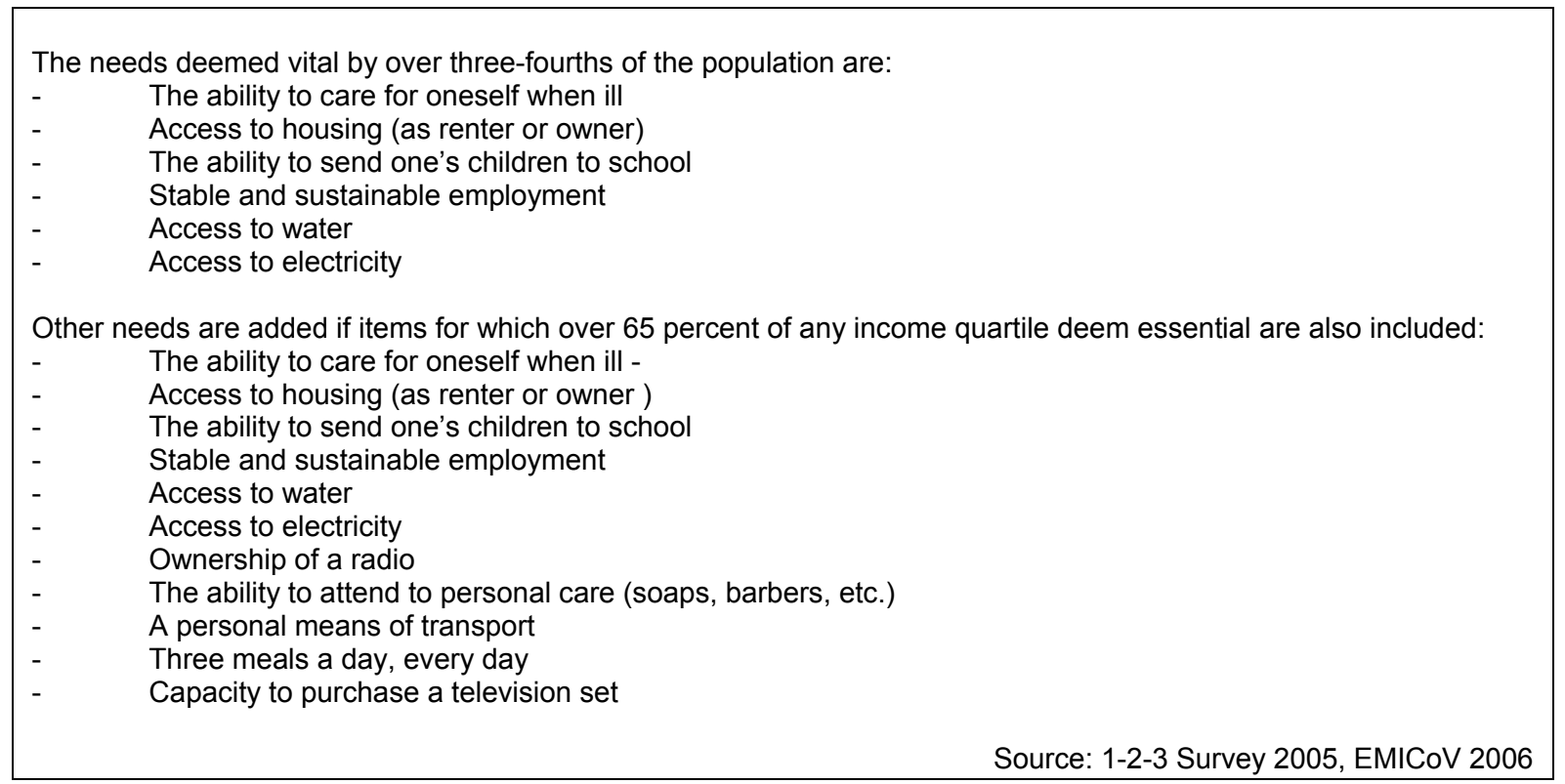

\subsection{Inequalities in Benin}

62. Analysis of changes in the incidence of poverty does not, in and of itself, make it possible properly to assess the poverty situation. Such analysis must be supplemented by analysis of changes in inequalities in income distribution or expenditures in order to have a full sense of the dynamics of income poverty. 
63. Analysis of household consumption expenditures on the basis of the preliminary and partial results of the EMICoV 2006 survey indicates that inequalities were reduced between 2002 and 2006. Indeed, nationwide, the Gini index declined from 0.430 in 2002 to 0.398 to 2006, a drop of 7.4 percent. The same trend may also be observed for urban households, but with a much more pronounced drop on the order of 21.3 percent. In contrast, for rural households, inequalities rose by 6.4 percent. This said, the urban areas, despite the drop noted, are those with the greatest inequalities.

Table 7: Inequality in Benin between 2002 and 2006

\begin{tabular}{lll} 
& $\mathbf{2 0 0 2}$ & $\mathbf{2 0 0 6}$ \\
\hline Urban areas & 0.478 & 0.395 \\
Rural areas & 0.361 & 0.384 \\
\hline Together & 0.437 & 0.398 \\
\hline Sources: CWIQ 2002 and provisional and partial results from the first round of EMICoV 2006.
\end{tabular}

\subsection{Sociodemographic characteristics of poverty}

64. Poverty and household size: a positive correlation. In 2002, household poverty increased proportionally with size. Households of more than six people had an incidence of poverty twice that of households of fewer than three, both in rural areas and urban areas. The effect household size on poverty incidence does, however, appear to be more perceptible in urban areas, where the incidence of poverty of households of six people or more is four times higher than that of households of less than three.

65. In 2006, this relationship between the standard of living and the household size of is confirmed both from the standpoint of income poverty and from that of nonmonetary poverty. Indeed, the incidence of nonmonetary poverty is 1.25 times greater in households of more than six people than in those of less than three. This ratio, which was 2 in 2002, is less pronounced in the case of nonmonetary poverty in 2006, but for income poverty increased from 2 in 2002 to 3 in 2006.

66. Poverty and education level: a strong negative correlation. Generally, poverty decreases as the education level increases. Having a sizable stock of human capital enables an individual to seize more economic opportunities and thereby improve his or her standard of living. Households headed by someone with no education are 2.5 times more likely to suffer from nonmonetary poverty than those headed by a person with primary education. This ratio is 10.8 when households are headed by someone with secondary education and 29.2 for higher education. These wide gaps are explained by the fact that the level of instruction is positively correlated with the standard of living. The ratio ranges from 1.1 to 5.5 for income poverty.

67. According to a World Bank study ${ }^{8}$ (2003) based on data from the CWIQ 2002 in Benin, beyond the first three years of elementary school, which have little impact on the level of the consumption expenditure, each additional year study by the head of household makes

\footnotetext{
${ }^{8}$ Report on poverty in Benin.
} 
substantially improves the household consumption level. For two households of the same size and in the same location, the one headed by a person who has completed the four years of the primary cycle will, on average, have a level of consumption that is 14 percent higher than the one in which the had of household received no education.

68. In 2006, the relation ship between poverty and education level continued. Households headed by an individual with no formal education have twice the number of poor as those headed by an individual with primary education, and seven times more in the case of secondary education. These results show that the returns on investment in education are perceptible beyond four years of primary study and even greater beyond primary education. The data considerably reinforce the importance of formal education as a means of combating poverty.

69. Poverty and gender: a pronounced shift in favor of women. The effect on poverty of the gender of the head of household is pronounced. In 2002, the nonmonetary poverty index of households headed by men was 45 percent, as compared to 33 percent for households headed by women. The difference between these two rates is statistically significant at the 5 percent level. In 2006, there fewer poor in households headed by women than in those headed by men. The incidence of nonmonetary poverty is 42.3 percent for men as compared to 34.6 percent for women. There are thus 1.33 times poorer in male-headed households than in female-headed households. A substantial proportion of poor female heads of household are widowed, divorced, or separated (approximately 45 percent). As regards income poverty, there are 1.09 times poorer in households headed by men.

70. Migration and poverty: a negative correlation. Migratory movements have significant economic, sociocultural, and demographic impacts on the departure area, host area, and households. According to the 2006 World Economic Outlook, migration can improve wellbeing and reduce poverty. Indeed, remittances from workers abroad, in particular, are an important means of escaping extreme poverty for many individuals. ${ }^{9}$

71. In 2006, non migrants are, overall, poorer than migrants. The incidence of poverty for these households is estimated at 41.95 percent, as compared to 21.7 percent for migrants. This confirms the trend observed in 2002, when there were 2.5 times poorer among non migrants than among migrants.

\subsection{Determinants of the various forms of poverty}

72. The factors behind poverty in Benin are fundamentally the socioeconomic characteristics of households and access to social services. In both urban and rural areas, the determinants that are seen over and over again are household size, the age of the head of household, his or her level of education, his or her gender, migratory status, access to economic infrastructures (housing, health, water and electricity, telecommunications), and access to production factors.

73. Overall, the education level of the head of household has a positive influence on the household's standard of living. Heads of household with no education are less likely to

\footnotetext{
${ }^{9}$ Bourguillon, 2006.
} 
experience an improvement in living standards than are those completing primary, secondary, or higher education. Migratory status also has a positive influence on household living standards. This corroborates the fact that migration can improve well-being and reduce poverty.

\subsection{Contribution of growth and inequality: a weak growth effect}

74. The increase in poverty between 2002 and 2006 could stem from low growth in average expenditure ("growth effect") or from deterioration in inequalities ("distribution effect").

75. Point-by-point analysis of evolution of poverty shows that the decline is attributable primarily to slow economic growth, attenuated, however, by the significant decrease in inequalities, in particular in urban areas. Rural areas showed the greatest increase in the incidence of poverty. There, it increased by 9 percentage points as against 3.6 in urban areas. This deterioration observed in rural areas is attributable to the unfavorable impact of the low growth in average rural household consumption and to the increased disparities in the distribution of such spending. 
Table 8: Changes in poverty incidence between 2002 and 2006 (in percent)

\begin{tabular}{|lccc|}
\hline & Total change & Growth effect & Redistribution effect \\
\hline Urban & 3.6 & 8.8 & -5.2 \\
Rural & 9.0 & 4.9 & 4.1 \\
\hline Total & 8.3 & 9.7 & -1.4 \\
\hline Sources: CWIQ 2002 and provisional and partial results from first round of EMICoV 2006 & \\
\hline
\end{tabular}

76. Overall, the breakdown of changes in poverty incidence between 2002 and 2006 illustrates the highly unfavorable effect of the low growth in household consumption expenditure. These results, even partial as they are, should lead to an emphasis on pro-poor growth.

Box 5: Growth Incidence Curve (GIC)

This approach considers the cumulative distribution function $F_{t}(y)$ of expenditure on consumption, yielding the proportion of households having resources of less than $y$ at time $t$, so that the inverse $F_{t}^{-1}(p)$ in the $p^{\text {th }}$ quintile shows the expenditure of that quintile:

$y_{t}(p)=F_{t}^{-1}(p)=L_{t}^{\prime}(p) \mu_{t} \quad\left[y_{t}(p)>0\right]$

where $L_{t}^{\prime}(p)$ designates the derivative of the Lorenz curve and $\mu_{t}$ the average consumption expenditure at date $\mathrm{t}$.

If we take account of the two periods of investigation $(1,2)$, the growth rate of expenditure in the $p^{\text {th }}$ quintile is given by:

$g(p)=\left[\left(y_{2}(p) / y_{1}(p)\right)-1\right]$

By stipulating that $\mathrm{p}$ ranges for 0 to $1, g(p)$ shows what is known as the Growth Incidence Curve (GIC), or:

$g(p)=\left\{\left[L_{2}^{\prime}(p) / L_{1}(p)\right]\left(\gamma_{1}+1\right)\right\}-1 \quad \quad(3)$

where $\gamma=\left[\left(\mu_{2} / \mu_{1}\right)-1\right]$ expresses the growth rate of $\mu$ between the two periods. When ${ }^{g(p)>\gamma}$ for any $\mathrm{p}$ covering the poor, it may be concluded that economic growth is unambiguously "pro-poor" or, in other words, that the benefits derived by the poor from said economic growth are proportionally greater than those accruing to the wealthy.

77. The growth incidence curve falls below the right axis (Figure 2) representing the growth rate of average expenditure between 2002 and 2006 for the poorest. This confirms that economic growth in Benin would not have been beneficial to the poor. 
Figure 2: Growth curve of consumption expenditure between 2002 and 2006

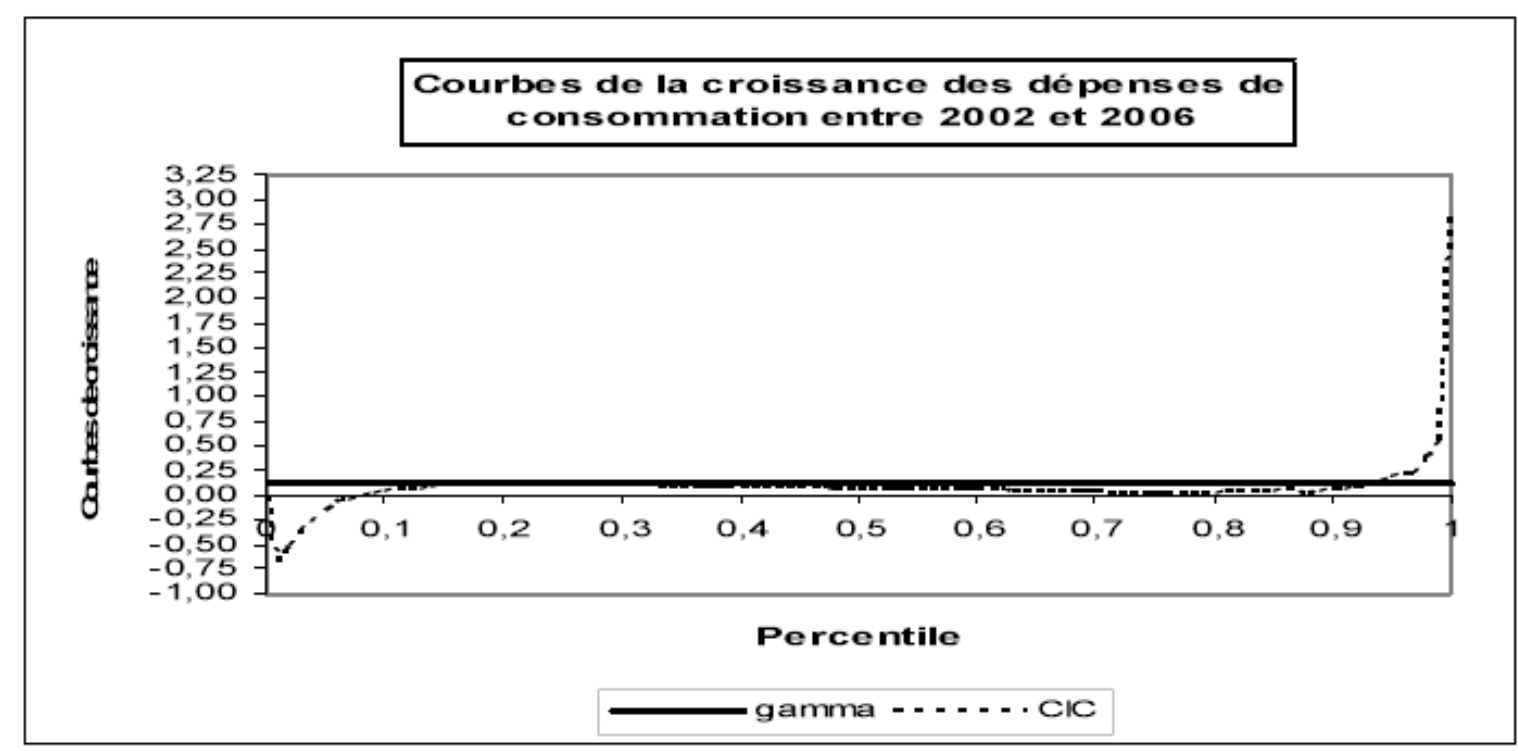

Growth curves

Percentile

Gamma GIC

78. Analysis of the determinants and evolution of poverty clearly shows that economic growth is the essential factor in poverty reduction. Moreover, national consultations have shown that corruption is harmful to the business-enabling environment. For these reasons, the strategic approach is aimed at accelerating economic growth, promoting good governance, and ensuring equitable social development in a poverty reduction context.

79. The ultimate objective of the Beninese authorities targeted by this strategy is sustainable and effective improvement in the living conditions of the people through attacking the root causes of poverty. For it to succeed, the Government intends to implement a policy of accelerated economic growth and poverty reduction compatible with the Millennium Development Goals (MDGs) which it supports. The Government is aware of the fact that economic growth is a necessary but not sufficient condition for poverty reduction. Indeed, the poor lack services, resources, and prospects as much as they lack money. Accordingly, in addition to economic growth, the Actions of the Government will place priority on building human capital, emphasizing developing the capacities of individuals who have been excluded. In this context, actions will particularly stress health, education, adult literacy, relations between the sexes, and the degree of social inclusion, all of which are factors that promote or reduce the wellbeing of each and every individual and help determine the prevalence of poverty. In the short term, educational and health-related policies, especially reproductive health and the major epidemics, while contributing to the training and development of human capital, will have a direct impact on growth. In the long term, social investments will help achieve the objective of slowing population growth. To enhance the effectiveness of this strategy, the Government will use grassroots development and decentralization in order to create wealth and jobs through regional economic and agricultural poles. 
PART TWO: STRATEGIC PILLARS OF THE SCRP STRATEGY 
80. The population of Benin is growing at an annual rate of 3.25 percent. The structural characteristics of this population, which is growing that fast essentially due to a still high birth rate and a declining - but still high - mortality rate, pose numerous challenges for Beninese society, especially satisfaction of ever greater needs for human capital development (nutrition, education, health), employment, housing, urban management, and so on. The total number of inhabitants increased from 6.77 million in 2002 to 7.6 million in 2006. By 2009, the total population is projected to reach 8.3 million, with 43 percent living in urban areas, up from 41 percent in 2006. In 2009, the school-age population (6-11 years) will account for 18.8 percent of the total population, while children under 5 years of age will account for 16.5 percent. These segments of the population will exert considerable social demand in terms of nutrition, health, and schooling needs. Satisfying that demand will help improve the well-being of the population and require actions in both the economic and social sectors in 2007-2009. The core challenge is to match demographic growth with economic growth and implementation of appropriate income distribution, social solidarity, and environmental policies.

81. Despite the Government's and Technical and Financial Partners' efforts during implementation of the PRS in 2003-2005, monetary poverty persists due to the subdued rate of growth of the economy, which appears, moreover, to have mostly benefited the better-off socioeconomic strata. On the other hand, certain social indicators have evidently improved and contributed to a marked improvement in the standard of living of the population. These developments have led the Government to pursue an accelerated growth policy geared to generating sufficient wealth to improve the living conditions of the population and reduce poverty. This policy is described in the paper entitled "Strategic Development Guidelines (SDG) of Benin, 2006-2011," which are designed to underscore the following two challenges: (i) enhancement of the overall and sectoral competitiveness of the economy; and (ii) eradication of poverty and improvement of the population's standard of living.

82. The Government's goal, as set forth in the SDG, is to turn Benin into "a country that attracts investments, expedites economic growth, and equitably distributes the outcomes, a country that achieves successful integration in the global economy thanks to its export capacities." This aspiration can only materialize if the economy undergoes a far-reaching structural transformation triggering new, sectorally diversified, growth poles with project clusters maximizing demonstration effects, and if good governance is reinforced in the public sector.

83. The Government intends to achieve its goal by implementing a Growth Strategy for Poverty Reduction in 2007-2009. This framework, with built-in sectoral strategies, comprises responses to the concerns and needs of the different segments of the population. Overall, it aims to generate the conditions for accelerated growth as a mechanism for reducing poverty.

84. Five (5) strategic axes have been singled out as priority intervention areas, in which actions and measures will need to be adopted in 2007-2009. They are:

Axis 1: Acceleration of growth;

Axis 2: Development of infrastructure;

Axis 3: Human capital building;

Axis 4: Promotion of good governance; and

Axis 5: Balanced and sustainable regional development.

Box 6: Conceptual Framework of the SCRP [See original French for diagram] 


\section{[Vertical:] GROWTH STRATEGY FOR POVERTY REDUCTION}

\section{Acceleration of growth}

1. Stabilization of the macroeconomic framework

2. Revitalization of the private sector

3. Diversification of the economy

4. Promotion of regional integration

\section{Development of infrastructure}

1. Transportation infrastructure

2. Energy infrastructure

3. Hydraulic and sewer system infrastructure

\section{Human capital building}

1. Promotion of development education

2. Strengthening of professional training

3. Improvement of access to, and quality of, health and nutrition services

\section{Promotion of good governance}

1. Expediting of administrative reforms

2. Strengthening of the rule of law and individual liberties

\section{Balanced and sustainable regional development}

1. Sustainable regional and community development

2. Emergence of development and growth poles

3. Environment, natural resource management, and living environment

[Right column: Accelerated Growth Strategy

Poverty Reduction Strategy 


\section{CHAPTER 4: ACCELERATION OF GROWTH}

85. Despite the Government's efforts implementation of the 2003-2005 PRS led to weaker than anticipated rates of economic growth that approximated the rate of growth of the population. That meant that there was almost no per capita growth of gross domestic product in that period and, instead, a marked increase in monetary poverty. In order to reverse that trend, the Government aims, on the one hand, to increase investment in economic infrastructure and, on the other, to promote industrial diversification and integration.

86. To achieve that objective, under an "Emergent Benin Scenario," the Government has set itself four specific targets that will allow it to achieve average annual economic growth of 7 percent in 2007-2009.

87. Those targets entail priority interventions in the following four areas: (i) stabilization of the macroeconomic framework; (ii) revitalization of the private sector; (iii) diversification of the economy; and (iv) promotion of regional integration.

\subsection{Stabilization of the macroeconomic framework}

88. Over the past few years, Benin has observed most of the macroeconomic framework stabilization objectives adopted as European Union - West African Economic and Monetary Union (WAEMU) convergence criteria. In spite of those efforts, the measures put in place to consolidate the macroeconomic framework have proved incapable of withstanding the pressures exerted by the international and regional environment, which altered the assumptions on which projections had been based. To address these problems, the Government intends to: (i) strengthen the macroeconomic framework; (ii) monitor the macroeconomic environment; and (iii) improve the fiscal framework.

89. Strengthening of the Macroeconomic framework: With the support of Technical and Financial Partners, Benin has made a major effort to conceive and implement reforms aimed at strengthening the macroeconomic framework. Over the next three years, the Government intends to build on the progress made with those reforms. To that end, it will pursue fiscal consolidation policies and seek to curb inflation. The Government has opted for policies that, combined, will have a positive impact on competitiveness and economic growth.

90. Under the 2007-2009 SCRP, fiscal consolidation policies will continue. They will aim to: (i) raise Government revenue, mainly by broadening the tax base ${ }^{10}$ and making collection agencies more efficient; and (ii) make public expenditure more effective by introducing performance-oriented public administration. In addition, the Government will make sure that increased budgetary resources are allocated to the priority social sectors, at least in proportion to increases in the overall budget, despite the investments it plans to embark on through large economic infrastructure works. By so doing, by combining resource allocations and targeted transfers, the Government will ensure greater equity in the distribution of the fruits of growth. Particular attention will be paid to improving expenditure quality and control.

\footnotetext{
${ }^{10}$ Without, however, overtaxing energy, because that could lead to high demand for firewood and, consequently, to deforestation and degradation of their biodiversity.
} 
91. The Government will be rigorous in its implementation of fiscal policy. It will strengthen sectoral program-budgets to reflect the Priority Actions Program (PAP) derived from the SCRP strategy. The sustainability of fiscal policy will be assured by observing WAEMU convergence criteria. To that end, the Government will ensure that the level of indebtedness is viable and that financing shortfalls are covered by debt relief and bilateral and multilateral assistance, as well as by bond issues.

92. To improve the purchasing power of the population, the Government commits to guaranteeing price stability by: (i) reducing factor costs by expediting structural reforms; and (ii) eliminating overcharging by enforcing market mechanisms.

93. Monitoring the macroeconomic environment: In 2003-2005, Benin endured external shocks (closing of the Nigerian border for transit trade, plummeting cotton prices, higher oil prices) that had a major impact on economic growth. To anticipate, and possibly implement measures to mitigate, the effects of such external shocks on the economy, the Government has decided to establish a mechanism for monitoring factors in the domestic and external environments whose fluctuations affect the business cycle. To that end, the Government has decided to (i) promote the mechanism for economic and financial monitoring of the environment for the major economic sectors; and (ii) to coordinate that monitoring process at the national level.

94. Improving the tax framework: The SCRP accords high priority to promoting the private sector and large economic infrastructure projects. To finance these investment programs and the development of the private sector, considerable internal and external resources have to be mobilized. The Government intends to place particular emphasis on domestic taxation. Thus, it will (i) expand the tax base; (ii) embark on a restructuring and modernization of tax and customs administration by reorganizing departments, computerizing procedures, and stronger and equitable human resource capacity building; and (iii) strengthening tax audits with a view to eradicating tax fraud.

\subsection{Revitalization of the private sector}

95. The SCRP emphasizes promotion of the private sector as the engine of wealth and employment. To maintain that dynamism, the Government intends to: (i) embark on structural reforms; (ii) improve the business climate; and (iii) facilitate financial intermediation for this sector.

96. Structural reforms: As part of its efforts to improve the business climate, the Government has adopted a number of structural measures aimed at expediting the State's withdrawal from the productive sector and encouraging the development of private enterprise. There are still obstacles to the unfettered development of the private sector, especially with respect to the restructuring of key sectors and the introduction of regulatory systems.

97. In this context, the idea is to continue and to expedite the privatizations that are currently under way, taking care, in particular, to: (i) improve the legal and institutional framework for privatizations; (ii) enact the electricity sector policy; (iii) adopt the regulatory framework and establish the regulatory authority for the water and electricity sectors; (iv) complete privatization of the Post and Telecommunications Office and establish the regulatory authority for 
telecommunications; and (v) expedite the implementation of measures to enhance Cotonou port competitiveness.

98. The Government hopes to complete privatization of the industrial plant of the National Agricultural Promotion Company (SONAPRA) as soon as possible. To do so, it envisages setting up a private-law company, most of whose shareholders would be private individuals, to take over the gin mills. Moreover, to sustain growth and development of the private sector, the Government will expedite the structural reforms needed to attract foreign direct investment (FDI)

99. Improvement of the business climate: Accelerated and sustainable economic growth will require private sector development. That must translate into increased private investment and private sector competitiveness. In 2007-2009, the Government intends to implement its enhanced private sector development strategy, with particular emphasis on key actions in the areas of land ownership, taxation, the industrial free trade zone, and new agricultural activities. In this context, the Government will honor its commitment to businessmen to carry out the actions described in the enhanced private sector development strategy letter. In addition, the Government will ensure that the investments are accompanied by environmental and social risk management safeguards.

100. Financial intermediation in support of the private sector: In Benin, the difficulty of accessing financial capital is still a major constraint on private sector development, especially for small and medium-sized enterprises (SME) and farmers. In recent years, the development of microfinance has, to a modest extent, eased this constraint. Its contribution to SME and farmer financing could be much more significant with increased professionalism and Government support in the form of a Microfinance Support Fund to serve the least privileged strata, with particular attention to women. As for commercial bank loans, the Government is committed to promoting term deposits, so as to free up financial capital for investment.

101. Private sector promotion and project clusters maximizing demonstration effects will require considerable volumes of finance. The Government will create incentives for the formal financial sector to support private investment in lead sectors. It will also use the "BOT" (Build, Operate, Transfer) mechanism for the investments planned in its large-scale works program. 


\section{Box 7: Private sector development policy}

The private sector development policy letter sets out the reform program that the Government of Benin intends to implement, in order to reinforce the existing private sector revitalization strategy and support implementation of the 2007-2009 poverty reduction strategy. It describes the principal obstacles to development of the private sector, the main components of its plan to strengthen the private sector development strategy, and the specific reforms and actions to be undertaken.

Principal obstacles to private sector development. The main obstacles identified are: (i) land ownership hurdles; (ii) shortcomings of the judicial system and failure to honor contractual obligations; (iii) tax system deficiencies; (v) [Tr. sic] hindrances to domestic and foreign trade; (vi) high factor costs; (vii) lack of technical support to enterprises; (viii) dependence of the economy on cotton and the re-export trade; (ix) the limited range of export products; (x) corruption; (xi) weak public sector-private sector dialogue; and (xii) difficulty for enterprises of meeting quality requirements and standards.

Main lines of the private sector development strategy. The Government regards revitalization of the private sector as an opportunity to expedite growth and poverty reduction. That is why it proposes to boost the private sector development strategy by undertaking to rationalize the business environment, bring about a more diversified economy, and improve facilities for trade. The private sector revitalization strategy is geared, in particular, to:

- Improving the legal, juridical, and regulatory framework;

- $\quad$ Enhancing factor markets efficiency;

- Improving facilities for trade;

- $\quad$ Developing incipient productive activities and tourism;

- Developing infrastructure services; and

- $\quad$ Strengthening private sector support mechanisms.

Principal reforms and actions to be undertaken. Essentially, the reforms to be carried out are: (i) judicial reform, streamlining of the regulatory framework, enhancing the competitiveness of local enterprises and rationalizing protection mechanisms, tax reform, and stepping up the fight against corruption; (ii) land/real estate market reform, increasing the efficiency of the labor market and enhancing the quality of labor, improving access to bank financing and microfinance; (iii) raising the quality of port and transit services, rationalization of customs administration; (iv) strengthening research, support for private sector associations, and intensifying public-private partnership, and so on.

\subsection{Diversification of the economy}

102. The Beninese economy is essentially based on cotton. Between the early 1980s and the early 2000s, Benin's share of world cotton exports increased substantially: from 0.06 percent to 2.3 percent. Cotton currently accounts for approximately 40 percent of export (including reexport) revenue. However, in recent years, Benin's that share has declined due to the fall in cotton prices on the world market and lower output.

The fact that export revenue relies so heavily on a single product renders the economy vulnerable to external shocks. Moreover, the data indicate that, of the countries in the WAEMU, Benin's export performance is one of the weakest (Table 9).

103. Indeed, in 1998-2004, Benin's export ratio (exports as a percentage of the value of nominal GDP) averaged 15.3 percent, compared with 30.8 percent for WAEMU as a whole. Furthermore, that rate was under half that of the other countries, with the exception of Burkina Faso and Niger, both of which are landlocked. 
Table 9: Average annual export ratio (1998-2004)

\begin{tabular}{|l|c|c|c|c|}
\hline \multicolumn{1}{|c|}{ Years } & $\mathbf{1 9 9 8}$ & $\mathbf{2 0 0 2}$ & $\mathbf{2 0 0 4}$ & Average \\
\hline Benin & $\mathbf{1 7 . 1}$ & $\mathbf{1 4 . 3}$ & $\mathbf{1 5 . 1}$ & $\mathbf{1 5 . 3}$ \\
\hline Burkina Faso & 12.9 & 8.5 & 8.6 & $\mathbf{9 . 6}$ \\
\hline Côte d'Ivoire & 39.4 & 49.6 & 48.1 & $\mathbf{4 3 . 6}$ \\
\hline Guinea-Bissau & 14.4 & 29.9 & 34.9 & $\mathbf{2 8 . 1}$ \\
\hline Mali & 24.8 & 31.9 & 28.0 & $\mathbf{2 8 . 3}$ \\
\hline Niger & 17.8 & 15.2 & 15.9 & $\mathbf{1 6 . 5}$ \\
\hline Senegal & 30.3 & 30.6 & 27.8 & $\mathbf{2 9 . 8}$ \\
\hline Togo & 29.7 & 33.8 & 33.5 & $\mathbf{3 1 . 7}$ \\
\hline WAEMU & 30.0 & 33.3 & 31.3 & $\mathbf{3 0 . 8}$ \\
\hline \multicolumn{5}{|l|}{ Source: WDI 2006 } \\
\hline
\end{tabular}

104. Concern to increase exports and gradually reduce vulnerability to external shocks has led the Government to opt for diversification of the economy. This diversification will be undertaken in two directions: (i) the diversification of agriculture; and (ii) the development of project clusters with demonstration effects. Having learnt from the disappointing performance of the cotton sector in recent years, the Government intends to embark on a transition to an economy less dependent on a single product, above all by pursuing a policy of diversification of agriculture. Thus, in collaboration with the private sector, the Government is embarking on a program to support the development of new farm products and crops, namely: palm oil, cashew nuts, rice, market garden produce, pineapple, shea, cassava, and fisheries products (shrimp). To that end, the Government will step up agricultural research so as to support this diversification.

105. Because of the relative decline of primary sector products in world trade, Benin also intends to diversify its economy by developing products with high value-added, so as to take advantage of the opportunities afforded by the growth of world trade in processed products. Consequently, the Government will pillar on the processing of agricultural produce, targeting market niches for which Benin enjoys comparative advantages. Such niches might, for instance, be the clothing industry for textile cotton, the cosmetic industry for shea and palm oil, confectionery for fresh pineapple, and other food-processing or pharmaceutical industries for cashew, and so on. Moreover, this approach, targeting above all markets in the region, would appear to be more promising than the commodity markets served by countries like China and Brazil, which produce on a huge scale and at lower cost. Energy and telecommunications are vital for socio-economic development, as several studies have demonstrated, ${ }^{11}$ and they are key factors for enhancing the productivity of enterprises in Benin

\footnotetext{
${ }^{11}$ See, for instance: Étude Diagnostique d'Intégration Commerciale (2005), Étude sur le climat des investissements (2005), Étude de la compétitivité des filières exportatrices (2005), and Études sur les sources de la croissance (2005).
} 


\section{Box 8: Strategy for boosting the agricultural sector}

In Benin, poverty is predominantly rural, given that the economy is mainly characterized by the preponderance of the agricultural sector. The sector consists largely of small farms: over 550,000 of them, according to the census (DPP, MAEP 2002). It remains essentially subject to the whims of the weather. Farm income and productivity are low and the work force is largely unskilled, which means that farm output is barely competitive. Bereft of financial resources during the sowing season, most farmers are forced by the absence of an effective agricultural loan system to make do with very few inputs. Mining company practices in farming and agro-pastoral areas, fishing grounds, and in forests designated as conservation areas exacerbate natural resource degradation.

Five core objectives have been assigned to the agricultural sector with a view to changing this state of affairs:

1. Increase the availability of food products to both the rural and urban population, ensuring that they are of high quality and affordable for all.

2. Increase the income of those working in this sector.

3. Increase the sector's resources or lower its foreign exchange expenditure.

4. Maintain or increase employment in the sector.

5. Guarantee sustainable management of land, livestock farming areas, and fishing grounds.

To achieve these overall objectives of the agricultural sector, the guidelines and strategies listed below will be developed over the next three years.

To lay the foundations for sustainable agricultural development, it will be necessary to pursue the following strategies:

- $\quad$ Complete the rural land ownership reform, formulate a rural land ownership policy, provide villages with rural land development plans, strengthen the rural land management capabilities of stakeholders, improve women's access to land; and update village soil fitness maps.

- $\quad$ Provide the agricultural sector with a National Agricultural and Rural Extension Strategy (SNFAR).

- $\quad$ Establish a decentralized mechanism for collecting and processing reliable agricultural statistics.

- $\quad$ Provide the sector with sustainable financing arrangements, taking special care to adopt measures aimed at improving the terms on which loans are granted and repaid, paying particular attention to developers of agricultural enterprises.

- Develop human capital in order to strengthen the capacity of institutions and professional organizations in the agricultural sector to develop and disseminate technological innovations, and to analyze farms and produce with a view to achieving optimal distribution of value-added.

- $\quad$ Conduct studies of the potential for hydro-agriculture (small scale irrigation).

- In the water management context, use modified irrigation models and develop baseline infrastructure.

- Opt for farm mechanization adapted to local conditions. The aim is to enable farmers and food processors, individually or in organized groups, to have access to farm mechanization facilities tailored to the ecological and social environment and to their economic and financial situation.

As regards the second guideline concerning the creation of wealth by means of a sound choice of crops and their promotion, the following strategies will be pursued:

- Diversification and expansion of agricultural output, with the following expected outcomes:

(a) A 30 percent increase in agricultural output within three years;

(b) A 25 percent improvement in yields;

(c) Five new product-lines (crops) developed.

- Improvement of market quality and access.

The goal is to develop produce that meets safety and quality standards.

106. The development of project clusters maximizing demonstration effects is warranted by the dearth of industrial processing. In Benin, it is generally limited to the first stage of processing of raw materials, with little value added. That being so, the Government has set about identifying potential mainstays of the Beninese economy. A survey of the principal branches of the economy 
of Benin indicates that no cluster exists: all sectors are at the "incipient cluster" stage. Six of the "incipient clusters" identified are: (i) textile cotton; (ii) food processing, trade, and international trade; (iii) buildings and civil engineering works (BTP) and construction materials; (iv) tourism, crafts, and culture; (v) transportation, logistics, and international trade; (vi) telecommunications and information and communications technologies (ICTs). The Government plans to base its accelerated growth policy on tightly-woven development of these incipient clusters, turning them into veritable mainstays of the Beninese economy. This intensification of project cluster development is to be accompanied by specific anti-HIV/AIDS campaigns aimed at preserving the population and ensuring that these projects have a greater impact.

107. Textile cotton: The Beninese economy depends heavily on cotton output and today cotton-growing remains the country's chief export-oriented activity. Over 95 percent of the fiber cotton produced in Benin is sold on the international market. Today, it accounts for almost 40 percent of export revenue and 90 percent of revenue from agriculture. It provides a monetary income for more than 120,000 farmers and is the product that most contributes to exports. Unfortunately, the activity has been hard hit in recent years by unfavorable developments in international trade, disruptions caused by an unevenly managed liberalization of the sector, and under-utilization of gin mill production capacity because of low levels of grain cotton output. To revive the textile cotton industry, the Government intends not just to boost cotton production but also to create the conditions required for Benin to process a large part of the grain cotton produced. The Government will take the necessary steps to guarantee quality control of the chemical inputs and proper use of them, in order to protect the health of the population and ecosystems. In looking for highly promising market niches, emphasis will be placed on subcontracting to clothing industry companies abroad, following the example of countries like Tunisia and Mauritius which, although they do not produce grain cotton, have still managed to develop a competitive processing sector.

Table 10: Structure of exports, Benin (CFAF billions)

\begin{tabular}{|l|c|c|c|c|}
\hline & \multicolumn{2}{|c|}{ Period prior to PRSP I } & \multicolumn{2}{c|}{ PRSP I period } \\
\hline & $2000-2002$ & Share (\%) & $2003-2005$ & Share (\%) \\
\hline Cotton fiber & 92.5 & 32.1 & 103.8 & 34.1 \\
\hline Cottonseed & 4.2 & 1.5 & 0.8 & 0.3 \\
\hline Cottonseed meals & 2.5 & 0.9 & 2.9 & 1.0 \\
\hline Palm oil & 0.0 & 0.0 & 0.9 & 0.3 \\
\hline Palm-kernel meals & 0.0 & 0.0 & 0.3 & 0.1 \\
\hline Cashew nuts & 10.8 & 3.8 & 9.2 & 3.0 \\
\hline Tobacco and cigarettes & 2.1 & 0.7 & 8.8 & 2.9 \\
\hline Wood and woodwork & 3.1 & 1.1 & 2.3 & 0.8 \\
\hline Miscellaneous products & 10.3 & 3.6 & 17.1 & 5.6 \\
\hline Re-exporting & 134.9 & 46.8 & 132.1 & 43.4 \\
\hline Unregistered trade & 28.0 & 9.7 & 26.4 & 8.7 \\
\hline Total exports & $\mathbf{2 8 8 . 4}$ & $\mathbf{1 0 0 . 0}$ & $\mathbf{3 0 4 . 7}$ & $\mathbf{1 0 0 . 0}$ \\
\hline
\end{tabular}

Source: BCEAO

108. Food processing, trade and international trade: The food processing industry in Benin is still incipient. With a view to promoting the processing of agricultural produce (cashew nuts, pineapple, palm seeds, cassava) for which Benin enjoys comparative advantages, the Government intends: (i) to boost palm oil cultivation, tailored to local ecological conditions, and to encourage investors to install modern processing plants; (ii) support the efforts under way to improve the percentage of cashew nut output processed locally and to initiate talks with private enterprises developing exports of this product; (iii) see to the proper working of the traceability 
system put in place by the Benin Center for Standardization and Quality Management (CEBENOR); (iv) strengthen the technical capacity of existing processing units; and (v) establish conditions conducive to the installation of nee processing units and support producer initiatives with respect to both processing and preservation. The Government will continue its support for the groups of farmers producing the aforementioned products so as to enable them to improve the quality of their products for export. The processing of shea nuts and some subsistence crops are activities predominantly performed by women and will be strongly supported by the Government.

109. Finally, the Government is counting on implementing the proposed consolidation of foreign trade support structures by establishing the Exports and Investments Promotion Agency (APEI), as indicated in the workshop to approve the trade integration diagnostic assessment.

110. Buildings and civil engineering works (BTP) and local construction materials: BTP have played a very important part in the resumption and consolidation of growth in Benin in recent years. Local BTP companies appear to be low on financial resources and physical fixed assets, but they also seem weak in terms of organizational and managerial capacity. To address that, the Government plans to carry out major works that could attract multinational BTP enterprises and lead to subcontracting to domestic companies and a skills transfer process.

111. Tourism, crafts, and culture: Despite the country's considerable natural, historical, and cultural heritage, tourism in Benin is still incipient. Mindful that it is the second largest source of foreign exchange, after cotton, the Government has set about developing a national policy to develop the tourist industry, aimed at: (i) significantly improving the hotel and tourism services provided for businessmen and businesswomen; (ii) laying the foundations for the development of international tourism; (iii) promoting tourism related to conferences and meetings; and (iv) promoting Benin's tourism potential in international travel markets. The low qualifications and lack of professionalism in the enterprises operating in this sector have hampered the implementation of these measures. For that reason, the Government is committed to raising the capacities of these commercial players over the next three years and to rehabilitating and developing tourist sites. The idea is to carry out major infrastructure projects for this purpose, especially the "fishing route project."

112. Unlike the countries of South, East, and North Africa, West African countries have not yet developed their tourism potential. Benin, however, has a hugely diversified and rich ancestral cultural tradition as a result of the diversity of its population groups and habitats and its position at the crossroads of great historical currents and migratory movements, which the Government intends to exploit in its efforts to promote tourism and crafts.

113. Here, too, it is important to ensure high quality in the provision of such services as electricity, telephony, transportation, and logistics. For instance, the investment climate study showed that brownouts caused turnover losses of approximately 13.4 percent. More than 59 percent of enterprises have to go to the extra expense of purchasing electricity generators. In the tourist sector, 67 percent of firms regard electricity supply deficiencies as a major problem.

114. The Beninese crafts sector preserves, develops, and processes local resources and, as such, constitutes a veritable reservoir of jobs. Indeed, in employment generation terms, it is the third most important sector, after agriculture and commerce. It comprises approximately 210 trades, among them several activities that generate monetary income for the population. Today, it 
accounts for approximately 12 percent of Gross Domestic Product. Being aware of the importance of crafts for poverty reduction, the Government will strive to make it an engine of economic development. It will therefore attempt to bring about the proper conditions for implementing the National Crafts Development Policy (PNDA) by, above all: (i) strengthening and expanding the foundations for a crafts industry; (ii) strengthening the managerial capacities of the decentralized financing institutions, by training their staff and tracking and monitoring their activities; (iii) tailoring the financing system to the needs of the crafts industry; (iv) enhancing the quality of crafts products in order to both increase domestic sales and improve positioning in regional and international markets; and (v) ensuring promotion of women's craft activities (basket weaving, weaving, pottery...) .

115. Transportation, logistics, and international trade: A well-maintained infrastructure network and efficient and competitive transportation services allow companies to reduce their production costs, keep markets well supplied, and facilitate the development of economic activities. In Benin, it will be a question of developing baseline transportation infrastructure and continuing implementation of the reforms currently being carried out in the sector to encourage private investment.

116. Information and Communications Technologies (ICTs): As pointed out earlier, telecommunications are core aspects of business and growth. In terms of telecom infrastructure, Benin has markedly increased its number of fixed and mobile telephone lines, service providers, and Internet users. However, the high cost of accessing these services and poor quality customer service are two problems that need to be overcome in this key sector for boosting investment.

117. Quite apart from the run-down state of the equipment used by "Bénin Télécom S.A." and network malfunctions, Benin telecom fees are higher than those in most countries in the subregion. The same is true of the cost of installing a company telephone line: US\$280 in Benin, US\$81 in Mali, US\$32 in Senegal, US\$50 in Ghana, US\$78 in Thailand, and US\$ in Malaysia.

118. The most striking comparison is with Senegal, where liberalization of the sector has been a success and where rates are among the most competitive in Africa, thanks to a strategy of broad, low-cost access to ADSL [splitter less asymmetric digital subscriber lines]. That has enabled Senegal to develop e-commerce, as in the processing of newspapers published in France. Moreover, by opting for a broad subscriber base, the telecom company has achieved excellent financial earnings.

119. To improve services to the general public, the Government has begun reforming the post office and telecommunications sector by introducing private players as a way to increase the supply of infrastructure and telecommunication and postal services. The strategy has resulted in a marked reduction of costs and has encouraged the development of information and communication technologies. This reform needs to be supported by enhancing the following: (i) liberalization of the telecommunications and post office sector by establishing a new legal and regulatory framework; (ii) privatization of the state telecom enterprise; and (iii) the development of services exploiting the availability of submarine cable and an educated population. 
Table 11: Average cost of a three-minute dial-up call to the USA in US\$

\begin{tabular}{|l|l|l|l|l|l|l|l|l|}
\hline & Benin & Ghana & Senegal & Mali & Togo & Bangladesh & Thailand & Malaysia \\
\hline 1998 & $\mathbf{7 . 1 6}$ & NA & 4.48 & NA & 11.44 & 6.00 & 6.98 & 3.82 \\
\hline 1999 & $\mathbf{6 . 8 6}$ & 2.92 & 3.19 & 14.62 & 7.80 & 4.40 & 2.54 & 2.76 \\
\hline 2000 & $\mathbf{5 . 9 3}$ & 1.65 & 2.23 & 12.64 & 7.90 & 4.14 & 2.19 & 2.37 \\
\hline 2001 & $\mathbf{5 . 7 6}$ & 1.26 & 1.81 & 12.28 & 7.67 & 2.47 & 1.49 & 2.37 \\
\hline
\end{tabular}

\subsection{Promotion of regional integration}

120. Promotion of regional integration to enhance competitiveness: Given the need to involve Benin in a dynamic process of accelerated and sustainable economic growth, a change of approach is required in order to make the most of membership of regional groupings (WAEMU, ECOWAS, and the African Union) and of insertion in the global economy... This integration will be based on regional exchange complementarities among Benin and neighboring countries. The Government plans to take greater advantage of its strategic position as a link between Nigeria and WAEMU, on the one hand, and, on the other, of openness toward the countries in the hinterland. To do so, the Government has decided to: (i) develop its transit services potential and make the country a platform for trade; (ii) develop channels for the exchange of subsistence crops, for which there is strong demand in the region (above all in Nigeria and Niger), with a view to increasing output of those crops; and (iii) strive to establish joint ventures capable of ensuring complementarity of production factors and thereby boost Benin's industrial potential. These options will be accompanied by programs to strengthen efforts to combat HIV/AIDS along borders.

121. Within regional organizations, the Government is committed to ongoing support for efforts to modernize ECOWAS bodies, and, especially, to strengthen its bilateral cooperation with Nigeria. That might held reduce the volume of illicit trade with that country. To that end, the Government will continue talks on the lifting of non-tariff barriers adopted by Nigeria pursuant to the Badagry memorandum. Thus, Benin's unstructured trade may become more diversified and better organized as Nigeria liberalizes its economy, just as Hong Kong adapted to the opening up of China in 1978. In WAEMU, these developments will translate into a stronger regional market in government securities and private bond issues. 


\section{CHAPTER 5: DEVELOPMENT OF INFRASTRUCTURE}

122. Economic infrastructure plays a key part in the development process. Because of its cross-cutting impacts, it contributes to the development of all sectors and directly affects all strata of the population. Since it is so important for growth, the Government has made it a core component of the PRSP, in the form of huge works to be inaugurated by the Head of State. In addition, bearing in mind that the development of infrastructure requires the mobilization of human resources, who will be exposed to the risk of contracting HIV/AIDS, the Government will make sure that infrastructure development programs are accompanied by specific programs to prevent and combat the spread of the disease.

123. A network of properly maintained infrastructure and efficient and competitive transportation services will enable enterprises to lower their production costs, help ensure that markets are well supplied, and develop economic activities.

124. The energy sector is vital for economic development and an important factor for improving the well-being of the population. Electricity, in particular, is of prime importance in the productive sector; for service industries, such as tourism; and for improving household living standards. The same is true of oil and gas, which are needed for the circulation of both goods and persons, and play a key role in both industrial and domestic output. Conscious of the sector's major contribution to growth and improvement of the population's standard of living, the Government attaches considerable importance to the energy sector in the PRSP.

125. Sanitation and water management are essential for a population's well-being, because they improve both health and the environment. Access to safe water is a baseline need for every human being and therefore figures prominently in both the PRSP and the MDG. Harnessing water for productive purposes is key to reducing the vulnerability of rural households to the vagaries of the weather and to raising agricultural productivity.

126. Economic infrastructure is thus an effective lever for furthering development and economic growth. Moreover, development of this sector will enable Benin to make the most of its geographical position. Indeed, it could really act as a transit corridor to Nigeria and the WAEMU countries. The PRSP highlights the following Government priorities: (i) transportation infrastructure; (ii) energy; and (iii) water management and sanitation.

\subsection{Transportation infrastructure}

127. Transportation infrastructure refers to development and maintenance of the road network, including rural roads, the railways, the development of maritime and river-based transportation, and port and airport facilities.

128. Benin lacks proper transportation infrastructure, despite the fact that it is essential for trade to develop. A comparison of Benin with certain West African countries reveals huge discrepancies. Benin has the least developed rail and road network, the least road traffic density ratio, and the fewest up-to-standard airports. 
Table 12: Comparison of transportation infrastructure in a number of countries

\begin{tabular}{|l|c|c|c|c|c|}
\hline & Benin & Togo & Nigeria & Burkina Faso & Côte d'Ivoire \\
\hline $\begin{array}{l}\text { Length of } \\
\text { railroad network }\end{array}$ & 578 & 525 & 3557 & 622 & 660 \\
\hline Railways $\left(\mathrm{km}^{2}\right)$ & $0.005 \mathrm{~km}$ & $0.009 \mathrm{~km}$ & $0.004 \mathrm{~km}$ & $0.002 \mathrm{~km}$ & $0.002 \mathrm{~km}$ \\
\hline $\begin{array}{l}\text { Length of road } \\
\text { network }\end{array}$ & 6,076 & 7,520 & 194,394 & 12,506 & 50,400 \\
\hline Roads in $\left(\mathrm{km}^{2}\right)$ & $0.05 \mathrm{~km}$ & $0.13 \mathrm{~km}$ & $0.21 \mathrm{~km}$ & $0.05 \mathrm{~km}$ & $0.16 \mathrm{~km}$ \\
\hline Tarmac roads & $30 \%$ & $32 \%$ & $31 \%$ & $16 \%$ & $10 \%$ \\
\hline $\begin{array}{l}\text { Airports with } \\
\text { tarmac runways }\end{array}$ & 1 & 2 & 36 & 2 & 7 \\
\hline $\begin{array}{l}\text { Sources: CIA (2004) cited by UNCTAD (2004), Investment Policy Review of Benin, and documents of the } \\
\text { MDCTT/PR. }\end{array}$
\end{tabular}

\section{Road network}

129. As for the road network, investments since 1970 have achieved a fully asphalted transit infrastructure network. The two North-South corridors, between Cotonou and Niger, on the one hand, and between Cotonou and Burkina Faso, in the direction of Mali, on the other, play an important part in regional integration. The coastal Togo-Benin-Nigeria road is also asphalted. The two highways crossing the Centre and North of Togo-Benin-Nigeria also perform a useful function and the current transport sector strategy envisages completion of tarmac surfaces for these roads, as well. However, heavy use of these corridors by overloaded trucks is causing degradation and could render them less competitive unless urgent steps are taken, especially freight and axle load controls Throughout the road network, in terms of frequency and effectiveness, the controls leave much to be desired.

130. The network of urban and interurban road connections needs to be improved in light of decentralization and urbanization. The weakest aspect of the road network, however, is lack of maintenance. Even today, the resources raised by the Road Fund only cover 60.79 percent of the road network's current maintenance requirement, which totaled CFAF 28,427 million in 2007. A budget allocation provides for periodic maintenance of part of the network. As Road Fund resources dwindle, some thought must be given to a financing mechanism. The Government therefore will continue setting up highway toll booths, while identifying new sources of road maintenance funding.

131. Rural roads are vital for collecting and distributing agricultural products. Overcoming the isolation of rural areas is thus an important ingredient of economic, social, and political development. The rural road network is, however, still insufficient. Of the $25,575 \mathrm{~km}$ of registered roads, so far only $7,827 \mathrm{~km}$ have been developed and only $1,075 \mathrm{~km}$ are properly maintained. In the search for funds to cover the maintenance of already rehabilitated roads, certain local authorities - now responsible for road maintenance and management under the decentralization plan - have begun setting up toll booths on existing roads, as a way of covering part of maintenance costs. These practices will not be sustainable on an erratic basis. Toward the end of the 1990s, the Beninese authorities had developed and begun implementing a national rural roads planning and financing strategy, which the Government now intends to update, with a view to finding a sustainable solution to this problem within the framework of the SCRP. 
Box 9: National Rural Roads Strategy and Implementation of Pilot Projects

A national rural roads planning and financing strategy was developed and put into effect as of the end of the 1990s. Its overall objective is to ensure the sustainability of infrastructure as a contribution to poverty reduction in rural areas.

The specific goals of the strategy are: (i) effective "ownership" of rural road network management by its beneficiaries; (ii) rational development of the rural road network and tailoring it to better serve the need to open up remote rural areas and satisfy its transportation requirements; and (iii) identification and determination of an appropriate mechanism for sustaining long-term financing for the existing road network.

This strategy was tested in three (3) pilot projects financed, respectively, by the World Bank (IDA), the Danish International Development Agency (DANIDA), and the French Development Agency (AFD) and the European Union.

These experiments proved useful for both the beneficiaries and the authorities.

For the beneficiaries, they entailed, broadly speaking, real involvement of the communities in the process of identifying and carrying out construction works or road rehabilitation.

For the central authorities, those pilot projects gave them an opportunity to share their new vision of planning and maintenance with grass-roots communities, which benefited from the awareness-raising activities and manual maintenance training sessions.

Overall, the synergy created in this way resulted in: (i) a considerable stretch of roads selected and maintained by their beneficiaries; (ii) heightened awareness of the population of its rural road management responsibilities; (iii) the development of local skills for the upkeep of rural roads, using the labor-intensive methodology (SMEs, think tanks, and labor); and (iv) the generation of alternative gap-bridging jobs.

Source: Ministry of Transport

132. Certain deficiencies still exist in the departments responsible for the subsector, especially at the decentralized level. Reforms are needed in order to reshape the tasks of the regional departments and to make more efficient use of human and financial resources.

133. In the road network sector, the Government has set several priorities regarding the expansion and maintenance of the network, as well as road safety. The priority areas are:

134. Improving mobility for people and goods. To accomplish this, the Government intends to: (i) ensure correct maintenance of the existing road network, taking decentralization into account; (ii) develop road infrastructure in order to consolidate relations among regions in the interior; (iii) enhance management of mobility, safety, and protection against environmental disruptions (noise, air pollution) caused by traffic (vehicles, bicycles, pedestrians) in large towns; (iv) strengthen environmental managements and environmental protection measures in the road subsector; and (iv) strengthen road safety.

135. Supporting the productive sector to contribute to economic growth. In the SCRP framework, the Government wishes to undertake large works, encourage the arrival of civil engineering multinationals, and, through subcontracting arrangements, develop private sector (SME) capacity for road works.

136. Contributing to poverty reduction by developing rural roads. The Government wants to turn rural roads into a real instrument of development. For that, the actions required are: (i) national coordination capacity-building; (ii) improvement of rural access road network 
management; (iii) devolution of responsibility to local governments; and (iv) implementation of the financing system modified so as to support and subsequently maintain rehabilitated roads.

137. Increasing the international competitiveness of the Beninese transport system. To make the transport sector competitive, the Government plans to: (i) strengthen road infrastructure with a view to consolidating subregional integration; and (ii) improve conditions and facilitate transportation on international routes.

138. Recovering infrastructure usage costs from users. This will require consolidating the road maintenance financing mechanism (the Road Fund), above all by strengthening highway toll systems, and so on....

139. Finally, enhancing the sector's planning and management capacity. Here, over the next few years, the Government plans to consolidate planning and programming mechanisms for development of the roads sector.

\section{River and sea transportation network}

140. River and lake transportation systems have not really been developed in Benin, even though they could potentially help open up remote areas, boost tourism, and even create a public transportation system for the population living near to Cotonou.

141. The port of Cotonou is capable of handling (loading or unloading) approximately 2.3 million metric tons of freight per year. According to previous calculations, that capacity was supposed to suffice until 1998, and, possibly, 2001, given some improvement in productivity. However, the volume of traffic rose faster than forecasted, to reach 3 million tons by $2000,4.3$ million tons by 2003, and 5.3 million tons in 2006. Thus, demand now exceeds the port's capacity. Moreover, at low tide, the water in the port is only 10 meters deep, when nowadays container-carrying ships need 12 to 14 meters. As a result, such ships sometimes have to be diverted to other ports, such as Abidjan. The port platform is tiny, which makes port operations difficult. The port of Cotonou's transaction costs are noticeably higher than those of other ports in the subregion.

142. Given the importance of the shipping sector, especially the key part that the Port of Cotonou plays in the Beninese economy, the Government is keen to preserve it and to make it more competitive. To that end, it will embark on institutional reforms aimed at: (i) enhancing the performance and quality of service provided to users of the Port of Cotonou; (ii) revamping the port's installations, expanding the port, and issuing a new Maritime Code; (iii) tightening port platform security and improving the quality and promptness of the services provided; (iv) strengthening environmental management and environmental protection measures in the maritime and port subsector; (v) hooking up all services to the port management software and expanding computerization of port operations with a view to expediting them and reducing discharge costs; (vi) involving the private sector in port and shipping activities; (vii) tailoring maritime policy to community needs; (viii) enhancing the institutional capacity and professional qualifications of the Merchant Navy Directorate; and (ix) constructing a dry dock at Parakou. Furthermore, the Government intends to facilitate the development of a transportation system that takes advantage of the country's numerous waterways and man-made lakes. 


\section{Air transportation}

143. Benin has just one international airport, at Cotonou. Its runway is $2.4 \mathrm{~km}$ long, which in the future might not be long enough to accommodate jumbo aircraft. However, it cannot, physically, be extended. There are seven smaller airfields in the interior, but there are very few inland domestic flights.

144. Under the 2007-2009 SCRP arrangement, an effort will be made to: (i) upgrade, expand, and strengthen security at Cotonou's international airport; (ii) strengthening environmental management and environmental protection measures in the aviation subsector; (iii) privatize Cotonou airport management; (iv) have a second airport built by the private sector, under a Build, Operate, and Transfer (BOT) arrangement; and (iv) gradually turn the secondary Parakou and Natitingou airfields into airports meeting International Civil Aviation Organization (ICAO) standards.

\section{Railroad network}

145. The railroad network consists of a single meter-gauge track between Cotonou and Parakou $(438 \mathrm{~km})$. However, both the track and the rolling stock are in very poor shape, so that parts of the route are currently not used. Since the highway was asphalted, the railroad has to compete with it on this stretch. The Cotonou - Pobé and Cotonou - Sègboroué railway lines are currently not in use, but are supposed to form part of the ECOWAS international connection system.

146. To promote railroad sector development, the Government intends to: (i) formulate and implement a rail transportation policy; (ii) strengthen environmental management and environmental protection measures in the railroad subsector; (iii) continue rehabilitating the railroad in the Lama area; (iv) establish the conditions for fair competition between North-South rail and road transport options; (v) privatize the running of the Benin-Niger Railway (OCBN); and (vi) rebuild the coastal road with a connection to Nigeria.

\subsection{Energy infrastructure}

147. As regards electricity, the investment climate study conducted in 2004-2005 showed that it takes 104 days for a manufacturing enterprise in Benin to be hooked up to the electricity grid, compared to 12 days in Senegal, 32 days in Mali, and 18 days in China. Moreover, brownouts cause output losses in the order of 7.4 percent in Benin, compared to 2.6 percent in Mali, and 1.8 percent in China. As for the duration of such brownouts, in days per year, the figure for Benin in 2003/2004 was 44 compared to 14 days in Mali.

Table 13: Bottlenecks caused by electricity supply problems: an international comparison

\begin{tabular}{|l|l|l|l|l|}
\hline Problem & Benin & Mali & Senegal & China \\
\hline \% loss of output & 7.4 & 2.6 & 5.1 & 1.8 \\
\hline Number of brownouts & 43.9 & 14.5 & 31.5 & n.a. \\
\hline \% of firms that have their own generator & 26.9 & 45.3 & 61.6 & 17.0 \\
\hline Time it takes to hook up to the grid & 104.4 & 31.7 & 12.4 & 18.2 \\
\hline Source: ECI Benin (2005) & \multicolumn{5}{l}{} \\
\hline
\end{tabular}


148. Benin is a net importer of electricity from Côte d'Ivoire and Ghana, while, on average, WAEMU and African countries are net exporters of it. To address this capacity issue, it is important for Benin to acquire a degree of autonomy and reduce its dependence on energy imports. To that end, the Government plans to build a power station.

Table 14: Electric energy capacity, Benin (millions of Kw)

\begin{tabular}{|l|c|c|c|c|c|}
\hline & $1980-1985$ & $1986-1990$ & $1991-1995$ & $1996-2000$ & $2001-2002$ \\
\hline WAEMU & 1.54 & 1.66 & 1.72 & 1.86 & 1.77 \\
\hline Nigeria & 2.86 & 4.57 & 5.91 & 5.89 & 5.89 \\
\hline Benin & $\mathbf{0 . 0 2}$ & $\mathbf{0 . 0 2}$ & $\mathbf{0 . 0 3}$ & $\mathbf{0 . 1 1}$ & $\mathbf{0 . 1 2}$ \\
\hline Source: U.S. Department of Energy, November 2004 (quoted in DTIS 2005) \\
\hline
\end{tabular}

149. To address the challenges it faces in the energy sector, under the SCRP strategy, the Government will adopt ambitious measures and programs to satisfy current and potential demand for energy. It will do so by: (i) establishing an appropriate institutional, legal, and regulatory framework; (ii) consolidating implementation of an energy information system to provide tools for energy policy decision-making; (iii) promoting rational use of energy in all branches of the economy; (iv) diversification of domestic sources of energy; (v) taking advantage of national, economically viable, energy resources; (vi) improving the pricing (rates) system for energy use; and (vii) shortening the time it takes to hook up to the grid. Implementation of these measures in line with those designed to boost the private sector should attract DFI and encourage local investment as well.

150. With respect to electrification in rural areas, energy sector activities have to do with the consumption of biomass energy (firewood), oil and gas, and electricity. Total end-consumption of energy over the past five years has averaged approximately 1,584 kilo tons of oil equivalent (ktoe), which constitutes a relatively low level of per capita consumption of 0.252 toe per annum. Not much progress has taken place in Benin with respect to the consumption of electricity. In households and in services it increased from 154,849 MWh in 1996 to 392, $558 \mathrm{MWh}$ in 2002, an increase of 15.6 percent [Tr. sic]. This translates into: (i) a low percentage of households with electricity (approximately 22 percent nationwide in 2003 and less than 5 percent in rural areas; (ii) still incipient development of the industrial sector, comprising only a limited number of industries (food processing, textile cotton ginning, pharmaceutical companies, and cement factories) accounting for only 2.1 percent of the total demand for electricity in 2002.

151. The Government's rural electrification goal is to establish the conditions needed to bring electricity to150 rural localities each year (an average of 10 per rural electrification concession) and, at the same time, to ensure that, by 2009 , the average electrification rate for all those rural localities is at least 20 percent. The achievement of that goal, which would also ease the pressure on forest resources, must depend on: (i) the electrification options chosen; (ii) the way in which electrification of rural areas is organized; (iii) rural electrification priorities; (iv) the pricing of electricity in rural areas; (v) the use of renewable and local sources of energy; (vi) support for local rural electrification initiatives; (vii) financial assistance for the installation of household electric appliances and hook-ups; and (viii) synergy with other sectoral programs.

\subsection{Waterworks and sanitation}

152. This priority area involves the following sectors: safe water in rural and urban areas; water management works for productive purposes, and sanitation infrastructure. 


\section{Safe water supplies}

153. Recent statistics show that approximately two-thirds of the rural population in Benin lack access to safe water. Apart from that supply shortage, there is also no proper legislative and regulatory framework for integrated management of water resources. These shortcomings stem from: (i) failure to meet the goal of constructing, on average, 1,350 watering places a year, needed to meet Millennium Development Goals (MDG); (ii) delays in organizing the financial participation of local communities; (iii) red tape in procurement procedures; and (iv) the large number of bodies involved in water resource management decisions.

154. In rural areas, as of December 31, 2005, 12,089 watering places had been constructed in Benin, covering 41 percent of the country's rural population. By 2015, if today's distribution of the population and safe water supply coverage remain unchanged, the number of people living in rural areas without access to safe water will have risen to 8 million. Without underestimating the efforts to be undertaken by then, these figures show that, despite them, much remains to be done to ensure that the population has access to safe water. Thus, to address this challenge and strive for attainment of the MDGs, the Government plans to: (i) expedite the expansion of access to safe water for approximately 4 million people; (ii) ensure that investments are sustainable; and (iii) enhance the impact of investments in the sector.

155. In urban areas, SONEB is currently supplying 69 urban districts. Eighty percent of the demand for water is concentrated in Cotonou, Porto Novo, Parakou, and Abomey/Bohicon. The rest comes from smaller towns and small urban localities. It was estimated that in 2005 approximately half the population had access to safe water, based on the figure of 120,328 customers and an average of 12 people supplied by each connections. By that count, approximately half the urban population still lacks access to safe water. Most of these people live on the outskirts of urban areas. Between 1991 and 2004, the sale of water, in cubic meter terms, grew by approximately 12 percent a year, compared to 5 percent a year between 2000 and 2004 .

156. To address the challenge regarding access to safe water in urban areas, the Government proposes to: (i) rehabilitate and expand the water processing plants in Védoko and Godomey; (ii) hook-up two wells in the new drilling field; (iii) rehabilitate the six (6) old wells and hook up 20 new ones; (iv) rehabilitate the water towers; (v) install water pipes; (vi) systematize measures to protect against water pollution; (vii) prepare and propose regulations and standards to govern water resource catchment and management, on the one hand, and rational use of it, on the other; (viii) ensure proper management of water resources in the public domain, such as wetlands, rivers, lakes, lagoons, springs, and artesian wells, etc; (ix) guide and coordinate actions by the Government and external partners in the water sector; (x) coordinate actions relating to different uses of water and encourage Integrated Water Resource Management (GIRE); (xi) provide advice and support to villages and other stakeholders in the water sector though briefings, training, and technical assistance; and (xii) see to it that safe water supply policy is implemented.

\section{Works to harness water supplies}

157. Surface water accounts for approximately 3.8 percent of the known, potentially available supply for irrigation. Beninese agriculture therefore essentially uses rain water, with all the attendant uncertainty regarding output, low productivity, precarious food security, and so on. Today, fewer than 3,000 hectares of land are properly irrigated and farmed. They are mainly old, 
rehabilitated rice fields, micro-irrigation schemes constructed since 1984, and a few private farms.

158. The Government's determination to turn agriculture into an engine of growth, and hence more productive and competitive, will therefore require considerable investment in irrigation and other water management works.

159. The Government's priorities in this sector in 2007-2009 are to: (i) perfect the tools for rational water use and ground water resource management; (ii) create an environment conducive to - and with incentives for - the development of water management infrastructure; (iii) promote private irrigation in order to ensure rapid economic growth, strengthen the financial capacity of local governments, and grant certain segments of the population greater autonomy; (iv) increase the area of land under irrigation by using reliable water management systems; (v) construct and restore watering places for pastoral uses; and (vi) develop fish farming facilities.

\section{Sanitation works}

160. Sector studies on sanitation point to a number of problems that have arisen in recent years, particularly as a result of rapid urbanization. Urbanization is particularly disorganized on land that has not been divided into plots and is not connected to mains services. This lack of urban management is the result of the dearth of both community management capacity and the financial resources to respond adequately to the growing demand for services, as well as the anarchical occupation of plots in areas unfit for habitation. Finally, there is a shortage of sanitation infrastructure to channel rain and waste water and to handle solid waste.

161. The Government's urban management program envisages: (i) producing urban planning documents, such as master plans for town planning and urban development; (ii) installing drains in the streets of Benin's principal urban centers and secondary towns; (iii) proceeding to make landed and residential property more secure (titling); (iv) identifying low-cost and welfare housing areas and fitting them out with mains services; (v) promoting real estate operations in order to increase the supply of decent housing; and, finally, (vi) investing in sanitation infrastructure in both towns and rural areas. 


\section{CHAPTER 6: HUMAN RESOURCE DEVELOPMENT}

162. In an awareness of the urgency of the population issue, Benin approved a Declaration of Population Policy (Déclaration de politique de population, DEPOLIPO) in 1996, and revised it in 2006, in an effort to address the problem. The purpose of the Declaration is to improve the standard of living and quality of life of the population and, over the long term, to arrive at an appropriate match between economic growth and population growth. The Declaration covers a twenty-year period (1996- 2016) and comprises 16 global objectives (Box 9). These objectives require substantial social investment over time, as well as an increase in both the quantity and quality of jobs. The challenge consists of boosting competitiveness through a combination of physical investment programs and human resource development. Prevention and treatment of HIV/AIDS are also a Government priority.

\section{Box 10: Main Objectives of the DEPOLIPO}

\begin{tabular}{|c|c|}
\hline 1. & Provide high-quality education to all citizens of Benin. \\
\hline 2. & Find in-depth and lasting solutions to the problems of vocational training and employment. \\
\hline 3. & Increase life expectancy at birth from 54 years in 1992 to 65 years by the year 2016. \\
\hline 4. & Promote responsible childbearing. \\
\hline 5. & Achieve better spatial distribution of the population. \\
\hline 6. & Take international migration into account as a factor in the development process. \\
\hline 7. & $\begin{array}{l}\text { Ensure that the entire population has available, at all times and in all locations, } \\
\text { wholesome food that ensures nutritional well-being. }\end{array}$ \\
\hline 8. & Promote safe housing, as well as protection of, and respect for, the $\quad$ environment. \\
\hline $\begin{array}{l}9 . \\
\text { thei }\end{array}$ & $\begin{array}{l}\text { Create conditions conducive to full participation by women in the development process and } \\
\text { oyment of the resulting benefits. }\end{array}$ \\
\hline 10. & Create conditions conducive to optimal fulfillment of the potential of young people. \\
\hline 11. & Ensure sure that the elderly receive a comfortable social security allocation. \\
\hline 12. & Integrate handicapped persons into the development process. \\
\hline 13. & Adjust the implementation of population policy to regional specificities. \\
\hline 14. & Integrate elements of said policy into development plans and programs. \\
\hline 15. & Mobilize the people of Benin to address the country's socio-economic and demographic \\
\hline 16. & Improve the state of socio-economic and demographic knowledge of the country. \\
\hline
\end{tabular}

163. The development of human capital - i.e., strategic theme 3 - constitutes a response to this challenge and is a prerequisite for improvement of personal income and economic growth, especially in the new globalized environment in which knowledge, know-how and interpersonal skills play a central role in boosting productivity and reducing poverty. It is now generally acknowledged that poverty is not exclusively attributable to low incomes, but that it also results from lack of access to the various forms of capital. Indeed, non-monetary poverty, which is an aspect of human poverty, is defined as an array of things that an individual does not have: e.g., it is the inability to live long and in a good state of health, to obtain education, to enjoy decent living conditions, and to participate in community life. The SCRP, by promoting education and improved health care, identifies the development of human capital as a pillar of growth and poverty reduction.

164. The education sector plays a strategic role because it is the primary mechanism through which social values are transmitted, and skills developed, that enable individuals to find the means and motivation to build a country that offers a good life. With this in mind, the Government feels that baseline education is a priority sector and has decreed that schooling shall 
be cost-free and expenses covered, as from the 2006-2007 academic year, for children enrolled in public schools, and that private educational establishments shall also receive a government subsidy to defray their costs. However, the Government has not lost sight of the fact that the secondary and tertiary levels are of strategic importance in ensuring strong growth. It therefore plans to continue its support for secondary and higher education in order to train competent and competitive managers who can help spur the modernization of the economy. Given the threat posed by the HIV/AIDS pandemic, the Government intends to promote behavioral change by introducing, among other things, prevention programs into training curricula.

165. In addition to interventions directly geared to the formal educational sector, the SCRP places particular emphasis on vocational training. To this end, the Government intends to allocate resources to vocational training and to functional literacy of young people and adults in order to encourage their integration into the labor market. These are effective ways to foster insertion into professional life, particularly in the growth sectors on which the government intends to pillar its efforts over the next few years. There will therefore be a need for innovation and for shortterm training options to train the specialized and skilled labor that will be crucial to the development of clusters of projects with multiplier effects.

166. Health is also an essential dimension of the population's well-being, as well as a key factor in its productivity. Poverty manifests itself throughout the health sector in: (i) a low level of access to health services and high quality care; (ii) a lack of healthcare, hygiene and sanitation infrastructures; and (iii) a resurgence of malnutrition and poor diet. Beyond these issues, the HIV/AIDS pandemic, the emergence of new endemic diseases, and the mutation of known endemic diseases (e.g., malaria) also pose major challenges for the healthcare system.

167. Finally, if poverty is to be reduced, the needs of vulnerable groups must be addressed through a system of social protections. Vulnerable groups include women, children, the handicapped, and the elderly. To attain its objectives of accelerated growth and poverty reduction, the Government will emphasize social protections, promotion of the family unit, and gender equity.

168. The Government has thus identified four objectives that are reflected in the following four (4) priority areas of intervention: (i) promotion of development-oriented education; (ii) strengthening of vocational training in keeping with the requirements of the labor market; (iii) improved accessibility and higher quality of health and nutrition services; and (iv) strengthening of social protections.

\subsection{Promotion of development-oriented education}

169. Since education is a condition for economic takeoff, ambitious educational policies are called for. Despite its important role in accelerating of economic growth and poverty reduction, the educational sector is plagued by numerous problems, including in particular: (i) the scarcity of pre-school facilities; (ii) a primary education system characterized by low retention rates and poor performance, especially for girls; (iii) the limited scope of higher education; and (iv) the threat posed by the HIV/AIDS pandemic.

170. Access to high quality baseline education is an important factor in poverty reduction. The Government has therefore made primary education one of its main priorities. The main goal is to 
ensure primary education for all by the year 2015, in accordance with the MDGs. The importance of baseline education for development should be reflected, not only in the sequencing of activities, but also in budgetary allocations. In order to achieve this, the following strategic interventions, broken down by educational level, are envisaged.

171. Pre-school level. The goal here will be, among other things: (i) to improve access to preschool through the promotion of community-level facilities, raising the awareness of communities and local elected officials of issues related to early childhood stimulation, in order to obtain their support for the creation of pre-schools by communities. The Government will ensure equitable coverage of rural and urban areas through: (i) a communication plan, encouragement for relevant educational initiatives by Non-Governmental Organizations (NGOs), the private sector, and communities for very young children, and by raising popular awareness of the importance of schooling for girls; and (ii) efforts to ensure the quality of services for very young children through the enhancement of outreach programs dispensed in intake facilities.

172. Primary and secondary levels. The government has decided to: (i) boost the elementary school completion rate to 100 percent by the year 2015; (ii) substantially improve retention of pupils during the cycle, a sine qua non condition of achieving a universal completion rate, particularly by ensuring educational continuity over the six years of instruction; (iii) reduce grade repetition; (iv) support private education through subsidies from 2007 onward; (v) improve the quality of teaching; (vi) improve the retention rate for girls in the school system; (vii) generalize the system of financial aid sponsorship for the schooling of girls; (viii) promote residential homes and high schools for girls and orphans; (ix) substantially improve teachers' working conditions; (x) adapt the school map to regional requirements; (xi) develop environmental education programs; (xii) provide incentives to promote the training of girls in educational tracks in which they are underrepresented; and (xiii) improve the system for the gathering and processing of educational statistics.

173. Higher education. The Government will continue to support this level of education to train high-level managers capable of driving the development process. This Government support will be reflected in: (i) improved management and policy guidance in higher education; (ii) improved quality and greater gender equity; (iii) promotion of scientific and technical research geared to sustainable development; (iv) repillaring of higher education on the country's development needs with regard to regional integration and globalization, using an approach linking the university to the milieu it serves; and (v) stipends for girls and facilitation of girls' access to on-campus housing.

174. Literacy. The Government will emphasize: (i) equitable access to literacy programs; (ii) promotion of women's literacy; and (iii) improvement of the quality of human resources, programs and curricula, and enhancement of the system of subsectoral monitoring/evaluation, policy guidance and management, with a view to making literacy an instrument of social change. In addition, the Government will endeavor, in implementing these activities, to integrate environmental concerns into training curricula.

175. In addition, and in order to best exploit the opportunities associated with the country's geographic location vis-à-vis Nigeria, the Government will develop and progressively implement a strategy aimed at imparting mastery of spoken and written English by as many people as possible. 


\section{Box 11: Ten-year plan for educational development in Benin}

The results of the past ten years, as indicated by various studies (e.g., the Benin National Action Plan for implementation of the Educational for All program, the Report on the National Educational System (RESEN), the Orientation Law on the Beninese Educational System, documents emerging from the Education Sector Roundtable, etc.) make it possible to identify the strengths and weakness of Benin's educational system. These studies show where there has been progress, point out areas characterized by dysfunction and inadequacy, and suggest prospects for improvement. Despite the considerable quantitative and qualitative efforts put forth, the system's overall performance has been far from satisfactory.

Having taken note of these results, and taking into account its international commitments, and particularly those emerging from the Millennium Summit 2000 and the Dakar Forum in 2000 concerning the preparation of a National Action Plan for Education for All (NAP/EFA), the Beninese Government approved a Letter of Educational Policy on February 23, 2005. It defines and clarifies the broad options for expanding education in Benin, following the development and validation of the NAP/EFA. The preparation of a Ten -Year Plan for the 2006-2015 period is a logical follow-up to this series of initiatives on behalf of Benin's educational system.

The ten-year development policy for education is based on the following themes: (i) improved policy guidance based on capacity building in the areas of planning, management, ongoing system evaluation, and recruitment planning; (ii) enhancement of the quality of teaching, which will depend to a great extent on the revamping of pedagogical programs and tools, the professionalization and structuring of initial and in-service training, improvements in administrative and educational outreach/support [to teachers], and reduced class size; (iii) broadening of the array of educational options offered, which will entail, apart from a great increase in the number of teachers at all levels, the development of an educational map and the reorganization of technical, vocational and university training programs; (iv) improved human resource management through the establishment of a career monitoring and advancement mechanism linked to performance assessment and rational job assignments, as well as the improvement of mechanisms for the assignment of expenditures; (v) diminishment of gender and regional disparities, underpinned by a policy of affirmative action for girls and for disadvantaged groups and regions; (vi) an expanded role for the private sector and for local communities in terms of educational offerings, which will be pursued through the formulation of an appropriate promotional policy.

During the implementation of the ten-year program, measures will be taken at all instructional levels to respond to specific issues.

Promotion of girls' schooling. The Government will develop special measures to encourage the enrollment of girls and to keep them in the system. These measures include an intensification of grassroots interventions involving teachers, local elected officials, women's' groups and NGOs, supported by the establishment of an effective system for monitoring the interventions identified. This incentive policy will help remove the handicaps facing girls in their schooling, help them pass exams, and at the same time increase their representation in educational establishments and ensure their safety in those establishments.

School health and environment. Partnerships with the health and environmental sectors will be strengthened in order to make students at all instructional levels aware of the broad issues related to their civic and social integration and the protection of their health. HIV/AIDS outreach and awareness efforts are a major theme of this policy, which will pillar on the following areas:

- $\quad$ Adaptation and strengthening of programs aimed at improving school health and environmental protection;

Adaptation of teacher and pupil training modules on school health and environmental protection;

Establishment of a health, hygiene, and nutrition policy in educational establishments

Source: Ten-Year Plan 2006-2015, October 2006, MEPS.

\subsection{Strengthening of vocational training}

176. The people of Benin have expressed their desire for high-quality and useful education. They want schools and apprenticeship programs that are relevant and that take local concerns about sustainable development into consideration. This approach is seen by the population as a possible solution to the unemployment problem, since it encourages a match between training and labor market requirements.

177. Vocational training. To enhance the credentials of apprentices and skilled artisans, the Government approved a National Policy of In-Service Vocational Training (1998), which was implemented through the Development Fund for In-Service Training and Apprenticeship (2001). As part of this same effort, the Government opted in 2001 to reform technical and vocational training according to four themes, namely: professionalization of initial training through a revision of programs according to the skill-set approach; introduction of a dual apprenticeship 
system; expansion of in-service vocational training offerings and development of in-service vocational training options for vulnerable and disadvantaged groups. Emphasis will be on the development and diversification of educational options. The Government has thus decided to implement the following actions over the 2007-2009 period: (i) develop and diversify educational offerings; (ii) improve quality and enhance gender equity; (iii) improve management and policy guidance; (iv) distribute and re-pillar vocational schools as a function of the comparative advantages of regions; (v) re-orient the training offered at vocational schools to take into account the employment opportunities at the département level; (vi) introduce a training plan that meets the needs of business owners and of the Chamber of Commerce and Industry of Benin (CCIB); (vii) offer incentives to encourage vocational training for girls; and (viii) develop specific HIV/AIDS prevention programs for those enrolled in training.

178. Employment. The educational policy assigns priority to technical and vocational training to fill the jobs that will be created by the development of clusters of structuring projects with multiplier effects. The SCRP also emphasizes: (i) the development of income-generating activities; (ii) the integration of young people into economic activity; (iii) promotion of the social economy (including the assignment of a monetary value to domestic labor); and (vi) the generalization of social security registration and efforts to combat child labor.

179. The Government has chosen to pillar, through its efforts to enhance human capital, on the issue of attitudes, with a view to encouraging the emergence of a new type of Beninese citizen no longer held back by behaviors inimical to development (e.g., inertia, a wait-and-see attitude, laziness), fostering the creation of a citizenry that is skilled, honest, and endowed with business sense and a spirit of initiative. The educational system will also endeavor to: (i) promote a sense of personal autonomy and responsibility and a sense of moral integrity; (iii) promote the entrepreneurial mindset in national and local development programs and activities; (iii) increase the number of people familiar with new information and communications technologies; and (iv) develop, with the technical and financial partners, scholarships and internship programs to train high-level managers and technicians in the design and management of development, and for private enterprise.

\subsection{Greater accessibility and quality of health and nutrition services}

180. Improvement of the health of the population is both an economic and social development objective. Good health helps to improve the quality and efficiency of human capital. Thus, the Government's vision with regard to public health incorporates three (3) of the Millennium Development Goals (MDGs), namely: (i) to reduce mortality among children aged 5 and under; (ii) to improve maternal health; and (iii) to combat HIV/AIDS, malaria and tuberculosis. In addition, the Government has opted to: (i) develop and equip healthcare infrastructures; (ii) ensure a stable supply of pharmaceutical products and medical consumables; (iii) develop a baselevel health care package at the regional level; (iv) improve diet and nutrition; and (iv) promote athletic and recreational activities.

181. Promotion of maternal health and reduction of infant mortality. Maternal and infant health indicators have stabilized over the past few years to around 473 maternal deaths for 100,000 live births and 38 newborn deaths for 1,000 live births. Although obstetrical complications are factors imperiling the lives of women, one of the main causes of maternal and neonatal death in Benin appears to be the dysfunctionality of the healthcare system. Thus, among the actions planned to enable Benin to achieve the MDGs, the Government has chosen to: 
improve the functioning of the system; increase access to reproductive health services through family planning; and promote responsible parenthood, prenatal care, medical care for obstetrical emergencies, coverage of STIs, and continuous availability of the optimal package of obstetrical and pediatric interventions (for diarrhea, ARIs, fever, malnutrition, vaccinations, anemia); and ensure adequate supply and availability of reproductive healthcare services for adolescents and young people.

182. Reliable supply of pharmaceuticals and medical consumables. This consists of ensuring constant availability of the high-quality pharmaceutical products and medical consumables needed to improve the health status of the population, particularly through: (i) comprehensive and reliable funding leading to financial autonomy; (ii) harmonization of financing mechanisms between partners and strengthening of cost recovery mechanisms; (iii) reliable and affordable supply of high-quality drugs and products; (iv) ongoing availability of a comprehensive array of services and products in order to meet increased demand; and (v) efforts to combat the informal market in pharmaceutical products.

183. HIV/AIDS prevention. Although HIV/AIDS is not the main cause of hospitalization and death, it is by far the most formidable malady in terms of its social impact on those infected, their offspring, and a country's future. HIV/AIDS prevalence rose from 0.3 percent in 1990 to 3.2 percent in 1996, and was 4.1 percent in 2001 and nearly 2 percent in 2004 . The inadequacy [of the prevention effort] is apparent since, according to national statistics, one person is infected every 28 minutes, for a rate of 52 people per day, whereas four years earlier the number of infections per day stood at only 35 (PNLS, 2003). To address this pandemic, the Government will emphasize: (i) primary prevention (especially among young people), treatment and care (particularly in connection with mother-to-child transmission and the management of pediatric cases, as well as support to AIDS orphans; and (ii) management of tuberculosis cases in accordance with the DOTS (Directly Observe Therapy Short-Course) strategy. ${ }^{13}$

\footnotetext{
${ }^{13}$ The incidence of tuberculosis has been rising since the emergence of HIV/AIDS, since it is an opportunistic infection.
} 


\section{Box 12: Trend in HIV/AIDS prevalence}

Biosurveillance of HIV infection has pillared on several population sub-groups: of these, pregnant women are the easiest to reach and yield the most data on sexual transmission and mother-to-child transmission. Other sub-groups are: those seeking medical attention for STIs, female sex workers, HIV-infected tuberculosis sufferers, blood donors, truck drivers, adolescents and young people, and uniformed personnel. Since 2005, Benin has integrated into its surveillance those who undergo voluntary screening and pregnant women being monitored in connection with the program to prevent mother-to-child transmission (PTME).

From 1990 to 2001, sentinel serosurveillance of pregnant women was conducted each year in seven (7) exclusively urban sites. Estimated prevalence during this period went from 0.3 percent in 1990 to 4.1 percent in 2001 . In an effort to improve the representativeness of sentinel sites, a nationwide survey of this same target population (i.e., pregnant women) was conducted in 2002 in 242 urban and rural sites. These sites are public or private maternity clinics. National prevalence is estimated at 1.9 percent, with regional variations, and ranges from 0.8 percent to 3 percent depending on the département, and from 1 percent to 6.4 percent depending on the municipality (commune).

In 2003, based on observations emerging from the national survey and from the assessment of the epidemiological surveillance system, Benin embarked upon a process of expanding sentinel sites in both rural and urban milieus, in order to achieve greater nationwide representativeness. Thus, from the seven sentinel sites used over the $1990-2001$ period, the system expanded from 2003 to 2005 to encompass 39.5 urban sites and 50 rural sites. Estimated prevalence over those three years hovers around 2 percent, independent of the number of sites being studied and without any statistically significant variation: 2 percent in 2002, 2003 and 2004, and 2.1 percent in 2005.

Regarding HIV prevalence according to milieu, it is noted that the prevalence rate was stable between 2002 and 2005 in urban areas, whereas in rural areas it rose from 1.5 percent to 1.9 percent. This deterioration of the situation in rural areas calls for an intensification of interventions.

Source: UNDP, MS, Strategies for Achieving the MDGs, August 2006

184. Prevention of malaria and other endemic diseases. Despite the Government's efforts, malaria has been neither eradicated nor controlled, and as of 2004 was still one of the main reasons for seeking medical attention. The Government plans to continue its prevention activities through its national anti-malaria program and to enhance access to curative care, particularly in rural areas.

\section{Box 13: Malaria prevalence in Benin}

Malaria is the primary disease afflicting the people of Benin. Indeed, it accounts for over one-third of visits to healthcare facilities, and for 40 percent of such visits for children under the age of 5 . The average rate of prevalence of simple malaria is 116.0 per thousand. This rate is significantly higher among children under the age of 5: 478.0 per thousand for infants under the age of one (1) year, compared to 214.0 for those aged one year to 4 years. Overall lethality was 13 percent in 2005 .

From the epidemiological standpoint, Benin is in a zone of stable transmission, with cases thus occurring throughout the year with a surge during the rainy season. Malaria causes much loss of human life. It is a cause of stillbirths, and has a great impact on the infant mortality rate. It also causes absenteeism and results in enormous economic losses for families and individuals, as well as for the nation.

Source: UNDP, MS, Strategies for Achieving the MDGs, August 2006

185. Implementation of the policy on safe blood transfusions. In order to support other disease-prevention programs and provide effective healthcare, Benin must establish a program to ensure the safety of blood transfusions. This entails policy-making as well as infrastructures and facilities to increase the capacity of the blood bank and ensure product quality. To this end, the Government has decided to implement the following: (i) construction and equipment of a 
national blood storage center; (iii) capacity-building for staff; and (iv) implementation of policies for rapid and equitable distribution of blood.

186. Development of baseline set of healthcare services at the regional level. Visits to healthcare facilities are an indispensable prerequisite of improved healthcare. Admittedly, however, access to healthcare services is still difficult for most citizens. Only 66 percent of all households have a healthcare facility available nearby, while primary healthcare facilities serve only 50 percent of the population. Faced with this situation, the Government has decided to: (i) put in place an appropriate legislative and regulatory framework; (ii) assign a special budgetary allocation to the sector; and (iii) strengthen the capacities and skills of those involved in the sector.

187. Development and equipment of healthcare infrastructures. Despite efforts made in this area, there are too few infrastructures and facilities. This situation essentially affects zone hospitals, municipal health centers, arrondissement-level health centers, and village health units. There is currently very little investment in these units, although they are an effective means of promoting grassroots health initiatives. Zone hospitals or health centers are sometimes inaccessible due to the remoteness of villages. The development of healthcare infrastructures must be accompanied by an ambitious program to either facilitate access to such infrastructures or provide access. Actions to be carried out are the following: (i) an increase in the number of infrastructures, and the equipping of such structures; and (ii) promotion of a detailed human resource development plan based on an inventory of skill deficits by type of personnel and by locality. This plan includes the cost of training new employees and takes into account the norms and standards required in the area of healthcare service coverage.

Box 14: Brief overview of the healthcare situation and of the healthcare sector

The mandate of the Ministry of Health has evolved to embrace poverty reduction, thereby becoming a mandate to:

"Improve the social and health conditions of families on the basis of a system integrating poor and/or indigent populations." The Health Sector Policy Paper sets forth five strategic themes, namely: (i) reorganization of the base of the healthcare pyramid and strengthening of healthcare service coverage; (ii) financing and improvement of the management of the sector's resources; (iii) prevention and treatment of the main diseases and improvement of the quality of care; (iv) prevention and treatment of endemic diseases (AIDS, malaria and tuberculosis); and (v) promotion of family health.

In accordance with conclusions emerging from the Health Sector Roundtable held on January 12-13, 1995 in Cotonou, the Ministry of Health recently repillared its health policy by adjusting it to fit the decentralization process in which the country is now engaged. A decision was thus made to reorganize the base of the healthcare pyramid in 34 health zones, and at the same time to built and equip 34 Zone Hospitals that serve as hubs for the Municipal Health Centers (Centres de santé de commune, CSC) and Arrondissement Health Centers (Centre de santé d'arrondissement, CSA).

The health situation is also characterized by periodic outbreaks of meningitis, choler and yellow fever, which are quickly brought under control thanks to the combined efforts of all participants in the health sector. Bucco-dental problems, blindness, lymphatic filariasis, sickle cell anemia, sleeping sickness and other common ailments have been addressed by specific programs combining preventive and curative measures. Grassroots hygiene and sanitation interventions, which prevent most infectious and parasitic infections, occur upstream of all these activities.

Source: Strategic Plan for the Health Sector

188. Improved nutrition. In Benin, daily energy consumption scarcely exceeds 1,300 kilocalories instead of the minimum of $2,400 \mathrm{kc}$ required by an average $65-\mathrm{kg}$ adult with a 
normal activity level. Under nutrition and the resulting malnutrition, as well as their attendant chronic or disabling diseases, the inability to tolerate physical exertion, and high levels of maternal and infant/child mortality, are indicative of the structural food and nutritional insecurity that has prevailed over the past several years. Thirty-three (33) of the county's 77 municipalities are in a state of chronic food and nutritional insecurity due to the precariousness of household supplies of high quality foodstuffs, large post-harvest losses, ineffective food storage/preservation systems, rudimental processing technologies with low yield and variable quality, inadequate policies and weak synergy between sectoral policies and programs, and the lack of pillar on nutrition (and particularly on community nutrition) in poverty reduction policies and programs.

189. Recognizing that the visible progress on the nutritional front would boost the productivity of human capital in the agricultural sector, and indeed in all economic sectors, the Government intends, over the next three years: (i) to develop a food and nutrition policy for Benin; (ii) to strengthen the mechanism for the prevention and management of food crises by adapting it to the decentralized environment; (iii) to conduct a prospective study, within the context of intermunicipal development, on ways to establish buffer stocks of foodstuffs for the benefit of municipalities; (iv) to promote income-generating activities, family gardens, urban horticulture, small-scale home-based livestock raising (whether traditional or not) and non-traditional foods (e.g., mushrooms, spirulina, apiary products, etc.); (v) develop and implement a communication plan on proper food processing and preservation techniques; (vi) re-energize the national committee on food and nutrition and its regional branches; (vii) step up monitoring of the population's dietary and nutritional status; and (viii) enhance the technical and material capacities of communities to assume responsibility for the care of malnourished children.

190. Development of athletic activities. The Government recognizes the value of massparticipation sports in the process of enhancing human capital, because of their impact on the population's well-being. The Government will install local athletic infrastructures in municipalities and will ensure that women's access to athletic pursuits is encouraged. Regarding soccer in particular, the Government will develop, along with countries with which it is on friendly terms, programs to train young Beninese nationals in the schools and training centers of those countries.

\subsection{Strengthening of the social safety net}

191. The family unit is the ideal environment for learning about life in society. It is a universe organized into a system that teaches an individual the baseline rules for achieving social equilibrium and personal fulfillment. The family circle is the starting point for the individual's social training, since it lays the groundwork for the individual's acquisition of knowledge, knowhow and social/life skills. The family is therefore the point of departure for educating the human capital needed for growth and poverty reduction. For the 2007-2009 period, the Government has decided to address issues concerning the family unit, women, gender inequality, the autonomy of women, the protection and development of children, social welfare protections, and mutual health insurance schemes.

192. Promotion of the family unit. Studies have shown that, in general, children reared in a stable and harmonious home tend to have less difficulty obtaining a good education, and to enjoy good health. The Government has therefore decided to attach particular importance to the family and to gender issues. Promotion of the family requires: (i) improving the living conditions of 
families; (ii) protection and preservation of the family; (iii) promotion of peace and social stability; (iv) strengthening of the capacities of family-promoting institutions and of foster homes that accommodate orphans and vulnerable children.

193. Promotion of the status of women. Experience has demonstrated the strong influence of African women in family stability, children's education, economic growth, and in development in general. An educated woman take better care of her family and encourages her children, and especially her daughters, to attend school. However, women occupy a disadvantaged position in Benin. To address this problem, the Government has decided "to improve the social, decision-making and economic status of women by promoting awareness of gender issues." The following actions will be required: (i) promotion of the education and training of girls and women; (ii) promotion of women's economic autonomy; (iii) promotion of women's health; (iv) improvement of, and respect for, the legal status of women; (v) valorization and recognition of women's labor; (vi) valuing of cultures and traditions that allow women to realize their potential; and (vii) continued efforts to combat relationship violence.

194. Promotion of gender equality and women's autonomy. As of the Third General Population and Housing Census (RGPH3) of 2002, women represented 51.4 percent of Benin's population and 58.3 percent of them are in rural areas where they perform agricultural labor for the most part. Women's demographic weight, their role in household stability, and their contributions to the sector producing goods and services mean that their status must be upgraded significantly and that all segments of the population must have equal opportunity for educational access through the elimination of all behaviors and practices detrimental to women. To this end, the Government will emphasize the following actions: (i) improvement of the land tenure code so as to grant women access to land; (ii) facilitation of access to micro-financing for women, and particularly poor women; (iii) functional French literacy; and (iv) management training as an accompaniment to micro-credit.

195. Child protection and development. The duty of parents, the community as a whole, the country, and its partners is to create for children an institutional, regulatory, educational, healthcare, and nutritional environment that can ensure the development of their full potential and enable them to become a high-quality human asset capable of contributing to economic and social development. Thus, the Government has set itself the goal, for the 2007-2009 period, of ensuring that the rights of children and adolescents are respected and that they have equal access to essential social services by: (i) protecting children and adolescents against mistreatment and child trafficking; (ii) promoting access for boys and girls to essential social services; (iii) improving the dietary and nutritional status of children; (iv) strengthening the capacities of agencies working on behalf of children; and (v) encouraging the familial and social reinsertion of orphans and vulnerable children.

196. Strengthening of social welfare protections. The Social Protection (SP) program is based on risk management. It restores labor policies, social insurance, and social security nets to their rightful position within an institutional framework involving prevention, mitigation and reaction against social risk and its effects, thanks to the efforts of numerous actors (individuals, households, local municipalities, NGOs, various echelons of public administrations and international organizations.) The goal is therefore to "ensure that the needs and socioprofessional integration of vulnerable persons and social groups are addressed" through (i) the socio-professional integration of handicapped persons; (ii) support to the elderly to encourage active maturity; (iii) psychosocial services to indigents and those victimized by HIV/AIDS and 
other disabling diseases; (iv) support for the establishment of social protection and social security mechanisms for workers in the informal sector; (v) improved management of vulnerability to crises; (vi) strengthening of the capacities of agencies working to promote social solidarity.

197. Promotion of mutual health insurance schemes. Health is a critical factor in the improvement of human capital, but it is in accessible for much of the population, especially in rural areas, due to its cost. Lack of access to healthcare services increases the risk of impoverishment for vulnerable groups. To enable the population to obtain care and enhance its productive capacity, the Government pledges to: (i) promote micro-insurance; (ii) create incentives for the establishment of mutual heath insurance programs; (iii) encourage the creation of community mutual health insurance schemes; and (iv) boost the population's awareness of the advantages of belonging to a healthcare mutual scheme. 


\section{CHAPTER 7: PROMOTION OF GOOD GOVERNANCE}

198. Good governance is a concern reflected in Article 35 of the Constitution of December 11, 1990, which states that "citizens charged with a public function or elected to political office have the duty to discharge it with conscience, competence, probity, devotion, and loyalty, in the interest of, and with respect for, the common good." Addressing the citizenry in general, the Constitution also emphasizes in its Article 37 that "public property is sacred and inviolable. All citizens of Benin must scrupulously respect and protect it. Any act of sabotage, vandalism, corruption, embezzlement, waste, or illicit enrichment shall be punished as provided for by law."

199. The Government has issued strong signals in favor of good governance by signing the Government operations charter and by instituting the formal declaration of the assets of all its members. The aspirations expressed by the Beninese people during the National Long-Term Prospective Studies (Benin, Alafia 2025) affirm this need for good governance to ensure that the general interest is served. Thus, Benin is projected to be "a role model, a well-governed, united and peaceful country with a prosperous and competitive economy, enjoying an influential cultural life and social well-being." Endorsing the same vision, the first Poverty Reduction Strategy Paper has as one of its priorities the "strengthening of good governance and institutional capacities."

200. Along these same lines, the Government designates good governance as one of the pillars on which Benin must base its Poverty Reduction and Growth Strategy. Several mechanisms are in place to ensure a practice and culture of good governance in Benin. These include, from the central level to that of local municipalities, structures with national purview and with unlimited spheres of oversight, such as: the National Assembly, the General Government Inspectorate, the General Inspectorate of Finance, the General Inspectorate of Administrative Affairs, the Supreme Court, and the Auditor General. Sectoral entities are also involved in the chain of oversight: the General Inspectorate of the Treasury, the General Tax Inspectorate, the General Inspectorate of Civil Service and Public Employment, the General Inspectorate of Security Forces, and the General Inspectorate of the Judiciary.

201. At the regional level, and within the framework of the New Partnership for Africa's Development (NEPAD), Benin has subscribed to the African Peer Review Mechanism (APRM). Greater participation in the activities of this mechanism will ensure further progress and improved strategies in the area of good governance. 


\section{Box 15: Various forms of governance}

Good governance, viewed as the entire array of good practices in the management of public and private affairs in furtherance of the population's well-being, the viability of enterprises, and the credibility of the nation, makes the highest demands in terms of the quality of services provided to users by government administrations. Governance has several operational aspects in Benin, including:

(i) Political governance, which concerns the facilitation of political life, transparency and the exercise of governmental power in the higher interest of the nation;

(ii) Administrative governance, which is the implementation by the public sector of republican values through the enforcement of rules, norms and procedures set forth in prevailing texts, and through accountability in their enforcement;

(iii) Economic governance, which is associated with conditions instituted by the central government and local governments to facilitate the creation of national and local wealth, and its equitable redistribution;

(iv) Governance of enterprises, which is based on competitiveness, particularly in the private sector, adherence to the rules of competition, the quality of employees' working conditions, observance of international procurement standards, and the fulfillment of tax obligations in the name of national solidarity. Crosscutting aspects also include:

(v) Local governance, which involves the implementation of grassroots development activities, and especially the commitment to an active process of decentralization and regionalization;

(vi) Collaborative governance pillaring on the promotion of opportunities for collaboration, cooperation and dialogue between all stakeholders (public actors, political actors, non-governmental actors, and other partners); and

(vii) Environmental governance, which requires that decision makers and all citizens recognize the need to take into account, for the benefit of current and future generations, the quality of the environment and respect for natural systems in modes of production, modes of consumption, and in systems of disposal and removal of waste from all sources.

202. The democratic process in Benin is taking shape to the extent that positive results are being obtained in terms of the separation of powers, the functioning of institutions, the organization of free and transparent elections, and respect for human rights and liberties. This political aspect of governance is regulated by a fairly elaborate legal framework comprised of several texts concerning the Charter of Political Parties, their roles as facilitators of the nation's political life, the ethical underpinnings of political activity, the status of the opposition, and elections. For about the past fifteen years, democratic life has been reflected in an alternation of political power holding that has generally gone smoothly. Thus, four (4) legislation elections (1991, 1995, 1999 and 2003), four (4) presidential elections (1991, 1996, 2001 and 2006) and one municipal election (2002) have been held. The institutional mechanism set forth in the Constitution of December 11, 1990, which grants the Beninese people collective rights, is completely in place. This mechanism consists of the Executive Branch (Government) and Legislative Branch (Parliament), which are installed through universal suffrage, the Constitutional Court, the Judicial Branch (Supreme Court, High Court of Justice), the Economic and Social Council, and the Supervisory Authority for Audiovisual Media and Communications, at the central level, and the Municipalities (communes) at the decentralized level. 
Box 16: Legal apparatus for fostering ethics in public life

In the area of human rights and justice, the Government is eager to promote a culture that acknowledges the primacy of law, and has undertaken since 1998 some reforms that need to be pursued and enhanced. These measures involve:

(i) Creation of the National Commission on Legislation and Codification;

(ii) Establishment of a Special Fund for Judicial Reform in 1998 and 1999;

(iii) Creation of the National Consultative Council on Human Rights;

(iv) Establishment of programs to rehabilitate and revamp certain judicial structures;

(v) Creation of the General Inspectorate of Judicial Departments;

(vi) Promulgation of the Organic Law on the Superior Council of the Magistrature in June 1999;

(vii) Approval of a comprehensive program to strengthen legal and judicial departments;

(viii) Staff recruitment and training measures;

(ix) Approval of a strategic plan to combat corruption and of the baseline legal texts of the Anti-Corruption Observatory;

(x) Ongoing examination, by the National Assembly, of a draft law on corruption and illicit enrichment.

These actions, which are aimed at promoting good governance, have been supported by several technical and financial partners, the most prominent of which are the World Bank, the European Union, the African Development Bank, and the bilateral cooperation arrangements.

Source: UNO

203. Regarding local governance, the Government has designated decentralization and town/regional management as an instrument for accelerating grassroots development and the participation of women and men in the management of matters affecting their localities. The Government plans to: (i) make prefectures operational in all departments; (ii) prompt local prefects to coordinate regionalized departments through better synergy and execution of Government interventions; (iii) develop the capacities of regionalized departments in keeping with the demands of the Reform of Territorial Administration (RAT) and the Government's financial framework; (iv) strengthen the human resources needed by prefectures and regionalized departments for the fulfillment of their mandates; (v) boost the effectiveness of municipalities in the exercise of duties under their purview; (vi) develop the capacity of municipalities to fully play their role in promoting the local economy; and (vii) enhance the oversight exercised by the prefectures (e.g., verification of legality, advisory assistance, coordination of development activities).

204. Despite this peaceable situation of political alternation within a multiparty environment, explosive expansion of civil society organizations, and the organization of public affairs oversight, governance needs to be much better organized and needs to be reflected in the behavior of civil servants, those belonging to the political class, and the citizenry, if poverty is to be reduced. The Government is therefore trying to decentralize the public administration and address the problem of its inability to innovate. It plans to improve the business climate and wage a vigorous war on corruption.

205. Over the next three years, the Government will strengthen good governance to increase the efficacy and efficiency of public affairs management. To realize its ambitions, the Government has set itself two goals that are reflected in two priority areas of intervention: (i) acceleration of administrative reforms; and (ii) strengthening of the rule of law and of individual liberties. 


\subsection{Acceleration of administrative reform}

206. The goal of the SCRP is to establish a creative and learning-oriented administrative culture that would optimally exploit the talents of men and women in the workplace without any type of discrimination. To that end, the Government plans to devote special attention to (i) reducing losses of public resources due to corruption and the institutional dysfunctionality of the civil service; (ii) restore Governmental authority; (iii) modernize and stabilize the civil service; (iv) accelerate territorial reform; and (v) develop mechanisms for collaborative governance.

\section{Reduction of public resource losses due to corruption and institutional}

dysfunctionality of the public administration. Recognizing the negative impact of corruption and the institutional dysfunctions affecting the administration of public resources, the Government intends to carry out a three-pronged effort over the next three years to: (i) systematize the practice of results-based management (RBM); (ii) combat corruption, especially by reforming public procurement procedures; and (iii) improve economic management.

208. Based on its experience with the progressive introduction of RBM since 2000 and the generalization of the practice of program budgets in all ministries in 2005, which has improved the rate of execution of public expenditures (for operations and investment), the Government intends to systematize the practice of results-oriented management. This is in keeping with a culture of accountability, assumption of responsibility, and self-assessment, all of which are values associated with good governance.

209. Within the framework of the reform of public procurement procedures, anti-corruption efforts are aimed at reducing the average public procurement timeframe to the absolute minimum. The inordinately long period required to conduct public procurement is due to either poor understanding of procedures or to the dysfunctionality of the agencies authorized to handle them. In order to render public procurement procedures transparent and equitable, Benin has approved a new institutional framework under Law 2004-18 of August 27, 2004 modifying the Order 96-04 of January 31, 1996 setting forth the public procurement code applicable to the Republic of Benin and the four associated enforcement texts deriving from it. In addition, the goal is to (i) organize joint workshops to build procurement expertise for the benefit of the public and private sectors, local municipalities, and civil society organizations; (ii) to draw up a reference pricing scale for the purchase of goods and services by sector, along with a plan to disseminate it by all modes of communication and in every language used in Benin; (iii) to assess the efficacy and impact of Government oversight bodies as well as the behaviors modeled by Government overseers; and (iv) introduce a national 'seal of approval' for public administration service providers and suppliers who adhere to anti-corruption and accurate invoicing clauses, a national distinction that would entitle them to exceptional tax breaks over a given period. 
Box 17: Legal and institutional framework of public procurement

\section{Legal and regulatory framework}

Public procurement in Benin is regulated mainly by Law 2004-18 of August 27, 2004 modifying Order 96-04 of January 31, 1996 setting forth the public procurement code applicable in the Republic of Benin, and by four enforcement texts, namely: (i) Decree 2004-562 of October 1, 2004 setting forth the mandate, composition and functions of the National Regulatory Commission for Public Procurement; (ii) Decree 2004-563 of October 1, 2004 setting forth the mandates, organization and functions of the National Directorate for Public Procurement; (iii) Decree 2004-564 of October 1, 2004 setting forth the mandate, organization and operation of the Public Procurement Units; and (iv) Decree 2004-565 of October 1, 2004 defining public procurement thresholds and the jurisdictional boundaries of the agencies responsible for public procurement.

\section{Procurement operations and private sector performance}

The granting and management of public contracts are entirely managed by the relevant contracting authorities (ministries or other public establishments and local municipalities). Actual execution of public contracts is conducted entirely by the private sector. This sector is organized through an independent private entity - the National Council of Business Owners of Benin - and a public entity called the Chamber of Commerce and Industry of Benin.

\section{Integrity of the public procurement system}

The Office of the Auditor General, an agency attached to the Supreme Court, is responsible for auditing public expenditures, and particularly public procurement. This institution should, in accordance with a WAEMU directive, be transformed into an Auditor General's Office (Cour des Comptes) to enhance its effectiveness and enable it to fully play the role assigned to it by law and regulation.

Source: Government of Benin

210. To improve economic management, the Government plans: (i) to continue the reform of budgets and public finance, putting particular emphasis on the quality of expenditures and endeavoring to eliminate, over time, expenditures made by means of Payment Orders and Advance Accounts; (ii) to continue and expand the Government's withdrawal from productive sectors; and (iii) to approve incentives encouraging dynamic involvement by the private sector in economic management.

211. Strengthening of Government authority. Firmer governmental authority is now needed to enable the Government to effectively perform its appointed tasks, which include: maintenance of the national territorial integrity, internal security, justice, and the protection of Beninese nationals throughout the world. Enhanced authority will ensure the influence and prestige of Government representatives in the exercise of their functions and the independence of the administration vis-à-vis all pressure groups. In this framework, the plan is to: (i) promote a culture that acknowledges work well done and the practice of applying sanctions, in order to encourage good practices in the management of public affairs; and (ii) institute a mandatory public service obligation geared to education in republican values, an understanding of governmental functions, the duties of civil servants, systems of prevention and avoidance of corrupt practices and embezzlement of public funds, and communication with users.

\section{Modernization and stabilization of the public administration. Cumbersome} administrative procedures are among the problems decried by users. Governmental continuity is critical for consolidating procedures, learning from past experience, and improving relations with users. Also, workers and users of public services consistently demand improved working 
conditions to facilitate the performance of tasks and shorten the time required to deliver services. In addition, Benin's ambition of taking its place in the community of nations, as well as its insertion into the world market, require access to new technologies and a better system of resource management. Thus, the emphasis will be on: (i) clarification of the mandates of the Government, taking into account the actual implementation of territorial reform and the revision of organic texts; (ii) promotion of a computerized system of administrative e-mail management by intranet and internet; (iii) computerization of the system of career path management and implementation of skill-building plans for Government employees; and (v) development of systems for conducting surveys of customers' satisfaction with services rendered to users by the public administration.

213. The mobility and politicization of managers are also an obstacle to the stabilization of the public administration. Therefore, the Government intends to: (i) develop and apply job descriptions and profiles, as well as objective employee performance evaluation criteria and a consistent system of sanctions; (ii) develop and implement a dynamic system of motivation and reward of the best employees; and (iii) promote a culture of social and administrative advancement based on dignity, professional ethics, conscientious work, initiative, and merit. In addition, a particular effort will be made to appoint women, assuming equal qualifications, to high public positions.

\section{Promotion of collaborative governance and avoidance of misuse of human}

resources. Recognizing the advantages of collaborative governance, the Government has undertaken to foster broad participation by the populace in production decisions, as is evidenced by gatherings of the various organizations and institutions producing traded goods and services that contribute to the creation and accumulation of the nation's wealth, organized at the behest of, and under the patronage of, the Head of State. This effort will continue over the next three years to deepen the democratic process within production systems through: (i) the institutionalization, in all public administrations, of the practice of general staff assemblies and the re-energizing of management committees; (ii) institutionalization, within each public agency, of a receiving department charged with hearing workers' and users comments and/or complaints; and (iii) strengthening of the managerial capacities of managers of public services at various decisionmaking levels.

215. To improve management of government personnel and avoid the squandering of human resources, the Government plans to compile a roster of civil servants in categories A and B who are without assignments for purposes of their redeployment and productive use. The Government intends to consult periodically with policy-makers, civil society and the private sector to share with them any ideas and assessments emerging from administrative reform. Finally, support will be provided to citizen watchdog organizations in order to strengthen the governance mechanism.

216. Acceleration of territorial reform. The main purpose of introducing territorial reform to Benin through decentralization and regionalization is to promote grassroots development and combat poverty and inequality. However, despite the legal apparatus supporting decentralization and regionalization, implementation of reforms appears to be lagging. The Government therefore intends to make the decentralization/regionalization combination a reality by (i) assessing the degree to which existing texts are being enforced; and (ii) developing modifying and supplemental texts as needed. 
217. In addition, each ministry will be given a strategic regionalization plan for effective implementation of the decentralization/regionalization combination. Likewise, coordination and coherence of département-level action, centering on the prefect, will be strengthened through the introduction of intersectoral département-level programs integrating all regionalized government departments possessing a département-level program budget. In order to achieve this, the operation of the Departmental Administrative Conferences and the Departmental Commission for Consultation and Coordination will be improved. The Government will endeavor to develop and implement a timetable for the actual transfer to the municipalities of the prerogatives, purviews, activities and financial and material resources accruing to them according to the terms of the legislative and regulatory texts on decentralization.

218. The major strategic actions that the Government intends to implement are: (i) boosting the capacity and effectiveness of municipalities in the exercise of their purviews; (ii) enhancing the effectiveness of verification of legality and advisory assistance; (iii) improving the legal framework; (iv) developing and implementing intermunicipal cooperation for the provision of high-quality services to citizens; (v) promotion of decentralized cooperation; (vi) promotion of good local governance; (vii) support to municipalities to strengthen their human resources; (viii) developing the capacity of municipalities to fully assume their role in promoting the local economy.

219. Within this context, the Government will examine the complementarity between the FIAT and mechanisms used to transfer of resources to municipalities.

\subsection{Strengthening of the rule of law and individual liberties}

220. The democratic system now in place in Benin is remarkably stable. The Government is not yet totally effectual, however. Indeed, the rule of law and the guarantee of security and tranquility are not yet adequately provided to all citizens, particularly due to the weak institutional capacities of the Government and the dysfunctions of the judicial system.

221. Implementation of the SCRP will: (i) improve the image of Benin's legal system in the eyes of those pursuing redress within it; (ii) consolidate progress already made toward democracy; (iii) enhance public safety and the neutrality of the army; (iv) heighten popular awareness of civic and patriotic duties.

222. The strengthening of the rule of law also requires environmental governance and the improvement of the population's living conditions. In addition, access to information and the emergence of a national body of public opinion entails the professionalization of the media so that grassroots populations can be better informed of their rights and duties as they help construct the Beninese nation.

\section{Strengthening of the legal and judicial system}

223. Where governance is concerned, collective surveillance of the progress and difficulties peculiar to every government requires a reinforcement of the legal and judicial system. To this end, the Government deems the following measures necessary: (i) revision of the Code of Penal Procedure so as to better guarantee individual rights; (ii) modernization of the national legal 
framework; (iii) strengthening of the organization and operation of courts and tribunals; (iv) outreach and training for officers of the criminal police and law enforcement personnel to ensure that arrestees are treated in accordance with human rights principles; (v) support to legal assistance organizations to enhance their institutional capacities and oversight of the quality of the services they offer to socially disadvantaged persons availing themselves of the legal system; (vi) enhancement of the capacities of people's juries in the areas of law, social mediation techniques, and conflict resolution; (vii) review of the cost of services to make judicial redress financially affordable to as many people as possible; and (viii) continued effort to provide the poor with affordable access to civil registry services .

224. The judicial system also needs to be decentralized so as to be more accessible to its users and to strengthen the democratic process and public security at the grassroots level. In this connection, the Government will emphasize: (i) creation of intake infrastructures for the newlycreated Courts of Appeal; (ii) creation of mediation tribunals; and (iii) recruitment and training of skilled judicial personnel to operate these regionalized structures.

225. Consolidation of progress in introducing democracy. Accelerated growth and poverty reduction can occur only if political parties, civil society and the private sector adhere to the baseline concepts of separation of powers and if their mode of organization and intervention is informed by such concepts. To this end, it seems important to open a discussion on human rights, baseline liberties, and universal suffrage, including a clarification of the status of the opposition, and the accompanying measures that the Government intends to implement over the next three years.

226. Enhancement of public security and neutrality of the army. Political stability, security, and free circulation of property and persons constitute the basis of the rule of law. If respected, these bases enhance investor confidence and enhance the country's image and influence abroad. Thus, it is vital to invest over the next three years in: (i) reinvigoration of neighborhood- and village-level councils as well as in their affiliated young people's organizations, in order to promote active popular participation in the national public security apparatus; (ii) strengthening of the system for combating crime, felony theft, drug trafficking, and the illegal trade in valuable objects and protected animal species; (iii) efforts to combat the disorganized proliferation of highway control stops to foster free circulation of property and persons between Benin and counties in the sub-region; (iv) establishment of a special program of community facilities and security enhancement in border areas to stabilize populations and protect the environment and national resources; and (v) consolidation of resources available to the Army to enhance the efficacy of surveillance and operational defense of the national territory in collaboration with other armies of the sub-region, in the interest of the peaceful coexistence of their populations.

227. Strengthening of environmental governance. The Government is concerned with passing on to future generations a healthy environment and with preserving ecological diversity, which is the basis for the nation's production system. The Government therefore plans to strengthen the system for the surveillance of transactions involving products posing threats to human health and the environment. Thus, mechanisms will be put in place to operationalize the charter on environmental governance. The Government is also concerned with toughening disciplinary measures applicable to attempted corruption in the issuance of certificates of environmental conformity, particularly with regard to port and industrial activities. It will also be 
necessary to strengthen the rapid intervention capacity of all policing bodies involved in environmental protection (health inspectors, environmental police, water quality inspectors, forest rangers, fire/rescue squads, highway patrols, etc.), as well as to reinforce the national mechanism for managing transborder livestock movements and strengthen of livestock entry points.

228. Promotion of civic and patriotic education. In order to restore a sense of the value of the State, the public interest, and national solidarity, so as to construct a unifying symbol that inspires national pride, the Government pledges to: (i) enhance the professionalism of the public and private media, particularly through support measures to benefit community radio stations, thereby ensuring ongoing civic education for the masses; (ii) strengthen the interventionary resources of human rights and consumer protection organizations; (iii) enhance training in civic affairs and human rights for public security officers; (iv) develop civic education in detention facilities; and (v) finally, set up communication aimed at behavioral change and at the community's assimilation of HIV/AIDS prevention messages. The dissemination of legislative and regulatory texts, programming and budgetary documents, and reports on the state of the Nation in each sector will strengthen and improve social and policy dialogue. These are the essential prerequisites for ensuring transparency, accountability and an engaged citizenry. 


\section{CHAPTER 8: BALANCED AND SUSTAINABLE DEVELOPMENT OF THE NATIONAL TERRITORY}

229. Given the constitutional stipulation requiring the Government to ensure the harmonious development of all territorial collectivities on a basis of national solidarity, regional potential, and interregional balance, several actions have been initiated over the past few years. In 2002, Benin developed a Declaration of National Land Management Policy (Déclaration de politique nationale d'aménagement du territoire, DEPONAT) and in 2004 created the Land Management Delegation (Délégation à l'aménagement du territoire, DAT) to ensure its implementation. Despite the Government's efforts, the national territory is still characterized by substantial disparities. In terms of population, the four (4) départements in the south (Littoral, Ouémé, Atlantique and Mono) account for only 5 percent of the national territory but are home to over 40 percent of the country's population.

230. These spatial imbalances exacerbate the poverty of rural areas since they provoke large population movements towards the south. Periurban development poses problems in terms of infrastructure and facilities in such areas as health, education, housing, transportation, and environmental degradation. Degradation of the environment and a deteriorating quality of life seriously compromise the numerous efforts undertaken at various levels to break the cycle of poverty in which the people of Benin are caught. Therefore, the incorporation of environmental concerns into policies, programs and projects has been a constitutional requirement in Benin since 1990.

231. Accelerated growth and poverty reduction therefore involves taking regional disparities into account with a view to greater territorial equity in the distribution of social and economic investments, as well as attention to the environment to ensure the sustainability of natural resources. Indeed, each component of the national territory must, as a function of its potential, take an active part in development while at the same time enjoying the benefits of national growth. This belief underlies the Government's decision to treat the issue of balanced and sustainable development of the national territory as a strategic theme under the SCRP. The effective integration of HIV/AIDS prevention measures into Municipal Development Plans (Plans de développement communaux, PDC) is a major concern of the Government.

232. To correct disparities, the Government wishes to base all development efforts on a balanced and sustainable spatial distribution of activities and infrastructures. Town and regional planning, environmental protection, and decentralization are the main tools that must accompany the implementation of sectoral policies that will place Benin in the category of emerging countries. Thus, under the strategic theme of "balanced and sustainable development of the national territory", the government is pursuing three (3) objectives that are in turn reflected in three (3) priority areas of intervention: (i) sustainable development of regions and localities; (ii) emergence of hubs of development and growth; and (iii) environment, natural resource management, and quality of life.

\subsection{Sustainable regional and local development}

233. Benin possesses an abundance of regional and local economic potentialities. The failure to exploit these to any degree, however, is still preventing the national economy from embarking on a true growth path, the effect of which would be poverty reduction and increased incomes. In 
order to spur local development, Benin has undertaken a reform of territorial administration leading to the enactment of the law concerning the establishment of municipalities, which subdivides Benin into 77 municipalities, or communes. Benin has also developed a town and regional planning strategagy that proposes the grouping of municipalities into shared development spaces capable of driving effective regional development.

234. However, much remains to be done in terms of regional and local development. Indeed, most municipalities are still fragile and need to pool their resources with those of other contiguous municipalities. The establishment of development spaces has not yet entered its active phase, although some pilot activities have been carried out. Spatial planning is in short supply and human capacity-building is needed for local development.

235. In order to address these realities, the Government has designated the promotion of sustainable regional and local development as a priority. To this end, the Government is embarking upon: (i) the promotion of structuring intermunicipal dynamics; (ii) the promotion of spatial planning; and (iii) capacity-building for the human resources involved in regional and local development.

\section{Promotion of structuring intermunicipal dynamics}

236. Benin will derive great benefit from having municipalities grouped into development territories while they at the same time maintain their autonomy. To make these intermunicipal dynamics viable, however, there will be a need for operational mechanisms through which local governments can manage regional and local development in partnership with the central Government. By spurring such intermunicipal dynamics, the Government intends to promote territorialized development and, thus, to place greater responsibility upon municipalities for the implementation of SCRP activities. The various activities required to achieve this end are: (i) the establishment of shared development spaces; (ii) the development of territorially based projects; (iii) the contractualization of territorially based projects; (iv) transfer of funds to the municipalities; and (v) establishment of intermunicipal agencies.

237. Establishment of shared development spaces. The Government wishes to support local governments in this process of grouping municipalities into development territories. The Government feels it necessary to support municipal councils as they create and formalize shared development spaces or development territories. Thus, on a consensual basis, several adjacent municipalities sharing the same geographic, historical, cultural and economic characteristics may join together into a development territory. The establishment of these territories will lead to the emergence of economic watersheds that create wealth and jobs, foster territorial development, and mitigate size and resource disparities between municipalities.

238. Development of territorially-based projects. The Government will also support municipalities joined together into development territories as they develop territorially-based projects. The territorial project is a document in which local actors will set poverty reduction and economic development goals for themselves. While it will have an intermunicipal component, a territorial project will include the Municipal Development Plans (Plans de développement communaux, PDC) of the various linked municipalities, along with attention to issues related to 
the environment, gender equity, HIV/AIDS, and human rights. Such projects will constitute the territorial manifestation of the SCRP at the level of the development space.

239. Contractualization of territorial projects. To the extent that implementation of territorial projects requires government support, municipalities joined together into development territories will be obliged to subject such projects to contractual arrangements with the Government. The contract will specify the commitments of the Government and of the territory thus constituted, in terms of objectives to be reached, distribution of roles, and financial and material resources required for its implementation. Through these performance contracts, the Government intends to promote a partnership approach in its relationship with the municipalities.

240. Creation of public establishments for intermunicipal cooperation. These establishments, created under Law 97-029 of January 15, 1999 at the initiative of the associated municipalities and managed under their sole responsibility, may guide the implementation of territorial projects. Their introduction will respond to the issue of territorial engineering, which has thus far been a serious obstacle to the exercise of authority by the municipalities. Without supplanting the municipalities, they will constitute a skills bank available to local governments. Through their regionalized departments, the Government will develop a capacity for technical support for the benefit of intermunicipal establishments.

Box 18: Operational Strategy for Implementation of the National Policy Declaration on Town and Regional Planning (DEPONAT)

Since it wishes to promote balanced development, the Government approved the National Policy Declaration on Town and Regional Planning (DEPONAT) in November 2002. The DEPONAT has three main themes: (i) promotion of territorial planning and rational resource management; (ii) promotion of decentralization and regionalization; (iii) enhancement of facilities and equipment at the local level.

The Operational Strategy Document (DSO) designed to implement the DEPONAT sets out the principles governing the reorganization of the institutional framework as well as new instruments of territorial management. The proposed innovations can be summed up in three points: (i) partnership and consultation between the Government and municipalities; (ii) territorialization through the promotion of associations of municipalities; (iii) contractualization of the relationship between the Government and local governments.

\section{Promotion of spatial planning}

241. Despite efforts to develop schemas and master plans at various scales in order to arrive at a better spatial planning, the results have fallen short of expectations. The desire to ensure coherent and equitable distribution of the national wealth, and thereby ensure balanced development, has led the Government to revisit spatial planning.

242. The Government intends to acquire national planning instruments that, in an approach based on territorial equity and coherence, define the broad guidelines regarding the distribution of people, activities, and infrastructures throughout the national territory. The various activities to be undertaken in this connection are: (i) development of spatial planning instruments; and (ii) integration of the territorial and environmental dimension into the budgetary resource allocations.

243. Development of spatial planning instruments. These instruments would be of a technical, regulatory and financial nature. The technical instruments are: the Master Plan for National Town and Regional Planning, planning schemas at the infranational levels, and 
collective services schemes. The collective services schemes drawn up by the relevant ministries will integrate service provision, a spatial and rational dimension of infrastructure development, and facilities. This is an approach geared to the population's needs and its access to goods and services. The Law on Town and Regional Planning and the Territorial Directives are regulatory and normative instruments still to be developed. The Town and Regional Planning Incentive Fund (Fonds d'incitation à l'aménagement du territoire, FIAT) instituted by decree ${ }^{14}$ is one of the financial instruments intended to support spatial planning.

244. Integration of the territorial dimension into budgetary resource allocations. This will entail adding to the budget allocation mechanism a process of territorial arbitration that will efficiently distribute public investment throughout the country. This measure is part of the decision taken jointly by WAEMU countries to include a contribution for structures responsible for town and regional planning when government budgets are drawn up. Thus, each sector will show, in its budget, the overall volume of investments received by each territory, as well as the volume of investment under municipal control, the execution of which is the responsibility of territorial collectivities. Along the same lines, the Government will ensure that micro-financing services cover the entire national territory to the extent possible, in order to bring these services within the reach of potential clients and to enable them to play a leveraging role in regional and local development.

\section{Human capacity-building for regional and local development}

245. To promote local development and support the establishment of development territories, human resources must be strengthened. The goal, through capacity-building measures, is to render the various actors more effective and efficient in their contributions to regional and local development. These capacity-building actions will target: (i) local elected officials; and (ii) the prefectural administration. In addition, the development of clusters of structuring projects with multiplier effects will require the development of targeted professional training programs aimed at provided the chosen sectors with skilled human capital.

246. Enhancement of the capacities of local elected officials. To help local governments better manage the mandates and resources transferred to them, the Government wishes to increase their ability to handle project management, project contracting functions, preparation of bidding documents, accounting, monitoring and evaluation systems, personnel management, and communications techniques.

247. Strengthening of the capacities of the prefectural administration. The Government feels that the role of prefects vis-à-vis local elected officials is important, especially in an environment in which the promotion of sustainable regional and local development is becoming a priority. The prefectural administration will therefore be equipped to better gauge the coherence between intermunicipal planning instruments and the national guidelines, and to verify local governments' close adherence to commitments they make in the context of their contractual arrangements with the Government concerning territorial projects.

\footnotetext{
${ }^{14}$ Decree 2003-374 of September 18, 2003 approving the statutes of the DAT.
} 
248. Capacity-building for NGOs and local consulting firms. Given the role of consulting firms and NGOs in the preparation of local planning documents and the construction of infrastructures, the Government deems the strengthening of their capacities to be an important prerequisite for ensuring that their provision of good quality services will help promote sustainable regional and local development.

\subsection{Emergence of development and growth hubs}

249. To ensure regional balance and stem the massive exodus of rural dwellers towards the large urban centers, the Beninese authorities wish to create several development hubs distributed throughout the national territory as a function of their comparative advantages. This development hub strategy also aims to diversify and boost production in the various regions of Benin. Thus, each development hub will eventually be a space organized around an economic engine, i.e., an important city surrounded by secondary cities and rural localities, all linked to each other by efficient transport and service networks. The main measures required for the emergence of development hubs are relevant to cities as well as to the adjacent rural localities. Such measures include: (i) the spatial distribution of project clusters; (ii) enhanced security and reliability of land tenure.

\section{Spatial distribution of project clusters}

250. The Government has identified priority pillars to put Benin on the path to becoming an emergent economy. Six embryonic project clusters have been identified. They are: (i) textile cotton; (ii) agrifood, trade and international business; (iii) construction, public works, and construction materials; (iv) tourism, handicrafts, and cultural activities; (v) transportation, logistics, and international trade; and (vi) telecommunications and information and communications technologies (ICTs). The development of each cluster will be organized spatially, by regional poles, and according to the regional emphases of the various production streams constituting the cluster.

251. The spatialization of project clusters requires an intersectoral discussion process that would clarify, for each cluster, the implications in terms of infrastructures and facilities to be built. Then, a spatial agenda would be drawn up for each cluster, or for a set of clusters, and would place the various work sites within an overall scheme providing a coherent vision, a more rational geographic positioning, and cartographic documents. By following such a procedure, the Government intends to avoid repeating past errors that have exacerbated interregional imbalances, limited the population's access to infrastructures and facilities, and provoked uncontrolled urban sprawl.

252. The Government will also take care to align project clusters with the strategy for strengthening Benin's medium-sized and secondary cities, so as to make them centers of activity with functions associated with the projects located in them. This matching is expected to create actual hubs of development and growth by strengthening urban centers in terms of their roads, tourism and leisure facilities, hotels, business centers, large national and regional schools, modern hospital centers, etc.

253. Tourism hubs. Benin possesses rich and varied tourism assets ranging from its natural resources to its sociocultural heritage. Sites and attractions of touristic interest in Benin include: (i) fine sandy beaches shaded by coconut palms, where fishermen weave their long nets; (ii) 
mountainous areas (such as the Atacora range) with waterfalls and remarkable landscapes; (iii) the Pendjari and ' $\mathrm{W}$ ' national parks with their game-rich hunting preserves; and (iv) cities of historic interest, such as Ouida, Abomey, and Porto-Novo. In addition, Benin has some impressive lake villages, such as Ganvié, where over 15,000 inhabitants live on the water itself in dwellings mounted on stilts. The Government has assigned priority to the enhancement of these touristic hubs through the development of clusters of tourism projects that are well thought-out and judiciously distributed throughout the national territory.

254. Agricultural hubs. Benin has several agroecological regions suited to the development of agricultural products such as cotton, cashew apples, oil palm, lumber, shea nut, pineapple, grains, tubers, root crops, fruits, and vegetables. The exploitation of this potential will enhance the contribution of the agricultural hubs of certain regions of the country. The Government therefore intends to promote a diversified, efficient and modern agricultural system based around valleys located along watercourses such as the Ouémé, Mono and Niger rivers, in the Lama depression, in hilly regions, cotton-producing regions, etc.

255. Commercial hubs. Benin has several trading centers with an influence that sometimes transcends its national borders. Indeed, the dynamism of certain cities such as Bohicon, Djougou, Glazoué, Comé, Malanville, and Asovè is due to the presence of a market that extends beyond the adjacent localities. The Government will take care to consolidate the attractiveness and competitiveness of these hubs by equipping them with modern commercial infrastructures and by enhancing their accessibility from other regions in Benin, and even from other countries in the sub-region.

256. Service hubs. Many services seem to hold promise for the emergence of the national economy. These include, among others, financial services, services to business, telecommunications and remote function services, health services, education, etc. Development of these services will enhance the service-based mandate of such large cities as Cotonou, PortoNovo and Parakou, and will also increase the reach of medium-sized cities (and other main departmental towns), turning them into veritable points of attraction for job seekers.

257. The spatialization of project clusters must also take sub-regional dynamics into account and aim at boosting the value of border locales. Indeed, Benin has over 2,000 km of borders that it shares with four neighbors, which means that the management of border areas is economically important. The development of project clusters and, thus, the creation of development and growth hubs, depends to a great extent on a good land tenure policy, and on the strengthening and modernization of infrastructures and facilities (e.g., transportation, energy and water, telecommunications, etc.)

\section{Providing secure land tenure}

258. With 58.5 percent of its land cultivable, Benin has ample scope for expanding its agriculture. However, problems of access to land ownership are an obstacle to strong agricultural expansion. In other production sectors, and even in housing, insecure land tenure remains an obstacle to investment. Public investment, savings, and private initiatives are on hold pending the regularization of property rights, and also because of a lack of confidence in the holders of traditional rights. 
259. Faced with this situation, the Government wants to pillar on improving land tenure security through the following measures: (i) development of a national land tenure policy that encompasses both rural and urban land tenure management; (ii) completion of the law on rural land tenure and development of rural land tenure plans; (iii) development of cadastral schemes in urban centers; (iv) improvement of the cartographic and topographic skills of institutions charged with land tenure management; (v) affordable procedures for formalizing property rights; (vi) information, education, and communication targeting the population; (vii) improvement of land registry services and management of land tenure information; and (viii) re-orientation of those who trade in hazardous products into other spheres of activity.

\subsection{Environment, natural resource management and quality of life}

260. Benin has substantial ecological, cultural, and anthropological assets. With about 65 percent of its territory covered with shrubs and trees, the country is home to one of sub-Saharan Africa's best known parks (the Pendjari Biosphere Reserve), which has an abundance of flora and fauna species. At the national level, however, the sector is essentially characterized by an ongoing deterioration of forest resources and fauna. Efforts to exploit these ecosystems cannot stop their degradation, which is the result of complex factors, the most important of which is human activity (i.e.. strong population pressure leaded to overuse of forestry and fisheries resources, ill-adapted extensive production systems, brush fires, cross-border transhumance, poaching, etc.) Indeed, the economic profile of Benin depends on its natural resources and is exhibiting a trend toward accelerated degradation of environmental quality in both rural and urban areas. This situation affects the sustainability of ecosystems, and especially the equilibrium of the biosphere.

261. In order to avoid the harm that would be caused by such a loss of ecological diversity and environmental quality, Benin has therefore signed several international conventions and agreements, and has endorsed, with its partners, the logic of ecosystem preservation through its 1994 Declaration of Forestry Policy and its implementation of important programs and projects such as the PGFTR, the PAMF, the PBF I and II, the ProCGRN, the PGDRN, the PCGPN and the PAGEFCOM. The Government intends to continue these interventions by improving the legal framework permitting sustainable natural resource management. It plans to approve the law on land tenure, the law on wildlife, the current update of tax regulations, and to improve institutional collaboration between public services and users.

262. The Government will also undertake to develop and implement a national reforestation program that accommodates the specificities of the various categories of forests and agroecological zones and that is aimed at: (i) broadening the supply of fuelwood, industrial roundwood, and timber; (ii) combating desertification and soil degradation; (iii) improving biodiversity; and (iv) improving carbon sequestration capacity. With regard to fauna, new community-level biological preserves will be created, especially in humid zones. In order to ensure the populations' support of this program, the participatory approach tested in the various programs underway will be expanded to the national scale, and income generated by the exploitation of forest resources will be equitably distributed among the various actors.

Privatization of the commercial lumber affiliate "Industrie du bois du Benin" (IBB S.A.) of the National Lumber Bureau (Office national du bois), and the resulting elimination of the monopoly on teakwood purchases, will be crucial factors in the promotion of private plantations, the resurgence of industrial activity, and the creation of new jobs. 
263. Apart from this natural resource sector, significant environmental problems are affecting the quality of life and health. These problems include: (i) the proliferation of shantytowns in the main cities, and particularly in Cotonou; (ii) the growing number of uncontrolled garbage dumps and the practice of open-air defecation; (iii) the growing scarcity and pollution of surface water supplies; (iv) air pollution in urban areas and the increasing importation of used vehicles withdrawn from circulation in Europe; (v) trafficking in hazardous substances (gasoline, drugs, agricultural and veterinary inputs); (vi) the scarcity of advisory support and education about the environment; and (vii) the lack of tools available to professional associations and grassroots contact persons for facilitating outreach on environment protection issues.

264. The Government is concerned by the scope of these problems, which aggravate environmental degradation and have negative impacts on the well-being of the population and on sustainable development. The National Environmental Management Program (Programme national de gestion de l'environnement, PNGE), begun in 2002 for a period of six (6) years, was presented as an array of coherent activities aimed at optimizing the links between the environment and poverty reduction, thus reflecting the themes of the Rio Summit on Sustainable Development. The overall objective of the PNGE, as formulated, is to "contribute to the sustainable economic and social development of the people of Benin through poverty reduction, promotion of internalized participatory planning, and local governance".

265. The Government plans to continue the efforts now underway. This commitment will be supported and maintained over the next three (3) years through (i) the strengthening of grassroots environmental management capacities; (ii) strengthening of the system through which environmental issues are incorporated into sectoral policies and the tax system; (iii) promotion of integrated natural resource management, and particularly of hydraulic and forestry resources; and (iv) promotion of local sanitation services. All of these measures are justified by the fact that the Government has chosen to incorporate environmental concerns into the SCRP.

\section{Box 19: The 'greening' of the SCRP}

What does 'greening' mean?

The term refers to the promotion of concrete policy measures aimed at integrating environmental concerns into relevant plans, programs and projects, with a view to ensuring their sustainability, with poverty taken into account in terms of its monetary, opportunity cost, human capacity, educational, health, and security aspects.

Why 'go green'?

- To promote sustainability in development programs;

- To integrate specific objectives and natural resource conservation and environmental quality activities into all programs derived from the SCRP;

- To plan in advance for external impacts and take into account the ecological costs of strategic options chosen under the SCRP,

How is 'greening' implemented?

The Strategic Environmental Assessment (SEA) is an anticipatory and proactive approach aimed at developing various sustainability scenarios. The SEA is therefore a tool for analyzing and weighing environmental potentialities and constraints against development objectives.

What have been the results?

- Environmental and social concerns are proactively and inevitably integrated into the SCRP and their impacts are acknowledged.

- The poverty-reducing impacts of environmental protection and natural resource conservation are identified. 
- Sectoral ministries have adopted the process and recognize the relationship between poverty and environment.

- A set of simple but precise indicators has been developed to evaluate results.

Source: ABE, 2006

266. Strengthening of grassroots environmental management capacities. All local governments are faced with serious natural resource management problems. Local authorities, and especially neighborhood leaders, have a weak capacity to mobilize those they administer around public health campaigns. For lack of resources, municipal communication plans pay only marginal attention to environmental protection issues. Master plans for municipal development have little chance of success unless efforts are made to support their implementation. In general, the lack of staff and technical capacities at the level of the municipalities and regionalized government departments charged with environmental and natural resource protection limits the support that local governments and their populations can expect.

267. To address these weaknesses, particular emphasis will be placed on information, education, and training of the population, along with supporting demonstration activities, in order to gradually introduce a culture of environmental management in the interest of a salubrious and appealing living environment.

268. To this end, the Government intends to strengthen the institutional capacities of municipal departments and commissions responsible for issues involving government-owned assets and environmental matters, through skills upgrades for personnel and elected officials, and by providing them with the resources they need for their work. Support will also be provided to local civil society organizations, including women's organizations and consumers' associations, in order to accustom them to assuming responsibility for managing the milieu in which they live.

269. The main measures to be undertaken will pillar on: (i) development of a communication plan with varied content, addressing the main environmental issues of each department; (ii) production of radio broadcasts meeting the information and outreach needs of young people; (iii) strengthening of the capacities of municipalities in the area of environmental management; and (iv) training of grassroots media facilitators and opinion leaders in order to promote behavioral change in terms of the attitudes that the population has regarding natural resources and its living environment.

270. Strengthening of the system for incorporating environmental issues into sectoral policies and the tax system. Great efforts have been deployed over the past ten years to put environmental management tools in place at the sectoral level, along with a dynamic of education at the national level. Examples include information, outreach and training activities, the creation of environmental units and an environmental police force, a resumption of public health policing, and support for officials responsible for policing forests and fisheries. A culture receptive to the preparation of environmental impact assessments of public and private projects is emerging. The decentralization process, which resulted in the establishment of municipalities (communes) in 2003 has, for its part, attached great importance to the responsibility to be borne by local elected officials for environmental protection and sustainable natural resource management.

271. Despite these efforts, behavioral change is proving to be slower than desired. The difficult economic situation, poverty, and the scarcity of resources available to local governments have made adherence to environmental protection rules somewhat sketchy. 
272. In order to address these deficiencies, the Government plans to deepen the strategies for incorporating environmental issues into public territorial management and into sectoral policies and programs. In this context, the means available to prevent environmental degradation will receive greater attention within the system of public investment programming, as well as in Benin's trade policy.

273. At the same time, and in order to more effectively promote a health environment, the Government plans to: (i) to systematically apply the Strategic Environmental Assessment (SEA) to all plans and programs; (ii) assess the environmental impact of Benin's tax system in sectors involving the importation of vehicles, household appliances, etc.; (iii) reform sectoral environmental units and provide them with the operating resources to increase their impact; (iv) develop a performance chart on sectoral priorities in the area of environmental protection at the level of each ministry and each prefecture, that would provide a clear overview of the relevant budgetary resources; and (v) strengthen the national system of environmental information and monitoring through a revamping of the various information collection and analysis formats that feed data into the national report on the state of the environment.

274. Promotion of integrated management of natural resources, and particularly hydraulic and forestry resources. The decentralization of mandates down to the municipal level with regard to environmental protection is an opportunity to strengthen cooperation between communities in the management of shared natural resources (cf. Article 94 of Law 97-029 of January 15, 1999 concerning the organization of municipalities (communes) in the Republic of Benin). Within this framework, the town and regional planning strategy provides for support to such dynamics at the intermunicpal level.

275. The Government pledges to promote environmental governance. In this connection, it intends to orient its intervention priorities within the framework of the SCRP to: (i) establish a framework for national, subregional and international partnership in the area of sustainable conservation and management of biodiversity of protected areas and fragile ecosystems; (ii) establish a national observatory of surface water quality; (iii) strengthen local government associations in institutional and operational terms, for purposes of integrated natural resource management; (iv) strengthen the environmental management capacities of mixed and womenonly farmers' and producers' organizations; (v) ensure baseline photographic/cartographic coverage of municipalities; (vi) promote alternative energies and fuelwood conservation systems; (vii) promote urban forestry and ecotourism; (viii) establish a system of sustainable financing of protected areas; and (ix) accelerate the establishment of measures to combat coastal erosion.

276. Promotion of local sanitation. Sanitation problems have emerged as serious handicaps for local populations, according to participatory surveys. Indeed, all large cities and main municipalities are experiencing difficulties associated with the removal and management of solid and liquid waste, biomedical waste, the absence of sanitary facilities in dwellings, and sanitation infrastructures in general. The budgets of most municipalities have few resources available for investment in sanitation.

277. Given this situation, which has multiple consequences (on both the health and productivity of the population), the Government has opted to continue its support to municipalities by: (i) promoting intermunicipal processes for household waste management; (ii) constructing and rehabilitating sanitation and sewer networks in selected cities; (iii) preparing and updating master plans and schemas for urban development and sanitation in main commune- 
level towns and municipalities; (iv) installing public utilities in inhabited zones or in zones slated for settlement; (v) identifying and closing-off areas unsuited for construction; and (vi) improving the management of biomedical waste in hospitals. 
III. IMPLEMENTATION OF THE SCRP 


\section{CHAPTER 9. MACROECONOMIC AND BUDGETARY FRAMEWORK}

278. The strategic approaches, macroeconomic and sectoral policies, and priority programs of the SCRP were described in the preceding chapters. The following sections analyze the quantitative implications of these policies for the growth profile and the allocation of resources to the sectors and ministries to finance the program budgets. This analysis comprises five phases:

(i) Baseline macroeconomic framework: This is the estimate of the quantitative impact of the sectoral strategies on the economic growth profile and the medium-term macroeconomic framework (the government real sector, balance-of-payments, and monetary situation accounts);

(ii) Baseline central budgetary framework: The projected medium-term expenditure framework (central MTEF) which proposes medium-term budgetary resource allocations between the SCRP sectors and ministries and estimates the overall cost of implementing the strategy;

(iii) Baseline sectoral frameworks: These frameworks are arbitrages between sectors in order to reconcile the sectoral ceilings of the central MTEF with the financing needs of the programs and projects and thus "align" the sectoral program budgets;

(iv) Variants of the baseline scenario in terms of the level of execution of the targeted programs and objectives (for example, the critical path of the MDGs) and the implications for the macroeconomic framework, the central MTEF, and the sectoral program budgets;

(v) Risk analysis in order to assess the implications for strategy implementation of shocks, structural rigidities, and other impediments, and their impact on the strategic objectives and the macroeconomic, budgetary, and sectoral frameworks.

279. From an operational standpoint, the approach adopted for the execution of the framework falls within the participatory process which is at the heart of the preparation and implementation of the SCRP. This approach was implemented in two phases. First, technical meetings were held with the DPPs of the sector ministries to appraise their various strategies, assess their cost, and estimate their impact on growth. In an extension of this participatory approach, the SCRP priority ministries and those which "house" the MDGs ${ }^{12}$ assessed the cost of their strategy for attaining the MDGs. As a result of this iterative and participatory process, which was carried out with the DPPs of the ministries and experts of the various sectors, the strategies could be quantified more precisely according to different levels of targeted objectives (e.g., the baseline scenario or the MDG scenario).

280. In a second phase, an iterative process was followed with the sector ministries in order to proceed with intrasectoral arbitrages and align the program budgets with the central MTEF ceilings. This makes it possible: (i) from the bottom up, to see the macroeconomic implications (macroeconomic growth and stability) of the sectoral programs' execution levels in relation to the levels of strategic objectives targeted (e.g., the MDG baseline scenario), and (ii) from the top down, to align the sectoral program budgets with the ceilings derived from the central MTEF of a targeted macroeconomic framework (e.g., the baseline scenario with a sustainable budget deficit given more or less secure financing).

${ }^{12}$ Costs were assessed for seven sectors: education, health, infrastructure, water and energy, environment, and gender. 


\subsection{SCRP baseline scenario}

281. The SCRP baseline scenario is the quantified translation of the various sectoral strategies that the government intends to implement to accelerate growth and reduce poverty during the years 2007-2009 while maintaining macroeconomic stability (targeted and sustainable inflation and deficit levels).

\subsubsection{Sectoral strategies and growth hypotheses}

282. As indicated above, growth acceleration will be based on the diversification of production, the strengthening of economic and social infrastructures, and the strengthening of good governance.

283. As a result of the implementation of the investment program in the priority sectors, public investment should increase strongly, by 20 percent per year. This, combined with the improvement in good governance and the business environment, will lead to an improved foreign investment ratio. As a result, the foreign investment ratio will increase from 22 percent in 2006 to around 25 percent by 2009 .

Table 15. Trend of economic growth and the investment ratio for 2000-2004

\begin{tabular}{|l|c|c|}
\hline & Growth & Investment Ratio \\
\hline Benin & 4.7 & 19.0 \\
\hline Burkina Faso & 4.5 & 19.4 \\
\hline Senegal & 4.3 & 19.1 \\
\hline East Asia and the Pacific & 8.0 & 31.5 \\
\hline China & 9.2 & 35.5 \\
\hline
\end{tabular}

Source: World Bank

284. Energy. One of the major constraints on the competitiveness of the Beninese economy is the high cost of energy, particularly electricity. Moreover, load shedding now influences the competitiveness of enterprises significantly. In 2006, the government took steps through the Energy Plan to increase its energy production capacity and reduce its medium-term cost. The completion of the CEB-NEPA project in 2007 and the implementation of the Energy Plan should thus help to reduce the costs and improve the competitiveness of Beninese enterprises. Accordingly, the volume of energy production should average around 8 percent annual growth over the period 2007-2009.

285. Agriculture. The implementation of the strategy in the rural sector will translate into improvements in productivity and agricultural outputs. The pace of growth of primary sector production should average around 8 percent for the period, as compared to 3 percent average growth for the period 2003-2005.

286. Services. As a result of the implementation of sectoral strategies (tourism, telecommunications, finance, and transport), it is estimated that growth in the market services 
CHAPTER 9. MACROECONOMIC AND BUDGETARY FRAMEWORK

sector will average around 6 percent, as compared to 4 percent on average during the period 2003-2005. 
Box 20. Summary description of the macroeconomic and budgetary framework model

The model. The SCRP macroeconomic framework was prepared using a quasi-accounting macroeconomic simulation model, the main characteristics of which are as follows: (i) it recapitulates the different relationships between the macroeconomic accounts; (ii) it is built around supply and rests on sectoral growth hypotheses reflecting the implementation of SCRP sectoral policies and strategies; (iii) it treats inflation as an objective of economic policy because of the WAEMU monetary convergence criteria. ${ }^{1}$ The macroeconomic simulation model is linked to a central MTEF, enabling resources to be allocated between ministries, and to sectoral modules, enabling sectoral program financing needs to be highlighted and reconciled with resource availability in order to "align" the program budgets.

The model utilized for the SCRP macroeconomic and financial framework observes the principles of financial programming and accounting equations, as the diagram below indicates. Growth is defined in a normative fashion, but takes into account the strategies that the government intends to implement.

Diagram: Macroeconomic and financial framework process

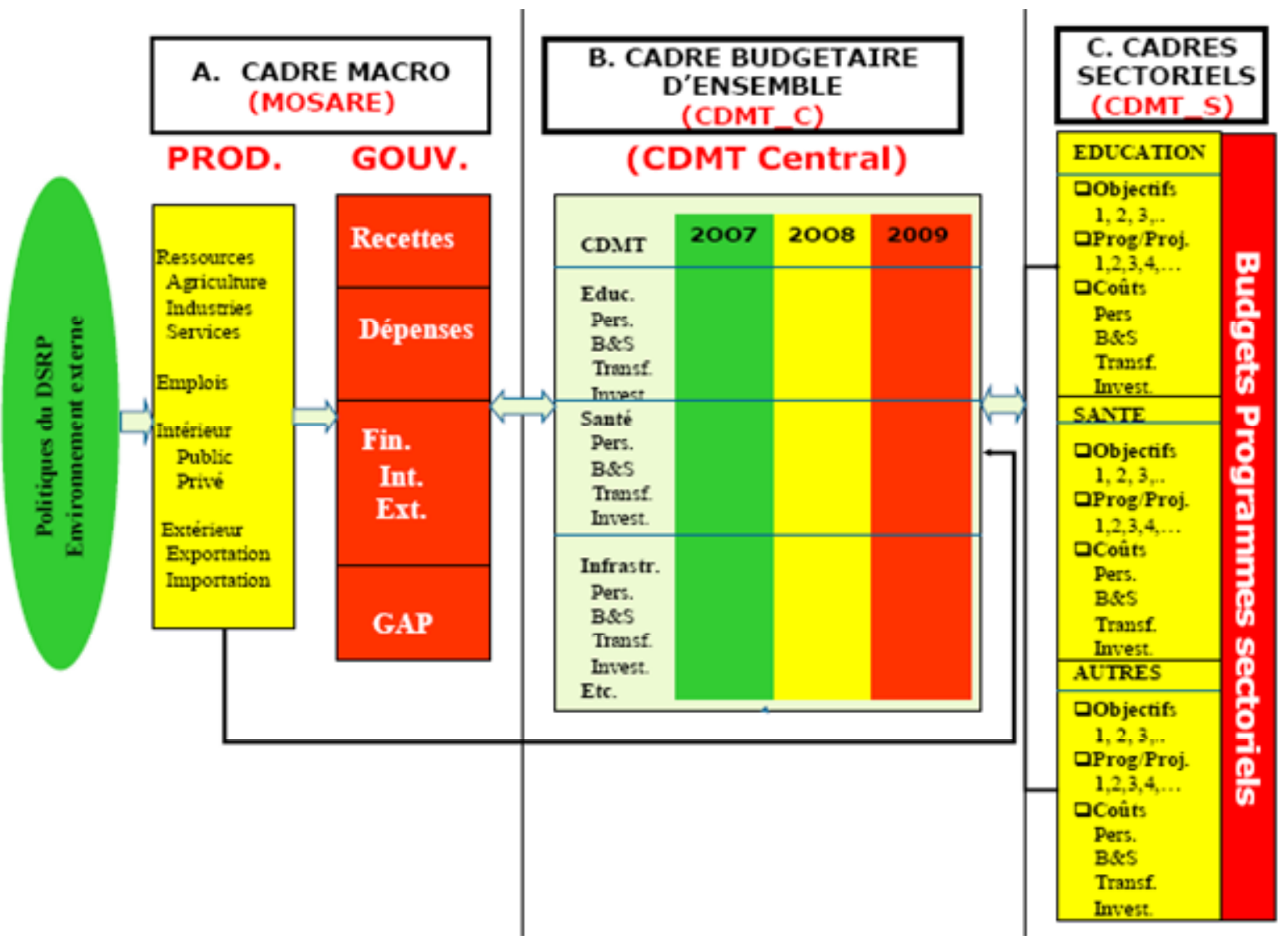

The model operates on the basis of an iterative process requiring an ongoing dialogue between the sectoral MTEFs and the macroeconomic framework 
Key to Diagram:

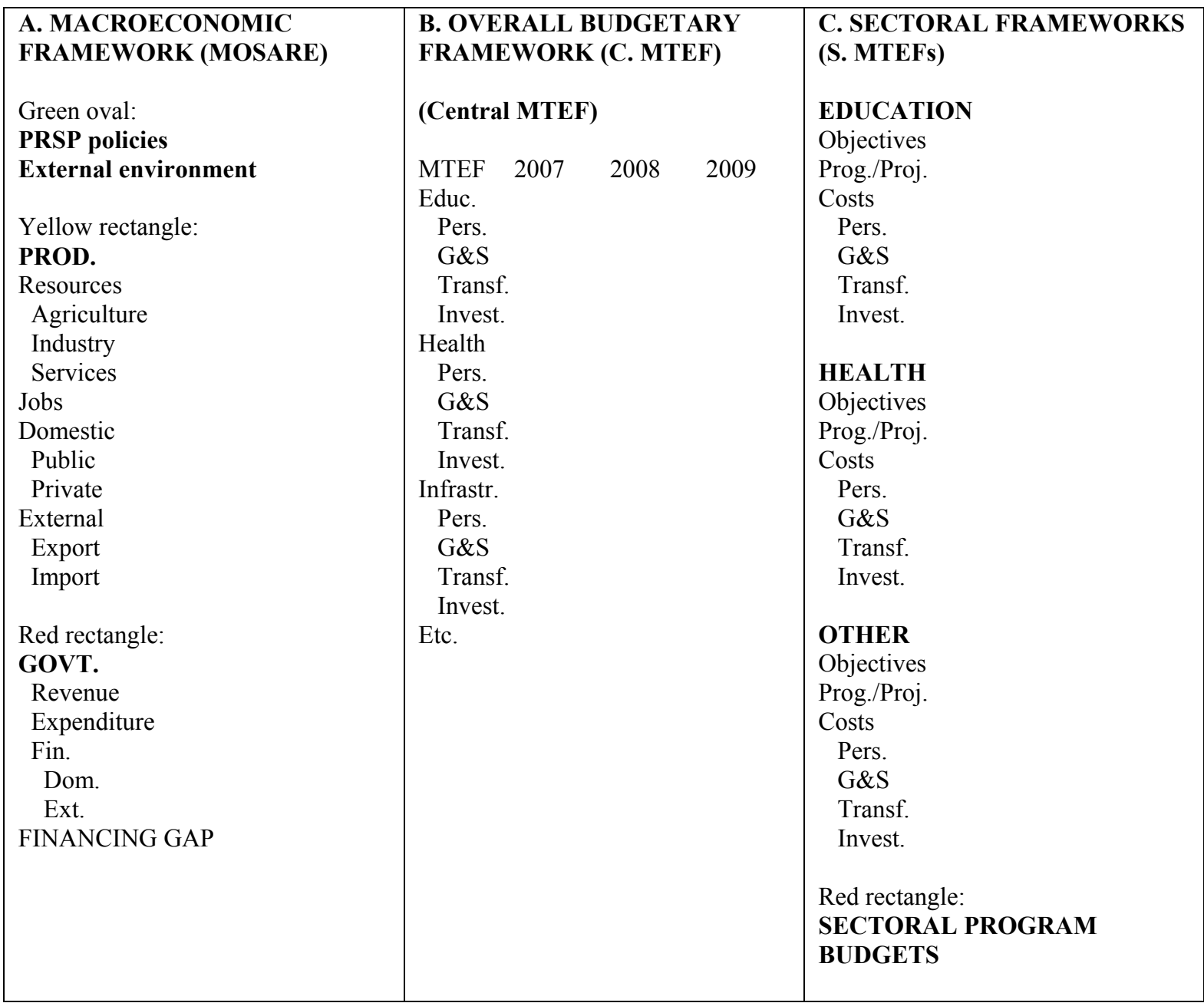

\subsubsection{Medium-term macroeconomic and financial framework}

On the basis of the preceding hypotheses concerning the growth fundamentals, the simulations indicate that the economic growth rate should rise by around 4 points over the period, moving from 3.6 percent in 2006 to 7.5 percent in 2009.

288. Strong medium-term growth. The effective implementation of the growth and poverty reduction strategy should enable the economy to gain 4 points of medium-term growth. The annual average growth rate would be around 7 percent for the period 2007-2009, which, in view of the projected average demographic growth of 3 percent for the period, will result in positive per capita revenue growth of around 3 percent for the period. 
Table 16. Trend of sectoral growth for 2006-2009

\begin{tabular}{|c|c|c|c|c|c|c|}
\hline & $2002-2004$ & 2005 & 2006 & 2007 & 2008 & 2009 \\
\hline Primary sector & & -0.8 & 7.1 & 7.4 & 7.4 & 7.8 \\
\hline Agriculture & 3.7 & -3.0 & 9.4 & 8.0 & 8.5 & 9.0 \\
\hline Livestock & 3.4 & 3.5 & 3.5 & 4.0 & 4.0 & 4.0 \\
\hline Fishing and forestry & 3.5 & 7.3 & -1.0 & 7.8 & 4.5 & 4.5 \\
\hline Secondary sector & & 5.4 & -1.3 & 6.6 & 7.4 & 7.4 \\
\hline Extractive industries & 7.0 & 5.0 & 6.0 & 6.0 & 6.0 & 6.0 \\
\hline Manufacturing industries & 1.6 & 5.3 & -4.6 & 6.0 & 7.0 & 7.0 \\
\hline Energy & 8.6 & 6.7 & 1.8 & 7.0 & 8.0 & 8.0 \\
\hline Construction and public works & 5.4 & 5.0 & 6.0 & 8.0 & 8.0 & 8.0 \\
\hline Tertiary sector & & 6.0 & 1.5 & 4.6 & 6.3 & 7.6 \\
\hline Commerce & 3.1 & 7.0 & 0.0 & 5.0 & 7.0 & 9.0 \\
\hline Transport and telecommunications & 3.8 & 5.7 & 2.2 & 5.0 & 6.0 & 7.0 \\
\hline Banks and insurance companies & 5.1 & 6.5 & 3.7 & 4.5 & 6.0 & 8.0 \\
\hline Other services & 4.0 & 4.8 & 2.9 & 4.0 & 5.5 & 6.0 \\
\hline Nonmarket services & & 4.0 & 4.1 & 5.0 & 6.0 & 6.0 \\
\hline GDP & 3.8 & 2.9 & 3.6 & 6.0 & 6.8 & 7.5 \\
\hline
\end{tabular}

Source: MDEF, 2006.

289. Growth rests mainly on the expected dynamism of commercial and transport activities and on the diversification and growth of export-oriented primary-sector production (export agriculture).

290. The year 2007 will be a year of transition toward double-digit growth by 2011 . To this end, the government intends to encourage the production of food crops (corn, rice, yams, manioc) and industrial crops, including, in particular, pineapples, peanuts, and palm oil, without neglecting cotton production. Indeed, cotton production should increase gradually, from 300,000 tons for the 2006-2007 crop year, to around 400,000 tons for the 2007-2008 crop year. Next, the full reestablishment of trade relations with Nigeria in 2007 and the improvement of the regulatory framework and business climate should revitalize commerce, particularly transit and re-export activities. Lastly, the strengthening of baseline infrastructure should energize the service industries and enterprises, particularly construction and public works enterprises. As a result of the implementation of these actions, the growth rate should reach 6 percent in 2007, as against 3.6 percent in 2006 .

291. These actions should continue and intensify in 2008 and 2009. Moreover, they will be accompanied by an improved business climate owing to judicial and land reforms and access to credit by enterprises, mainly SMEs. To accomplish this, growth would be stronger in 2008 and 2009 owing to competitiveness gains linked to improved factors of production, including energy, telecommunications, shipping, and economic and social infrastructures. The projected growth rate for 2008 and 2009 is around 7 percent.

292. On the demand side, the investment ratio should increase by around 3 points between 2006 and 2009 (from 22 percent to approximately 25 percent), led by public investment and the expected effects of the improved business environment on private and foreign investment. Note 
should be taken, however, of a deterioration in the saving-investment balance to around 6 percent of GDP, which could be improved substantially by an increase in transfers linked to the implementation of the SCRP and the MDGs.

293. The trade balance should stabilize in the medium term owing to a good performance of goods and services exports. Exports should increase as a percentage of GDP in relation to the improvement in productivity, not only of cotton, but also of food crops for export - a reflection of the government's desire to diversify exports. Imports should increase as a percentage of GDP in relation to private investment and the government's major works policy.

294. Price stability. Despite the increase in investments, domestic absorption pressure remains moderate in light of production growth. Indeed, a slight fall in private and public consumption as a ratio of GDP, combined with a strong growth of exports, will be noted. This has made it possible to maintain price stability and achieve the WAEMU convergence objective.

295. Strengthened public finance. Fiscal policy and overall ceiling levels consistent with an overall economic balance will be recapitulated during the period 2007-2009, taking into account the economic reform objectives. With the implementation of intensified resource mobilization measures, particularly the broadening of the tax base and the improvement in financial account earnings, the ratio of tax revenue to GDP is moving in a positive direction; from 15.1 percent of GDP in 2006, it is projected to reach 16 percent in 2009.

Table 17. Trend of revenue and expenditure as a percentage of GDP

\begin{tabular}{|c|c|c|c|c|}
\hline & 2006 & 2007 & 2008 & 2009 \\
\hline Total revenue & 17.0 & 17.6 & 18.0 & 18.1 \\
\hline Tax revenue & 15.1 & 15.8 & 16.2 & 16.3 \\
\hline Nontax revenue & 1.8 & 1.8 & 1.8 & 1.8 \\
\hline Total expenditure & 22.1 & 24.4 & 25.0 & 24.6 \\
\hline Wage bill & 5.7 & 5.9 & 5.8 & 5.5 \\
\hline Public investment & 7.6 & 8.6 & 9.5 & 9.9 \\
\hline Baseline primary balance & -0.9 & -1.5 & -1.6 & -1.2 \\
\hline Overall deficit (payment-order basis) & -5.1 & -6.8 & -6.9 & -6.5 \\
\hline
\end{tabular}

Source: MDEF, 2006.

296. During the program period, budgetary resources will be dedicated to current expenditure, representing 15 percent of GDP on average, and investment expenditure, representing 9 percent of GDP on average, among other items. The expenditure-control objectives will be pursued through a prudent wage policy. The volume of expenditure relative to GDP would stabilize at around 25 percent between 2007 and 2009, as against 21 percent during the three years of the poverty reduction strategy, owing to additional expenditures required for the implementation of the strategy's priority programs. As a result of improved revenue and the prudent growth of expenditure, the budget deficit (payment-order basis) remains contained, moving from 5 percent of GDP in 2006 to around 7 percent of GDP between 2007 and 2009.

297. A controlled money supply. In accordance with the common monetary policy of the WAEMU countries, the priority goal is price stability and a prudent policy of credit to the economy. It is expected that there will be an annual average nominal increase in the money supply and credit of around 10 percent, which is consistent with a real growth rate of 7 percent and an inflation rate of around 3 percent. 


\subsection{Medium-term expenditure framework (MTEF)}

298. The SCRP budgetary platform is a medium-term expenditure framework (MTEF) covering the period 2007-2009. The MTEF is prepared on the basis of a budgetary framework consistent with the macroeconomic framework presented above.

299. The framework's objective is a rational allocation to the sectors of the available resources freed by the macroeconomic framework, based on the SCRP priorities and taking into account the sectoral programs' financing needs. Arbitrage between the sectors took place on the basis of: (i) the ministries' functions and the SCRP priorities; (ii) the needs expressed by the sector ministries in the context of program budgets and/or cost assessments prepared in the MDG quantification framework; and (iii) new poverty reduction expenditure needs.

Table 18. Budgetary appropriation by sector for the period 2007-2009 (percent of expenditures excluding debt service)

\begin{tabular}{|l|r|r|r|r|r|r|r|}
\hline & \multicolumn{2}{|c|}{ PRSP Period $\left({ }^{*}\right)$} & \multicolumn{3}{|c|}{ SCRP Period } \\
\cline { 2 - 7 } & 2003 & 2004 & 2005 & 2006 & 2007 & 2008 & 2009 \\
\hline Social sectors & $\mathbf{2 8 . 3}$ & $\mathbf{2 7 . 6}$ & $\mathbf{2 9 . 2}$ & $\mathbf{3 1 . 0}$ & $\mathbf{3 0 . 6}$ & $\mathbf{3 0 . 7}$ & $\mathbf{3 1 . 2}$ \\
\hline \multicolumn{1}{|c|}{ Education } & 20.3 & 19.4 & 19.2 & 20.2 & 19.7 & 19.7 & 19.3 \\
\hline Health & 6.6 & 6.4 & 8.0 & 8.7 & 9.1 & 9.2 & 10.1 \\
\hline \multicolumn{1}{|c|}{ Other social sectors } & 1.4 & 1.7 & 2.1 & 2.1 & 1.8 & 1.8 & 1.9 \\
\hline Production and commerce & $\mathbf{6 . 9}$ & $\mathbf{9 . 7}$ & $\mathbf{8 . 8}$ & $\mathbf{8 . 3}$ & $\mathbf{8 . 5}$ & $\mathbf{8 . 3}$ & $\mathbf{9 . 1}$ \\
\hline Production infrastructure & $\mathbf{1 2 . 1}$ & $\mathbf{1 2 . 6}$ & $\mathbf{1 0 . 5}$ & $\mathbf{1 9 . 6}$ & $\mathbf{1 9 . 5}$ & $\mathbf{2 1 . 7}$ & $\mathbf{2 3 . 0}$ \\
\hline Governance & $\mathbf{1 0 . 9}$ & $\mathbf{1 0 , 8}$ & $\mathbf{1 2 . 4}$ & $\mathbf{9 . 0}$ & $\mathbf{8 . 7}$ & $\mathbf{8 . 0}$ & $\mathbf{7 . 5}$ \\
\hline Political & 2.6 & 3.2 & 4.7 & 3.1 & 3.4 & 3.2 & 3.2 \\
\hline Economic & 8.2 & 7.6 & 7.7 & 6.0 & 5.3 & 4.8 & 4.3 \\
\hline Defense and security & $\mathbf{9 . 0}$ & $\mathbf{9 . 1}$ & $\mathbf{1 2 . 6}$ & $\mathbf{7 . 6}$ & $\mathbf{8 . 0}$ & $\mathbf{7 . 5}$ & $\mathbf{6 . 6}$ \\
\hline Sovereignty & $\mathbf{4 . 6}$ & $\mathbf{4 . 6}$ & $\mathbf{6 . 8}$ & $\mathbf{3 . 8}$ & $\mathbf{3 . 8}$ & $\mathbf{3 . 6}$ & $\mathbf{3 . 5}$ \\
\hline Total ministries and institutions & $\mathbf{7 1 . 7}$ & $\mathbf{7 4 . 6}$ & $\mathbf{8 0 . 3}$ & $\mathbf{7 9 . 3}$ & $\mathbf{7 9 . 1}$ & $\mathbf{7 9 . 9}$ & $\mathbf{8 0 . 9}$ \\
\hline Other budgets & $\mathbf{2 8 . 3}$ & $\mathbf{2 5 . 4}$ & $\mathbf{1 9 . 7}$ & $\mathbf{2 0 . 7}$ & $\mathbf{2 0 . 9}$ & $\mathbf{2 0 . 1}$ & $\mathbf{1 9 . 1}$ \\
\hline Total budget & $\mathbf{1 0 0 . 0}$ & $\mathbf{1 0 0 . 0}$ & $\mathbf{1 0 0 . 0}$ & $\mathbf{1 0 0 . 0}$ & $\mathbf{1 0 0 . 0}$ & $\mathbf{1 0 0 . 0}$ & $\mathbf{1 0 0 . 0}$ \\
\hline
\end{tabular}

Source: MDEF, 2006.

Note: The data for 2003-2005 are payment-order expenditures and those for 2006-2009 are grants.

300. According to the MTEF, the priority sectors ${ }^{13}$ affected by these programs receive budgetary appropriations representing 48 percent, on average, of all expenditure appropriations for the period, after deduction of interest on the debt in 2007, 2008, and 2009. This proportion is around 24 percent for the education and health sectors alone.

301. On the basis of the information available on the probable financing to be mobilized, the residual financing to be sought is around CFAF 50 billion in 2007, CFAF 94 billion in 2008, and

${ }^{13}$ Education, health, road infrastructure, water and energy, agriculture, environment, and gender. 
CFAF 72 billion in 2009. Expenditures not directly linked to the SCRP should be subtracted from this volume of financing need to deduct their cost. A cost assessment is contained in table 19.

Table 19. Cost and financing of the SCRP

\begin{tabular}{|c|c|c|c|}
\hline & 2007 & 2008 & 2009 \\
\hline Estimated public expenditure* & 631.0 & 711.3 & 776.0 \\
\hline Domestic resources & 506.7 & 522.8 & 568.7 \\
\hline Tax and nontax revenue & 465.4 & 521.5 & $\overline{580.4}$ \\
\hline Other domestic public financing** & 41.3 & 1.3 & -11.7 \\
\hline External resources (excluding debt relief) & 113.0 & 132.1 & 146.5 \\
\hline Financing gap & 11.3 & 56.4 & 60.8 \\
\hline \multicolumn{4}{|c|}{$\begin{array}{l}\text { Source: MDEF, } 2006 . \\
\text { Notes: } * \text { Total expenditures minus pensions minus interest on the debt minus short-term payments. **Includes } \\
\text { variations in arrears. }\end{array}$} \\
\hline
\end{tabular}

\subsection{Alternative scenarios and prospects for the achievement of the MDGs}

302. MDG alternative scenario. As mentioned in the paragraph on methodology, the baseline scenario does not take into account all of the needs estimated in the framework of the MDG critical paths. Therefore, a so-called MDG scenario was projected which fully integrates the MDG sectoral cost assessments, but assumes an improvement in the absorption of assistance. The introduction of the results of the MDG cost assessments for seven sectors (education, health, road infrastructure, water and energy, agriculture, environment, and gender) led to an average increase of CFAF 175 billion per year in the volume of expenditure relative to the base situation, bringing the average investment ratio for the period to around 27 percent as against 24 percent for the base situation. This translates into a higher average GDP growth rate, which reaches 8 percent for the period 2007-2009, but also a more pronounced annual average budget deficit, which stands at around 11 percent. Likewise, the average current balance-of-payments deficit remains fairly high, in the neighborhood of 6 percent. The annual average residual financing need climbs to CFAF 225 billion.

303. Recent trends alternative scenario. Consideration was given to an alternative scenario which projects recent trends over the three programming years. Furthermore, a strong constraint on external resource mobilization, and a rigidity in the operation of the entire mechanism for utilization of the resources allocated to projects, was assumed. These constraints have a direct impact on the volume of public investment and on resource allocations to the sector ministries. The consequences for the pace of MDG attainment and growth are equally direct. In addition, there are the probable constraints linked to the supply sector, resulting mainly from contingencies in the agricultural production sector.

304. Hence, growth barely exceeds 5 percent, the investment ratio is in the neighborhood of 23 percent, and the deficit in the saving-investment balance deepens owing to the contraction of public saving. This deficit should represent 6 percent for the period on average.

305. Under the recent trends scenario, the volume of expenditure contracts by 62 billion in 2007 , 100 billion in 2008, and 132 billion in 2009, or by 2.4 percent, 3.6 percent, and 4.4 percent, respectively, of GDP, as compared to the baseline scenario. This makes it possible to hold the public deficit to around 4.8 percent in the first year and 3.4 percent in the last year. This public 
expenditure profile, which is completely delinked from the MDG targets, no longer falls within the context of the path to achievement of these objectives.

Table 20. Trend of the principal aggregates according to scenario

\begin{tabular}{|c|c|c|c|c|c|c|c|c|c|}
\hline & \multicolumn{3}{|c|}{2007} & \multicolumn{3}{|c|}{2008} & \multicolumn{2}{|c|}{2009} & \\
\hline & $\begin{array}{l}\text { Baseline } \\
\text { scenario }\end{array}$ & $\begin{array}{l}\text { MDG } \\
\text { scenario }\end{array}$ & $\begin{array}{l}\text { Trend } \\
\text { scenario }\end{array}$ & $\begin{array}{l}\text { Baseline } \\
\text { scenario }\end{array}$ & $\begin{array}{c}\text { MDG } \\
\text { scenario }\end{array}$ & $\begin{array}{c}\text { Trend } \\
\text { scenario }\end{array}$ & $\begin{array}{l}\text { Baseline } \\
\text { scenario }\end{array}$ & $\begin{array}{c}\text { MDG } \\
\text { scenario }\end{array}$ & $\begin{array}{l}\text { Trend } \\
\text { scenario }\end{array}$ \\
\hline $\begin{array}{l}\text { GDP growth } \\
\text { rate }(\%)\end{array}$ & 6.0 & 7.3 & 4.1 & 6.8 & 8.1 & 4.5 & 7.5 & 8.7 & 5.0 \\
\hline Investment ratio & 23.6 & 26.4 & 22.9 & 24.4 & 27.2 & 23.2 & 25.2 & 27.6 & 23.6 \\
\hline $\begin{array}{l}\text { Total } \\
\text { expenditure } \\
\text { as } \% \text { of GDP }\end{array}$ & 24.4 & 30.2 & 22.4 & 25.0 & 29.2 & 22.3 & 24.6 & 27.5 & 21.8 \\
\hline $\begin{array}{l}\text { Budget deficit } \\
\text { as } \% \text { of GDP }\end{array}$ & -6.8 & -12.7 & -4.8 & -6.9 & -11.5 & -4.2 & -6.5 & -9.9 & -3.4 \\
\hline $\begin{array}{l}\text { Financing gap } \\
\text { (CFAF billions) }\end{array}$ & 49.6 & 216.6 & 0.0 & 93.8 & 246.2 & 12.0 & 72.2 & 212.5 & 30.2 \\
\hline $\begin{array}{l}\text { Current deficit } \\
P B \text { as \% of } G D P\end{array}$ & -5.8 & -6.1 & -6.1 & -5.5 & -5.8 & -6.2 & -4.9 & -5.2 & -5.5 \\
\hline
\end{tabular}

Source: Beninese authorities.

\subsection{Risk analysis}

306. The SCRP baseline scenario is underpinned by key assumptions concerning the macroeconomic framework, the social situation, and the international environment. The appearance of adverse external shocks could reduce growth and therefore jeopardize the SCRP objectives. Such shocks might include: (i) a rise in petroleum prices; (ii) climate contingencies; (iii) the persistence of structural rigidities (reforms in the energy and telecommunications sectors; unsatisfactory privatizations of public enterprises); (iv) the unpredictability of assistance; (v) low inflows of foreign investment; and (vi) a low rate of budgetary resource absorption.

307. The Beninese economy remains heavily dependent on agricultural production, particularly cotton. The SCRP baseline scenario posited an improvement in cotton production and a diversification of agricultural production for export in order to improve the trade balance. However, the absence of good climate conditions and the weak mechanization of agriculture can significantly affect economic forecasts. Furthermore, the volatility of world market prices for agricultural products, particularly cotton, could affect the production level owing to the effects of negative producer expectations.

308. Delay in the implementation of various structural reforms, especially in the energy and telecommunications sectors, can constitute a major risk for the attainment of the SCRP objectives. Indeed, the problems related to energy (availability and high cost of energy) and telecommunications (organizational problem in the sector) flow from structural difficulties which hamper competitiveness and undermine the likelihood of economic diversification. 
309. External resource mobilization is an important element in the success of the SCRP and the attainment of the MDGs. However, the unpredictability of these resources affects the execution of the strategy's programs and projects. Furthermore, it would be desirable for the technical and financial partners to eliminate red tape in the disbursement processes so that the resources necessary for the success of the strategy can be mobilized efficiently.

310. The absorptive capacity of the sector ministries is also a constraint on the achievement of the SCRP objectives, to the extent that weak absorptive capacity lengthens the execution periods for the programs and projects.

311. Lastly, the lack of firm political support could be an impediment to the efficient implementation of the SCRP. It is therefore necessary to provide all the components of the implementation system with adequate resources and to generate support for the strategy among all stakeholders. 


\section{CHAPTER 10. IMPLEMENTATION AND MONITORING/EVALUATION MECHANISMS}

\subsection{Context}

312. As with respect to the other SCRP components, the strategy to strengthen the SCRP monitoring and evaluation mechanism is the result of a participatory effort comprising several phases. In the first phase, a thinking exercise was conducted to assess the monitoring and evaluation mechanism for the 2003-2005 poverty reduction strategy (PRS). This brought out the strengths and weaknesses of the system, making it possible to analyze the outputs in light of the expected results and to scrutinize the dysfunctions and other major obstacles to be eliminated for a more effective monitoring of the 2007-2009 SCRP. In particular, the central question of monitoring and evaluation was discussed in detail in the PRS review document and in various evaluation studies that were conducted. In the second phase, the assessments and the strengthening proposals adopted were discussed in various workshops with the participants, including the sector ministries, the central coordinating units (Permanent Secretariat, OCS, INSAE, etc.), and the development partners.

\subsection{Major gains and challenges to be faced}

313. Despite the problems involving resources and capacities, the monitoring mechanism for the 2003-2005 PRS registered noteworthy gains. In particular, the Permanent Secretariat of the CNDLP carried out effective monitoring, notably of: (i) the production of the first PRS and the preparation of the 2007-2009 SCRP; (ii) the arrangements for the preparation of the sectoral program budgets; (iii) the preparation of three PRS progress reports; (iv) the implementation of programs with partners, particularly the IMF, the World Bank, and the African Development Bank.

314. For its part, the OCS also made great strides in the monitoring of indicators and in program evaluations, and helped to build monitoring/evaluation capacities and to raise the awareness of decision-makers concerning the importance of evaluation activities. To this end, it conducted a number of impact studies, in particular: (i) the report on PRS indicators; (ii) the report on social characteristics; (iii) the impact of HIPC Initiative resources on poverty reduction; (iv) the impact of land reforms on poverty and the social situation; (v) the departmental report on the MDGs. However, the studies were carried out in an ad hoc fashion, and the results have yet to be utilized effectively for the updating of sectoral programs.

315. The two other major technical monitoring areas, i.e., statistical monitoring of development and monitoring of programs and projects, did of course produce several outputs, but these outputs, and the process itself, are not sufficiently synchronized and integrated with the PRS monitoring process. For example, a Social Scorecard (TBS) was produced, but is not synchronized with the PRS monitoring report, a factor that undermines its visibility, its functionality, and the added value of the PRS monitoring system. Similarly, evaluation reports have yet to be utilized for the preparation of performance reports for the sectoral program budgets and for making revisions to the action programs.

316. At the sector level, the PRS priority ministries are not sufficiently involved in the monitoring of indicators, and some still have difficulties in applying the proposed series of 
indicators to their work and contributing effectively to the monitoring effort. This weak involvement is due partially to capacity problems in the ministries (human resources, but especially adequate budgeting), but also to a coordination weakness in the mechanism. The decentralized level is not yet sufficiently active owing to the time needed to establish and activate the mechanism.

\subsection{Monitoring and evaluation mechanism for the 2007-2009 SCRP}

317. The government is cognizant of the inadequacies of the 2003-2005 PRS monitoring mechanism and is determined to resolve them to make the monitoring of the 2007-2009 SCRP more effective. The main challenges consist of: (i) giving greater responsibility to the sector ministries and the central statistical production units in the various areas of activity; and (ii) simplifying the institutional coordination mechanism to better synchronize technical monitoring with administrative monitoring. The government is also committed to making the decentralized monitoring units work in order to improve the people's "ownership" of the SCRP and the participatory process and thereby strengthen the quality of services and the effectiveness of policies and programs. To meet these challenges in light of the guiding principles referred to above, the following measures must be adopted.

318. A strengthened institutional framework. The initiatives taken by the government to merge the ministries of planning, the economy, and finance into the Ministry of Development, the Economy, and Finance (MDEF), and the implementation of two special technical structures ${ }^{14}$ within this ministry, offer a more appropriate institutional framework for monitoring the strategy. Furthermore, this framework guarantees the establishment of the simplified and effective system required to mitigate the dysfunctions observed during the first generation of the PRSP and to ensure better coordination of actions, and synergy, between the various stakeholders in the monitoring and evaluation of the PRS.

319. The new participatory institutional mechanism encompasses the four levels: national, sectoral, departmental, and local. At the national level, the Steering Committee is chaired by the Minister Responsible for Development and the Economy, and includes all the other ministers. It formulates the major policy and strategic approaches and supervises their execution through annual progress reports. The Government/Partners Committee is co-chaired by the Minister Responsible for Development and the Economy and a representative of the partners, and is the chosen forum for dialogue between the government of Benin and its technical and financial partners. The Monitoring Unit for Economic and Structural Reform Programs (CSPRES) is the kingpin of the mechanism and is responsible for monitoring the implementation of the SCRP in all areas. To this end, its specific tasks are as follows:

- coordinating the implementation and monitoring of the SCRP in close liaison with the ministries and other structures involved in SCRP implementation and monitoring;

- coordinating the three components of monitoring activities: (i) monitoring of indicators, (ii) monitoring of programs and projects, and (iii) impact assessments;

\footnotetext{
${ }^{14}$ These are the Monitoring Unit for Economic and Structural Reform Programs and the Directorate of Project and Program Monitoring.
} 
- coordinating the SCRP participatory process among the participants, including the government, local communities, the private sector, civil society, and trade-union organizations, as well as the technical and financial partners;

- preparing annual SCRP progress reports;

- conducting periodic reviews of the SCRP as a whole.

\title{
Box 21. Some guiding principles
}

\begin{abstract}
Generally speaking, the activities to monitor the implementation of the strategy have two very different, but complementary, dimensions: administrative monitoring of program execution and technical monitoring of development.
\end{abstract}

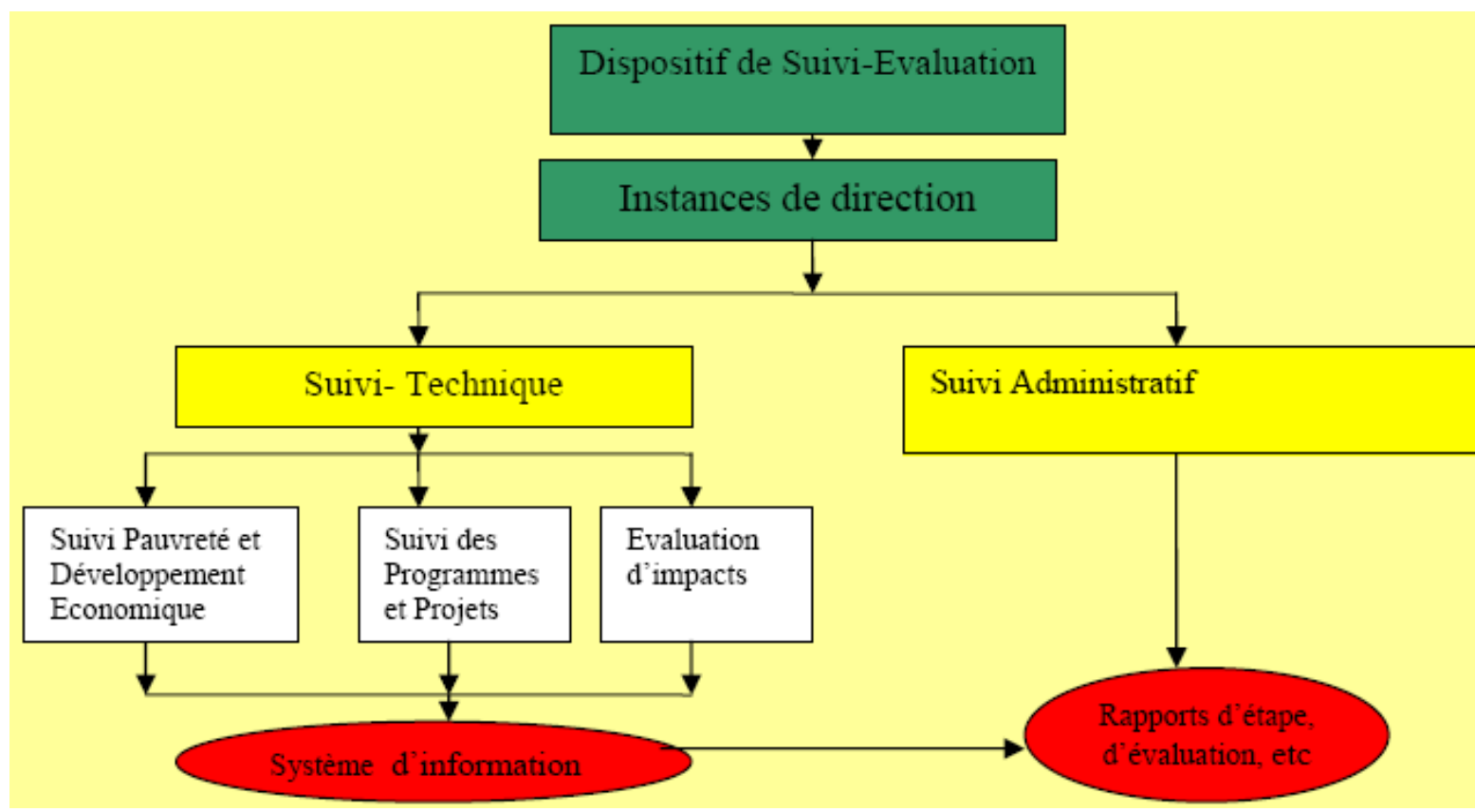

[green boxes:] Monitoring-Evaluation Mechanism

Leadership Bodies

[yellow boxes:] Technical Monitoring

Administrative Monitoring

[white boxes:] Poverty and Economic Development Monitoring

Program and Project Monitoring

Impact Assessments

[red ovals:] Information System

Phase/Evaluation Reports, etc.

Administrative monitoring of program execution. This consists of ensuring that the persons responsible for programs and actions execute them according to a well-established schedule, and that they report on them using "agreed" reports and indicators. Specifically, this involves: (i) monitoring of program execution in the different pillars by the technical ministries and subordinate units; (ii) coordination of activities for the preparation of progress reports and review of priority strategies and programs; (iii) coordination of the dialogue on policies and programs with the participants, including the sector ministries and development partners; and (iv) holding annual reviews.

Technical monitoring of development. This consists of measuring what has been accomplished in light of the strategic objectives and evaluating the effects of what has been done. Specifically, this involves measuring the 
progress made in program implementation and in attaining economic and social development objectives, as well as measuring the impact of specific actions on development objectives, using studies and precise indicators.

Technical monitoring of development has three dimensions:

- Statistical monitoring of economic and social development: This involves measuring the gains made over time in the different dimensions of development, including poverty and household living conditions, economic growth, development of infrastructure services, social development, and governance. Such monitoring is typically the responsibility of the structures specializing in production and management of statistics, such as INSAE and the statistical units of the technical ministries.

- Monitoring of program and project execution: This involves monitoring/observing the physical execution of programs and projects contained in the Priority Action Programs of the different ministries. Such monitoring is typically the responsibility of the central planning structures (Directorate of Project and Program Monitoring) and the DPPs in the ministries. It may be coupled with financial monitoring, in which case the Directorate of the Budget is involved.

- Policy and program impact assessments: This consists of measuring the impact of a particular program in a given sector on development objectives (growth, poverty, and social development), often through quantitative studies. Such quantitative analyses are often enriched by the results of perception surveys conducted among beneficiaries, which consist of assessing the quality of services according to users' opinions.

Giving the ministries responsibility for monitoring actions for effective results-based management. Monitoring is an essential component of strategic planning and results-based management (RBM). It is the main activity that enables accountability for performance and for the effectiveness of actions. It is also the activity that enables timely corrections and adjustments to be made to the action plan in light of accomplishments and changes in conditions. It is therefore necessary for the monitoring mechanism, like the budgeting mechanism, to give ultimate responsibility to the "executing agencies" - particularly the ministries - for the production, analysis, and use of statistical data in the implementation of the action plans. In return, these executing units have an obligation not only to produce results, but above all to report regularly on the progress made in the implementation of their respective action program components.

Source: Afristat

320. At the sectoral level, the monitoring of priority actions and programs is the responsibility of the ministries concerned, particularly the Monitoring and Evaluation Units and the statistical departments of the DPPs. These units rely on focal points to facilitate the coordination of the mechanism and the coherence of the information system. They also ensure the gathering of data useful to monitoring at the deconcentrated levels.

321. Monitoring at the deconcentrated and decentralized levels is carried out by the Departmental Monitoring Committees (CDSs) and the Municipal Monitoring Committees (CCSs).

322. The role of the CDSs is to monitor the implementation of departmental action programs and the gathering and analysis of sectoral statistical data for the department. They are chaired by the Departmental Prefects and secretariat services are provided to them by the Departmental Development Directors. The Committees comprise:

- the members of the Departmental Consultation and Coordination Council (CDCC), made up of the Departmental Prefect, the Mayors of the municipalities concerned and their deputies, a representative of the Departmental Producers' Union, a representative of the Departmental Consular Chamber, and a representative of the Departmental Federation of Student Parents Associations;

- the Directors of the government's decentralized units in the department; and

- a representative of civil society from each municipality; and 
- a representative of the trade-union organizations.

The CDSs meet once per quarter and the written records of these sessions, as well as a quarterly report on SCRP implementation in the department, will be conveyed to the Minister of Development, the Economy, and Finance.

At the local level, the Municipal Monitoring Committee (CCS) is responsible for monitoring the SCRP. The CCS is chaired by the Mayor, and its role is to ensure the gathering of statistical data for the municipality under the supervision of the CDSs. The CCSs meet once per quarter and the written records of these sessions, as well as a quarterly report on SCRP implementation in the municipality, will be conveyed to the Departmental Prefect for inclusion in the departmental report.

323. The Committees comprise:

- two municipal councilors;

- two representatives of NGOs active in the municipality;

- the Chief Physician of the Health Center;

- the official in charge of Rural Development;

- a representative of the farmers' organizations;

- the head of the local school district.

The government will endeavor to ensure the establishment and effective functioning of the CDSs and CCSs.

324. The monitoring/evaluation mechanism is divided into subsystems (see the layout below).

\section{Subsystem 1: Monitoring of macroeconomic and poverty indicators}

- Mission: This subsystem is designed to organize and supervise activities to monitor poverty, household living conditions, and the economic and social situation. This involves the systematic production of indicators on household living conditions and/or baseline data for each of the priority areas identified in the SCRP. To this end, it centralizes indicators on: (i) the poverty trend; (ii) growth and the macroeconomic framework; (iii) infrastructure development; (iv) the social sector; and (v) governance.

- Outputs: (i) Integrated Management System for Economic and Social Data (SIGIES); (ii) Economic and Social Scorecards (TBES); (iii) updating of the BenInfo database to accompany the progress report on SCRP implementation and the MDG monitoring report.

- Units responsible: The National Institute for Statistics and Economic Analysis (INSAE) coordinates this subsystem, which comprises the Directorate General of the Economy (DGE), the GDP-Table of Government Finance Operations (GDP-TOFE) Committee, the CSPRES, the Central Bank of West African States (BCEAO), the Directorate General of Development Policies (DGPD), and the statistical departments of the DPPs in the ministries.

\section{Subsystem 2: Monitoring of program and project execution}


- Mission: The role of this subsystem is to monitor the execution of the programs and projects falling within the Priority Action Program (PAP) of the SCRP. It makes it possible to monitor the physical and financial execution of the PAPs in the sectors. It is broken down into several compartments, namely: (i) physical monitoring of program execution; and (ii) monitoring of the financial execution of program budgets.

- Outputs: (i) annual program and project execution reports, including program budgets; (ii) a performance report; and (iii) a project database.

- Unit responsible: This subsystem is coordinated by the Directorate General of Project Monitoring (DGSP); it comprises the DPPs in the ministries and the central units, such as the Directorate General of the Budget (DGB) and the DGPD.

\section{Subsystem 3: Policy and program impact assessments}

- Mission: The mission of this subsystem is to measure the effects of policies and actions on the target groups and development objectives (growth, poverty reduction, and social development). The assessments make it possible to link program and project execution to outcomes in terms of the development and well-being of the target groups. The assessment studies have to be better synchronized with the programming of sectoral activities, the review of sectoral programs and strategies, and the SCRP review. They should also serve to assess the effectiveness of the priority programs in light of the longterm objectives defined in the strategy. In collaboration with the stakeholders of subsystems 1 and 2, this involves mainly: (i) identifying and making a selection of relevant issues for analysis; (ii) identifying service providers, who may be either domestic or external stakeholders (research centers, design and engineering firms, etc.); (iii) allocating resources; and (iv) supervising the preparation and dissemination of these studies and the utilization of the results to sharpen the pillar of the policies and programs.

- Outputs: (i) surveys of beneficiaries, which make it possible to ascertain what the people and users think of the services "obtained" for them by government structures or public enterprises; (ii) selective impact studies of policies and programs carried out in accordance with annually revised terms and conditions, taking into account the SCRP priorities and programming in the sectors (review of sectoral strategies or particular programs); (iii) a periodic territorial analysis that makes it possible to monitor the trend of intra- and interregional disparities in time and space and ensure balanced development in accordance with SCRP pillar 5.

- Unit responsible: The work of this subsystem is coordinated by the Social Change Observatory (OCS). Its members are the INSAE, the DGE, the DGSP, the DGPD, the Economic Policy Analysis Unit (CAPE), the Land Development Authority (DAT), ${ }^{15}$ and the monitoring/evaluation units of the priority sectors.

A minimum list of SCRP monitoring indicators is annexed to the strategy's PAP.

\footnotetext{
${ }^{15}$ On the basis of its prerogatives, the DAT is empowered to ensure the territorial dimension of the policy and program impact assessments through its National Territorial Analysis Observatory.
} 

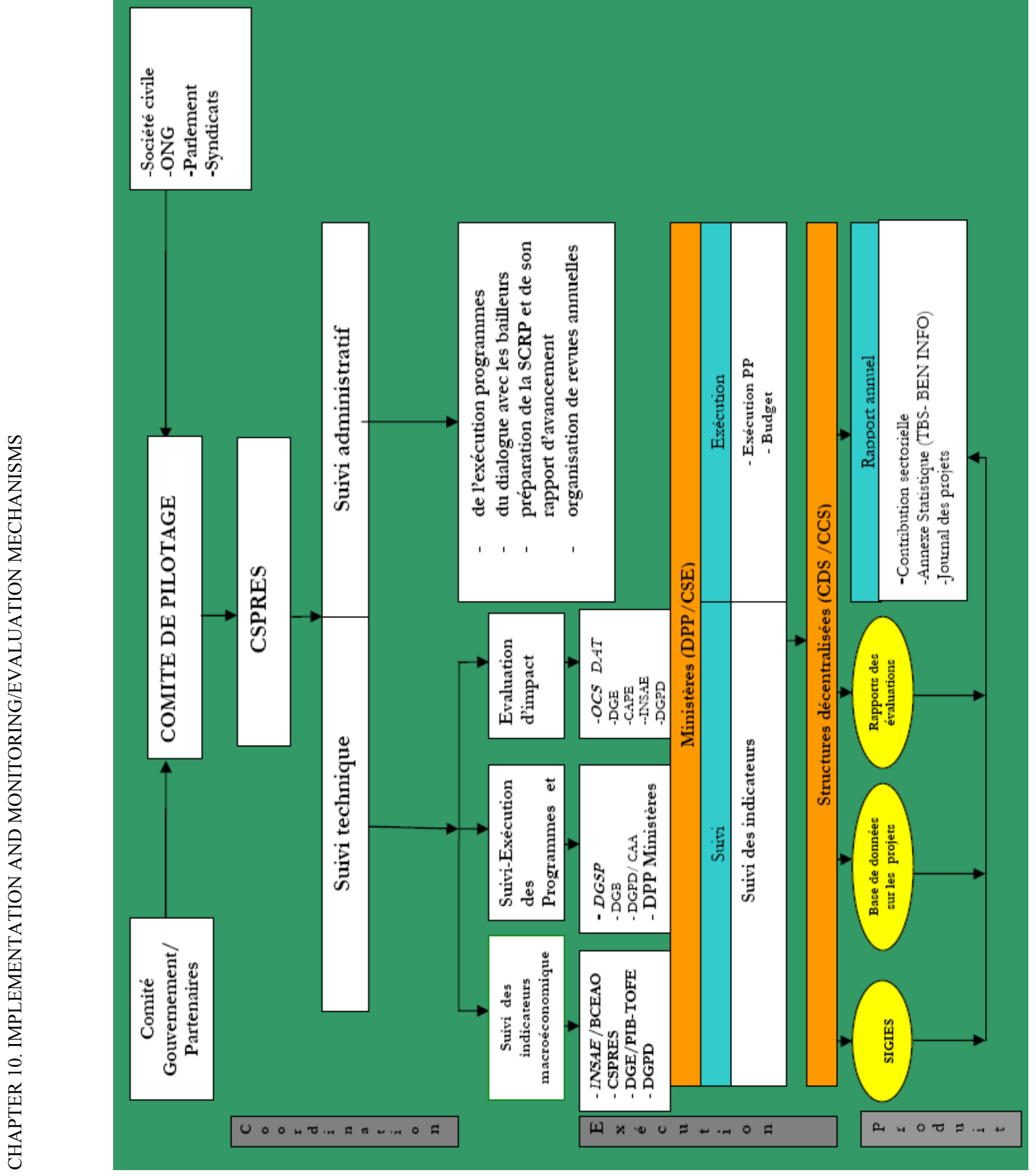
Key:

[1st gray box:] Coordination

[1st set of white boxes:]

Government/Partners Committee

STEERING COMMITTEE

-Civil Society

-NGOs

-Parliament

-Trade Unions

Technical Monitoring

Administrative Monitoring

[2nd gray box:] Execution

[2nd set of white boxes:]

Monitoring of Macroeconomic Indicators

Monitoring/Execution of Programs and

Impact Assessment

- of program execution

- of the dialogue with donors

- preparation of the SCRP and its progress report

- organization of annual reviews

- INSAE/BCEAO

- CSPRES

- DGE/GDP-TOFE

- DGPD

- DGSP

- DGB

- DGPD/CAA

- DPPs in the ministries

- OCS DAT

- DGE

- CAPE

- INSAE

- DGPD

[1st orange bar:]

Ministries (DPPs/CSE)

[blue bar:]

Monitoring

Execution

[white bar:]

Monitoring of Indicators 
- Program and Project Execution

- Budget

[3rd gray box:]

Output

[2nd orange bar:]

Decentralized Structures (CDS/CCS)

[yellow ovals:]

SIGIES

Project Databases

Evaluation Reports

[2nd blue bar:]

Annual Report

[last white box:]

- Sectoral Contribution

- Statistical Annex (TBS-BENINFO)

- Project Diaries

\subsection{Resource allocation for technical monitoring}

328. Generally speaking, budgetary resources should be allocated directly to the units responsible for data production in the technical monitoring mechanism, in particular to the units monitoring the sector ministries.

\subsection{Progress report and synchronization of outputs}

329. The progress report on SCRP implementation is the unifying document of the entire SCRP monitoring system. It is prepared annually in a participatory fashion by the CSPRES and comprises:

- A synthesis of recent developments, accomplishments in the implementation of the SCRP, structured according to the strategy's strategic pillars, and a summary of PAP execution;

- Sectoral annexes: these are progress reports on strategies and sectoral PAP execution reports prepared by the ministries. These reports analyze the physical execution of the programs and projects and the financial execution that was covered by the old "performance reports." The annual preparation of these reports is an administrative obligation of the ministries and the reports are the principal outputs of their individual monitoring systems;

- A statistical annex (TBES): this is an enhanced version of the current TBS. It consolidates the statistics on the different development spheres, notably poverty reduction, growth and the macroeconomic framework, infrastructure, the social sector, and governance. This table is the principal output of subsystem 1 of the technical 
monitoring mechanism. The table can be extracted from the computerized integrated statistical management system (see below);

- A program and project annex. This is a summary of the PAP, organized by sectors.

330. "Ongoing" outputs. For the timely production of the above elements, the mechanism has to maintain, feed, and centralize a database on (i) statistical monitoring of development, and (ii) the project banks. The first module can be housed in the INSAE, fed by the sectoral units housed in the ministries and the specialized units, and networked to facilitate exchanges, consistency checks, and timely extraction of the table of indicators. The second module can be housed in the DGSP and fed by the sectoral units.

331. Dissemination strategy. The various monitoring and evaluation reports and studies should be archived on an Internet site to facilitate their dissemination and consultation and lend greater visibility to the outputs. Such a site can serve as a resource base for training activities and raising public awareness with regard to the implementation and accomplishments of development and the fight against poverty in Benin.

\subsection{Implications for the statistical development strategy}

332. The SCRP monitoring and evaluation mechanism falls within the context of a deep understanding of the realities that determine the phenomenon of poverty, its trend, and its consequences. From this standpoint, it places emphasis on a number of criteria that should be assessed together. All the assessments and analyses will be based on strategic pillars as defined in the SCRP, namely: (i) economic growth and sectoral policies; (ii) infrastructure; (iii) the social sector; (iv) governance; and (v) balanced development of the national territory.

333. The monitoring/evaluation of actions supporting the strategic pillars requires a large mass of data, which in turn requires the strengthening of the national statistical system. From this standpoint, the preparation and implementation of the national statistical development strategy presents a good opportunity. The implementation of this strategy is also designed to address user needs by developing key data fields for monitoring poverty reduction strategies (PRS) and the MDGs, investing in baseline infrastructure, strengthening data analysis, improving data dissemination, and strengthening coordination with other system units.

334. Taking into account the institutional mechanism, responsibility for data gathering, processing, and dissemination will thus be assumed by the INSAE, in collaboration with the coordination unit of the SCRP technical system.

\subsection{Implications for capacity-building}

335. The multiple challenges related to the national statistical data management system, and the innovation that the implementation of a data, monitoring, and evaluation system centered on poverty reduction and participatory management will represent, bring to the fore several areas where support is needed for the smooth functioning of the planned system.

336. These areas have to do with institutional structure, training, logistics, and motivation management. 
(i) Institutional structure

Correct the dysfunctions to promote smooth circulation of data;

Establish and improve the functioning of consultation and steering structures;

Prepare specific terms of reference for all structures involved in SCRP monitoring/evaluation.

(ii) Training

Build the human resource capacities of the coordinators of the three monitoring and evaluation subsystems through training workshops.

(iii) Logistics

Design tools for data gathering, processing, analysis, and dissemination; Identify relevant indicators for the SCRP strategic pillars;

Design an appropriate policy monitoring and evaluation system.

(iv) Motivation management

Establish mechanisms to motivate the staff of the structures participating in the system.

\subsection{Involvement of the Paris Declaration in SCRP implementation}

337. The SCRP constitutes the reference point on which national priorities and the actions of all partners are pillared. A prior status report on aid effectiveness and the implementation of the Paris Declaration was prepared in 2006. Consultations between the government and donors showed the importance of continuing the mutual efforts to improve aid impact and reduce transaction costs. A joint partners-government group on aid effectiveness, chaired by the MDEF, was established to monitor the implementation of the Paris Declaration.

338. During the SCRP execution period, a joint action plan will be implemented by the government and the donors. Through this action plan, the government intends to: (i) strengthen aid coordination on the basis of national priorities and government leadership; (ii) improve transparency, effectiveness, and responsibility in managing resources allocated to development; (iii) consolidate program approaches and common mechanisms for aid implementation; (iv) harmonize the management of technical partner missions and analytical studies to reduce the costs related thereto.

339. Moreover, the government will endeavor to revitalize the mechanism for dialogue between the government and the donors through the establishment or strengthening of joint technical and thematic groups on the basis of the priorities outlined in the SCRP. In this framework, the following will be organized: (i) joint annual sectoral reviews, and (ii) a joint annual SCRP review. The government hopes that these reviews will be held by the end of the first half of each year so that the recommendations can be taken into account in the preparation of the general government budget. 


\section{CONCLUSION}

340. The Poverty Reduction and Growth Strategy (SCRP) is the new unifying framework for all sectoral strategies and constitutes the background document for government interventions for the period 2007-2009. Serving as an operationalization framework for the government's Strategic Development Approaches (SDAs), the 2007-2009 SCRP was prepared with the participation of all segments of Beninese society.

341. The success of this strategy will depend largely on its degree of ownership by the various stakeholders concerned. It thus requires that:

- the units responsible for implementing the strategy, both at the governmental level and at the level of grassroots communities, effectively own its content;

- the government makes sustained efforts to mobilize resources and utilize them on a priority basis for the effective implementation of the strategy, in accordance with the Paris Declaration;

- institutional and human capacities are strengthened at all levels (central and local);

- the actions of the government's technical and financial partners fall within and are harmonized with the frame of reference represented by the SCRP.

342. To minimize all these risks, the government intends to strengthen and perpetuate the periodic consultations with all stakeholders and to implement a high-performance monitoring and evaluation system that will make it possible at all times to assess the progress made and plan the necessary corrective measures.

343. In order to render the SCRP operational, the government prepared a Priority Action Program (PAP) for SCRP implementation. This PAP recapitulates the investments that will enhance the visibility of the major measures and actions which will help to accelerate growth and reduce poverty. It links the SCRP, the different sectoral strategies, and the program budgets of the ministries. 


\begin{abstract}
ANNEXES
Annex 1: Principal macroeconomic indicators of the central scenario

Annex 2: Education, cost of attaining the MDGs, 2007-2009

Annex 3: Health, cost of attaining the MDGs, 2007-2009

Annex 4: Road infrastructure, cost of attaining the MDGs, 2007-2009

Annex 5: Water and energy, cost of attaining the MDGs, 2007-2009

Annex 6: Rural development, cost of attaining the MDGs, 2007-2009

Annex 7: Environment, cost of attaining the MDGs, 2007-2009

Annex 8: Gender, cost of attaining the MDGs, 2007-2009

Annex 9: Medium-term expenditure framework as a percentage of GDP

Annex 10: Medium-term expenditure framework as a percentage of total expenditure

Annex 11: Distribution of the population according to the socioeconomic characteristics of the head of household and the standard of living

Annex 12: Determinants of poverty in Benin, 2006

Annex 13: Access to water and education, 2006

Annex 14: Monetary poverty indices, 2006 and 2002
\end{abstract}


ANNEXES

Annex 15: Principal macroeconomic indicators of the central scenario

\begin{tabular}{|c|c|c|c|c|c|c|}
\hline & 2004 & 2005 & 2006 & 2007 & 2008 & 2009 \\
\hline \multicolumn{7}{|l|}{ Change \% } \\
\hline Nominal GDP growth rate & 3.5 & 7.4 & 5.3 & 9.0 & 9.8 & 10.5 \\
\hline Real GDP growth rate & 3.1 & 2.9 & 3.6 & 6.0 & 6.8 & 7.5 \\
\hline \multicolumn{7}{|c|}{ As $\%$ of GDP } \\
\hline \multicolumn{7}{|l|}{ Saving - investment } \\
\hline Investment ratio & 20.7 & 18.2 & 22.4 & 23.6 & 24.4 & 25.2 \\
\hline Public & 5.6 & 6.3 & 7.6 & 8.6 & 9.5 & 9.9 \\
\hline Private & 15.1 & 11.9 & 14.8 & 15.0 & 14.9 & 15.3 \\
\hline Gross domestic saving & 12.2 & 10.1 & 13.3 & 16.5 & 17.7 & 19.1 \\
\hline Public & 5.2 & 5.5 & 5.9 & 6.2 & 6.7 & 7.5 \\
\hline Private & 7.0 & 4.6 & 7.4 & 10.3 & 10.9 & 11.7 \\
\hline National saving & 13.6 & 13.5 & 16.3 & 17.8 & 18.9 & 20.3 \\
\hline Saving - investment balance & -7.1 & -4.6 & -6.2 & -5.8 & -5.5 & -4.9 \\
\hline \multicolumn{7}{|l|}{ TOFE } \\
\hline Total revenue & 16.4 & 16.7 & 17.0 & 17.6 & 18.0 & 18.1 \\
\hline Tax revenue & 14.6 & 14.5 & 15.1 & 15.8 & 16.2 & 16.3 \\
\hline Nontax revenue & 1.8 & 2.1 & 1.8 & 1.8 & 1.8 & 1.8 \\
\hline Total expenditure & 19.9 & 21.3 & 22.1 & 24.4 & 25.0 & 24.6 \\
\hline Wage bill & 5.8 & 5.7 & 5.7 & 5.9 & 5.8 & 5.5 \\
\hline Public investment & 5.6 & 6.3 & 7.6 & 8.6 & 9.5 & 9.9 \\
\hline Budgetary contribution to investment & 2.7 & 3.3 & 3.6 & 3.9 & 4.6 & 4.9 \\
\hline Primary balance (narrow definition) & -0.3 & -1.4 & -0.9 & -1.5 & -1.6 & -1.2 \\
\hline Overall deficit (payment-order basis) & -3.5 & -4.6 & -5.1 & -6.8 & -6.9 & -6.5 \\
\hline \multicolumn{7}{|l|}{ External sector } \\
\hline Exports & 14.0 & 13.0 & 11.7 & 12.5 & 13.4 & 14.0 \\
\hline Imports & 20.8 & 19.8 & 19.5 & 18.9 & 19.3 & 19.0 \\
\hline Trade balance & -6.7 & -6.7 & -7.8 & -6.4 & -5.9 & -5.0 \\
\hline Openness ratio & 34.8 & 32.8 & 31.2 & 31.4 & 32.7 & 33.0 \\
\hline Current balance (- = deficit) & -7.1 & -4.6 & -6.2 & -5.8 & -5.5 & -4.9 \\
\hline Overall balance & -2.9 & 1.9 & 0.9 & 1.0 & 0.9 & 0.8 \\
\hline \multicolumn{7}{|l|}{ Debt indicators } \\
\hline Debt stock/GDP (\%) & 38.6 & 40.0 & 21.9 & 21.9 & 23.2 & 23.3 \\
\hline Debt stock/goods and services exports (\%) & 199.5 & 222.3 & 133.4 & 124.9 & 123.8 & 118.9 \\
\hline Debt service/goods and services exports (\%) & 11.9 & 7.6 & 8.9 & 8.4 & 8.3 & 8.0 \\
\hline p.m. GDP in CFAF billions & 2140.0 & 2298.7 & 2420.6 & 2637.7 & 2896.6 & 3200.9 \\
\hline
\end{tabular}


Sectoral MTEFs and related indicators

Annex 16: Education, cost of attaining the MDGs, 2007-2009

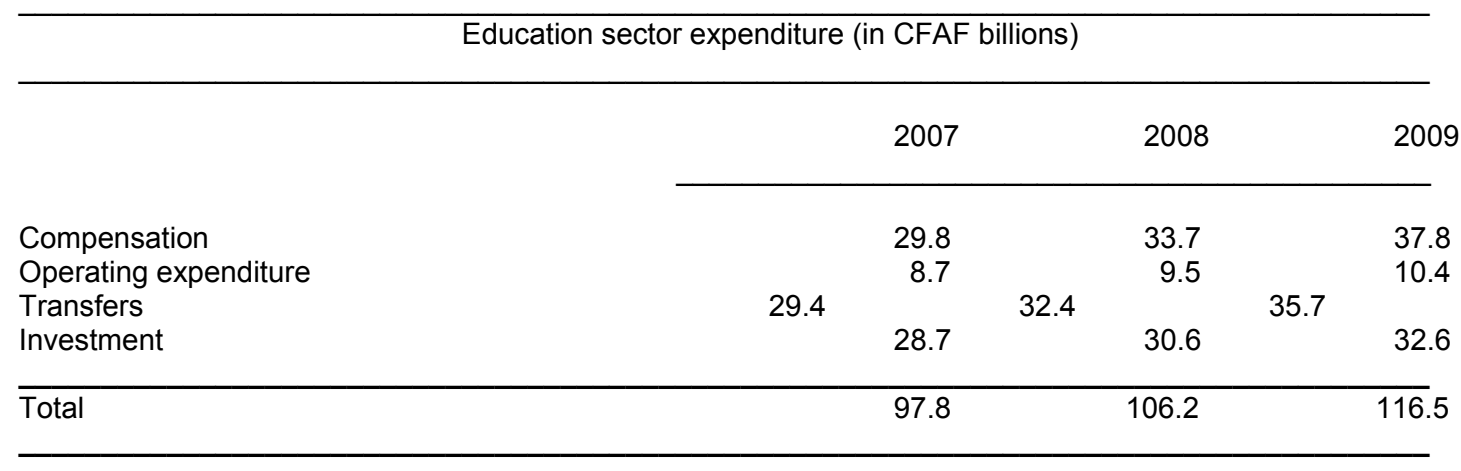

Education sector expenditure by program (in CFAF billions)

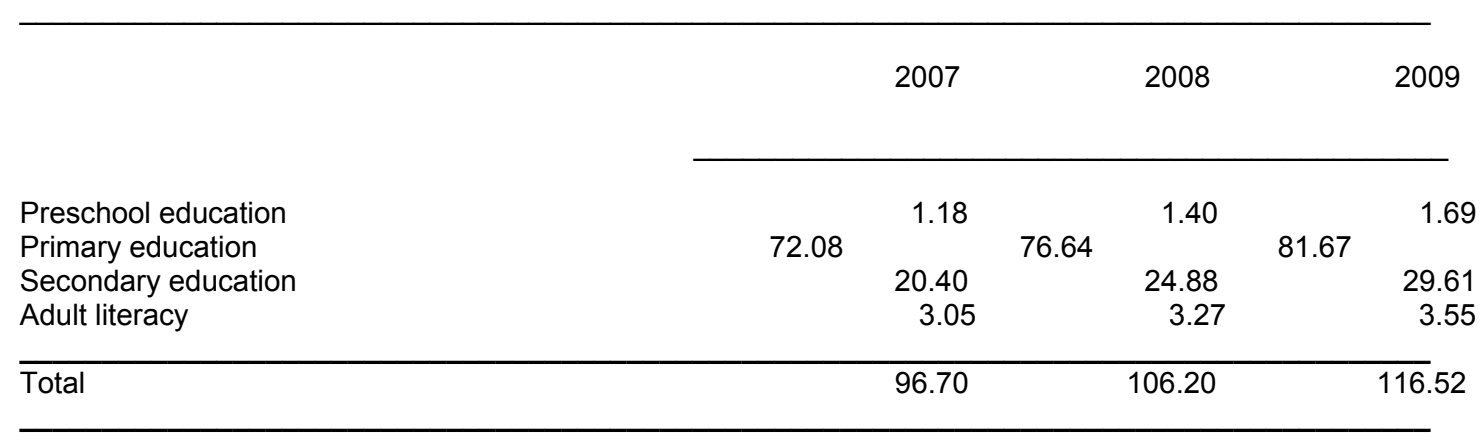

Related indicators

\begin{tabular}{|c|c|c|c|}
\hline & 2007 & 2008 & 2009 \\
\hline Preschool enrollment rate $(\%)$ & 6.5 & 7.6 & 8.9 \\
\hline Ratio of pupils/preschool education center & 51 & 51 & 51 \\
\hline Gross enrollment rate $(\%)$ & 97.2 & 97.6 & 98.0 \\
\hline Ratio of pupils/class & 48 & 47 & 46 \\
\hline Ratio of pupils/teacher & 50 & 48 & 47 \\
\hline Exclusion rate in secondary education (\%) & 17.0 & 15.5 & 14.0 \\
\hline Ratio of pupils/teacher & 28 & 28 & 28 \\
\hline Adult literacy rate (\%) & 69.0 & 72.9 & 76.8 \\
\hline
\end{tabular}


Annex 17: Health, cost of attaining the MDGs, 2007-2009

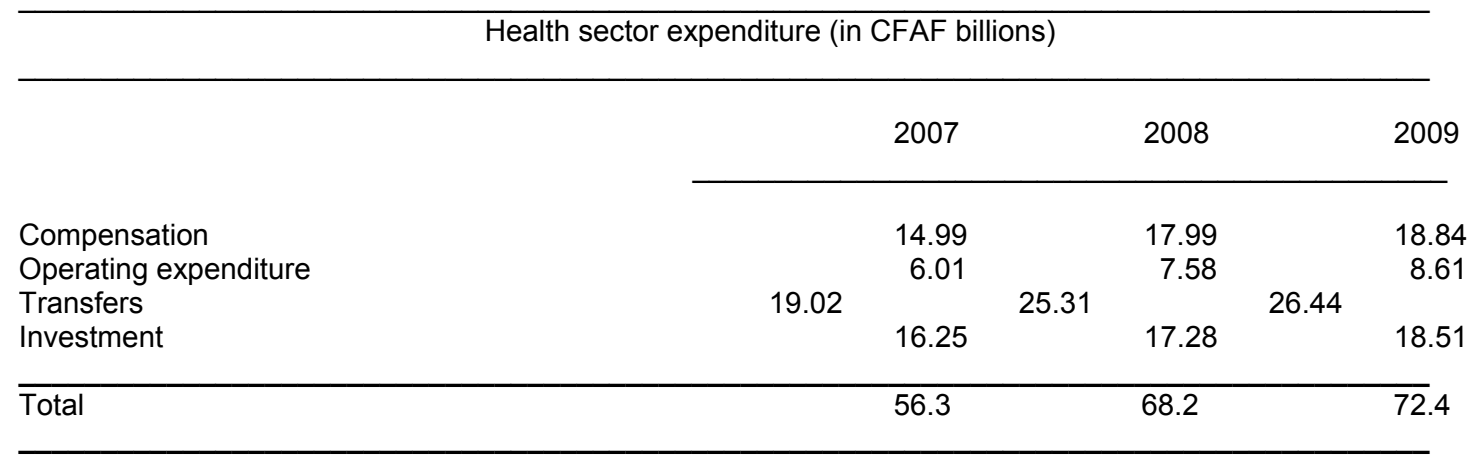

Health sector expenditure by program (in CFAF billions)

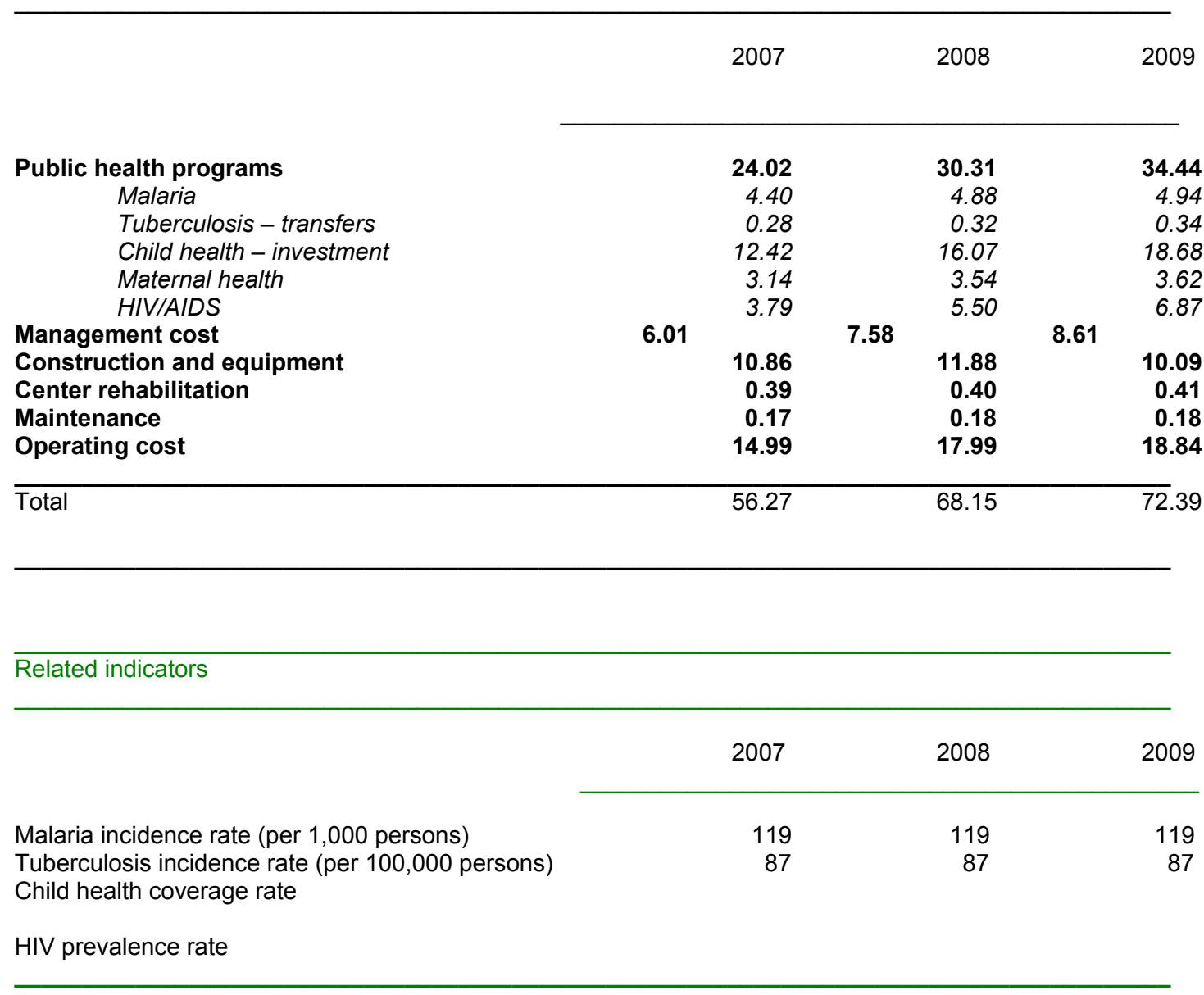


Annex 18: Road infrastructure, cost of attaining the MDGs, 2007-2009

\begin{tabular}{|c|c|c|c|}
\hline \multicolumn{4}{|c|}{ Road infrastructure sector expenditure (in CFAF billions) } \\
\hline & 2007 & 2008 & 2009 \\
\hline Compensation & 10.00 & 12.00 & 12.00 \\
\hline Operating expenditure & 26.60 & 25.84 & 22.15 \\
\hline Transfers & & & \\
\hline Investment & 39.81 & 40.99 & 52.26 \\
\hline Total & 76.4 & 78.8 & $\overline{86.4}$ \\
\hline
\end{tabular}

Road infrastructure sector expenditure by program (in CFAF billions)

\begin{tabular}{lcrr}
\hline & 2007 & 2008 & 2009 \\
& & & \\
\cline { 2 - 4 } & & 45.25 & 46.09 \\
Rural programs & 44.47 & 40.32 \\
Urban programs & 31.94 & 33.58 & 86.4 \\
\hline Total & 76.4 & 78.8 & \\
\hline
\end{tabular}

\begin{tabular}{|c|c|c|c|}
\hline \multicolumn{4}{|l|}{ Related indicator } \\
\hline & 2007 & 2008 & 2009 \\
\hline $\begin{array}{l}\text { Length of asphalted roads per } 1,000 \text { persons } \\
\text { (in } \mathrm{km} \text { ) }\end{array}$ & 0.29 & 0.31 & 0.33 \\
\hline
\end{tabular}


Annex 19: Water and energy, cost of attaining the MDGs, 2007-2009

\begin{tabular}{|c|c|c|c|c|c|c|}
\hline \multicolumn{7}{|c|}{ Water and energy sector expenditure (in CFAF billions) } \\
\hline & & 2007 & & 2008 & & 2009 \\
\hline $\begin{array}{l}\text { Compensation } \\
\text { Operating expenditure } \\
\text { Transfers } \\
\text { Investment }\end{array}$ & 0.11 & $\begin{array}{l}5.16 \\
9.78 \\
18.22\end{array}$ & 0.13 & $\begin{array}{l}6.64 \\
11.75 \\
18.90\end{array}$ & 0.17 & $\begin{array}{l}7.79 \\
13.40 \\
20.65\end{array}$ \\
\hline \multicolumn{7}{|l|}{$\overline{\text { Total }}$} \\
\hline \multicolumn{7}{|c|}{ Water and energy sector expenditure by program (in CFAF billions) } \\
\hline & & 2007 & & 2008 & & 2009 \\
\hline \multicolumn{7}{|l|}{ Water program } \\
\hline $\begin{array}{l}\text { Rural areas } \\
\text { Urban areas }\end{array}$ & & $\begin{array}{l}5.10 \\
5.42\end{array}$ & & $\begin{array}{l}5.48 \\
5.53\end{array}$ & & $\begin{array}{l}5.89 \\
5.85\end{array}$ \\
\hline \multicolumn{7}{|l|}{ Energy program } \\
\hline $\begin{array}{l}\text { Cooking system } \\
\text { Electricity } \\
\text { Mechanical energy }\end{array}$ & 1.27 & $\begin{array}{l}4.94 \\
16.55\end{array}$ & 1.67 & $\begin{array}{l}5.75 \\
18.98\end{array}$ & 2.10 & $\begin{array}{l}6.62 \\
21.55\end{array}$ \\
\hline
\end{tabular}

TOTAL 
Annex 20: Rural development, cost of attaining the MDGs, 2007-2009

\begin{tabular}{|c|c|c|c|}
\hline \multicolumn{4}{|c|}{ Rural development sector expenditure (in CFAF billions) } \\
\hline & 2007 & 2008 & 2009 \\
\hline Compensation & 5.64 & 8.39 & 7.08 \\
\hline Operating expenditure & 19.49 & 27.64 & 33.09 \\
\hline Transfers & & & \\
\hline Investment & 36.90 & 56.27 & 37.69 \\
\hline Total & 62.03 & 92.31 & 77.86 \\
\hline
\end{tabular}

Rural development sector expenditure by program (in CFAF billions)

\begin{tabular}{|c|c|c|c|c|c|c|}
\hline \multirow[b]{2}{*}{ Agricultural productivity program } & \multicolumn{3}{|c|}{2007} & \multicolumn{2}{|l|}{2008} & \multirow{2}{*}{$\begin{array}{r}2009 \\
49.42\end{array}$} \\
\hline & & 35.48 & & 53.73 & & \\
\hline Other revenue-generating activities program & & 16.43 & & 24.80 & & 15.06 \\
\hline Nutrition program & & 4.18 & & 5.08 & & 6.00 \\
\hline Awareness-raising program & 0.30 & & 0.30 & & 0.30 & \\
\hline Capacity-building program & & 5.64 & & 8.39 & & 7.08 \\
\hline TOTAL & & 62.03 & & 92.31 & & 77.86 \\
\hline
\end{tabular}

\begin{tabular}{|c|c|c|c|}
\hline \multicolumn{4}{|l|}{ Related indicators } \\
\hline & 2007 & 2008 & 2009 \\
\hline Share of small farmers targeted $(\%)$ & 20.0 & 25.0 & 30.0 \\
\hline \multicolumn{4}{|l|}{ Share of households with access to credit } \\
\hline Small farmers & 18.3 & 22.3 & 26.2 \\
\hline Stockbreeding & 2.0 & 3.0 & 4.0 \\
\hline Farmers who do not own their land & 13.5 & 18.1 & 22.6 \\
\hline $\begin{array}{l}\text { Ratio of coverage of supplementary food } \\
\text { programs }(\%)\end{array}$ & 14.3 & 18.8 & 23.2 \\
\hline
\end{tabular}


Annex 21: Environment, cost of attaining the MDGs, 2007-2009

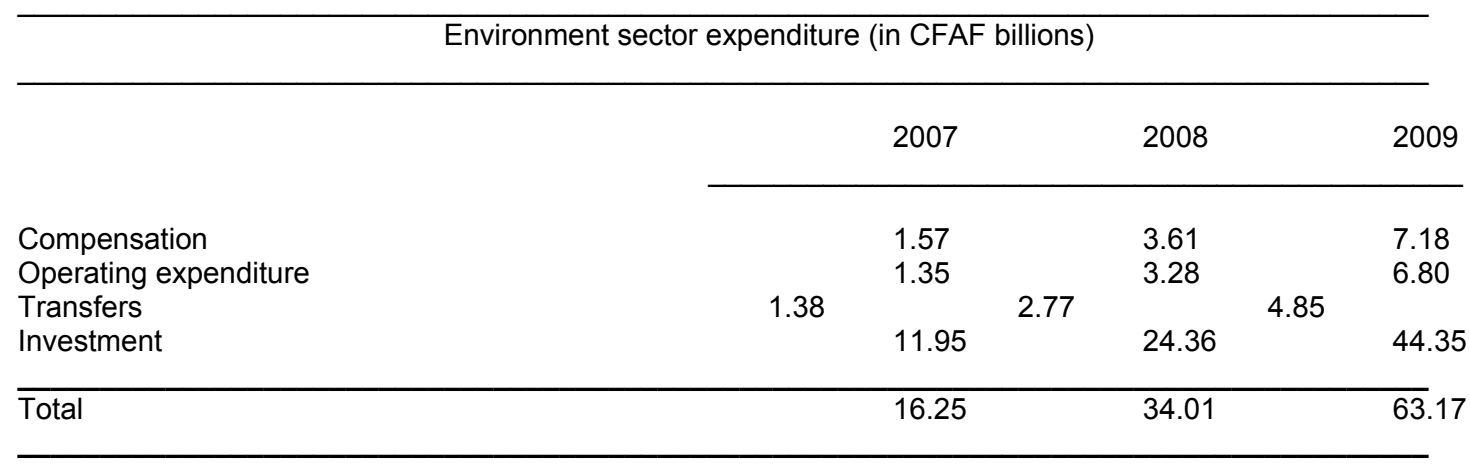

\section{Environment sector expenditure by program (in CFAF billions)}

\begin{tabular}{llll}
\hline & 2007 & 2008 & 2009 \\
& & & \\
\cline { 2 - 3 } & & & \\
Environment & 11.81 & 25.07 & 47.31 \\
Sanitation & 0.89 & 1.82 & 3.37 \\
Wastewater management & 1.72 & 3.44 & 6.02 \\
Hygiene and education & 1.72 & 3.44 & 6.02 \\
Total & 16.25 & 34.01 & 63.17 \\
\hline
\end{tabular}

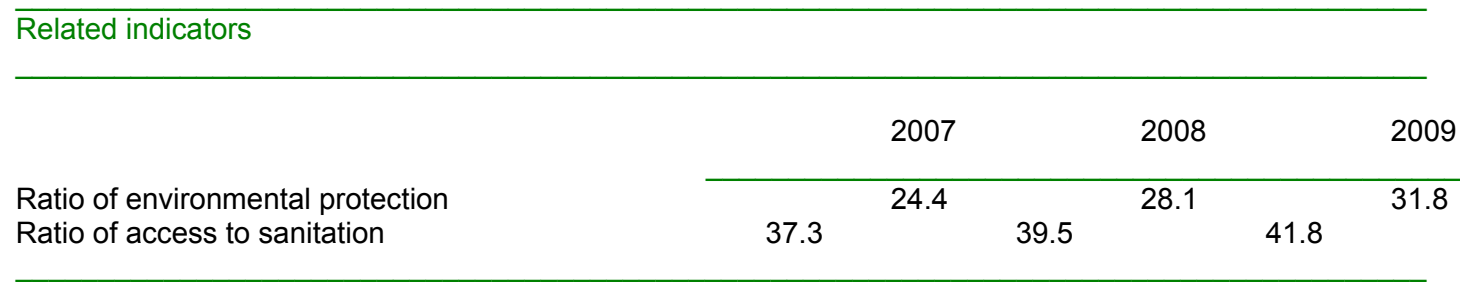


Annex 22: Gender, cost of attaining the MDGs, 2007-2009

\begin{tabular}{|c|c|c|c|}
\hline & CFAF & & \\
\hline & 2007 & 2008 & 2009 \\
\hline $\begin{array}{l}\text { Compensation } \\
\text { Operating expenditure } \\
\text { Transfers }\end{array}$ & 0.26 & 0.36 & 0.44 \\
\hline Investment & 2.56 & 3.61 & 4.42 \\
\hline Total & 2.81 & 3.97 & 4.86 \\
\hline
\end{tabular}

Gender sector expenditure by program (in CFAF billions)

\begin{tabular}{|c|c|c|c|c|c|c|}
\hline & & 2007 & & 2008 & & 2009 \\
\hline Awareness-raising program & 0.72 & & 1.32 & & 1.85 & \\
\hline $\begin{array}{l}\text { Assistance for young women's integration into } \\
\text { the labor market }\end{array}$ & 0.53 & & 0.79 & & 1.01 & \\
\hline Encouraging political participation & & 0.10 & & 0.10 & & 0.10 \\
\hline Eradicating violence against women & & 0.81 & & 0.98 & & 1.04 \\
\hline Systemic problems & 0.39 & & 0.42 & & 0.41 & \\
\hline Total & & 2.81 & & 3.97 & & $\overline{4.86}$ \\
\hline
\end{tabular}

Related indicators

\begin{tabular}{|c|c|c|c|}
\hline & 2007 & 2008 & 2009 \\
\hline $\begin{array}{l}\text { Ratio of women's reproductive health } \\
\text { coverage }(\%)\end{array}$ & 11.0 & 15.9 & 20.8 \\
\hline $\begin{array}{l}\text { Ratio of coverage of female secondary-school } \\
\text { dropouts }(\%)\end{array}$ & 6.8 & 9.7 & 12.6 \\
\hline
\end{tabular}




\section{Annex 23: Medium-term expenditure framework as a percentage of GDP}

\begin{tabular}{|c|c|c|c|}
\hline & 2007 & 2008 & 2009 \\
\hline Social sectors & 7.34 & 7.54 & 7.58 \\
\hline Education & 4.71 & 4.84 & 4.68 \\
\hline Primary and secondary education & 3.56 & 3.56 & 3.41 \\
\hline Higher education and vocational training & 1.15 & 1.28 & 1.27 \\
\hline Health & 2.19 & 2.26 & 2.44 \\
\hline Social and cultural development & 0.44 & 0.44 & 0.46 \\
\hline Family, women, and children & 0.18 & 0.20 & 0.23 \\
\hline Culture, sports, and leisure & 0.26 & 0.25 & 0.23 \\
\hline Production and commerce & 2.02 & 2.03 & 2.21 \\
\hline Agriculture, stockbreeding, and fishing & 1.30 & 1.32 & 1.44 \\
\hline Commerce and industry & 0.31 & 0.34 & 0.34 \\
\hline Tourism and handicrafts & 0.11 & 0.16 & 0.20 \\
\hline Microfinance and SMEs & 0.30 & 0.21 & 0.23 \\
\hline Production infrastructure & 4.68 & 5.34 & 5.58 \\
\hline Transport and public works & 2.90 & 3.60 & 3.86 \\
\hline Communication and new technologies & 0.11 & 0.10 & 0.10 \\
\hline Environment and nature preservation & 0.57 & 0.52 & 0.42 \\
\hline Mines, energy, and water & 1.10 & 1.12 & 1.20 \\
\hline Governance & 2.07 & 1.97 & 1.81 \\
\hline Political & 0.80 & 0.79 & 0.78 \\
\hline Justice & 0.31 & 0.29 & 0.31 \\
\hline Supreme Court & 0.08 & 0.08 & 0.08 \\
\hline Constitutional Court & 0.03 & 0.03 & 0.03 \\
\hline High Court of Justice & 0.02 & 0.02 & 0.02 \\
\hline Audiovisual & 0.05 & 0.05 & 0.05 \\
\hline National Assembly & 0.30 & 0.30 & 0.28 \\
\hline Economic & 1.27 & 1.19 & 1.03 \\
\hline Development, economy, and finance & 0.66 & 0.67 & 0.50 \\
\hline Budget & 0.43 & 0.36 & 0.38 \\
\hline Labor and civil service & 0.14 & 0.13 & 0.12 \\
\hline Administrative and institutional reform & 0.03 & 0.03 & 0.03 \\
\hline Defense and security & 1.92 & 1.85 & 1.60 \\
\hline Defense & 1.05 & 1.02 & 0.83 \\
\hline Public security & 0.87 & 0.83 & 0.77 \\
\hline Sovereignty & 0.91 & 0.89 & 0.85 \\
\hline Presidency of the Republic & 0.29 & 0.29 & 0.28 \\
\hline Economic and Social Council & 0.04 & 0.04 & 0.04 \\
\hline Foreign Affairs & 0.54 & 0.52 & 0.47 \\
\hline Beninese living abroad & 0.03 & 0.04 & 0.05 \\
\hline Total ministries and institutions & 18.95 & 19.63 & 19.61 \\
\hline Other budgets & 5.00 & 4.93 & 4.63 \\
\hline Total budget & 23.94 & 24.56 & 24.24 \\
\hline
\end{tabular}


Annex 24: Medium-term expenditure framework as a percentage of total expenditure

\begin{tabular}{|c|c|c|c|}
\hline & 2007 & 2008 & 2009 \\
\hline Social sectors & 30.6 & 30.7 & 31.2 \\
\hline Education & 19.7 & 19.7 & 19.3 \\
\hline Primary and secondary education & 14.9 & 14.5 & 14.1 \\
\hline Higher education and professional training & 4.8 & 5.2 & 5.2 \\
\hline Health & 9.1 & 9.2 & 10.1 \\
\hline Social and cultural development & 1.8 & 1.8 & 1.9 \\
\hline Family, women, and children & 0.7 & 0.8 & 1.0 \\
\hline Culture, sports, and leisure & 1.1 & 1.0 & 1.0 \\
\hline Production and commerce & 8.5 & 8.3 & 9.1 \\
\hline Agriculture, stockbreeding, and fishing & 5.4 & 5.4 & 5.9 \\
\hline Commerce and industry & 1.3 & 1.4 & 1.4 \\
\hline Tourism and handicrafts & 0.5 & 0.7 & 0.8 \\
\hline Microfinance and SMEs & 1.2 & 0.9 & 0.9 \\
\hline Production infrastructure & 19.5 & 21.7 & 23.0 \\
\hline Transport and public works & 12.1 & 14.6 & 15.9 \\
\hline Communication and new technologies & 0.4 & 0.4 & 0.4 \\
\hline Environment and nature preservation & 2.4 & 2.1 & 1.7 \\
\hline Mines, energy, and water & 4.6 & 4.6 & 5.0 \\
\hline Governance & 8.7 & 8.0 & 7.5 \\
\hline Political & 3.4 & 3.2 & 3.2 \\
\hline Justice & 1.3 & 1.2 & 1.3 \\
\hline Supreme Court & 0.4 & 0.3 & 0.3 \\
\hline Constitutional Court & 0.1 & 0.1 & 0.1 \\
\hline High Court of Justice & 0.1 & 0.1 & 0.1 \\
\hline Audiovisual & 0.2 & 0.2 & 0.2 \\
\hline National Assembly & 1.3 & 1.2 & 1.2 \\
\hline Economic & 5.3 & 4.8 & 4.3 \\
\hline Development, economy, and finance & 2.8 & 2.7 & 2.1 \\
\hline Budget & 1.8 & 1.5 & 1.6 \\
\hline Labor and civil service & 0.6 & 0.5 & 0.5 \\
\hline Administrative and institutional reform & 0.1 & 0.1 & 0.1 \\
\hline Defense and security & 8.0 & 7.5 & 6.6 \\
\hline Defense & 4.4 & 4.1 & 3.4 \\
\hline Public security & 3.6 & 3.4 & 3.2 \\
\hline Sovereignty & 3.8 & 3.6 & 3.5 \\
\hline Presidency of the Republic & 1.2 & 1.2 & 1.2 \\
\hline Economic and Social Council & 0.2 & 0.2 & 0.2 \\
\hline Foreign Affairs & 2.3 & 2.1 & 1.9 \\
\hline Beninese living abroad & 0.1 & 0.2 & 0.2 \\
\hline Total ministries and institutions & 79.1 & 79.9 & 80.9 \\
\hline Other budgets & 20.9 & 20.1 & 19.1 \\
\hline Total budget & 100.0 & 100.0 & 100.0 \\
\hline
\end{tabular}


Annex 25: Distribution of the population according to the socioeconomic characteristics of the head of household and the standard of living

\begin{tabular}{|c|c|c|c|c|c|c|}
\hline & \multicolumn{4}{|c|}{ Living Standard Quintile } & \multirow{2}{*}{\multicolumn{2}{|c|}{ Richest Total }} \\
\hline & Poorest & Poor & Middle & Rich & & \\
\hline \multicolumn{7}{|l|}{ Residential area } \\
\hline Urban & 8.7 & 13.4 & 12.1 & 23.4 & 42.4 & 100.0 \\
\hline Rural & 27.3 & 23.4 & 25.3 & 17.2 & 6.6 & 100.0 \\
\hline \multicolumn{7}{|l|}{ Department } \\
\hline Alibori & 42.5 & 23.7 & 19.8 & 9.5 & 4.5 & 100.0 \\
\hline Atacora & 38.7 & 32.3 & 17.8 & 10.0 & 1.2 & 100.0 \\
\hline Atlantique & 39.4 & 23.5 & 19.4 & 13.6 & 4.1 & 100.0 \\
\hline Borgou & 15.3 & 26.5 & 17.2 & 19.8 & 21.2 & 100.0 \\
\hline Collines & 8.6 & 14.6 & 42.8 & 26.0 & 8.1 & 100.0 \\
\hline Couffo & 12.1 & 29.5 & 28.0 & 22.3 & 8.1 & 100.0 \\
\hline Donga & 17.6 & 17.8 & 24.2 & 25.2 & 15.2 & 100.0 \\
\hline Littoral & & 0.9 & 2.1 & 20.7 & 76.3 & 100.0 \\
\hline Mono & 48.9 & 15.4 & 15.4 & 10.5 & 9.9 & 100.0 \\
\hline Ouémé & 16.1 & 12.6 & 19.8 & 27.6 & 23.9 & 100.0 \\
\hline Plateau & 15.3 & 20.4 & 25.1 & 29.1 & 10.2 & 100.0 \\
\hline Zou & 20.5 & 24.8 & 28.4 & 17.7 & 8.6 & 100.0 \\
\hline \multicolumn{7}{|c|}{ Sex of head of household } \\
\hline Male & 21.8 & 20.5 & 20.3 & 18.2 & 19.2 & 100 \\
\hline Female & 17.0 & 17.6 & 23.5 & 25.3 & 16.7 & 100 \\
\hline \multicolumn{7}{|c|}{ Age of head of household } \\
\hline Under 25 years & 20.5 & 15.1 & 28.6 & 23.1 & 12.7 & 100.0 \\
\hline $25-39$ years & 21.8 & 19.2 & 20.0 & 20.3 & 18.8 & 100.0 \\
\hline $40-59$ years & 20.8 & 20.1 & 17.9 & 19.0 & 22.1 & 100.0 \\
\hline 60 years and over & 20.0 & 22.3 & 27.7 & 17.7 & 12.3 & 100.0 \\
\hline \multicolumn{7}{|c|}{$\begin{array}{l}\text { Level of education of head of } \\
\text { household }\end{array}$} \\
\hline None & 28.4 & 25.7 & 23.3 & 15.8 & 6.8 & 100.0 \\
\hline Primary & 12.5 & 14.6 & 21.6 & 27.8 & 23.5 & 100.0 \\
\hline Secondary & 2.8 & 4.9 & 11.4 & 25.8 & 54.9 & 100.0 \\
\hline Higher & & & 0.9 & 4.4 & 94.7 & 100.0 \\
\hline Aggregate & 21.0 & 20.1 & 20.8 & 19.3 & 18.8 & 100.0 \\
\hline Number of households & 1453 & 1365 & 1524 & 1437 & 1452 & 7231 \\
\hline Average size & 5.7 & 5.8 & 5.4 & 5.3 & 5.1 & 5.4 \\
\hline
\end{tabular}


Annex 26: Determinants of poverty in Benin, 2006

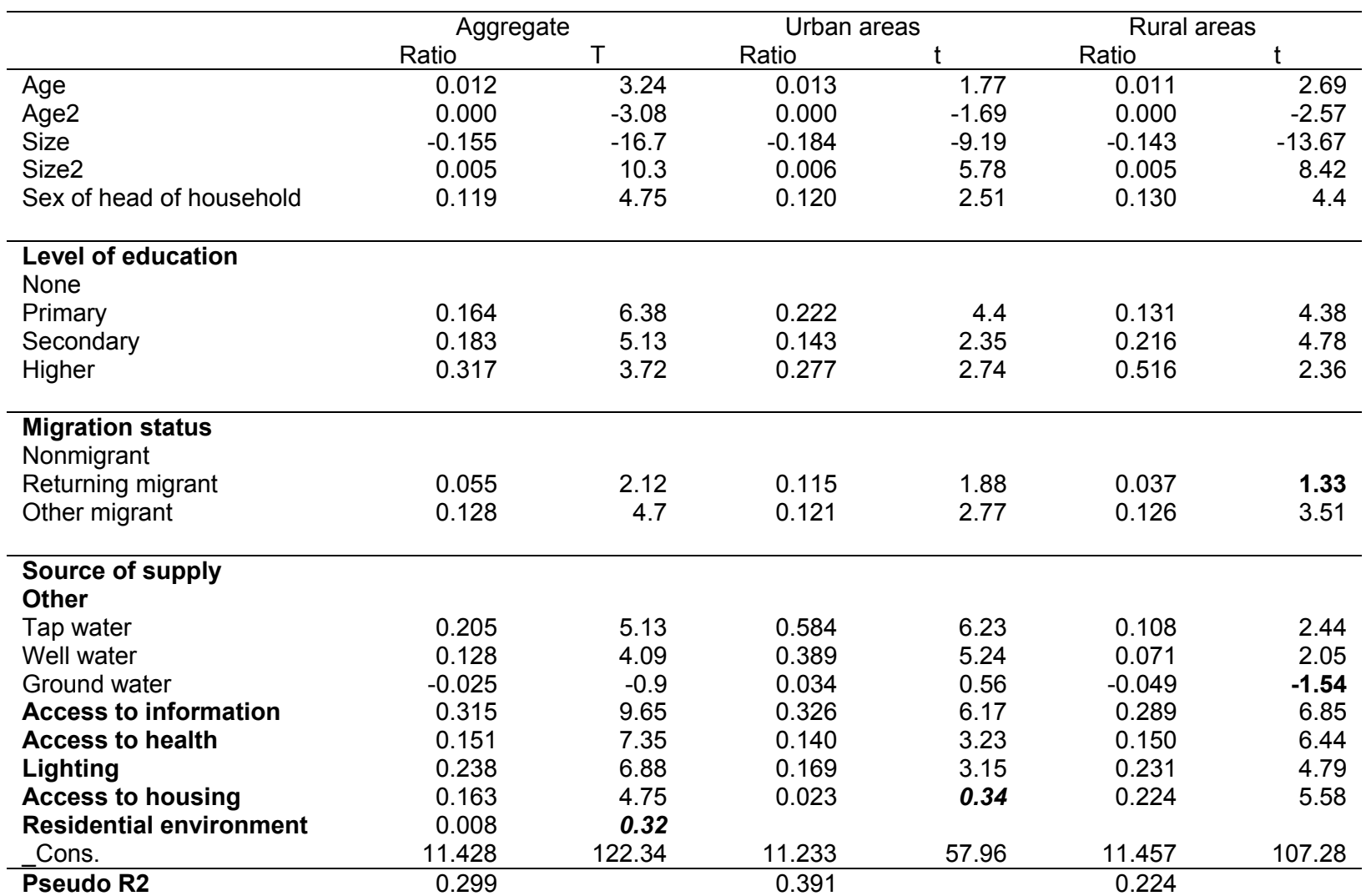

Note: The figures in bold mean that the variable is significant at the 10 percent threshold, whereas the figures in bold italic mean that the variable is not significant. 
Annex 27: Access to water and education, 2006

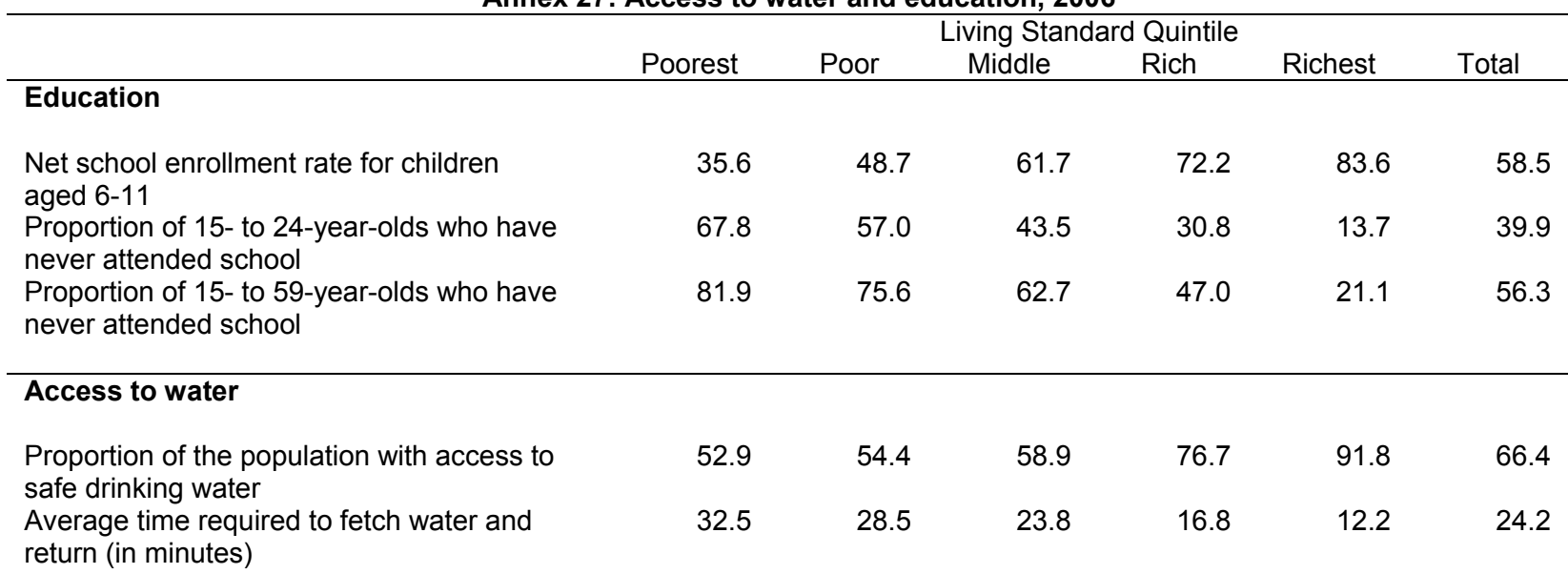

Source: Provisional results, EMICOV-EDS3, 2006. 
Annex 28: Monetary poverty indices, 2006 and 2002

\begin{tabular}{|c|c|c|c|c|c|c|}
\hline & \multicolumn{3}{|c|}{2002} & \multicolumn{3}{|c|}{2006} \\
\hline & P0 & $\mathrm{P} 1$ & P2 & P0 & P1 & $\mathrm{P} 2$ \\
\hline \multicolumn{7}{|l|}{ Residential area } \\
\hline Urban & $\begin{array}{l}23.6 \\
(0.9)\end{array}$ & $\begin{array}{r}0.107 \\
(0.005)\end{array}$ & $\begin{array}{r}0.069 \\
(0.004)\end{array}$ & $\begin{array}{l}27.2 \\
(1.2)\end{array}$ & $\begin{array}{r}0.110 \\
(0.006)\end{array}$ & $\begin{array}{r}0.060 \\
(0.004)\end{array}$ \\
\hline Rural & $\begin{array}{l}31.6 \\
(0.8)\end{array}$ & $\begin{array}{r}0.110 \\
(0.004)\end{array}$ & $\begin{array}{r}0.058 \\
(0.003)\end{array}$ & $\begin{array}{l}40.6 \\
(0.8)\end{array}$ & $\begin{array}{r}0.149 \\
(0.004)\end{array}$ & $\begin{array}{r}0.075 \\
(0.003)\end{array}$ \\
\hline \multicolumn{7}{|c|}{ Sex of head of household } \\
\hline Male & 28.9 & 0.109 & 0.062 & 37.5 & 0.142 & 0.073 \\
\hline & $(0.7)$ & $(0.003)$ & $(0.002)$ & $(0.8)$ & $(0.004)$ & $(0.003)$ \\
\hline Female & $\begin{array}{l}26.6 \\
(1.5)\end{array}$ & $\begin{array}{r}0.109 \\
(0.008)\end{array}$ & $\begin{array}{r}0.067 \\
(0.006)\end{array}$ & $\begin{array}{l}34.4 \\
(1.5)\end{array}$ & $\begin{array}{r}0.126 \\
(0.007)\end{array}$ & $\begin{array}{r}0.064 \\
(0.004)\end{array}$ \\
\hline \multicolumn{7}{|c|}{ Level of education of head of household } \\
\hline None & 33.0 & 0.119 & 0.065 & 43.7 & 0.170 & 0.089 \\
\hline & $(0.8)$ & $(0.004)$ & $(0.003)$ & $(0.9)$ & $(0.004)$ & $(0.003)$ \\
\hline Primary & $\begin{array}{l}28.8 \\
(1.3)\end{array}$ & $\begin{array}{r}0.119 \\
(0.007)\end{array}$ & $\begin{array}{r}0.073 \\
(0.006)\end{array}$ & $\begin{array}{l}26.6 \\
(1.4)\end{array}$ & $\begin{array}{r}0.086 \\
(0.006)\end{array}$ & $\begin{array}{r}0.038 \\
(0.003)\end{array}$ \\
\hline Secondary & $\begin{array}{l}17.6 \\
(1.2)\end{array}$ & $\begin{array}{r}0.079 \\
(0.007)\end{array}$ & $\begin{array}{r}0.050 \\
(0.005)\end{array}$ & $\begin{array}{l}18.1 \\
(1.7)\end{array}$ & $\begin{array}{c}0.061 \\
(0.007)\end{array}$ & $\begin{array}{r}0.028 \\
(0.004)\end{array}$ \\
\hline Higher & $\begin{array}{r}6.4 \\
(1.9)\end{array}$ & $\begin{array}{r}0.022 \\
(0.009)\end{array}$ & $\begin{array}{r}0.014 \\
(0.007)\end{array}$ & $\begin{array}{r}4.3 \\
(2.5)\end{array}$ & $\begin{array}{r}0.014 \\
(0.010)\end{array}$ & $\begin{array}{r}0.006 \\
(0.005)\end{array}$ \\
\hline \multicolumn{7}{|c|}{ Age of head of household } \\
\hline Under 25 years & 18.1 & 0.071 & 0.043 & 31.2 & 0.109 & 0.054 \\
\hline & $(2.6)$ & $(0.013)$ & $(0.010)$ & (3.1) & $(0.013)$ & $(0.009)$ \\
\hline $25-39$ years & $\begin{array}{l}25.9 \\
(1.0)\end{array}$ & $\begin{array}{r}0.099 \\
(0.005)\end{array}$ & $\begin{array}{r}0.058 \\
(0.004)\end{array}$ & $\begin{array}{l}35.2 \\
(1.1)\end{array}$ & $\begin{array}{r}0.130 \\
(0.005)\end{array}$ & $\begin{array}{r}0.065 \\
(0.003)\end{array}$ \\
\hline $40-59$ years & $\begin{array}{l}31.6 \\
(1.0)\end{array}$ & $\begin{array}{r}0.117 \\
(0.005)\end{array}$ & $\begin{array}{r}0.065 \\
(0.004)\end{array}$ & $\begin{array}{l}39.7 \\
(1.2)\end{array}$ & $\begin{array}{r}0.153 \\
(0.006)\end{array}$ & $\begin{array}{r}0.080 \\
(0.004)\end{array}$ \\
\hline 60 years and over & $\begin{array}{l}30.0 \\
(1.4)\end{array}$ & $\begin{array}{r}0.120 \\
(0.007)\end{array}$ & $\begin{array}{r}0.071 \\
(0.006)\end{array}$ & $\begin{array}{l}36.4 \\
(1.6)\end{array}$ & $\begin{array}{r}0.135 \\
(0.008)\end{array}$ & $\begin{array}{r}0.069 \\
(0.005)\end{array}$ \\
\hline \multicolumn{7}{|l|}{ Size of household } \\
\hline Fewer than 3 persons & 15.7 & 0.075 & 0.052 & 15.1 & 0.047 & 0.021 \\
\hline & $(1.1)$ & $(0.007)$ & $(0.005)$ & $(1.4)$ & $(0.005)$ & $(0.003)$ \\
\hline 3 to 5 persons & $\begin{array}{l}26.0 \\
(0.9)\end{array}$ & $\begin{array}{r}0.101 \\
(0.005)\end{array}$ & $\begin{array}{r}0.059 \\
(0.004)\end{array}$ & $\begin{array}{l}32.4 \\
(1.1)\end{array}$ & $\begin{array}{r}0.112 \\
(0.005)\end{array}$ & $\begin{array}{r}0.053 \\
(0.003)\end{array}$ \\
\hline 6 persons or more & $\begin{array}{l}38.2 \\
(1.1)\end{array}$ & $\begin{array}{r}0.136 \\
(0.005)\end{array}$ & $\begin{array}{r}0.072 \\
(0.004)\end{array}$ & $\begin{array}{l}48.2 \\
(1.1)\end{array}$ & $\begin{array}{r}0.193 \\
(0.006)\end{array}$ & $\begin{array}{r}0.104 \\
(0.004)\end{array}$ \\
\hline Aggregate & 28.5 & 0.109 & 0.062 & 36.8 & 0.138 & 0.071 \\
\hline & $(0.6)$ & $(0.003)$ & $(0.002)$ & $(0.7)$ & $(0.003)$ & $(0.002)$ \\
\hline
\end{tabular}

Source: Provisional and partial results, EMICOV (2006), on a sample of 5,221 households; Quibb Survey (2003) on a sample of 5,350 households, using 2002 data.

$\mathrm{P} 0=$ incidence of poverty; $\mathrm{P} 1$ = depth of poverty; $\mathrm{P} 2$ = severity of poverty index; figures in parentheses are standard deviations. 
REPUBLIC OF BENIN

\section{PRIORITY ACTION PLAN 2007-2009}




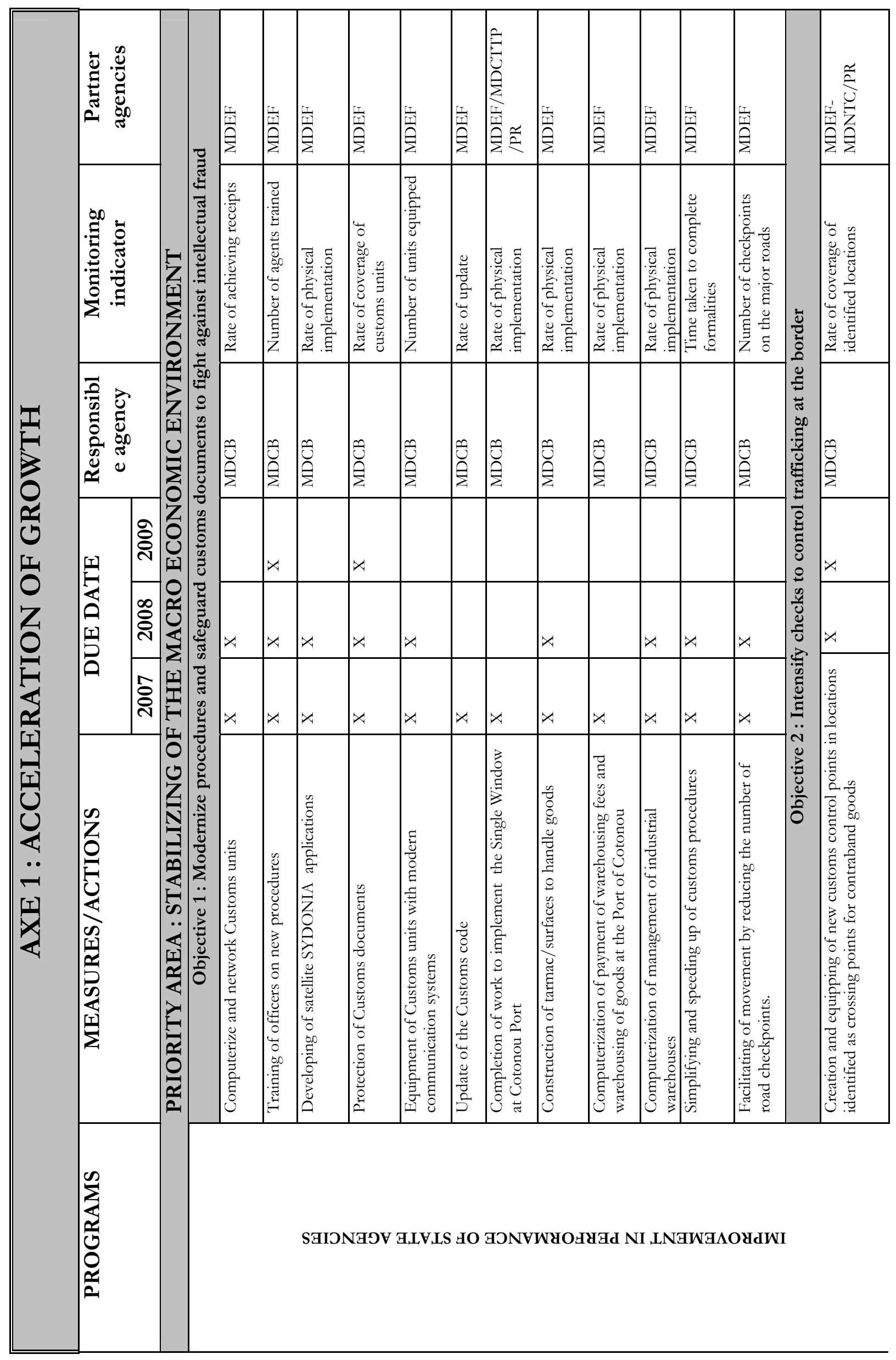




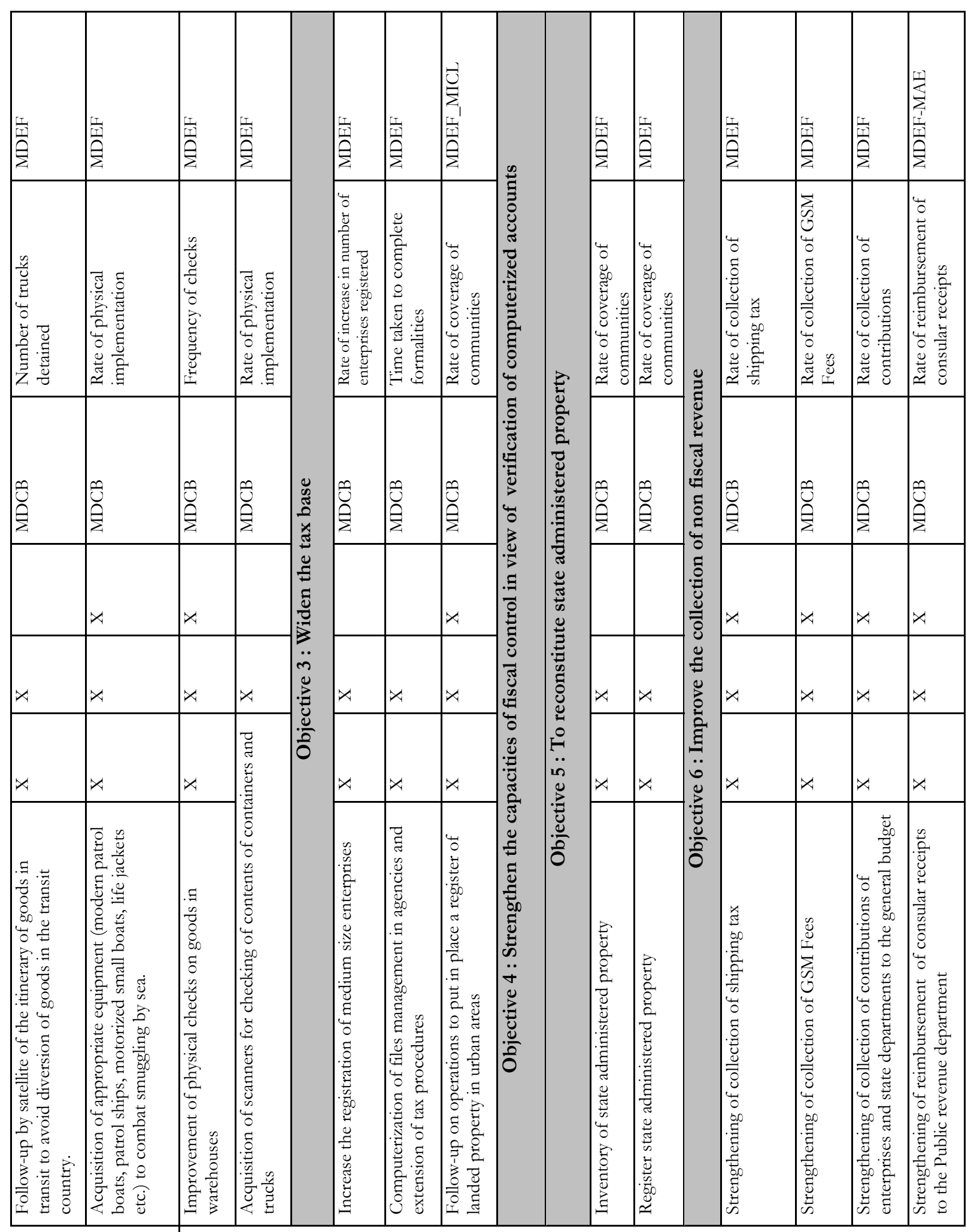




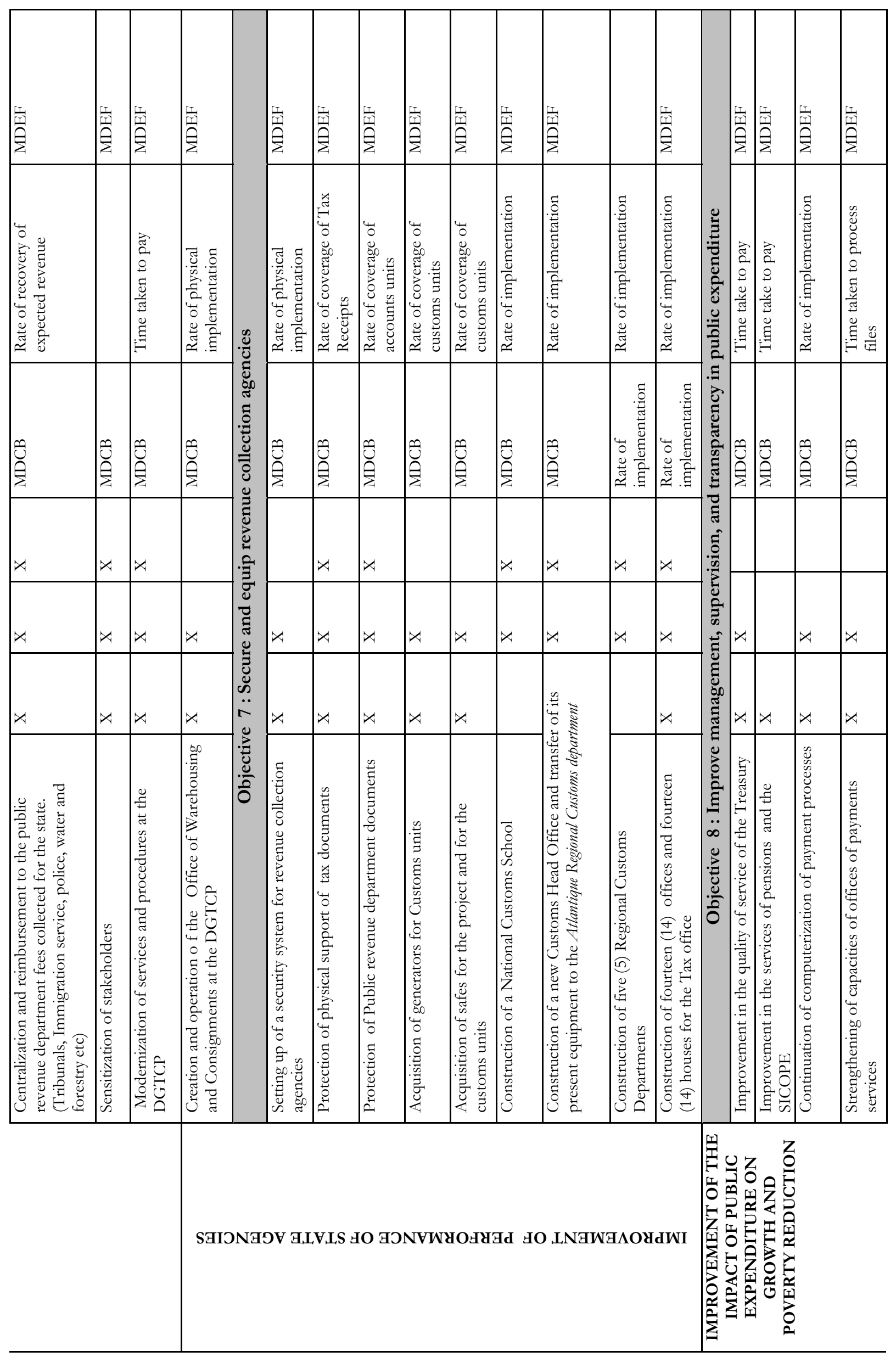




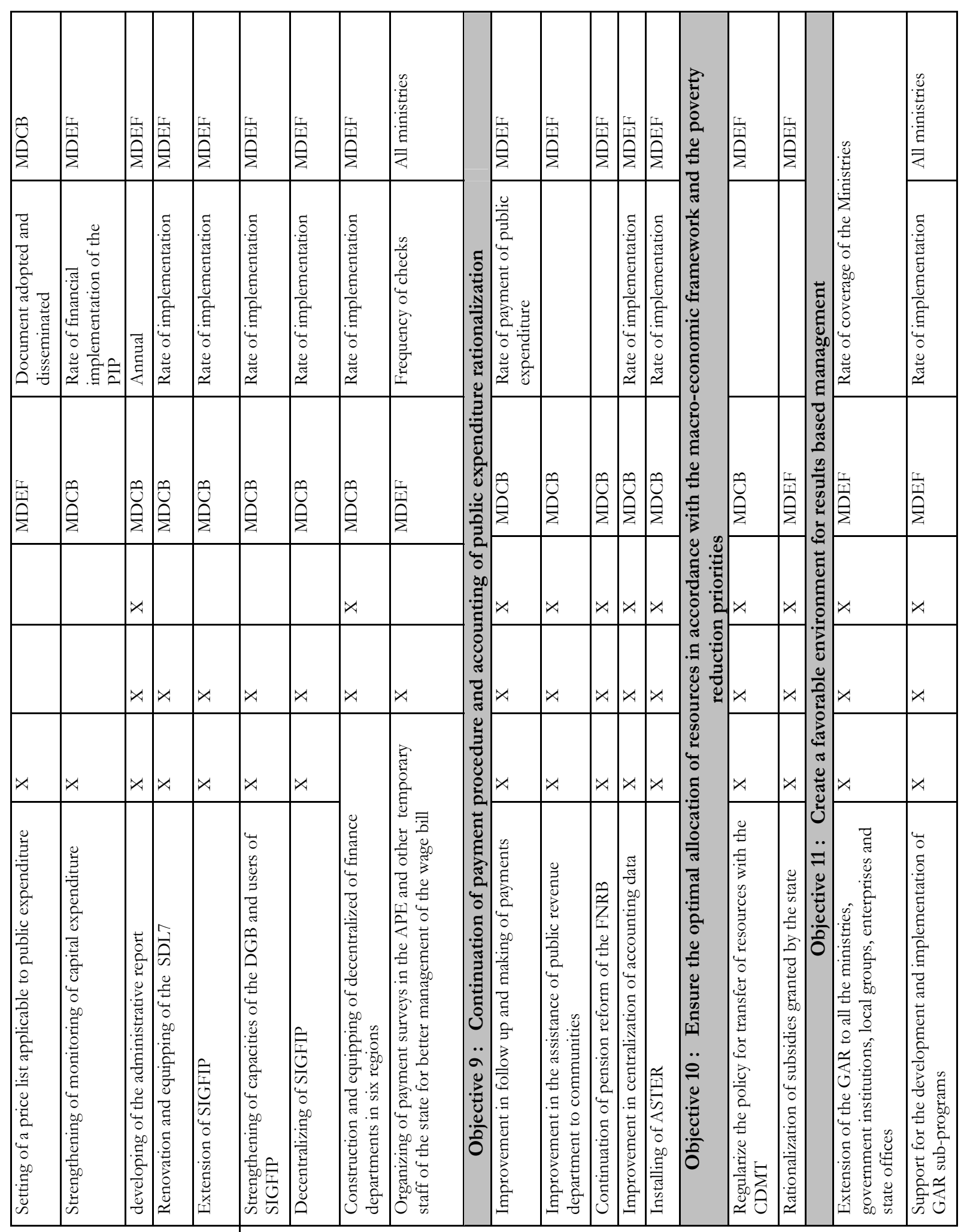

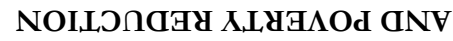

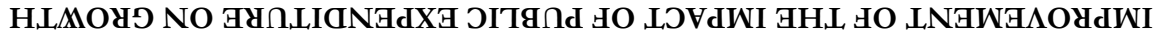




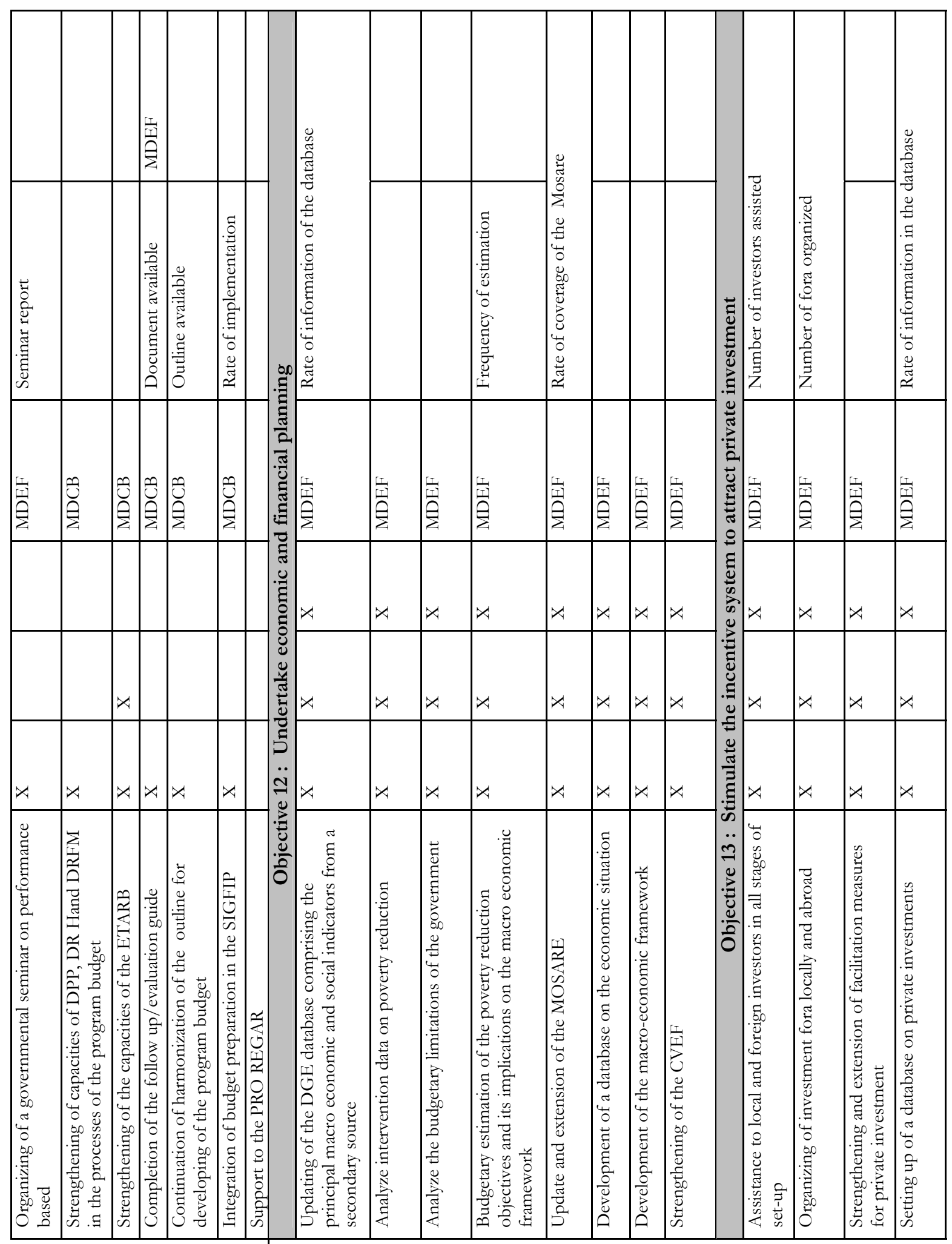




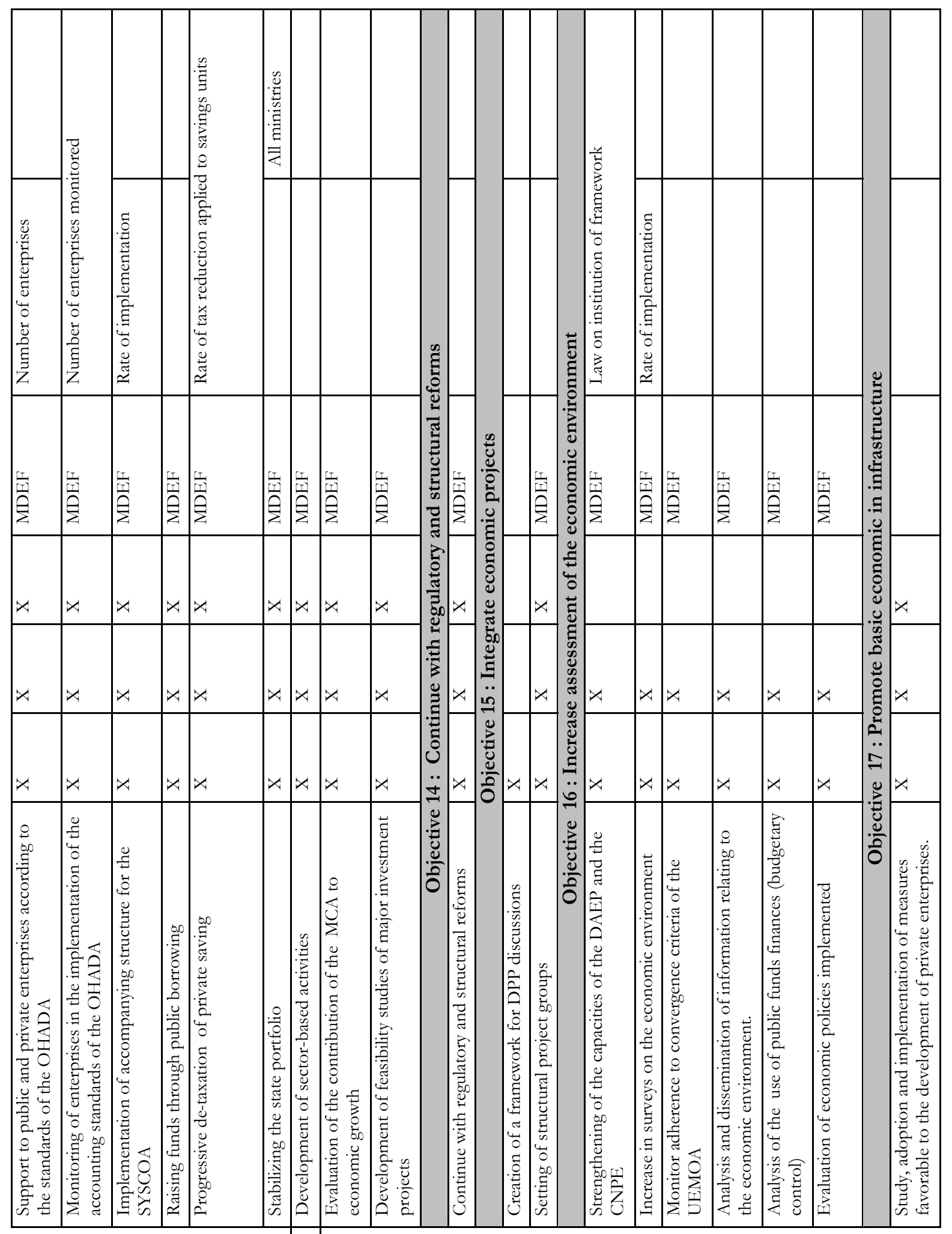

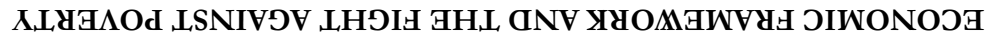

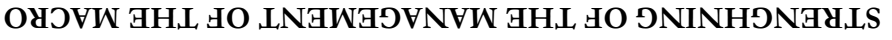




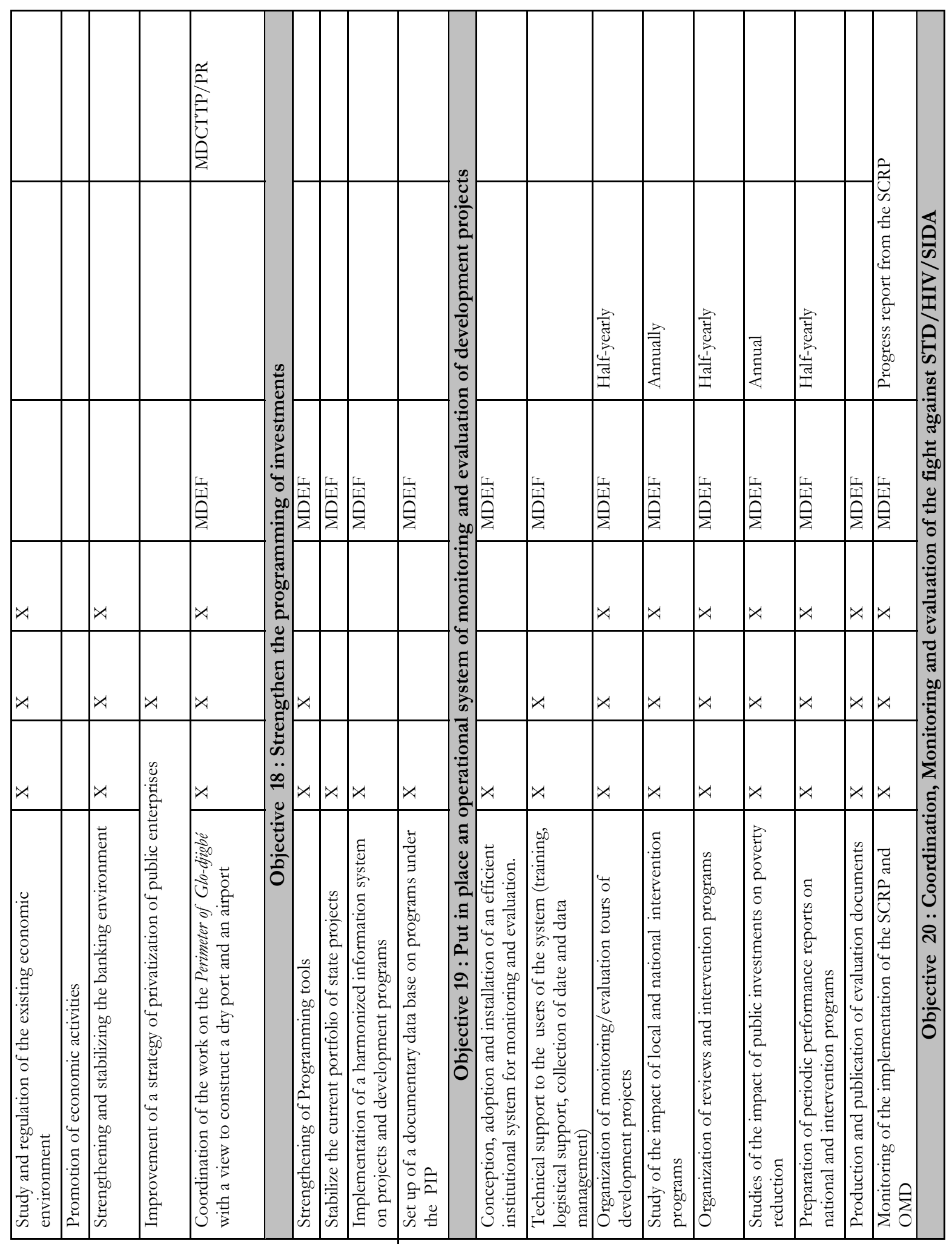

X.LYG AOd ISNIVOV 


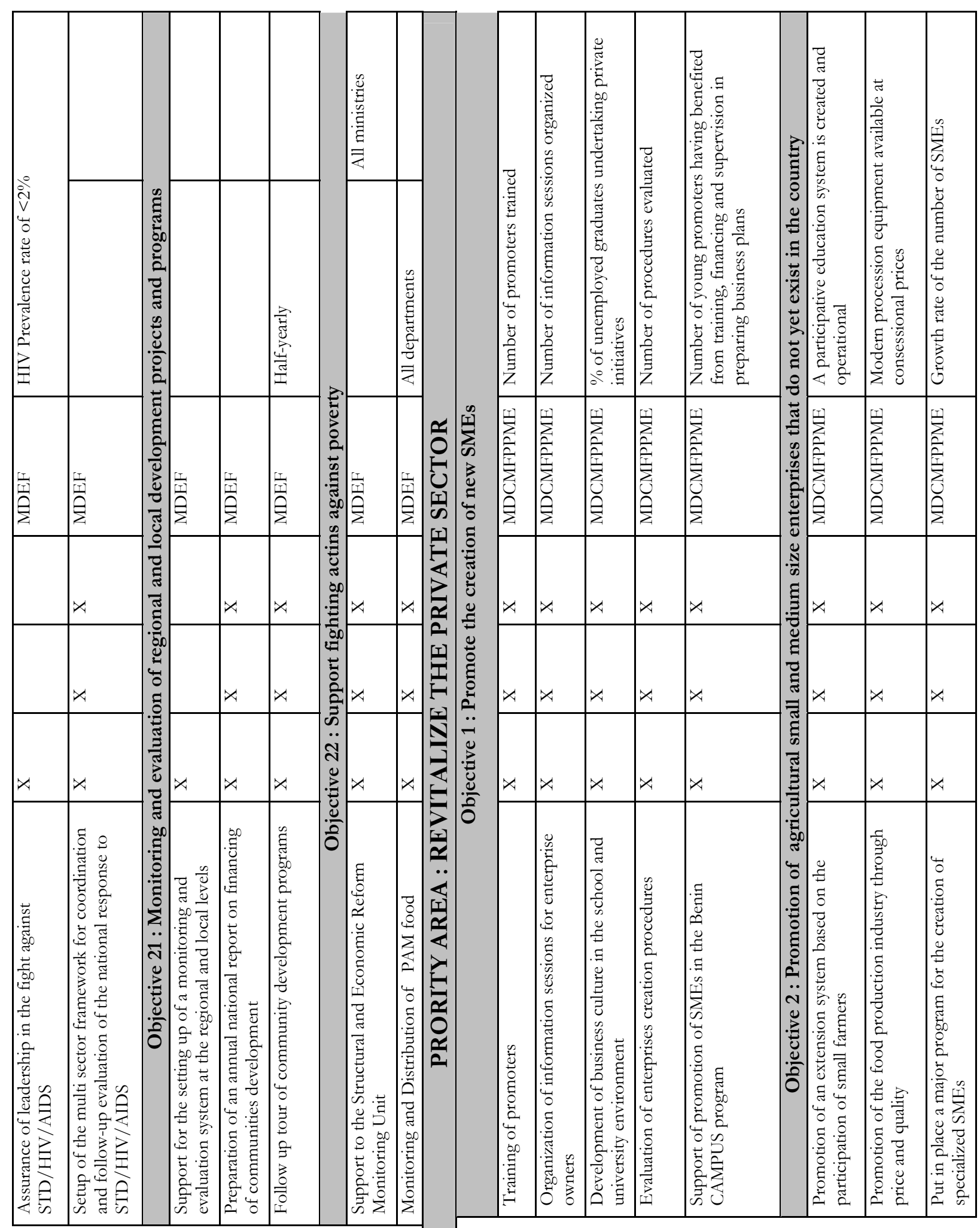




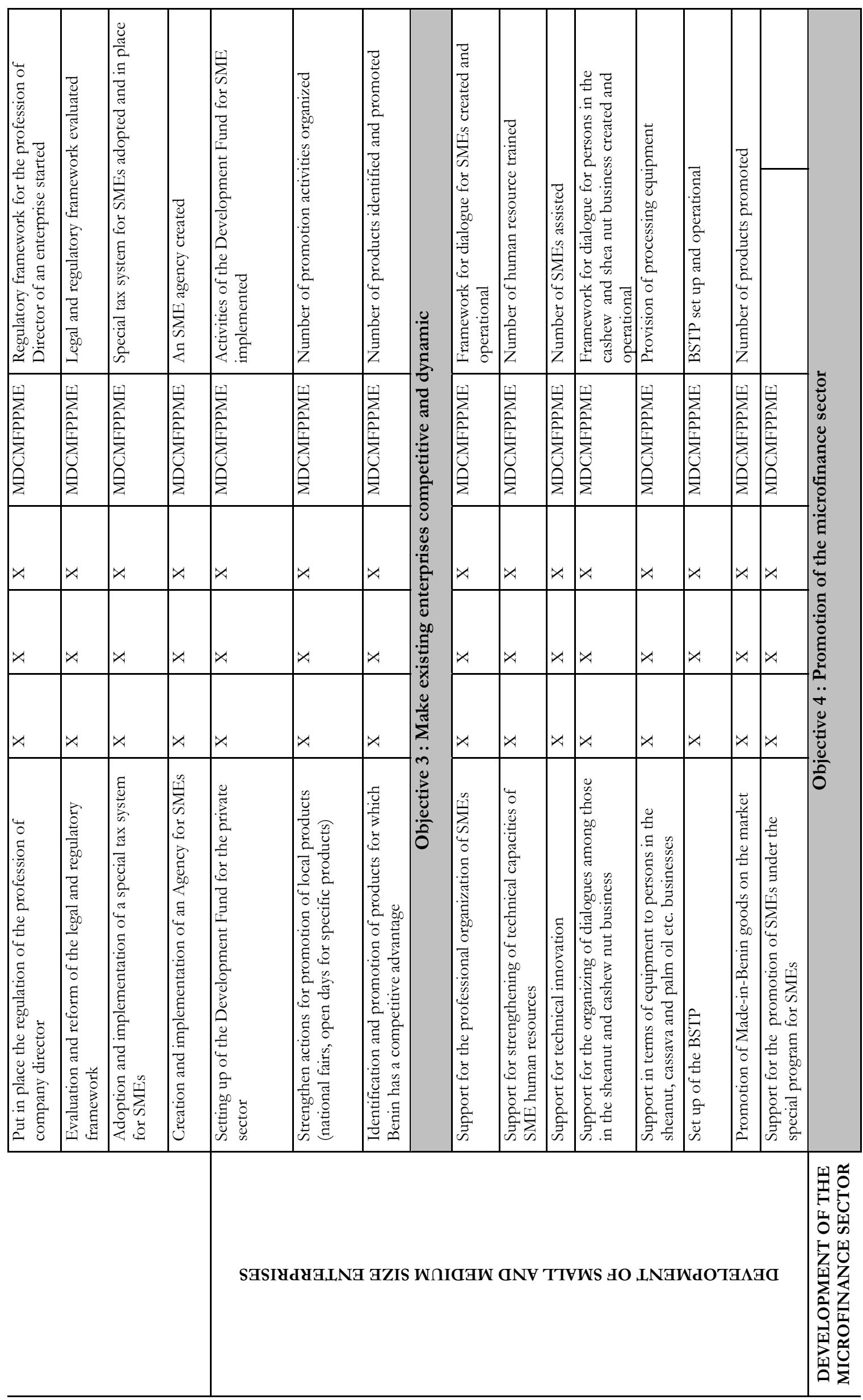




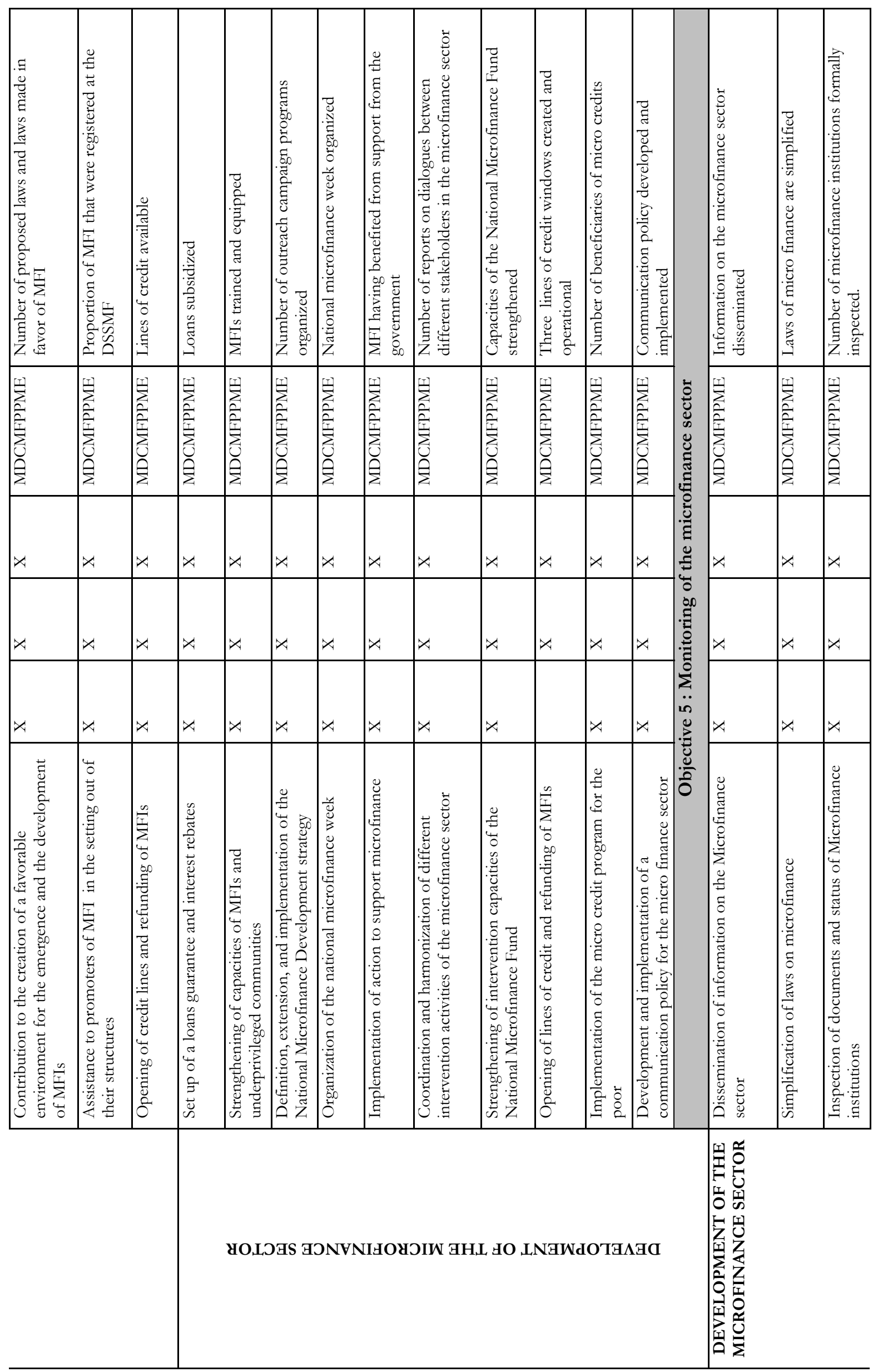




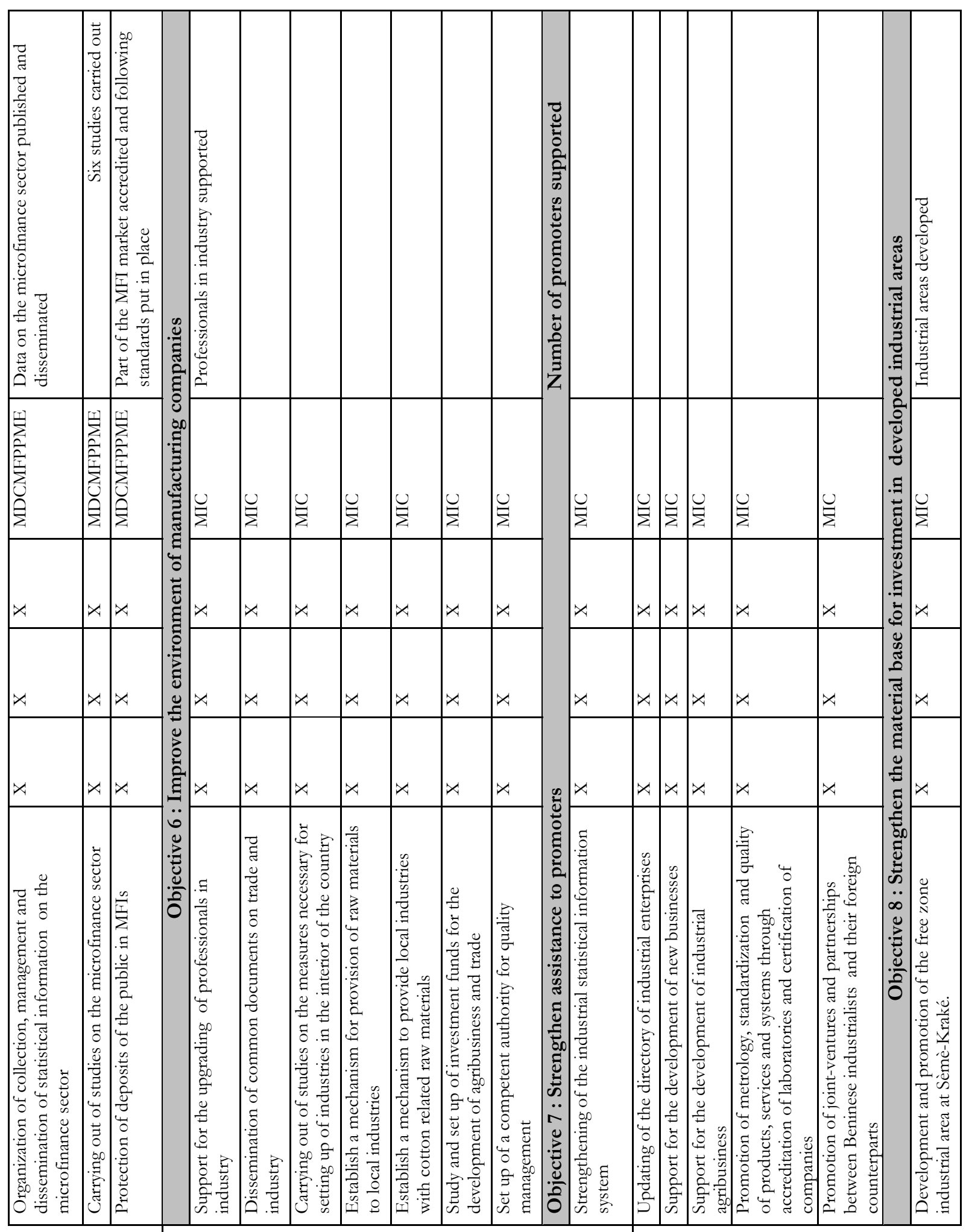




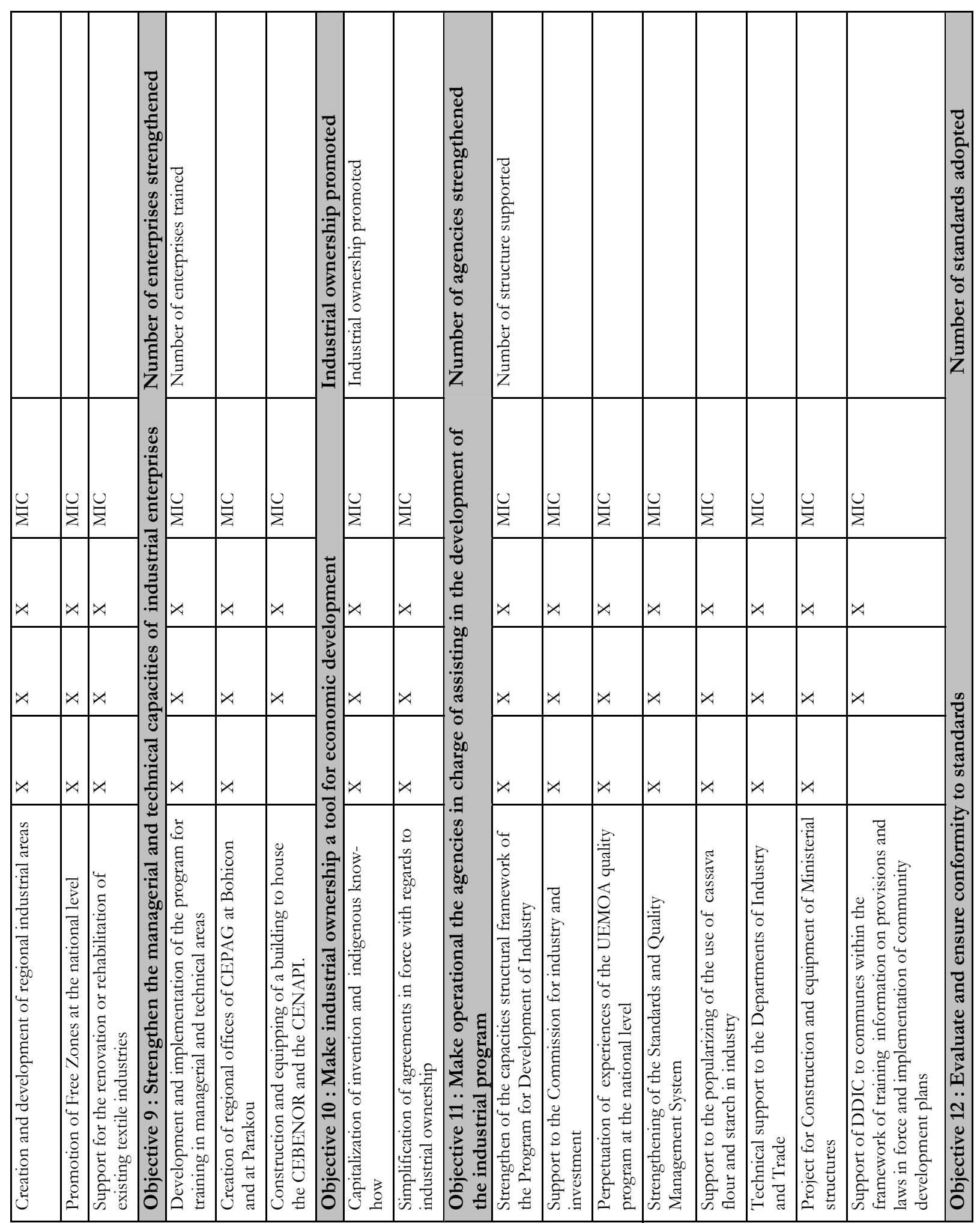




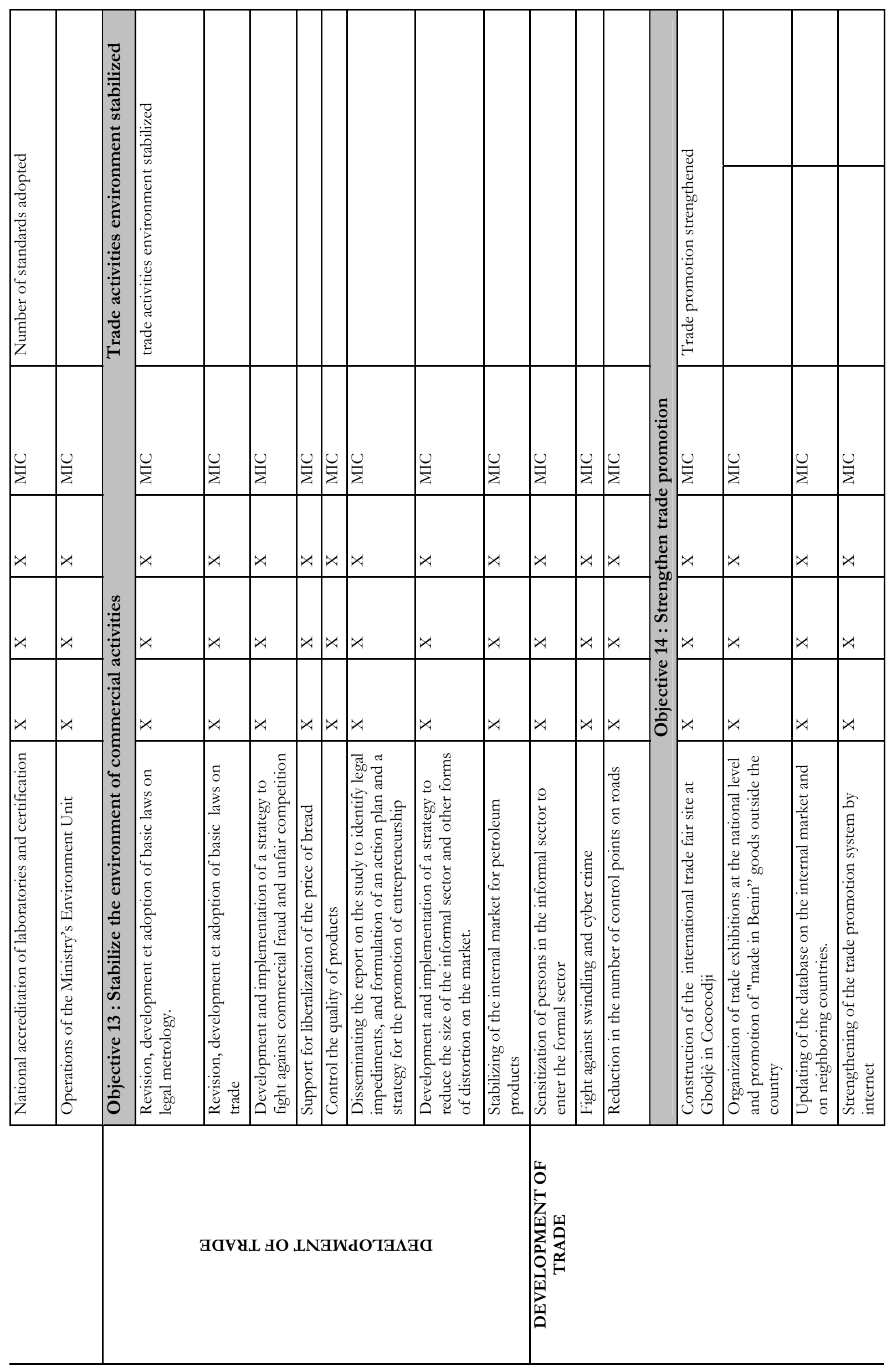




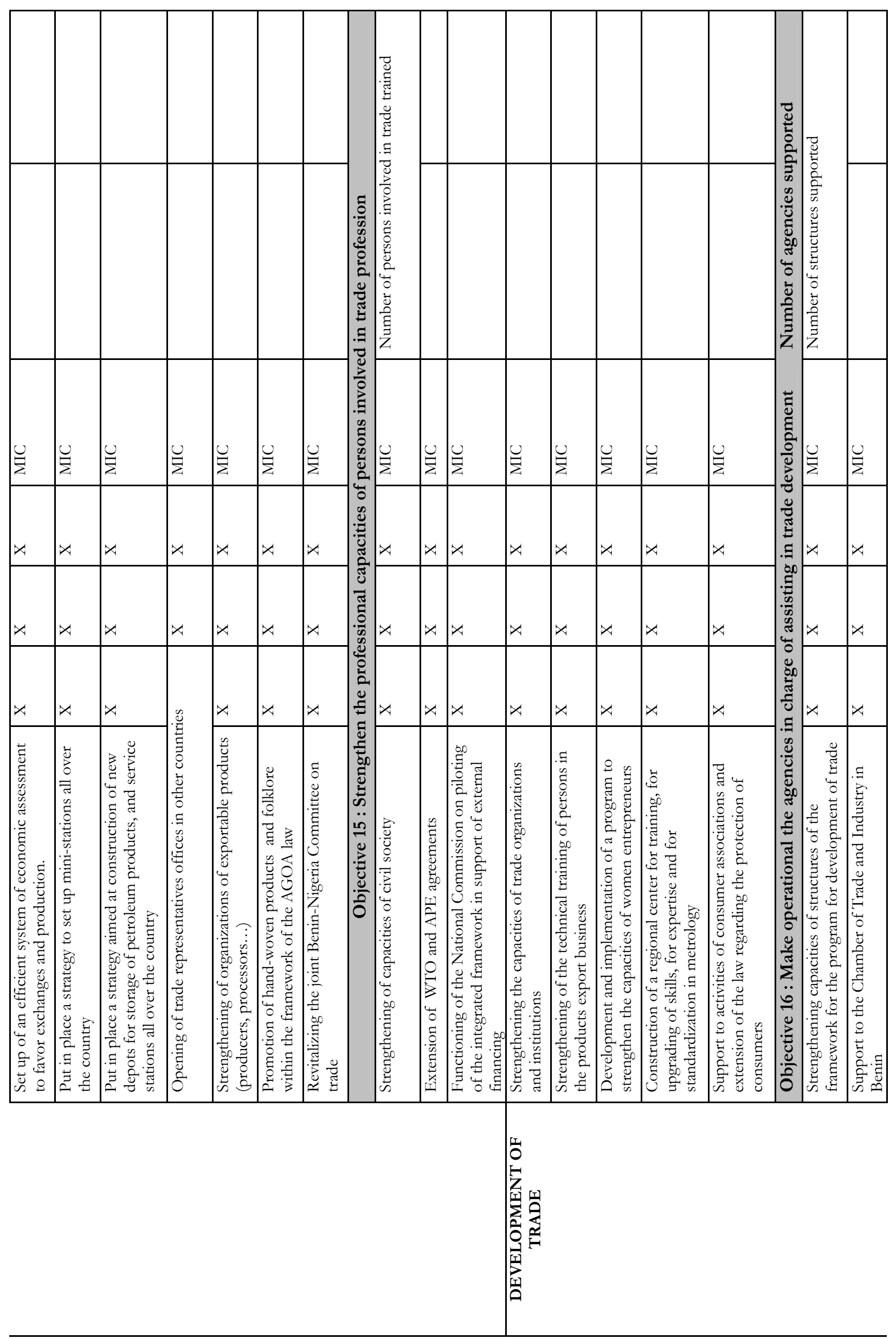




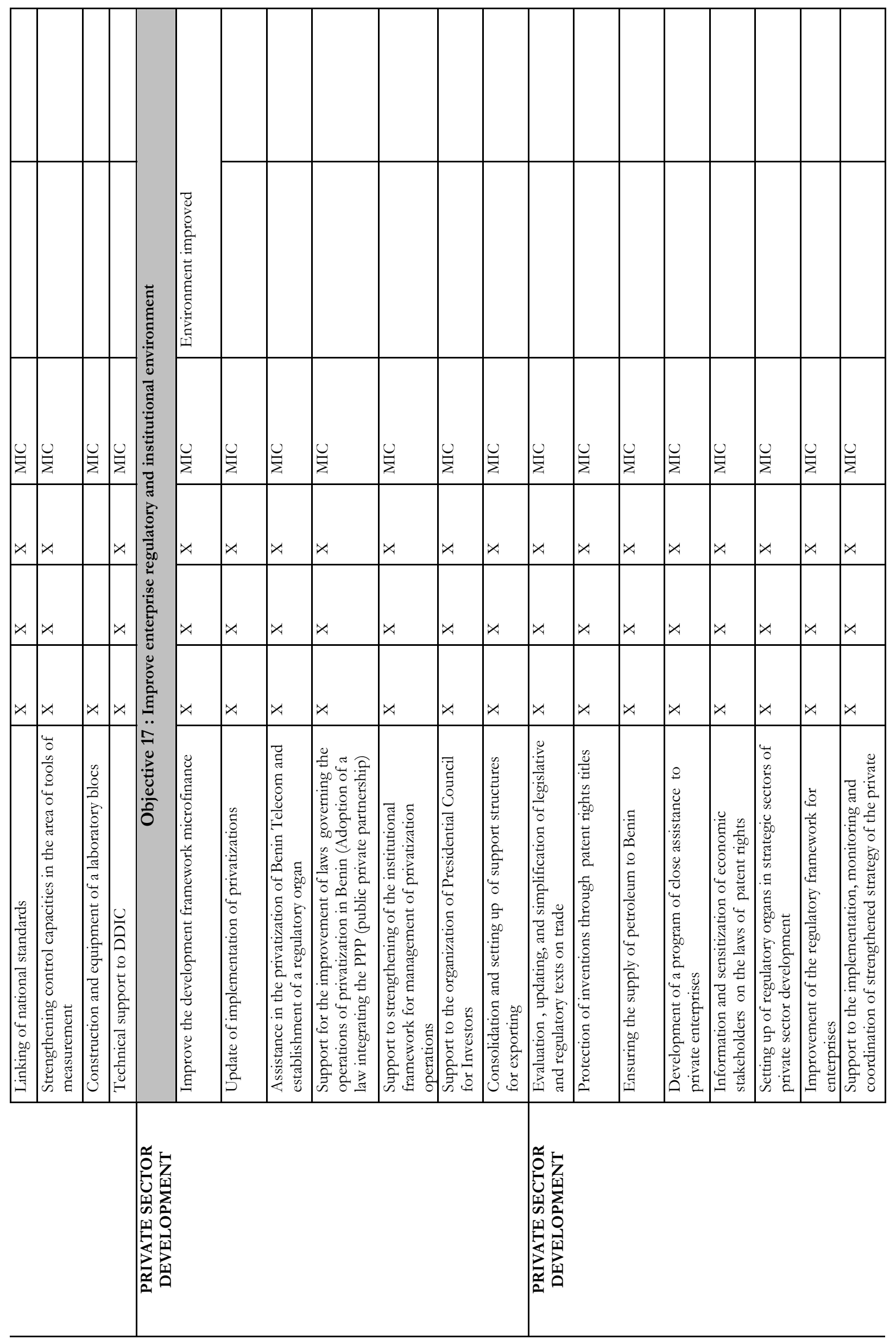




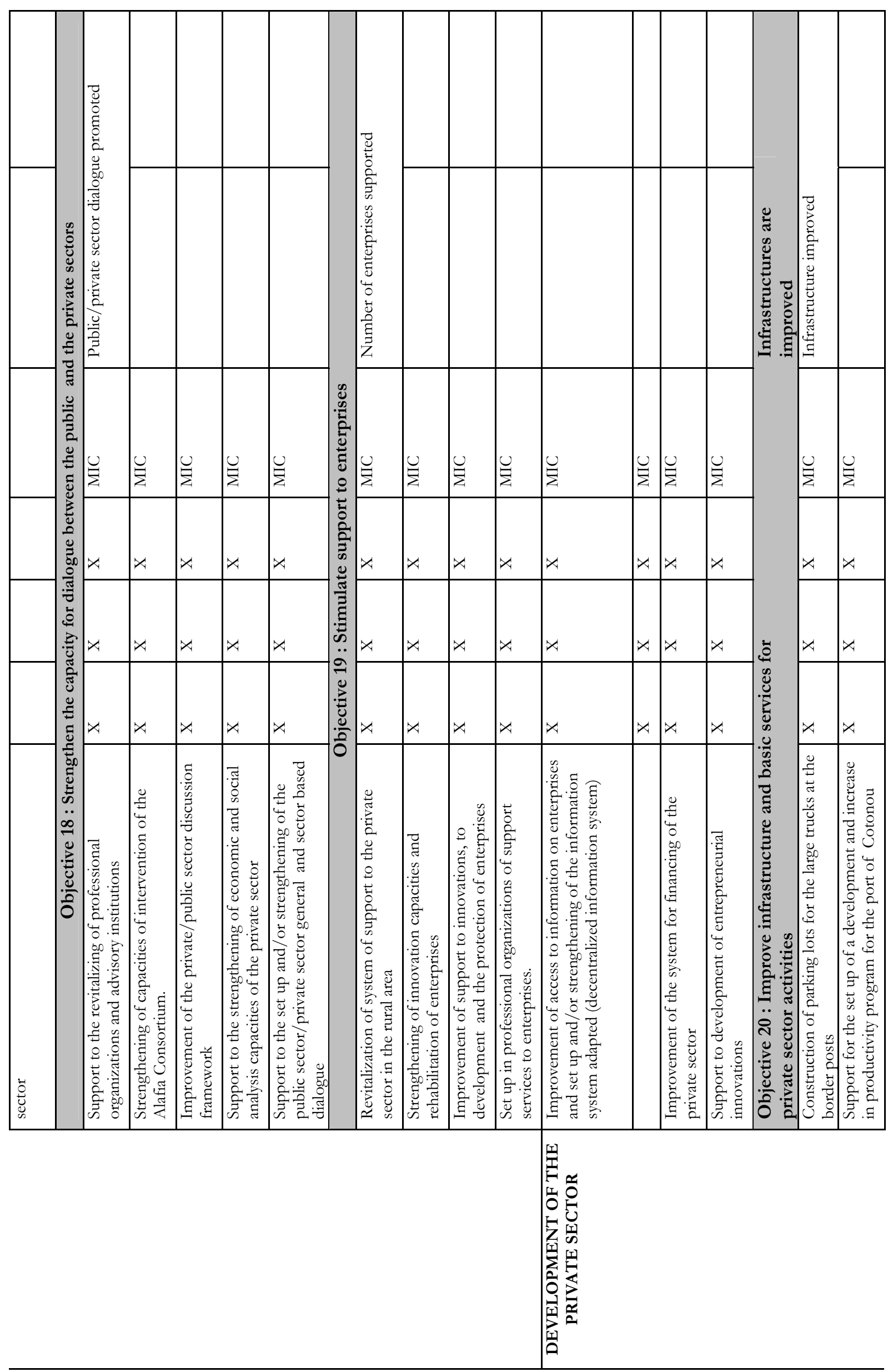




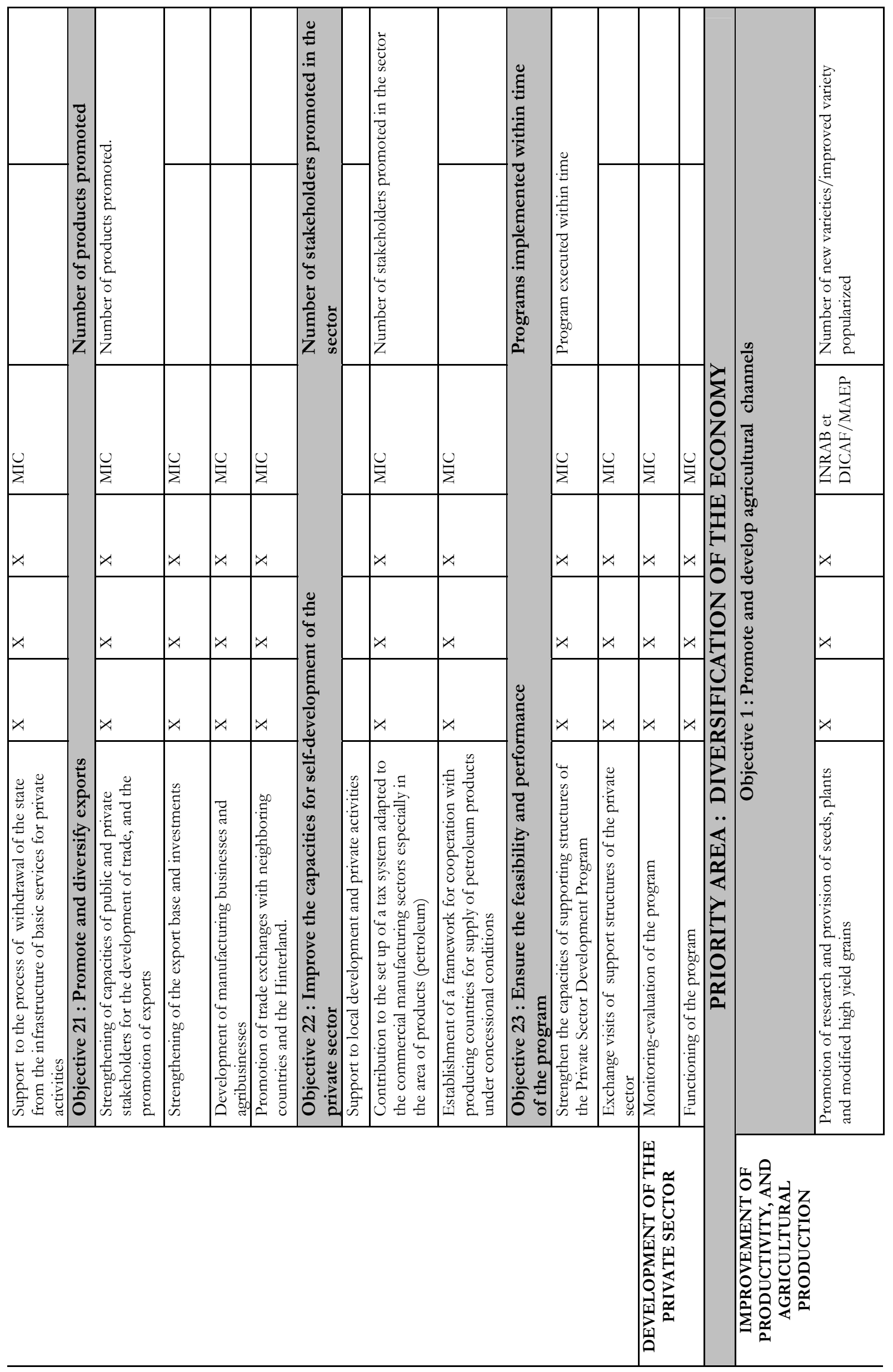




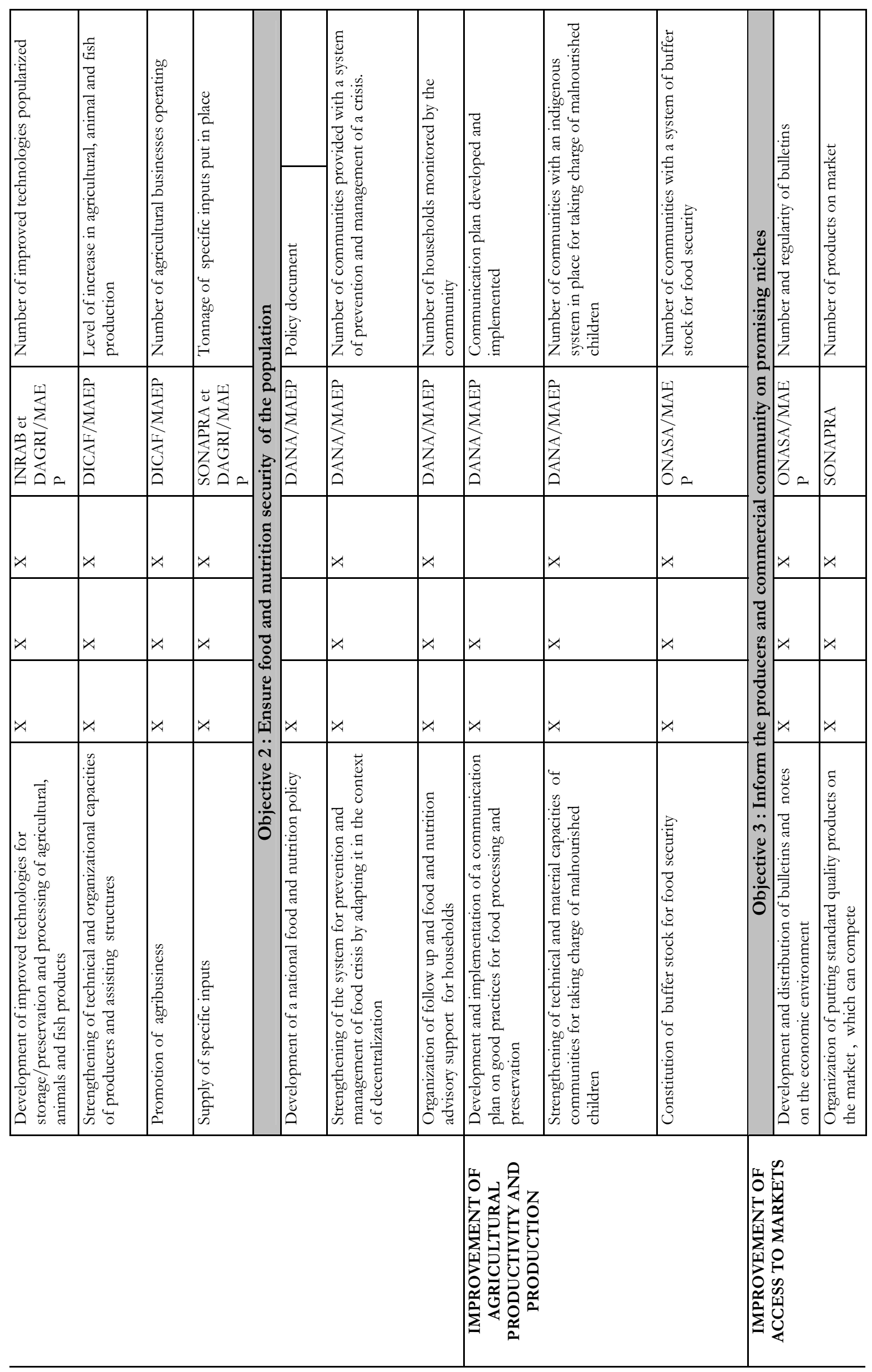




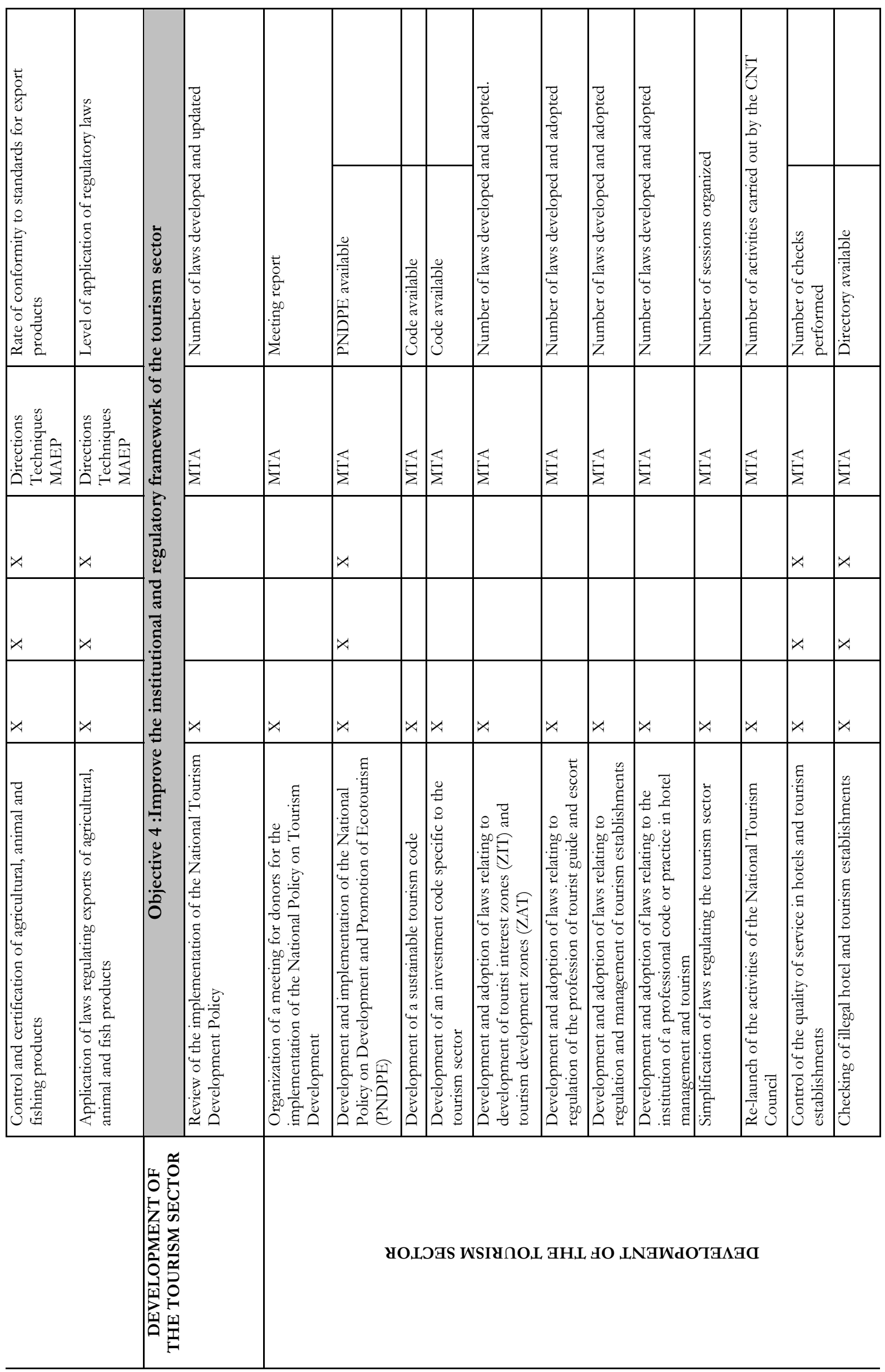




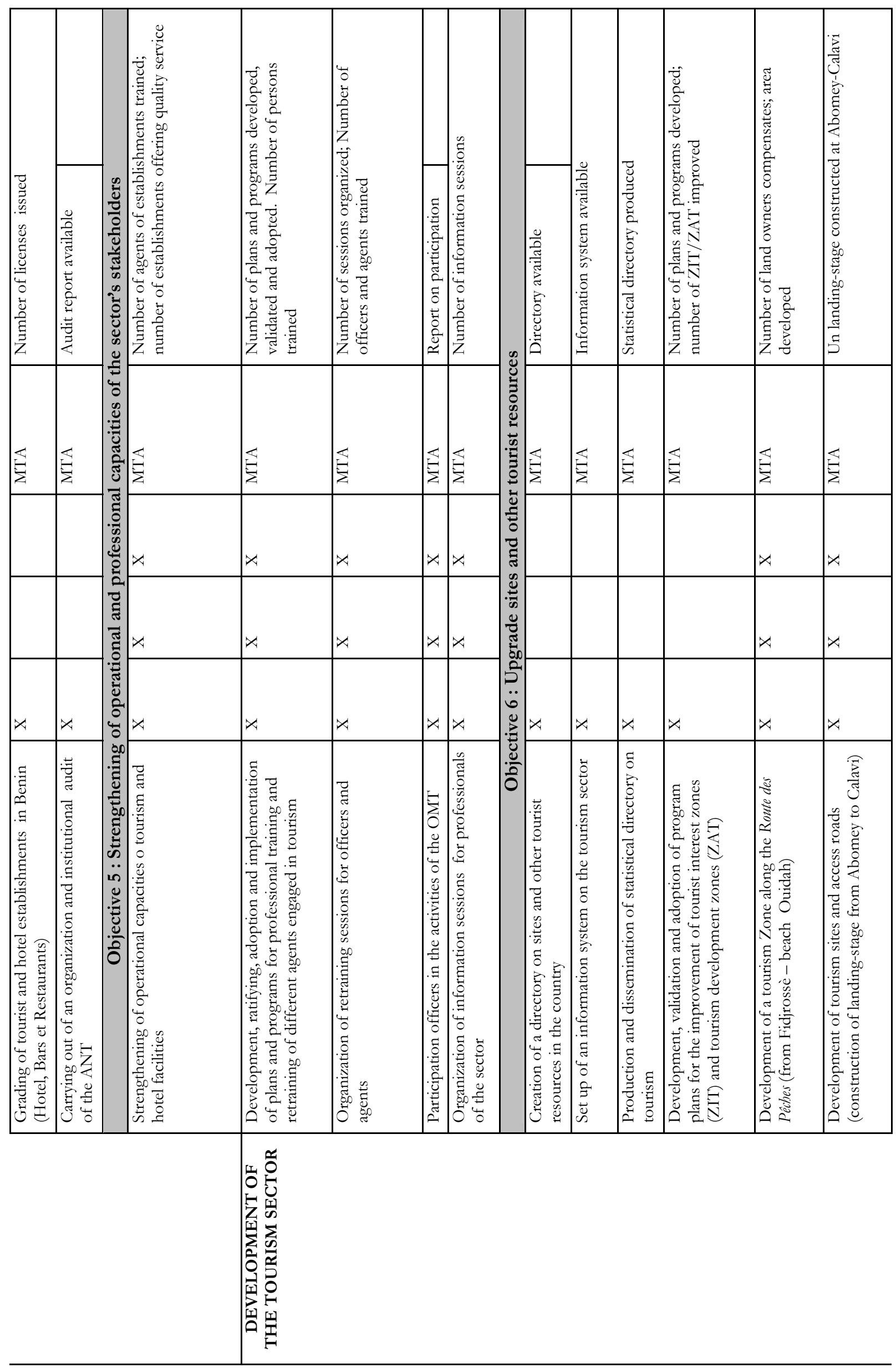




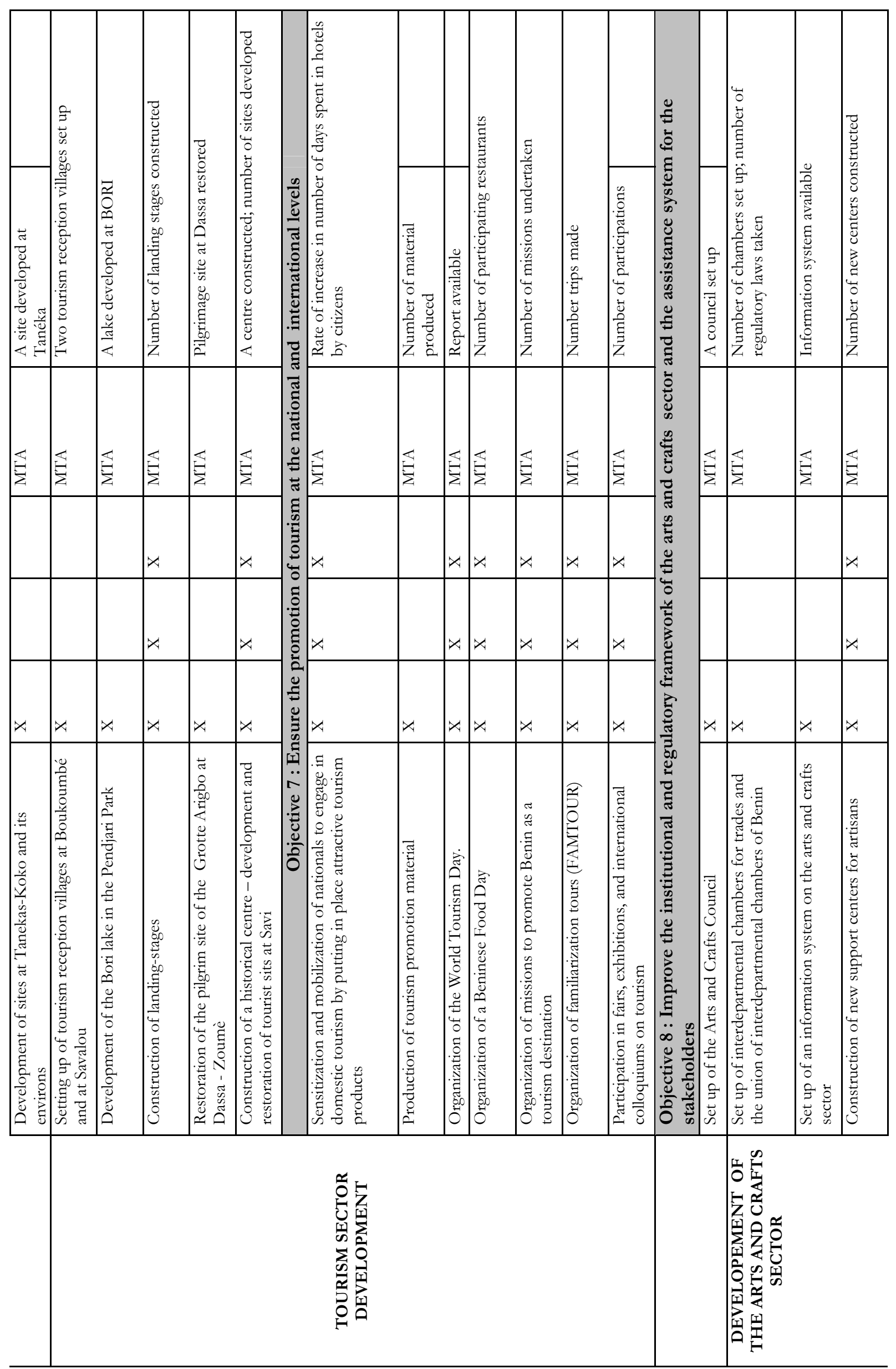




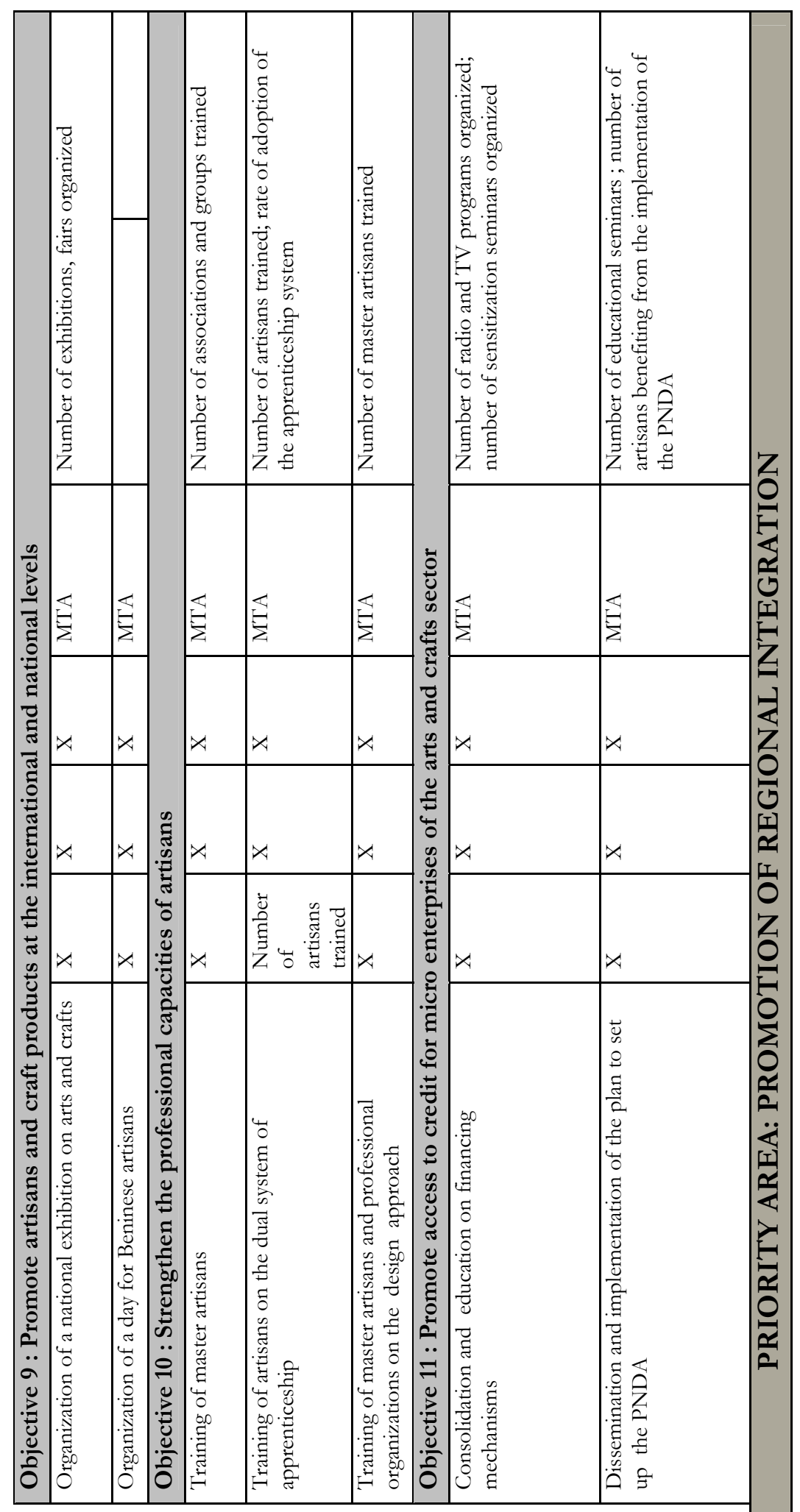




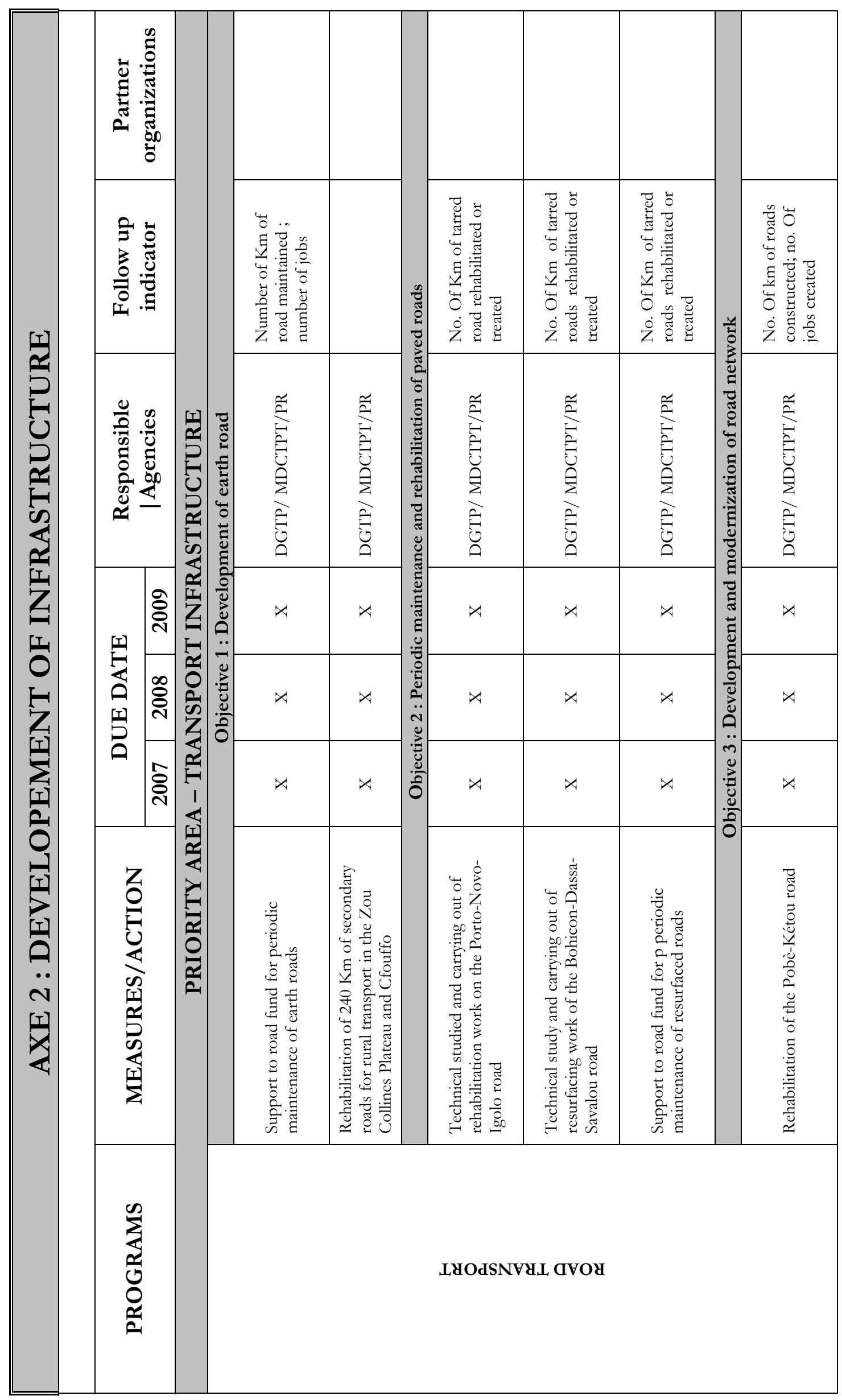




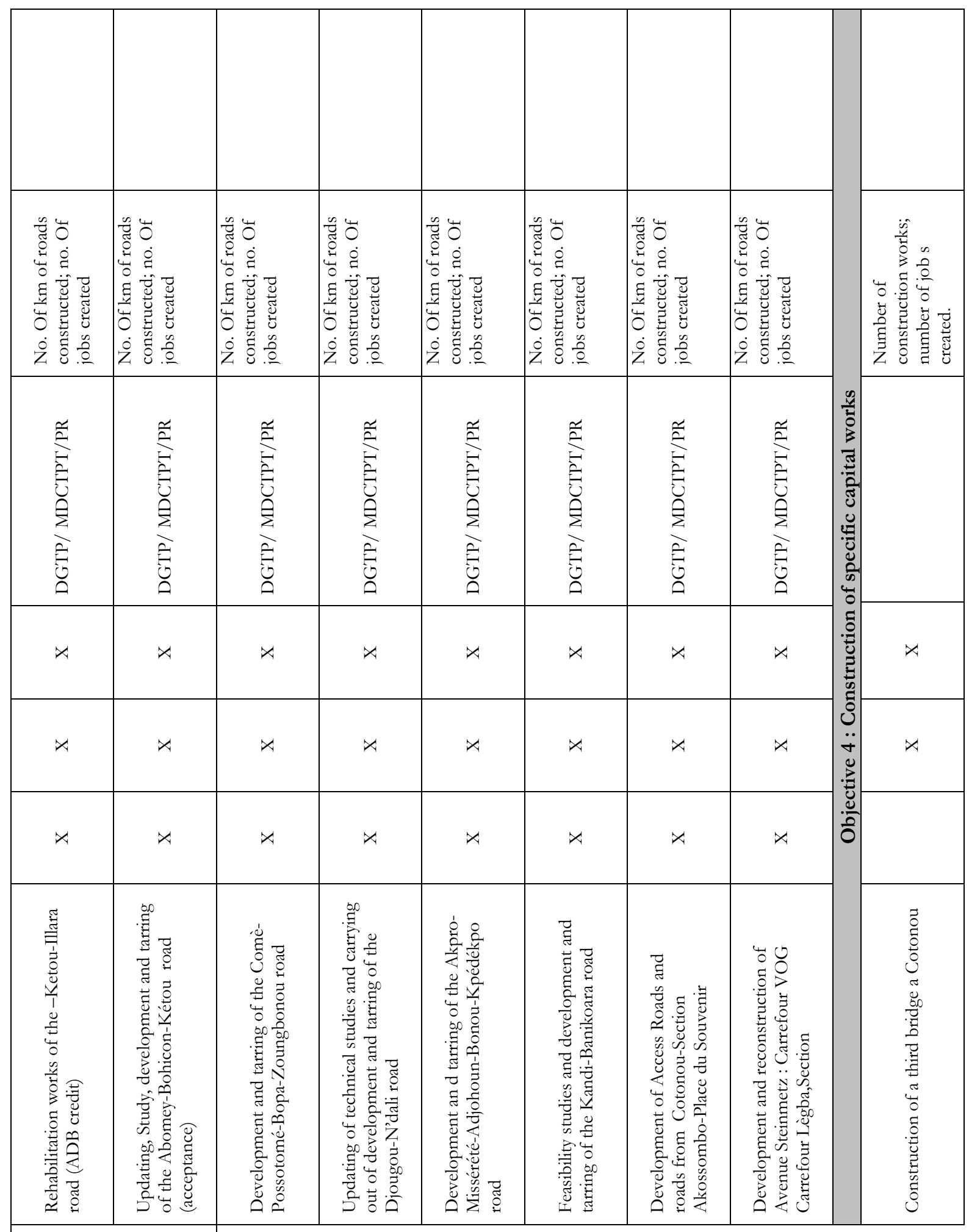




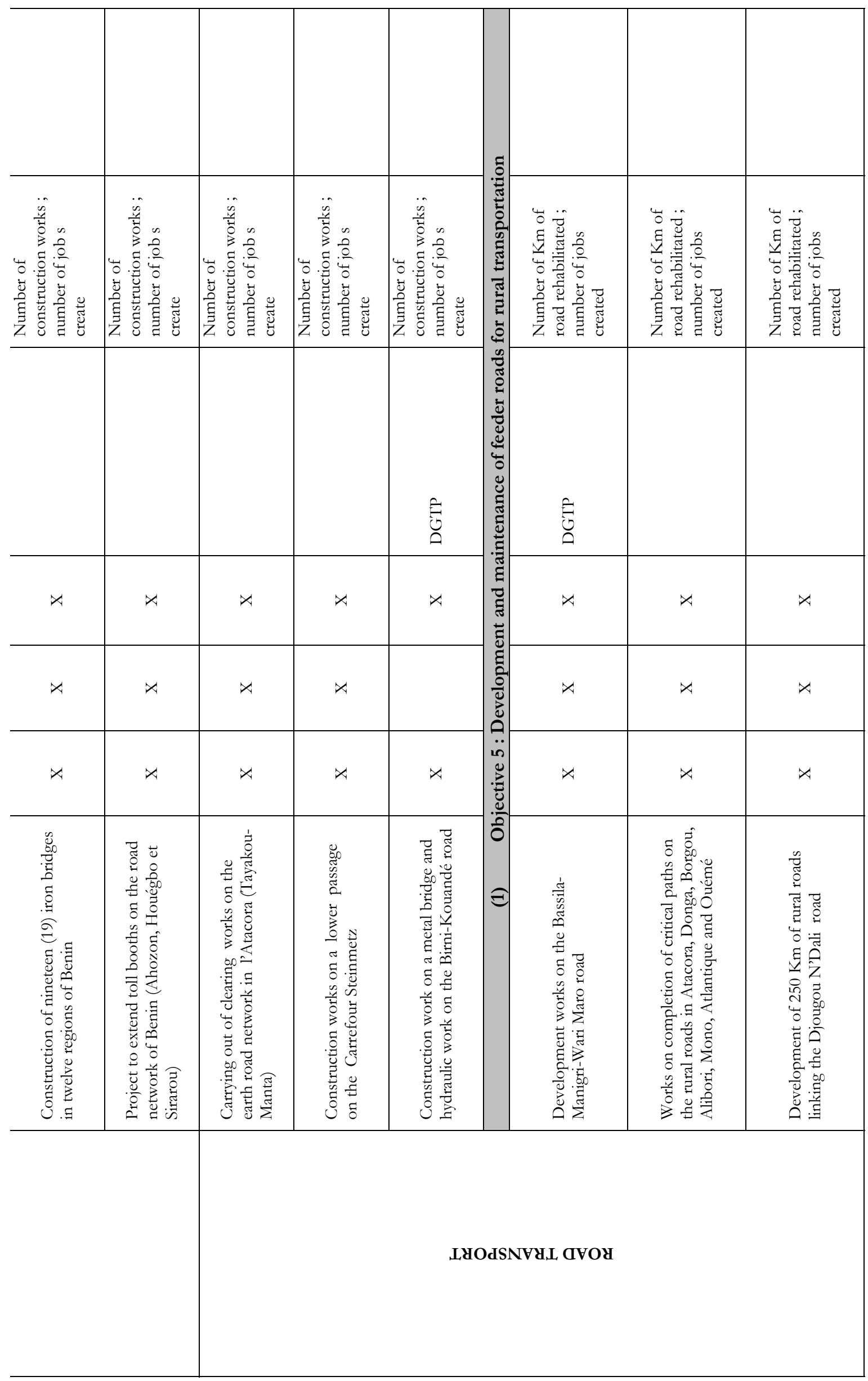




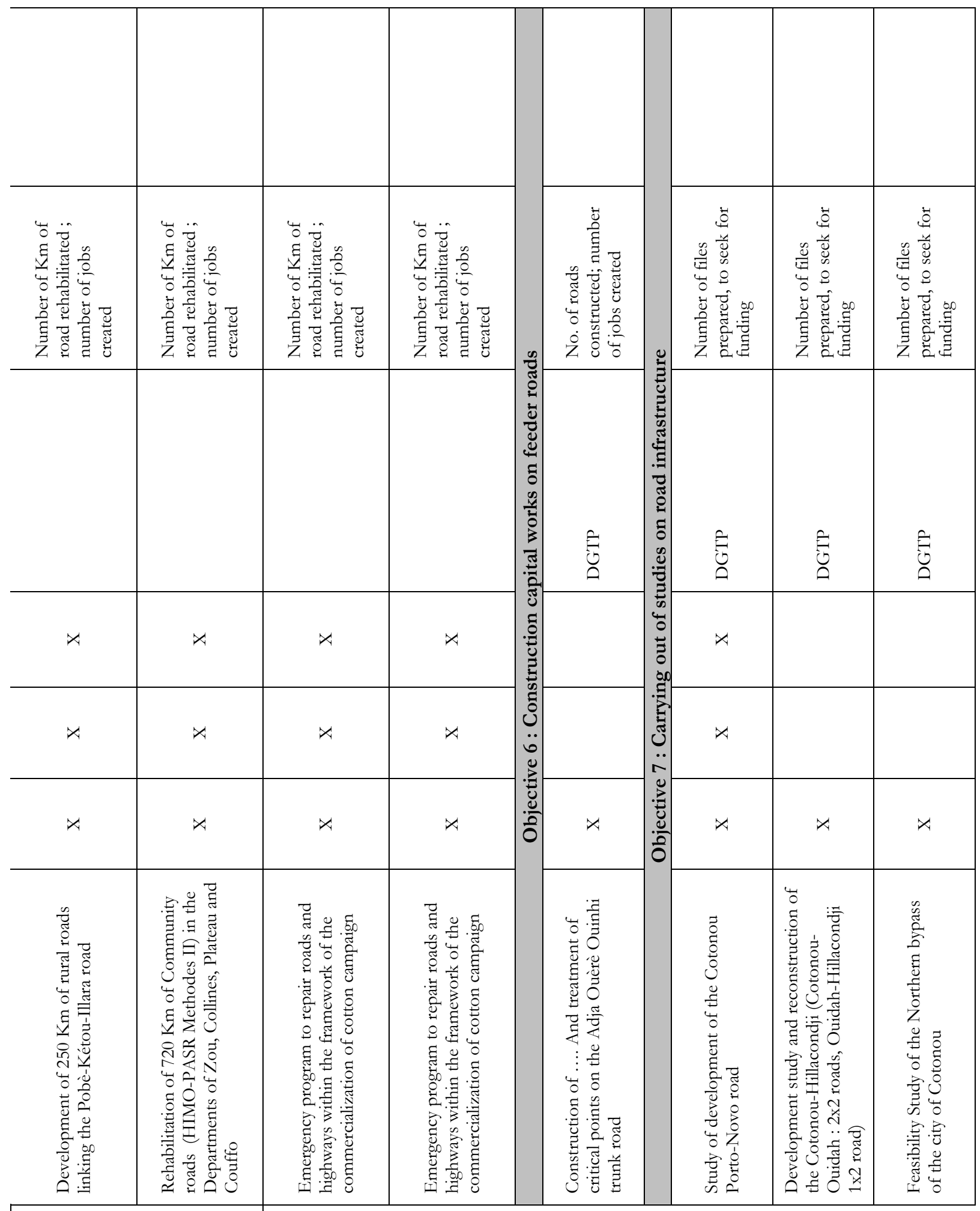




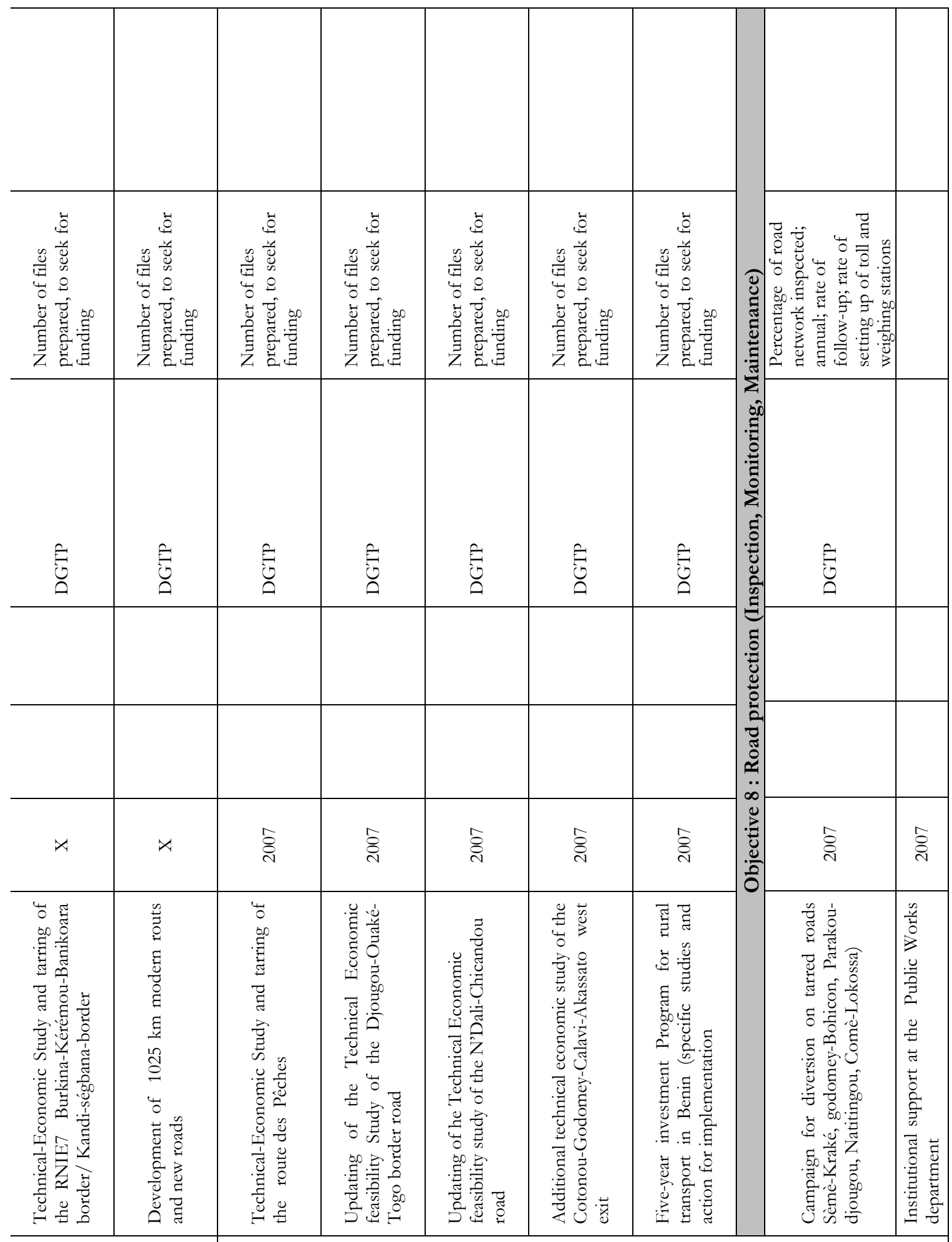

IYOdSNYYI GVOY 


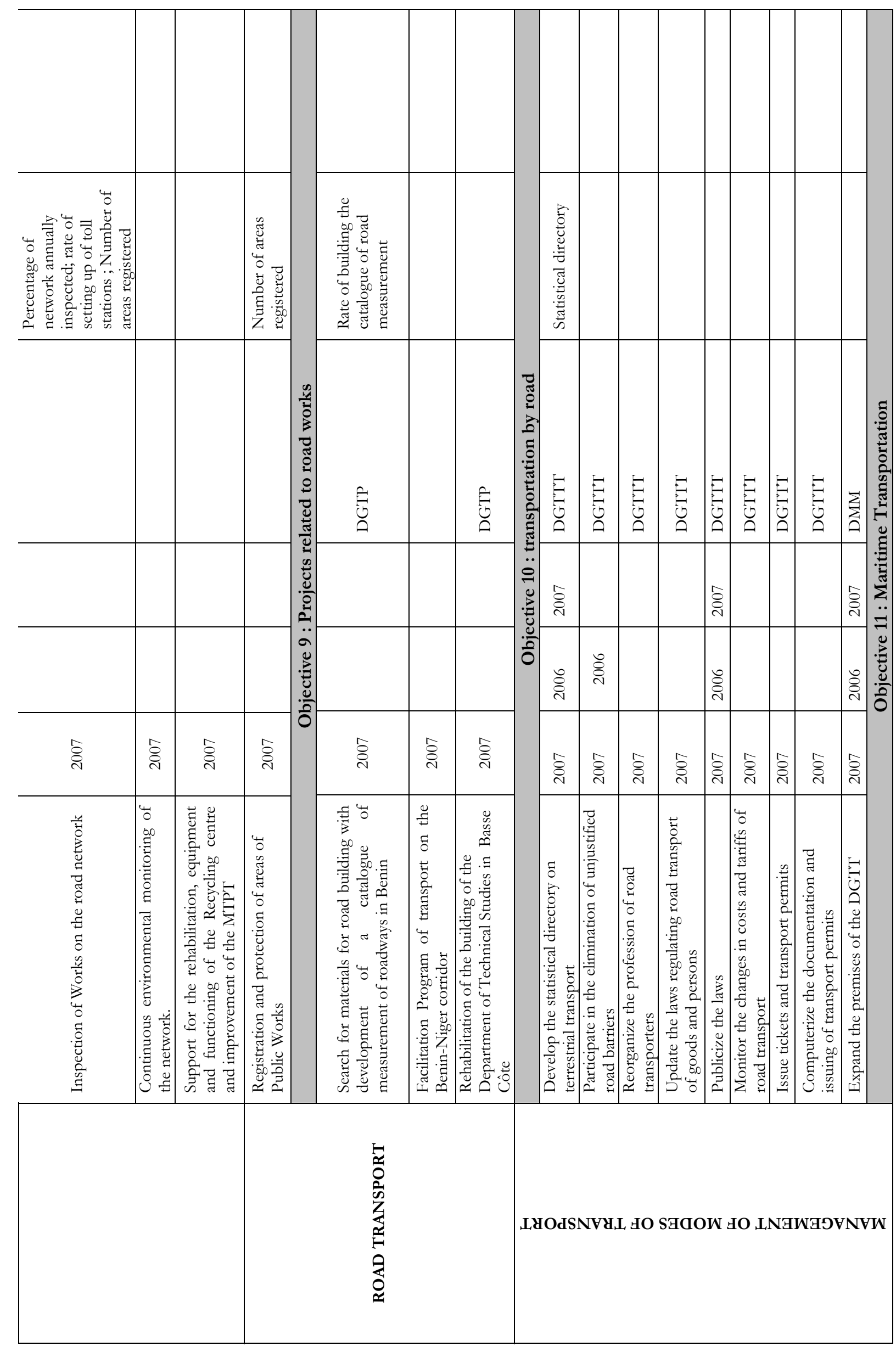




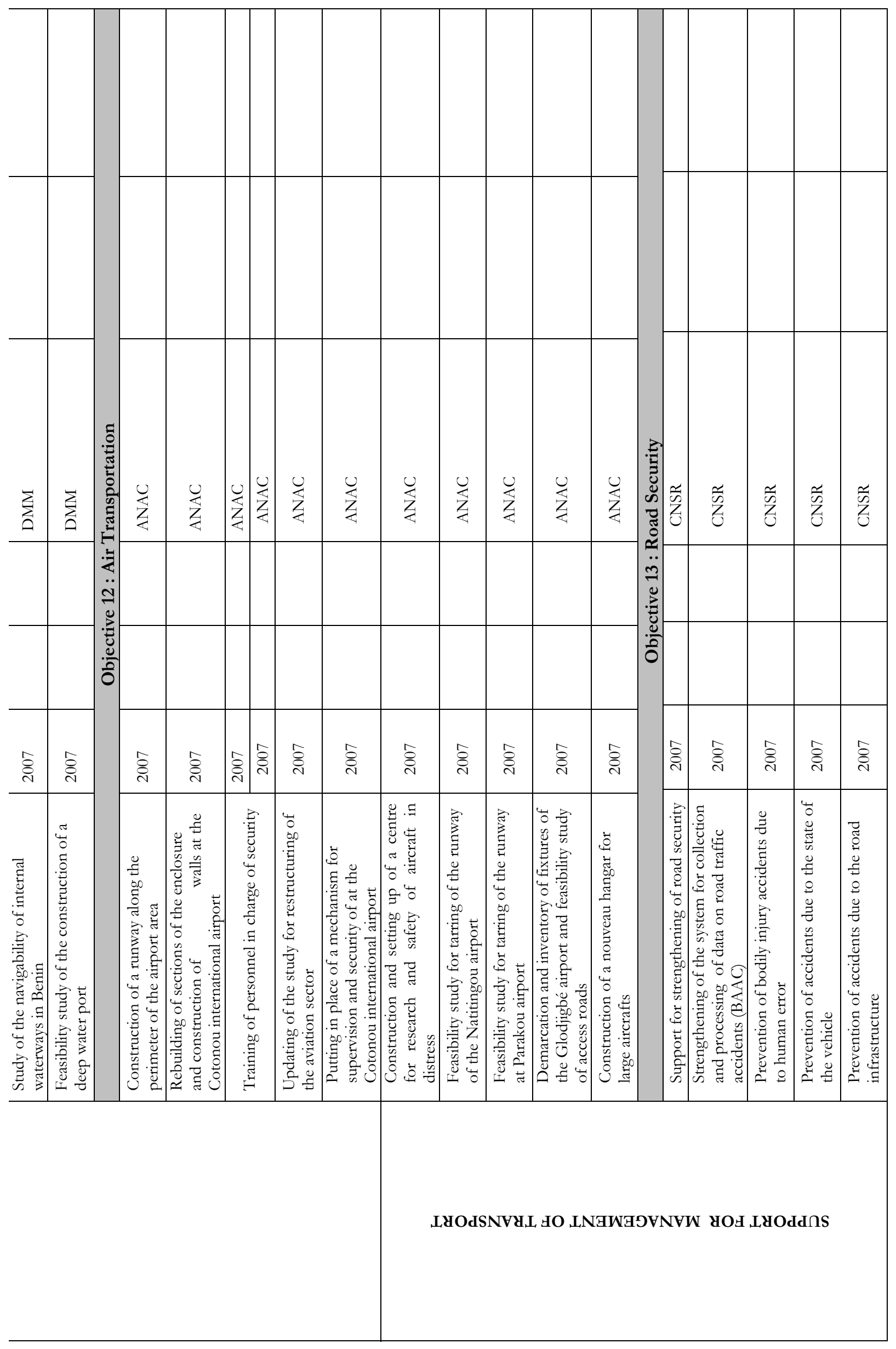




\begin{tabular}{|c|c|c|c|c|c|c|c|c|c|c|c|}
\hline & \multirow{2}{*}{ 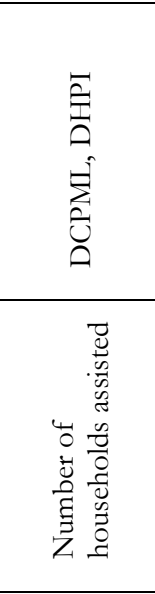 } & \multirow{2}{*}{ 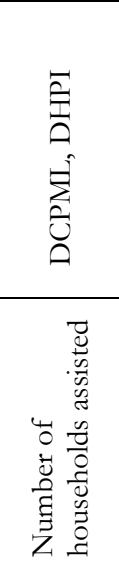 } & $\overline{\vec{\Xi}}$ & 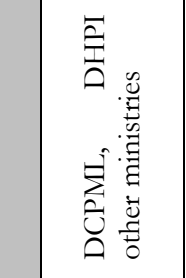 & 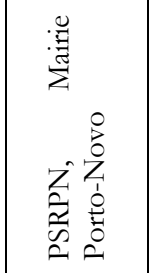 & 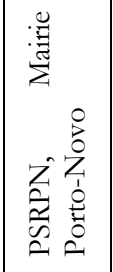 & 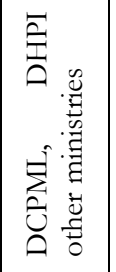 & 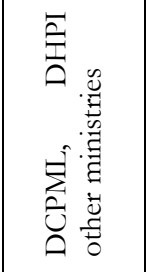 & 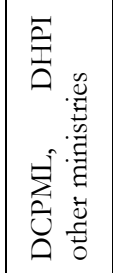 & 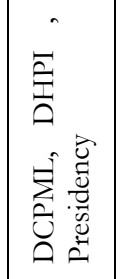 & 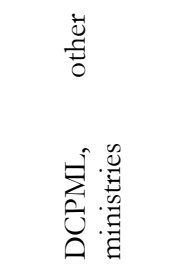 \\
\hline 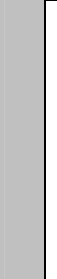 & & & 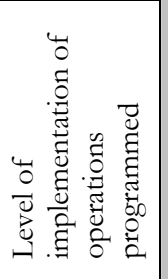 & 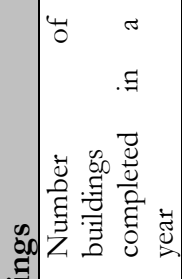 & 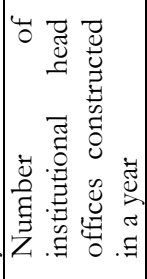 & 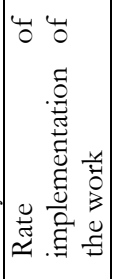 & 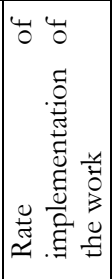 & 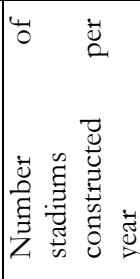 & 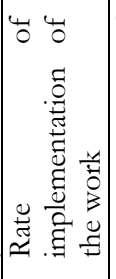 & 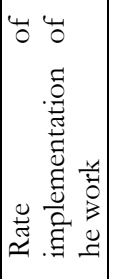 & 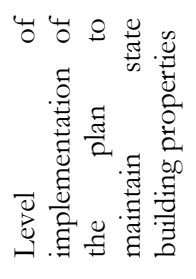 \\
\hline 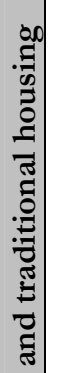 & 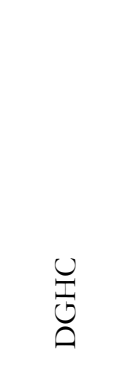 & $\begin{array}{l}\text { U⿱士心心 } \\
\text { U. }\end{array}$ & & 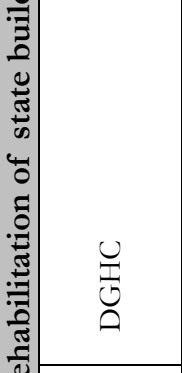 & 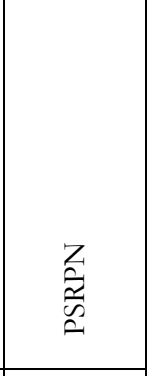 & $\begin{array}{l}\stackrel{U}{U} \\
\stackrel{U}{U}\end{array}$ & 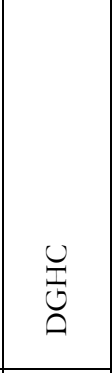 & 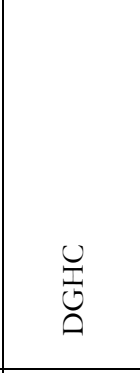 & 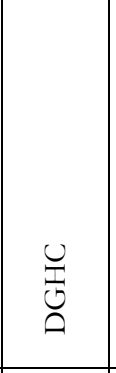 & 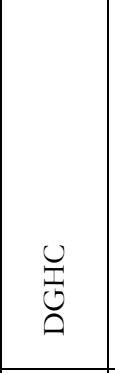 & $\begin{array}{l}\bigcup_{U}^{U} \\
\stackrel{0}{O}\end{array}$ \\
\hline 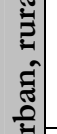 & $x$ & $x$ & $x$ & 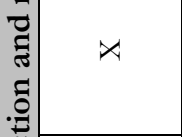 & $x$ & $x$ & & $x$ & $x$ & & $x$ \\
\hline 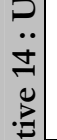 & $x$ & $x$ & $x$ & 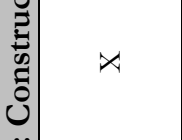 & $x$ & $x$ & $x$ & $x$ & $x$ & $x$ & $x$ \\
\hline$\frac{u}{0}$ & $x^{4}$ & & $x$ & 足 & $x$ & $x$ & $x$ & $x$ & $x$ & $x$ & $x$ \\
\hline & 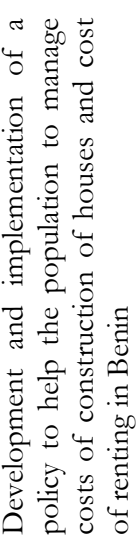 & 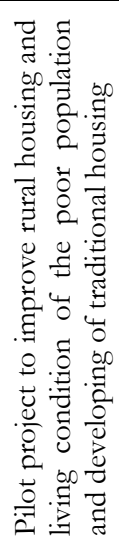 & 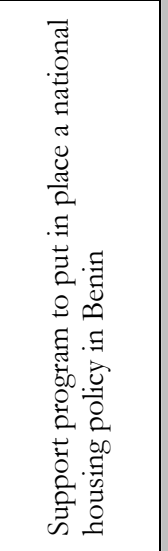 & 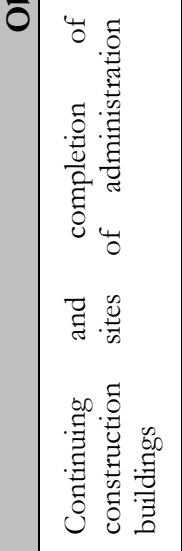 & 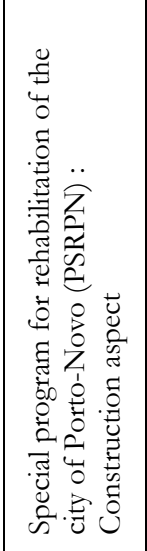 & 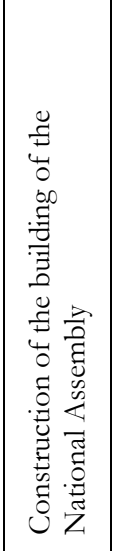 & 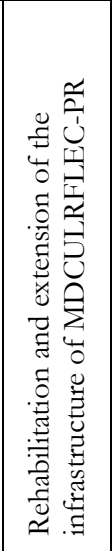 & 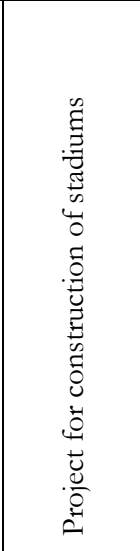 & 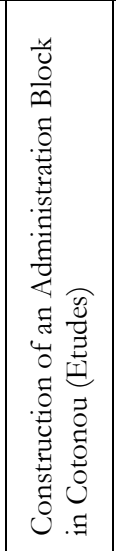 & 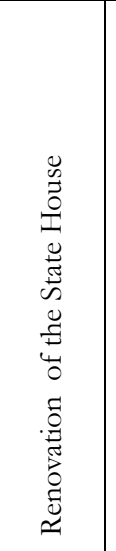 & 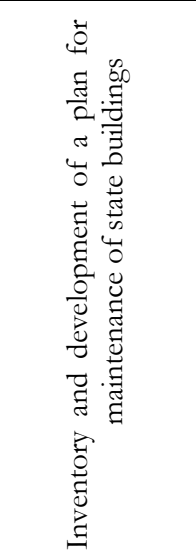 \\
\hline & & \multicolumn{4}{|c|}{ NOILJAYLSNOJ đNV OONISROH } & \multicolumn{6}{|c|}{ NOI,LOAY,LSNOJ đNV ONISกOH } \\
\hline
\end{tabular}




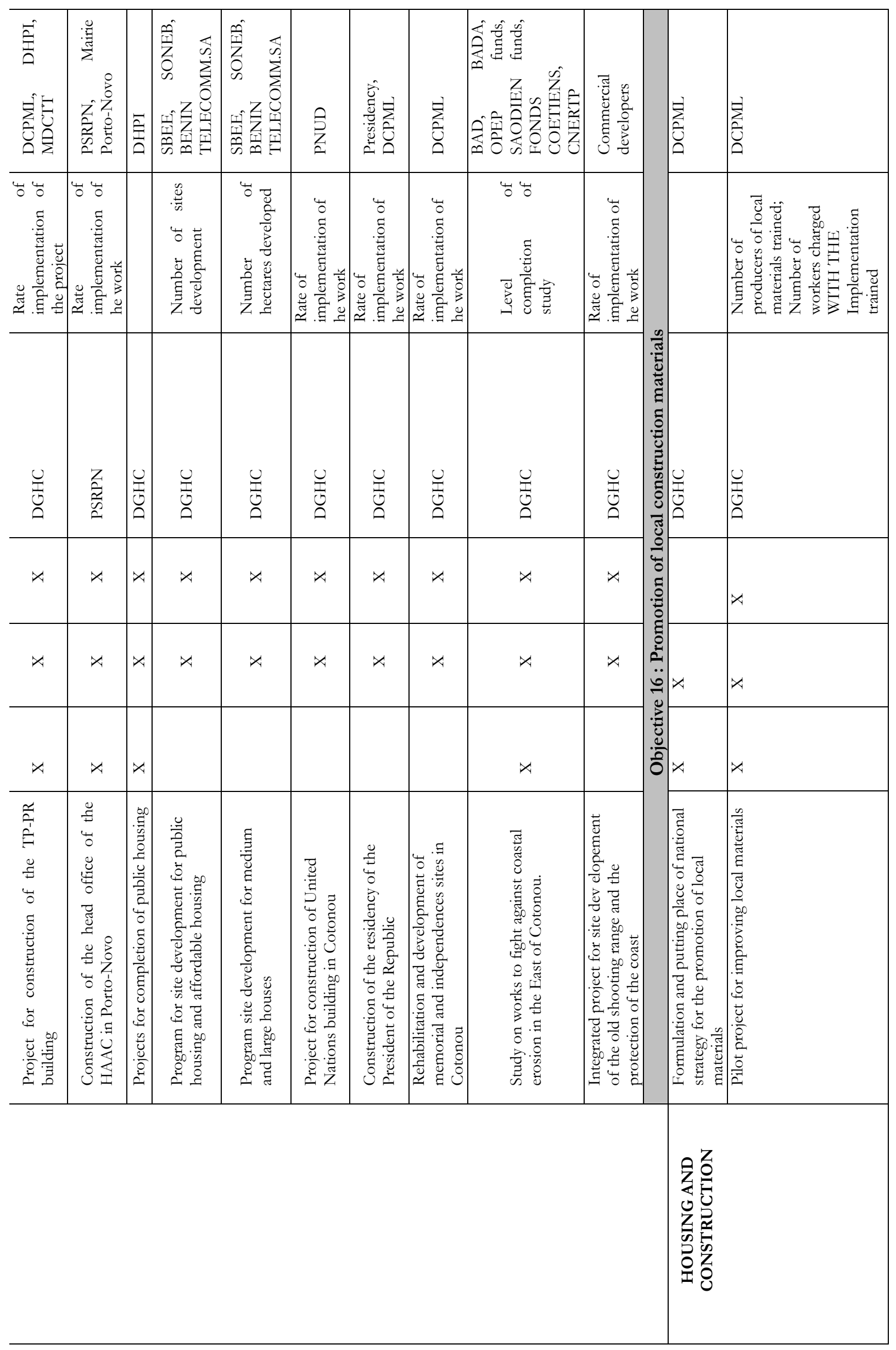




\begin{tabular}{|c|c|c|c|c|c|c|c|c|c|c|c|c|}
\hline 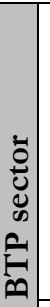 & 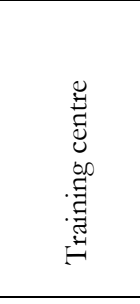 & 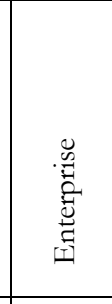 & 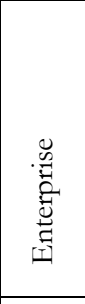 & 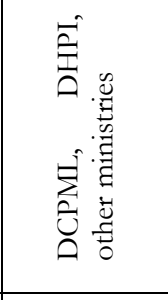 & 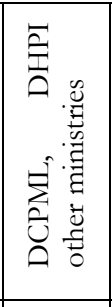 & 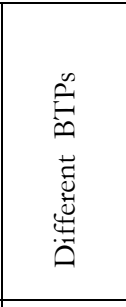 & 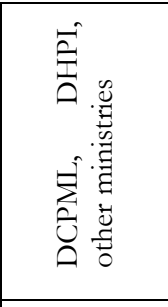 & 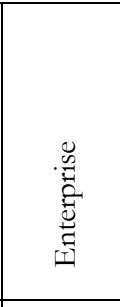 & 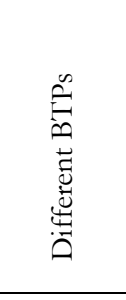 & \multirow{7}{*}{ 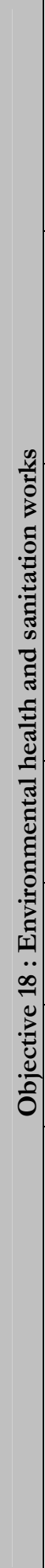 } & & 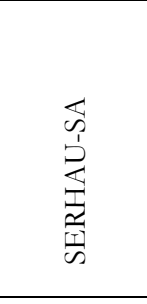 \\
\hline 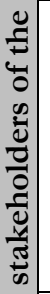 & 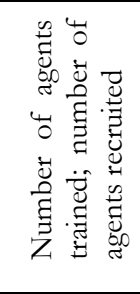 & 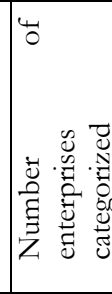 & 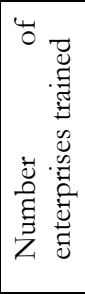 & 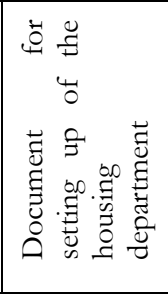 & 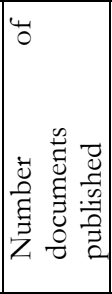 & 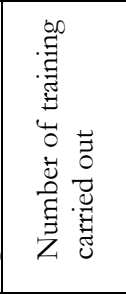 & 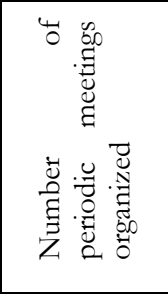 & 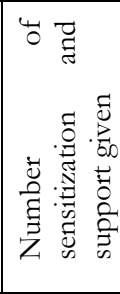 & 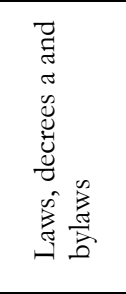 & & 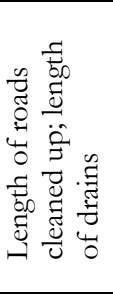 & 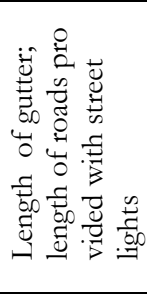 \\
\hline 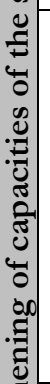 & 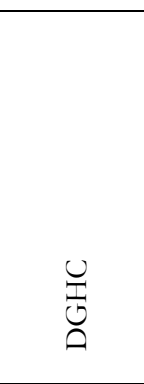 & 岳 & 岳 & 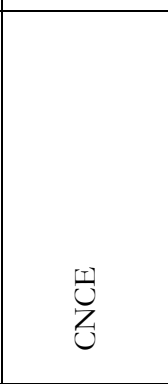 & 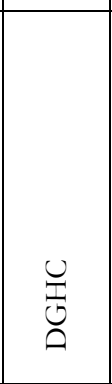 & 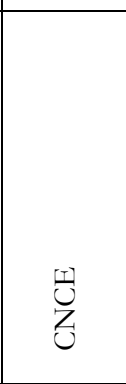 & 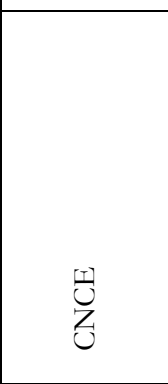 & 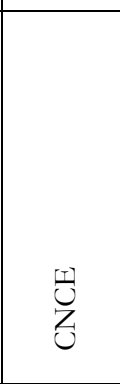 & 赑 & & 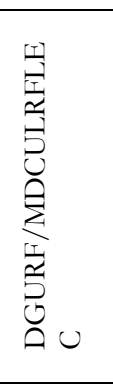 & 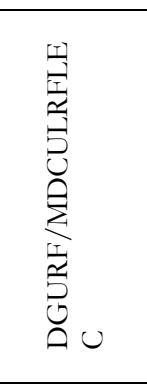 \\
\hline 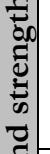 & $x$ & $x$ & $x$ & $x$ & $x$ & $x$ & $x$ & $x$ & $x$ & & ڤ્ণ & ڤ્ণ \\
\hline 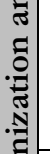 & $x$ & $x$ & $x$ & $x$ & $x$ & $x$ & $x$ & $x$ & $x$ & & $\stackrel{\infty}{\stackrel{\leftrightarrow}{े}}$ & $\stackrel{\infty}{\stackrel{\leftrightarrow}{े}}$ \\
\hline 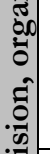 & $x$ & $x$ & $x$ & $x$ & $x$ & $x$ & $x$ & $x$ & $x$ & & ڤ్రి & 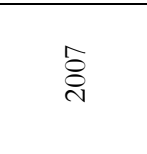 \\
\hline 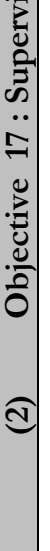 & 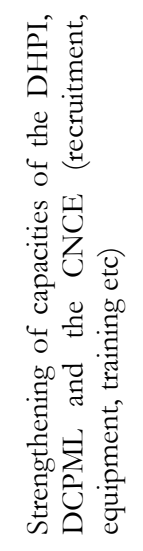 & 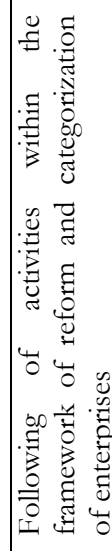 & 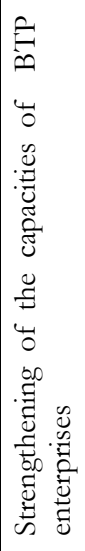 & 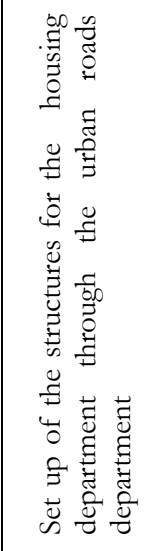 & 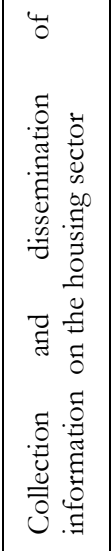 & 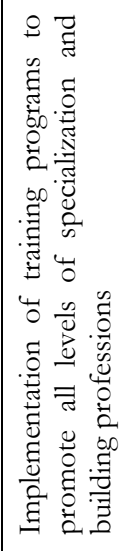 & 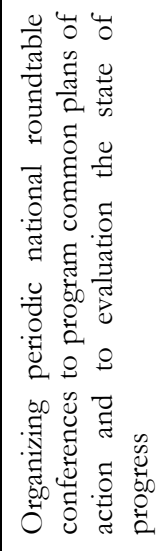 & 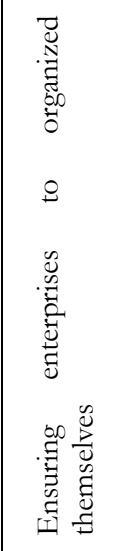 & 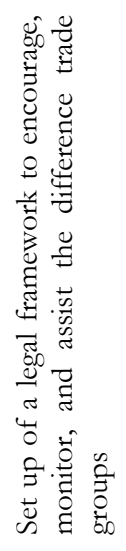 & & 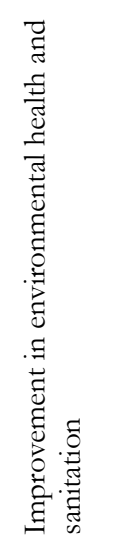 & 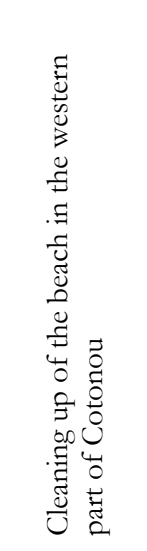 \\
\hline & & & & & & & & & & $\begin{array}{r}\text { IN } \\
\text { NVE } \\
\text { O. }\end{array}$ & 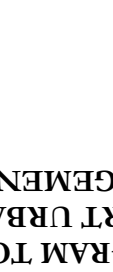 & $\begin{array}{l}\text { VNVW } \\
\text { IOdd } 1 \text { S } \\
\text { goyd }\end{array}$ \\
\hline
\end{tabular}




\begin{tabular}{|c|c|c|c|c|c|c|c|c|c|c|}
\hline 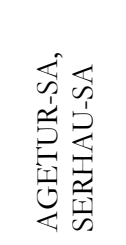 & 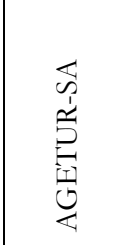 & 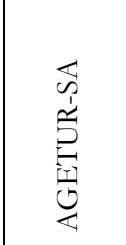 & 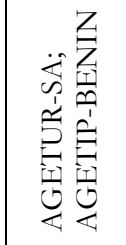 & 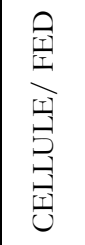 & 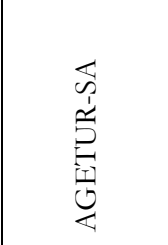 & & & & & \\
\hline 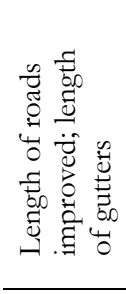 & 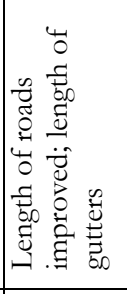 & 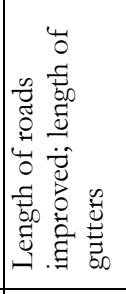 & 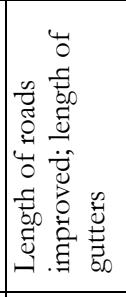 & 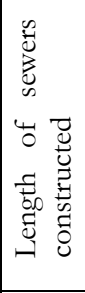 & 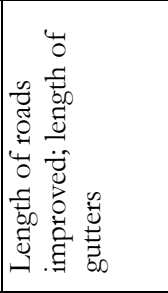 & 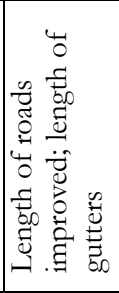 & 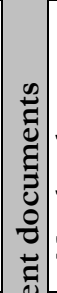 & 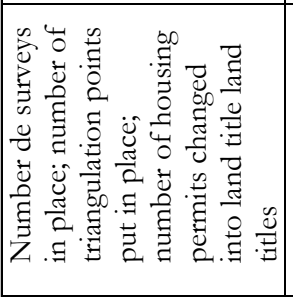 & 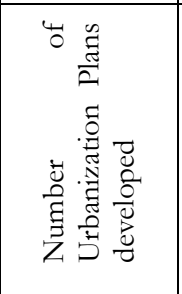 & 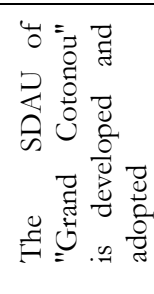 \\
\hline 㖫 & 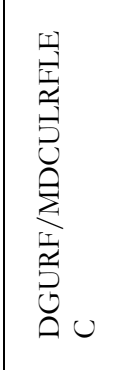 & 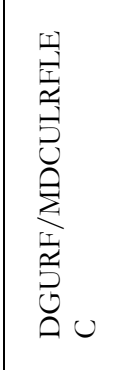 & 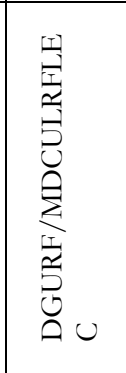 & 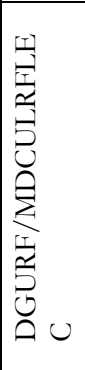 & 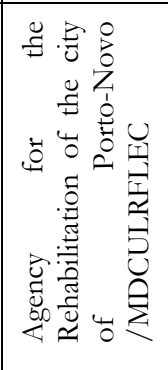 & 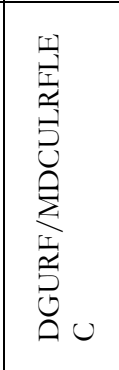 & 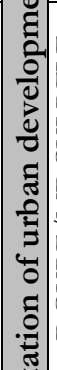 & 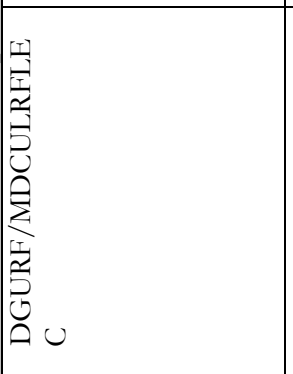 & 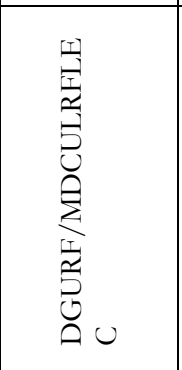 & 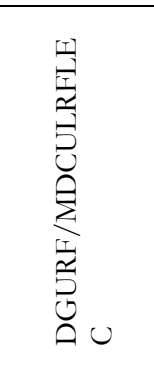 \\
\hline \&્ઠ & & & & ڤ్రి & ఫ્సે & ڤ్రి & 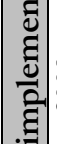 & ڤิे & ङ્ڤે & ఫ్రి \\
\hline$\stackrel{\infty}{\stackrel{\leftrightarrow}{े}}$ & 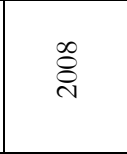 & $\begin{array}{l}\infty \\
\stackrel{\sim}{\circ}\end{array}$ & 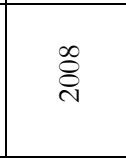 & 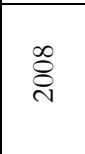 & $\stackrel{\infty}{\stackrel{\sim}{~}}$ & $\begin{array}{l}\infty \\
\stackrel{\sim}{े}\end{array}$ & 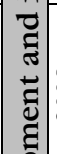 & م & $\begin{array}{l}\infty \\
\stackrel{\sim}{े}\end{array}$ & $\begin{array}{l}\infty \\
\stackrel{\sim}{*}\end{array}$ \\
\hline 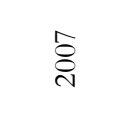 & $\hat{\stackrel{े}{ }}$ & ڤ్̀ి & $\hat{\tilde{d}}$ & $\hat{\tilde{d}}$ & ڤ్̀ి & 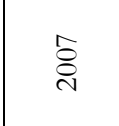 & $\begin{array}{l}0 \\
\frac{0}{0} \\
\grave{0} \\
0\end{array}$ & ¿ิ & ڤ్రి & ڤ్రి \\
\hline 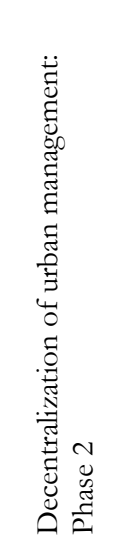 & 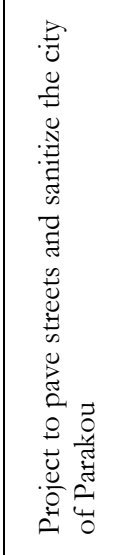 & 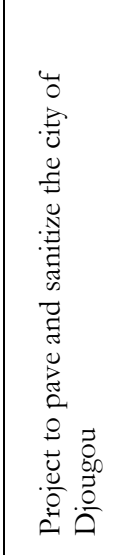 & 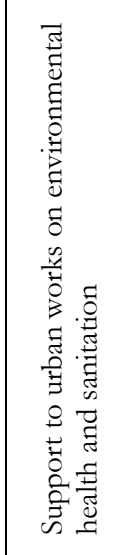 & 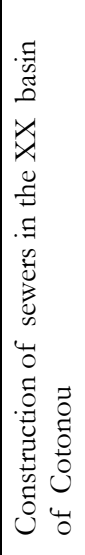 & 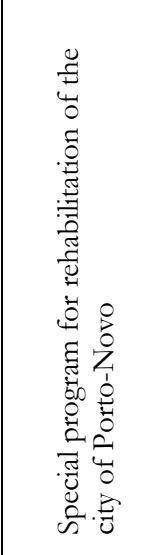 & 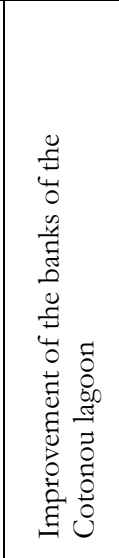 & 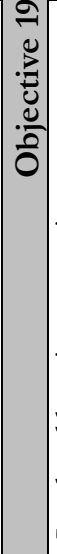 & 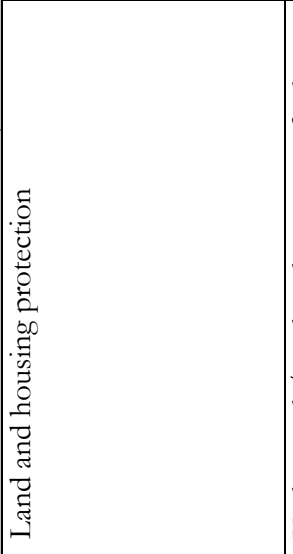 & 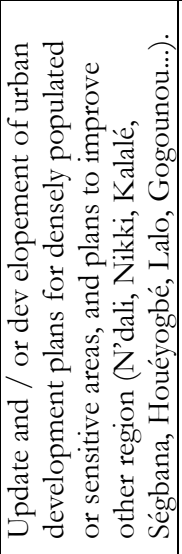 & 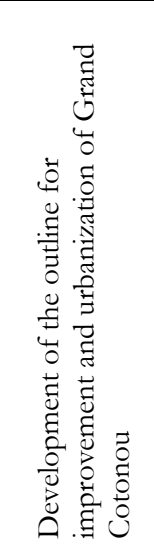 \\
\hline & & & & & & & & & \multicolumn{2}{|c|}{$\begin{array}{l}\text { LNGWHOVNVW } \\
\text { NVG4 LYOdd S } \\
\text { OLL WVYOO\&d }\end{array}$} \\
\hline
\end{tabular}




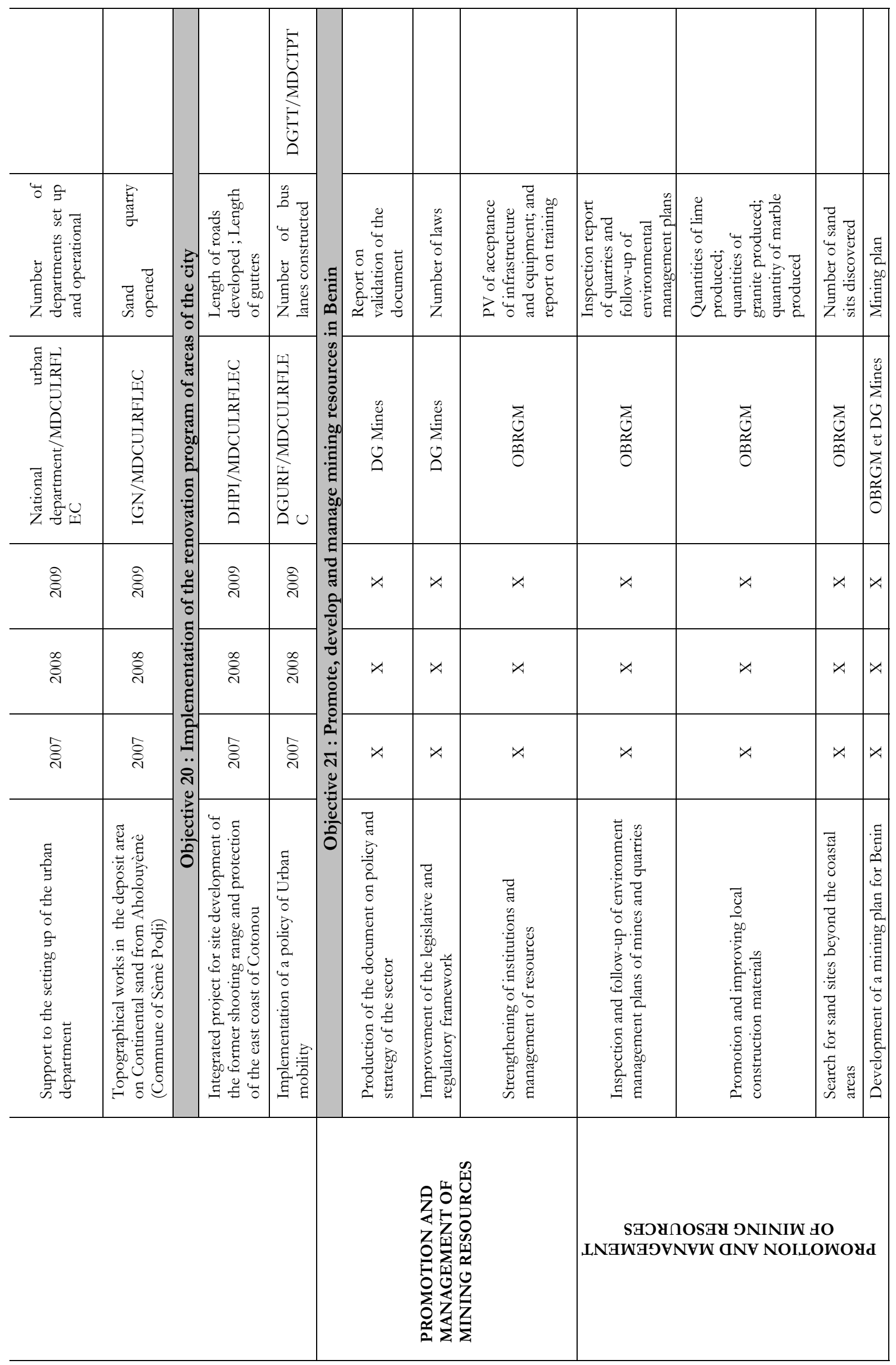




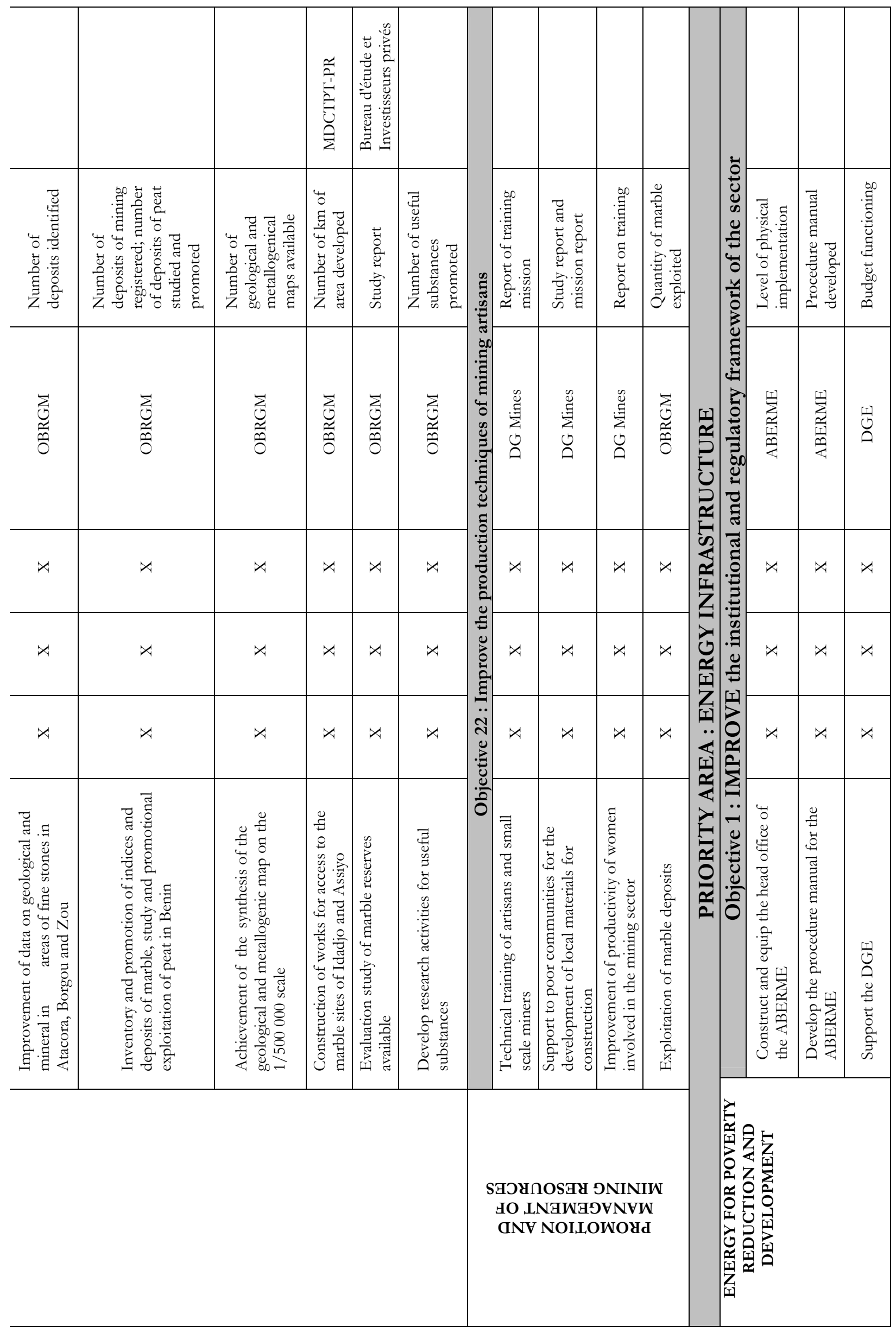




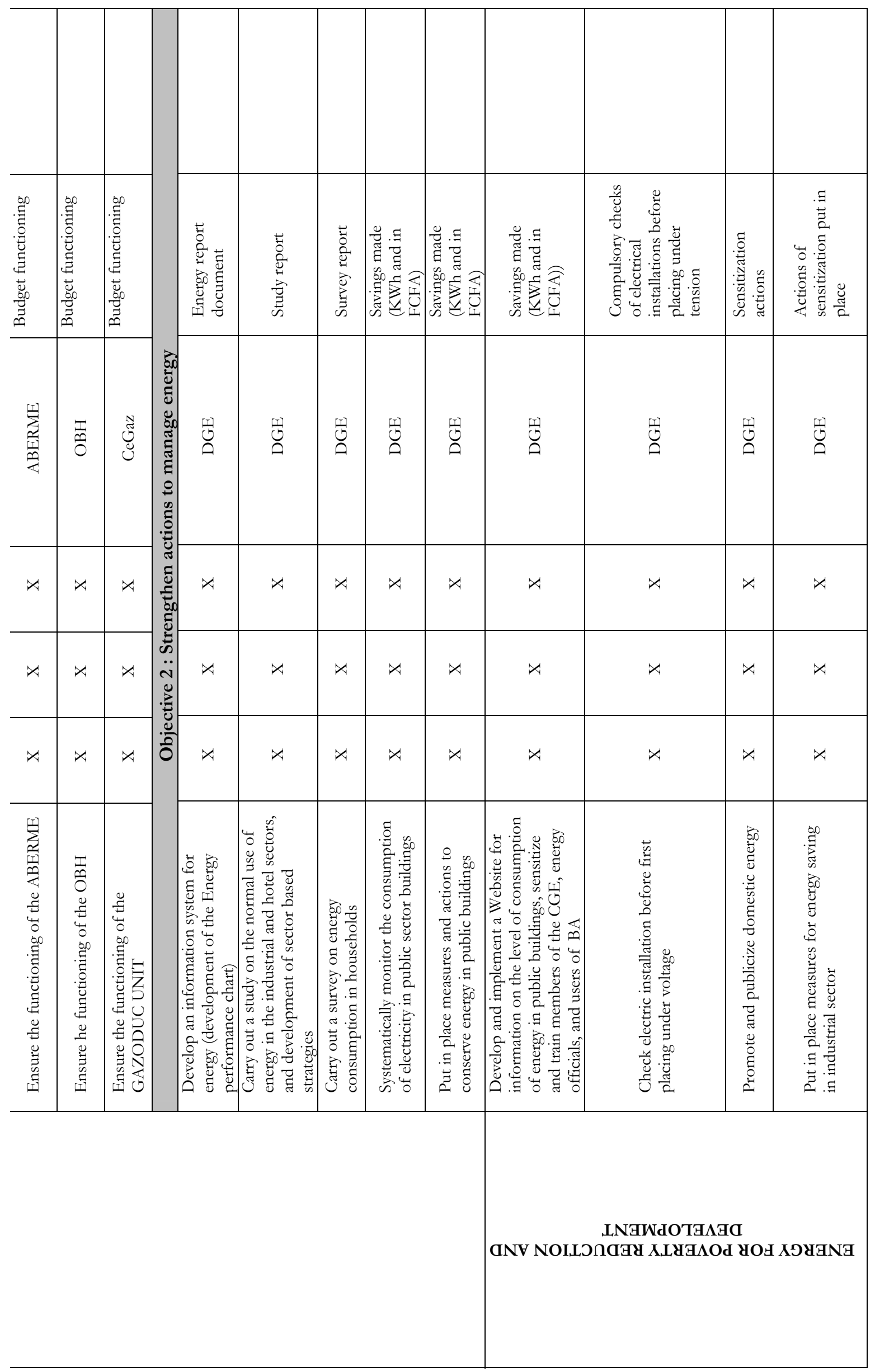




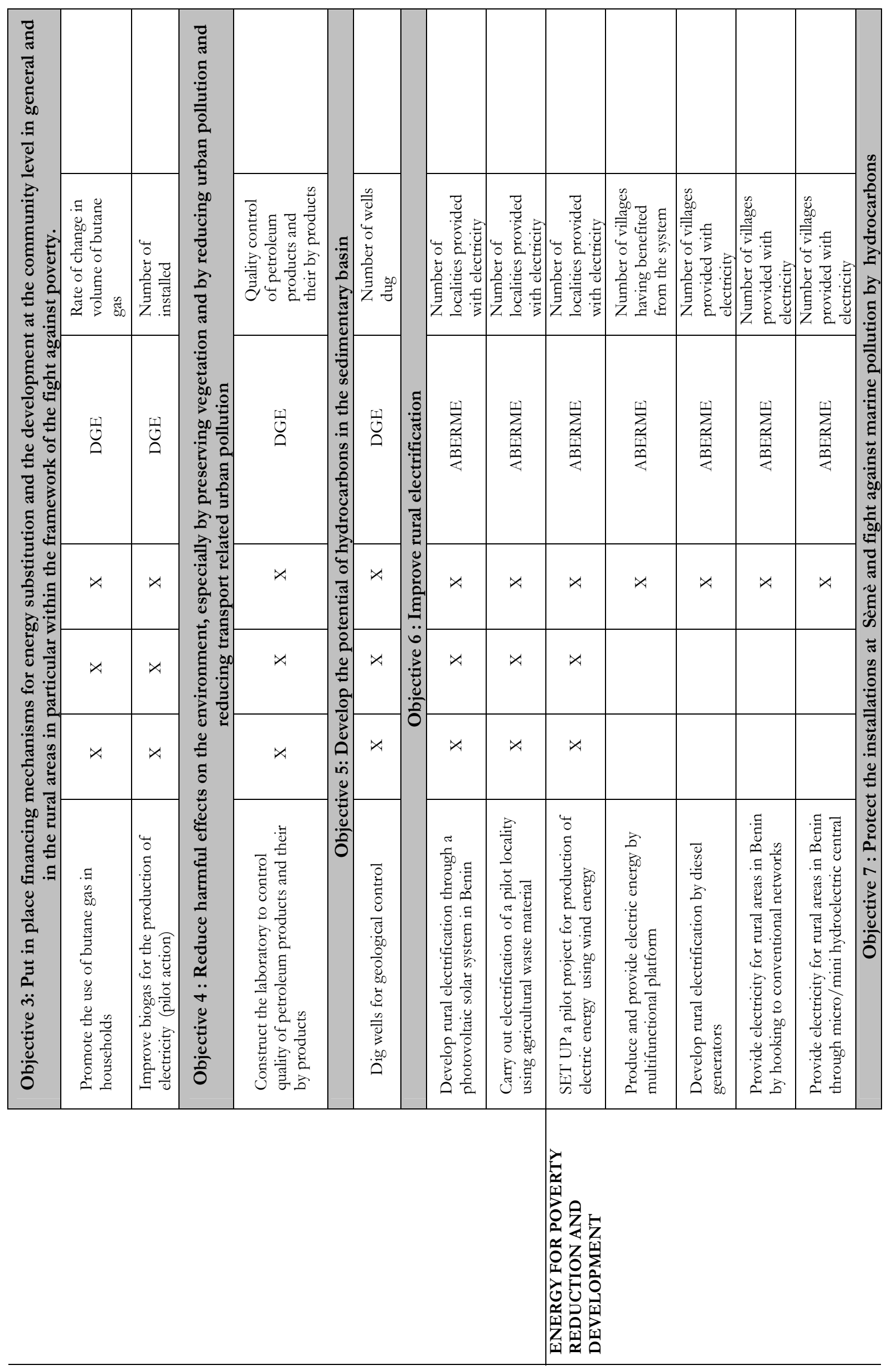




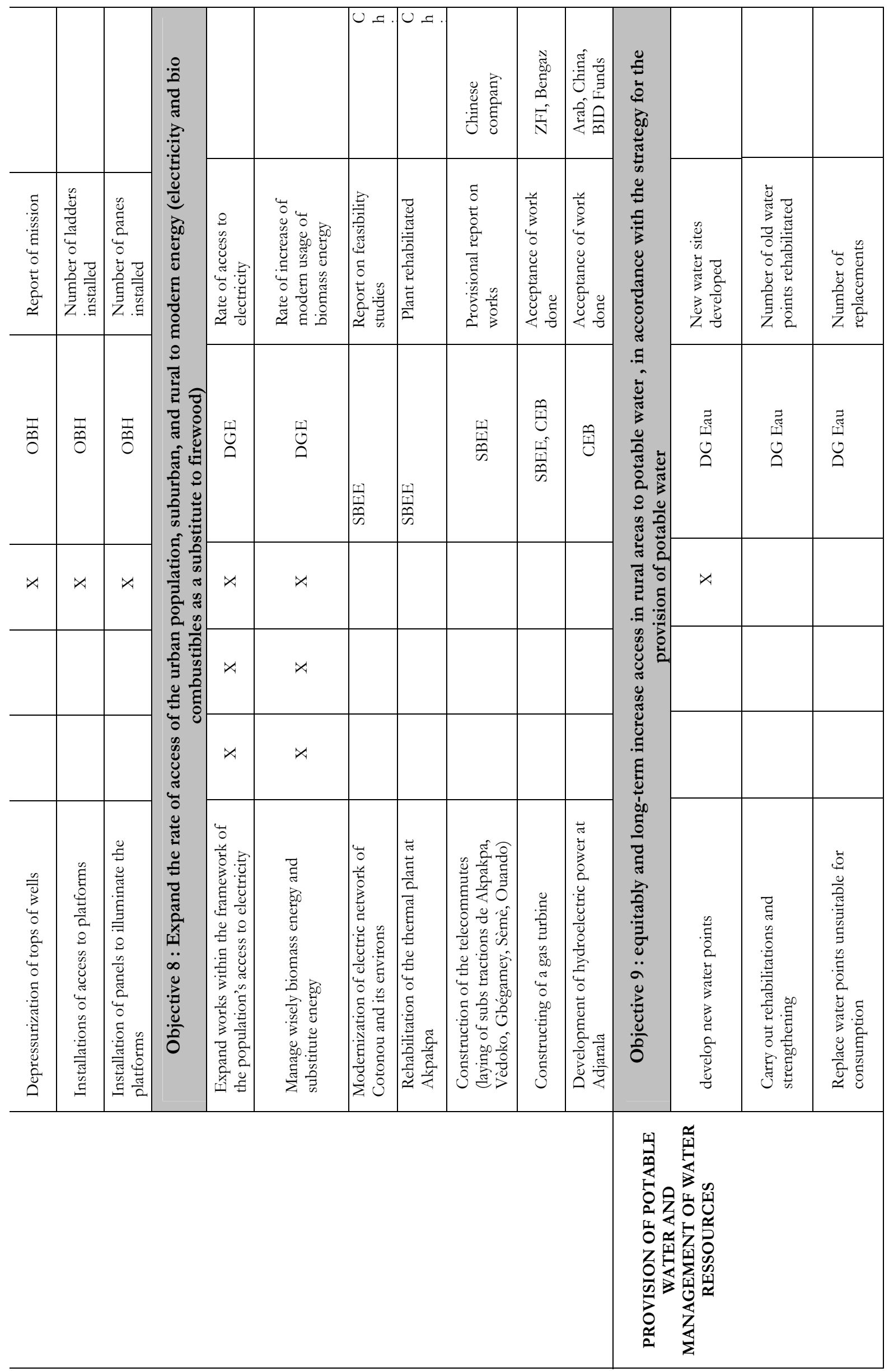




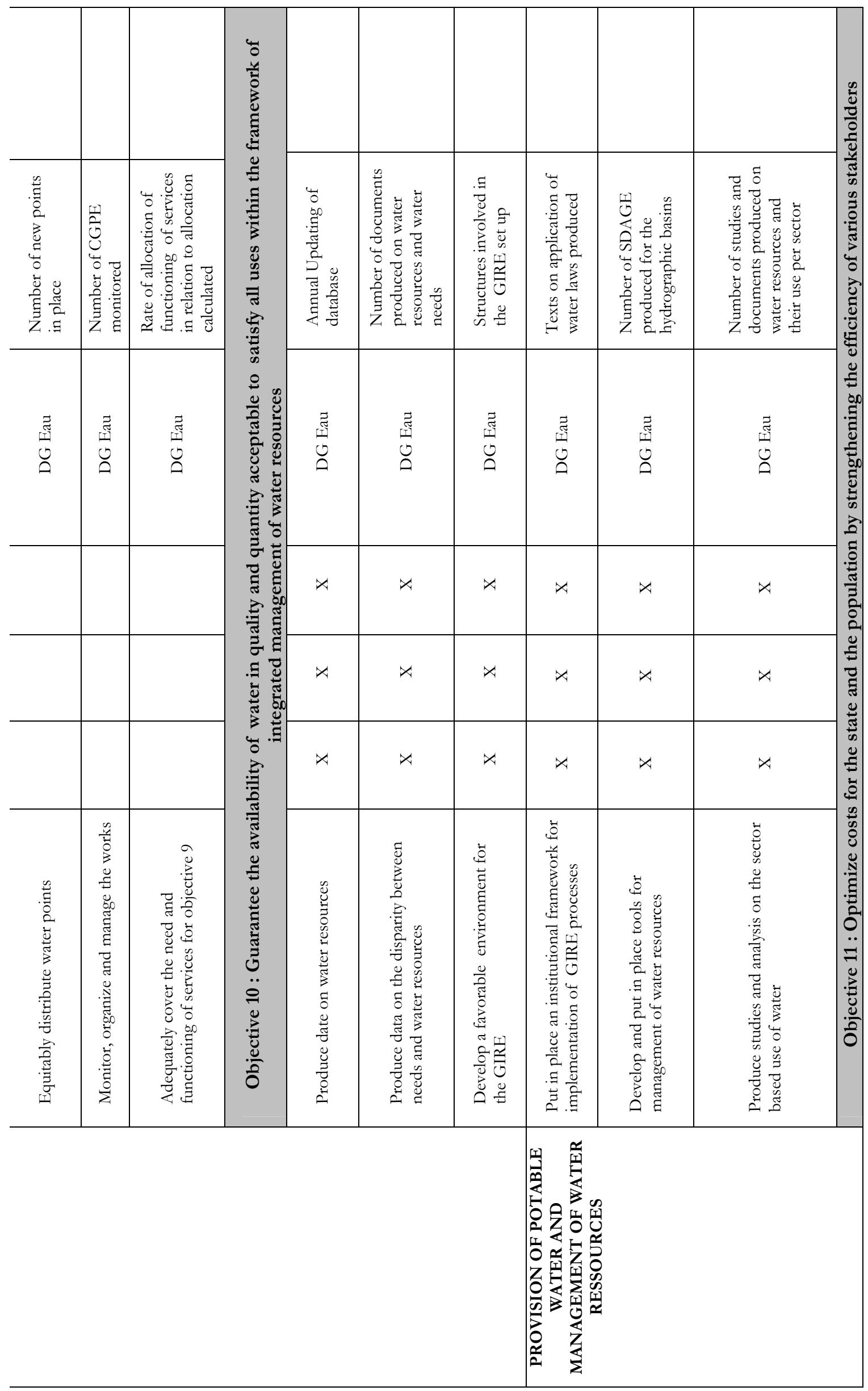




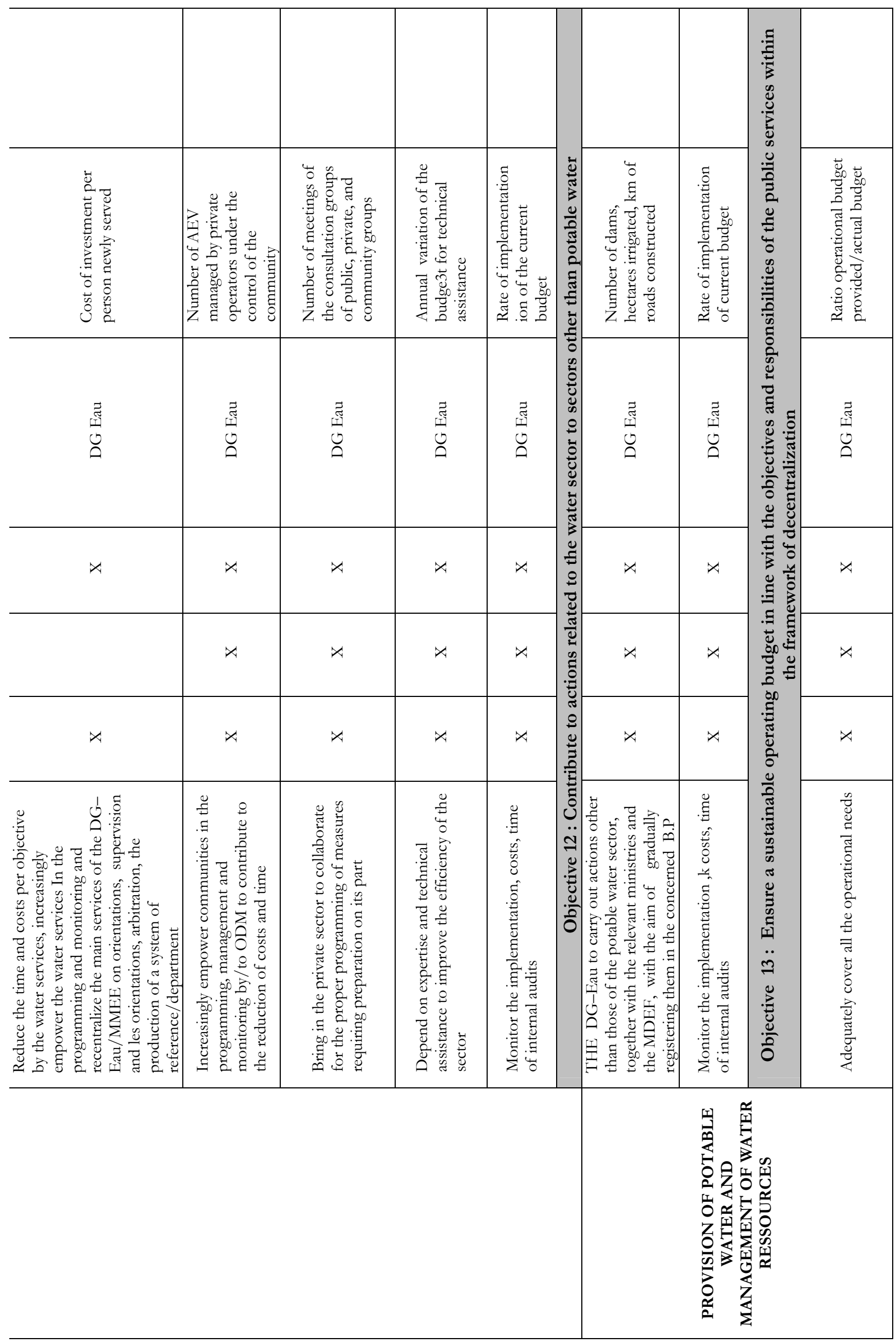




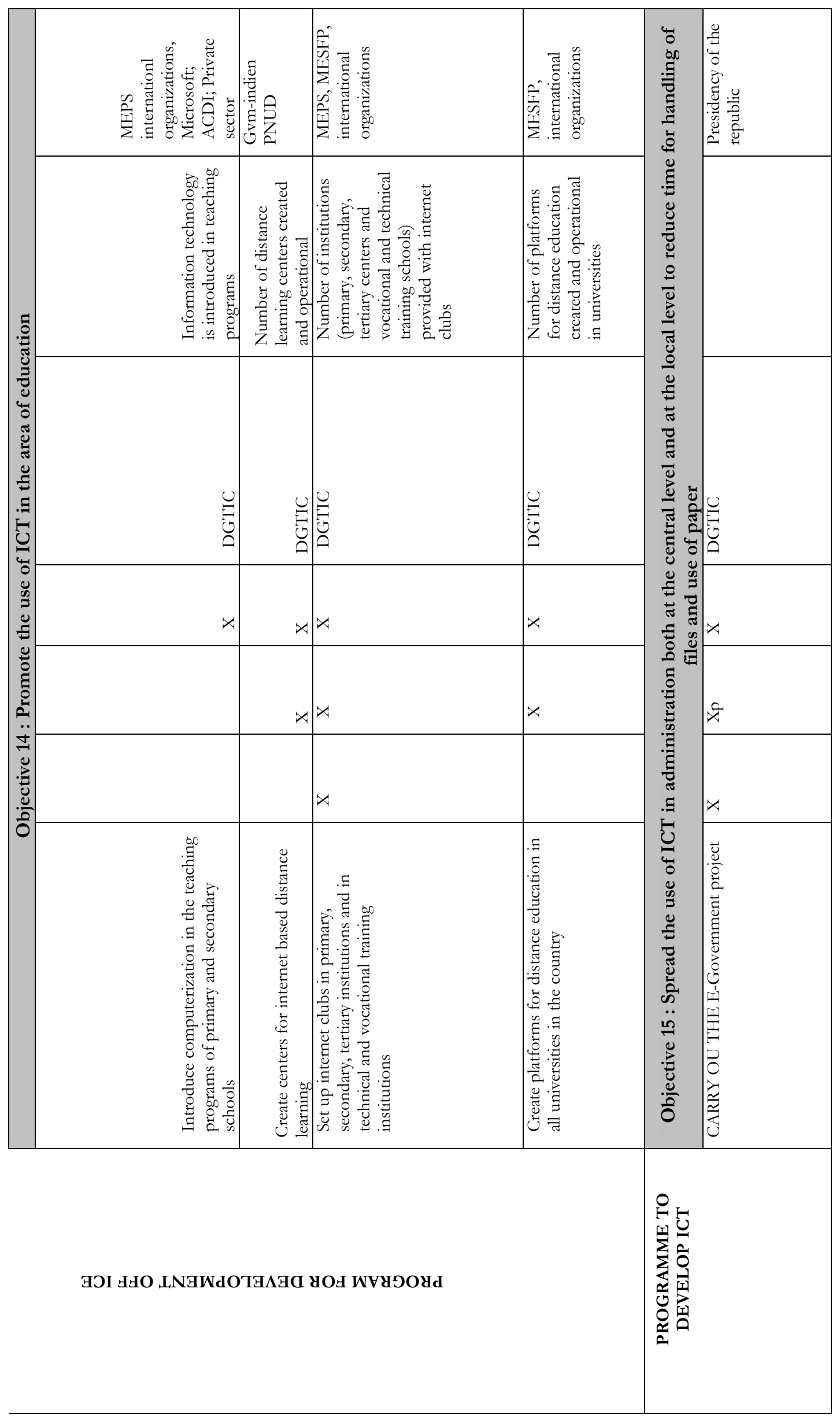




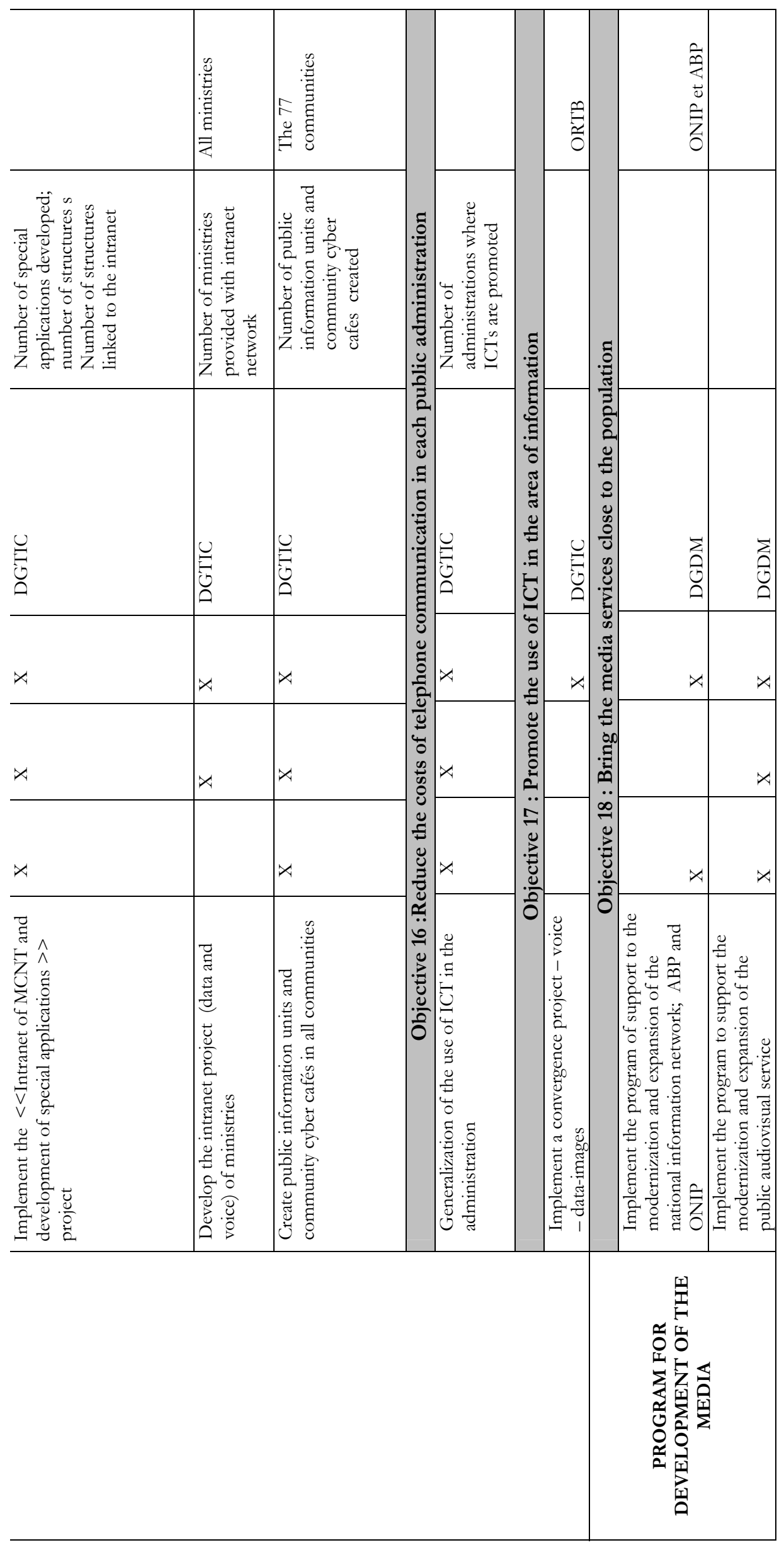




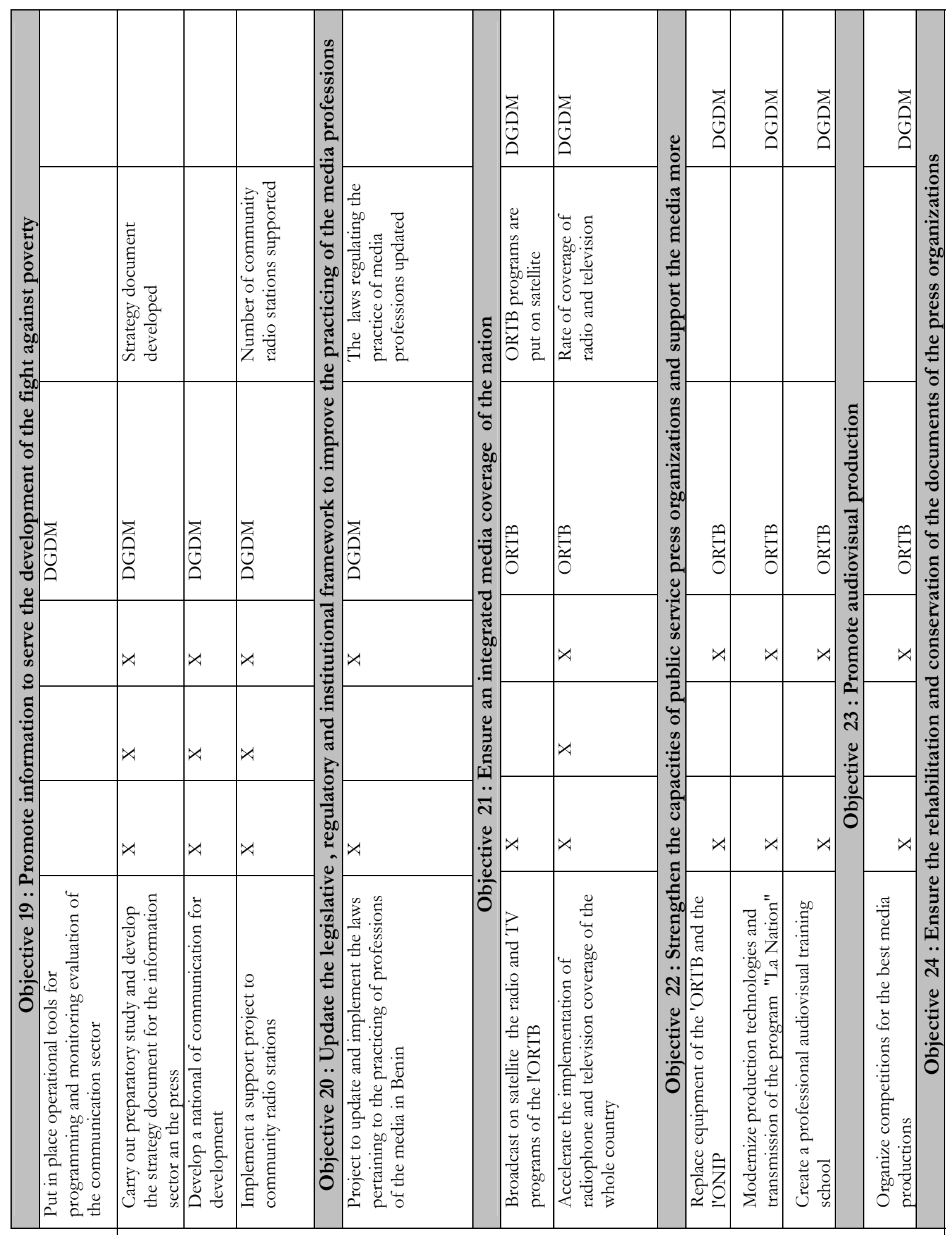




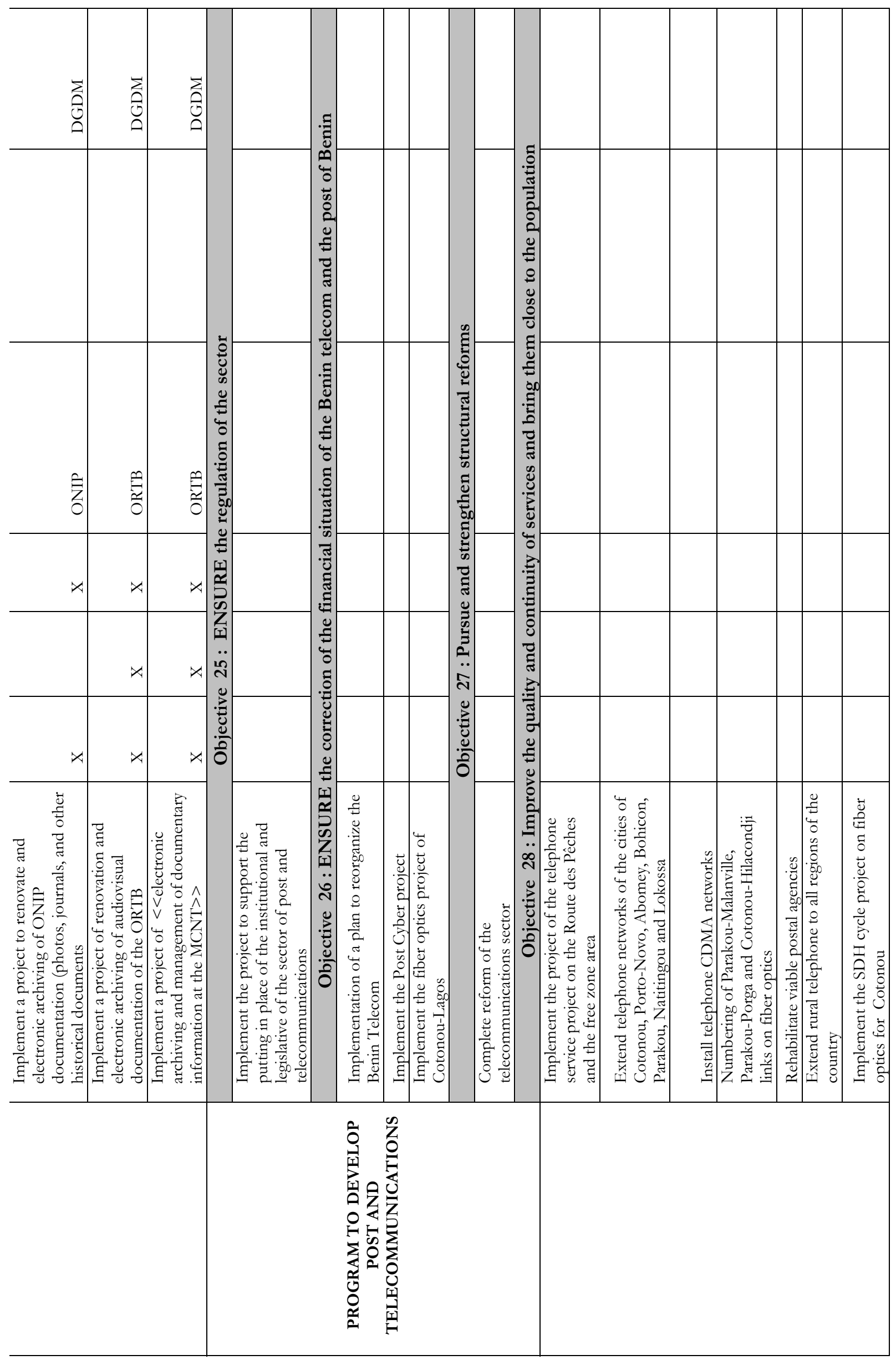




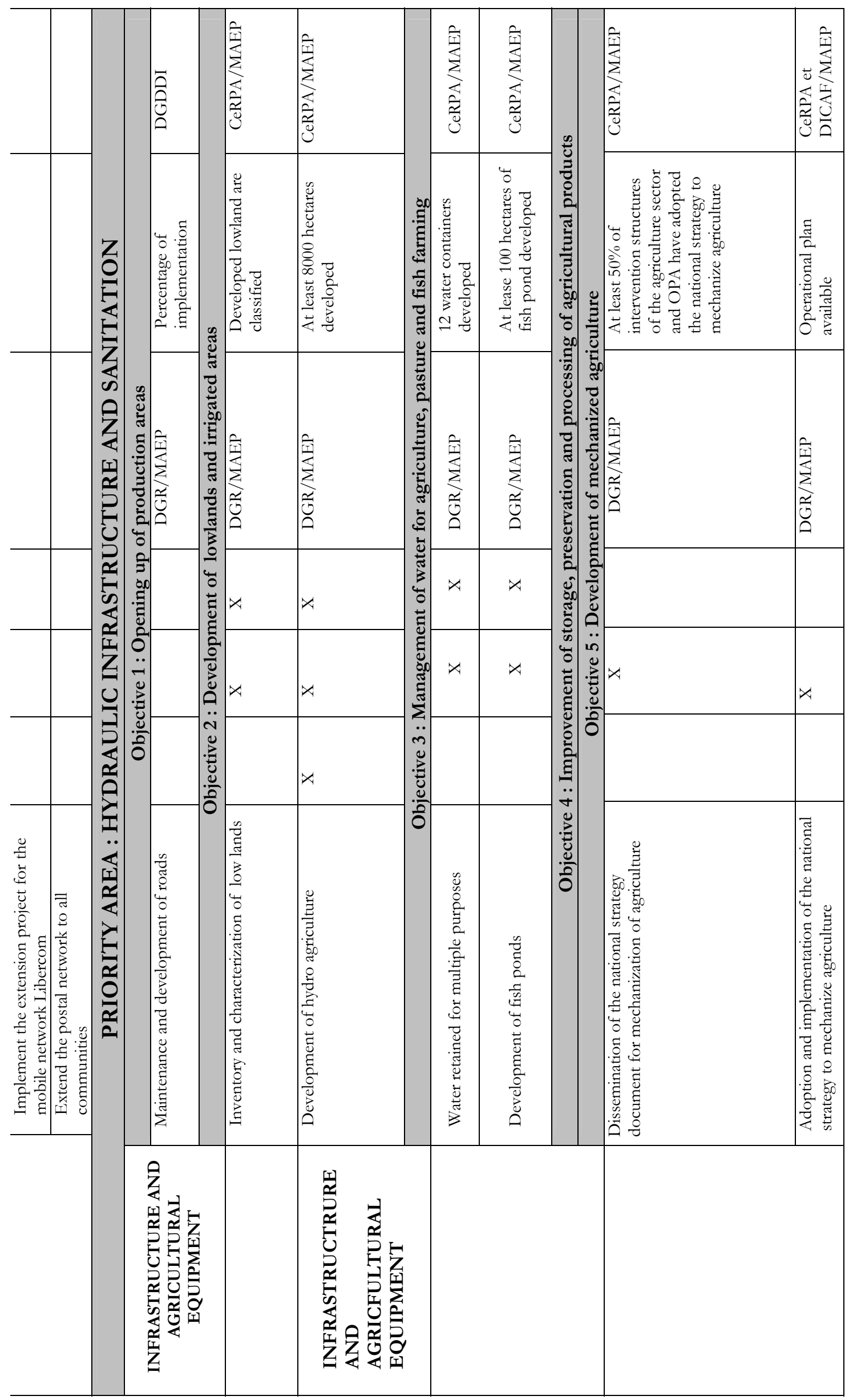



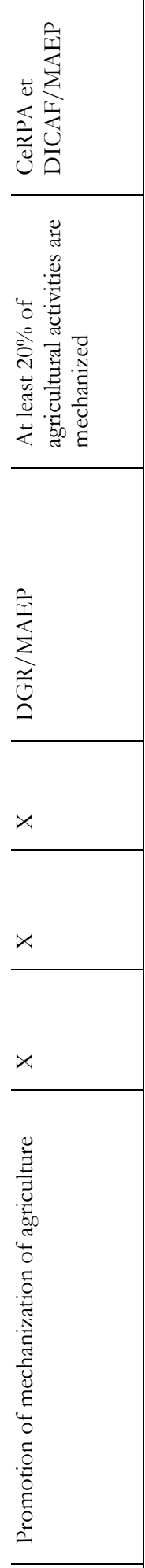


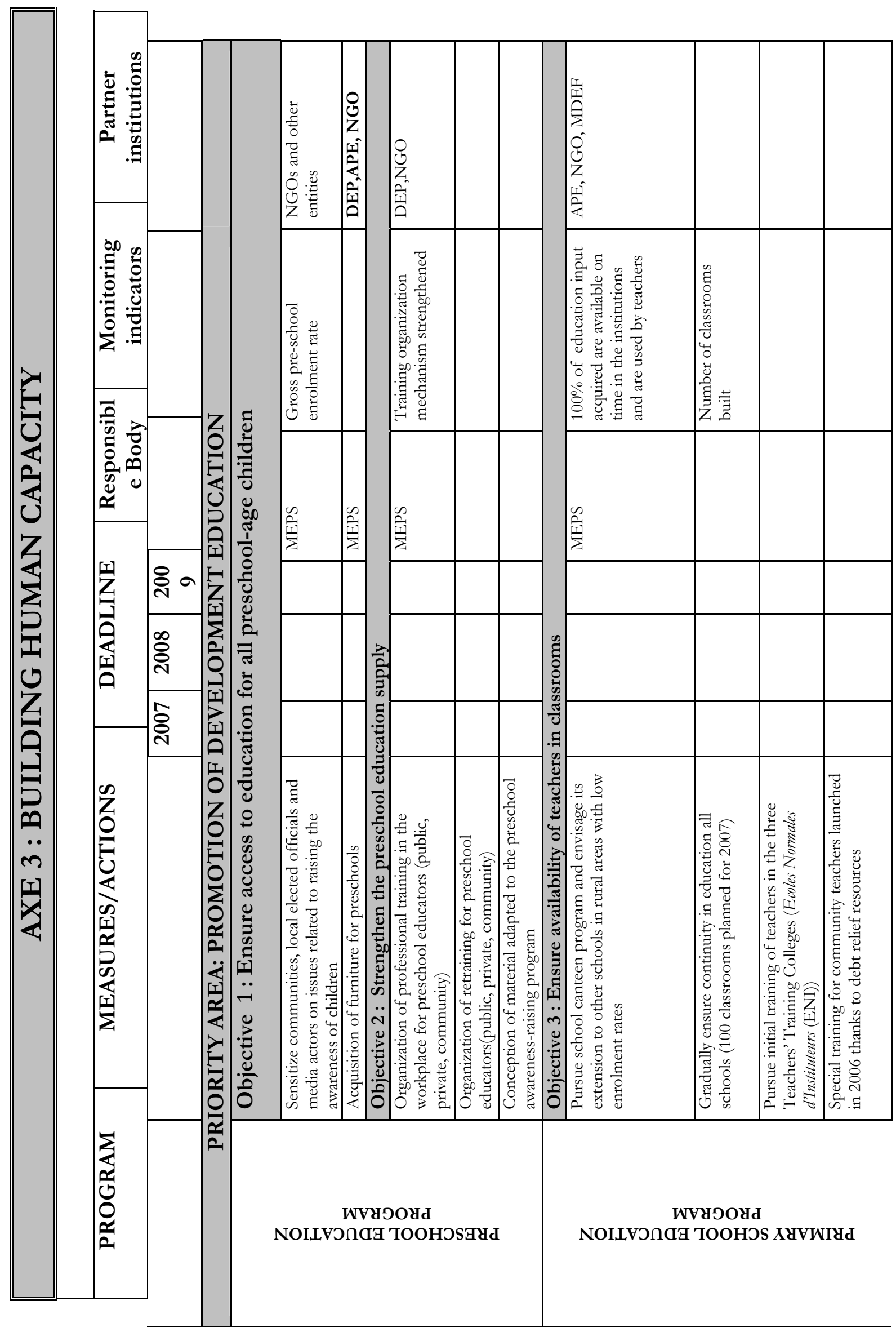




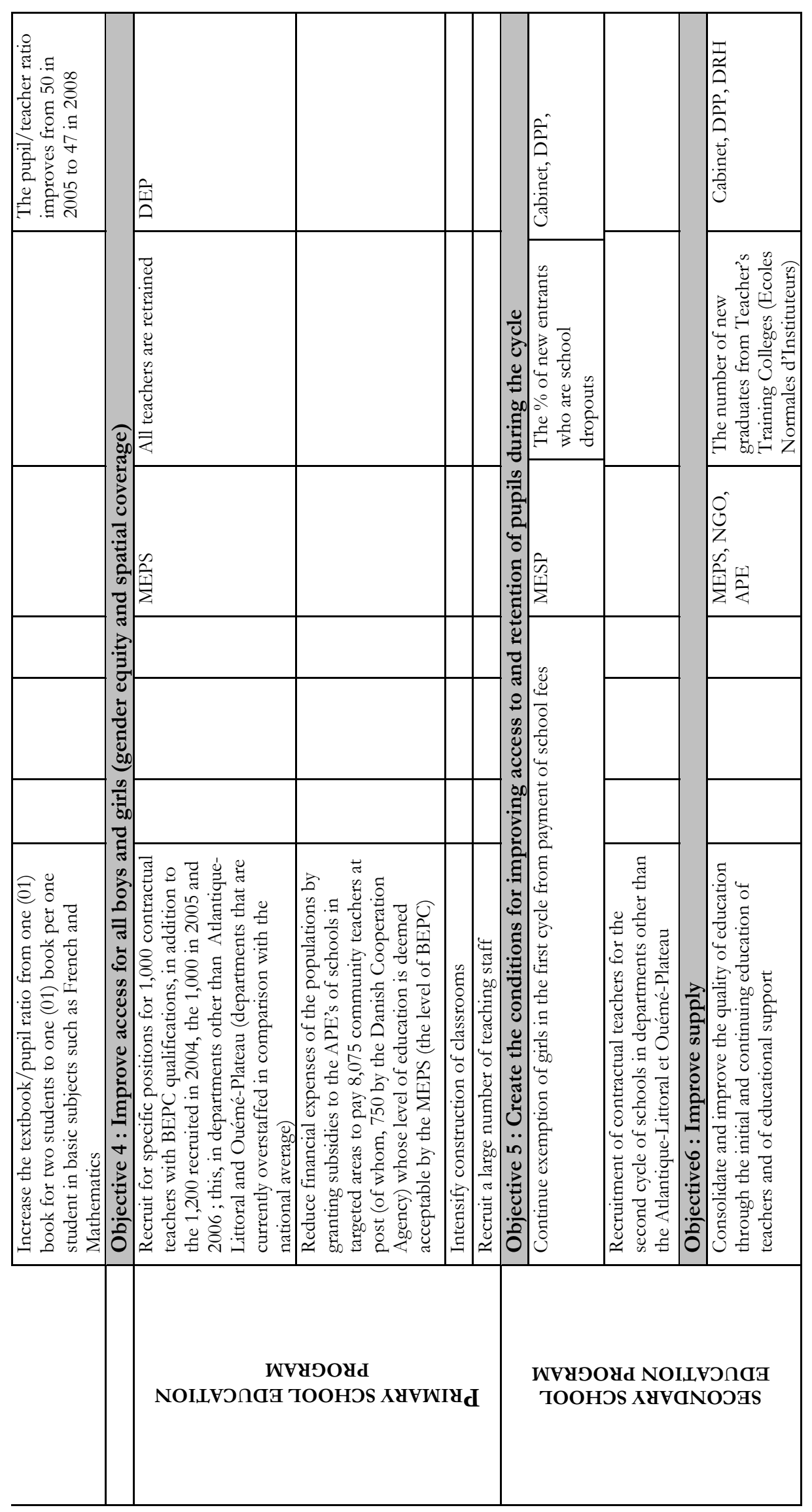




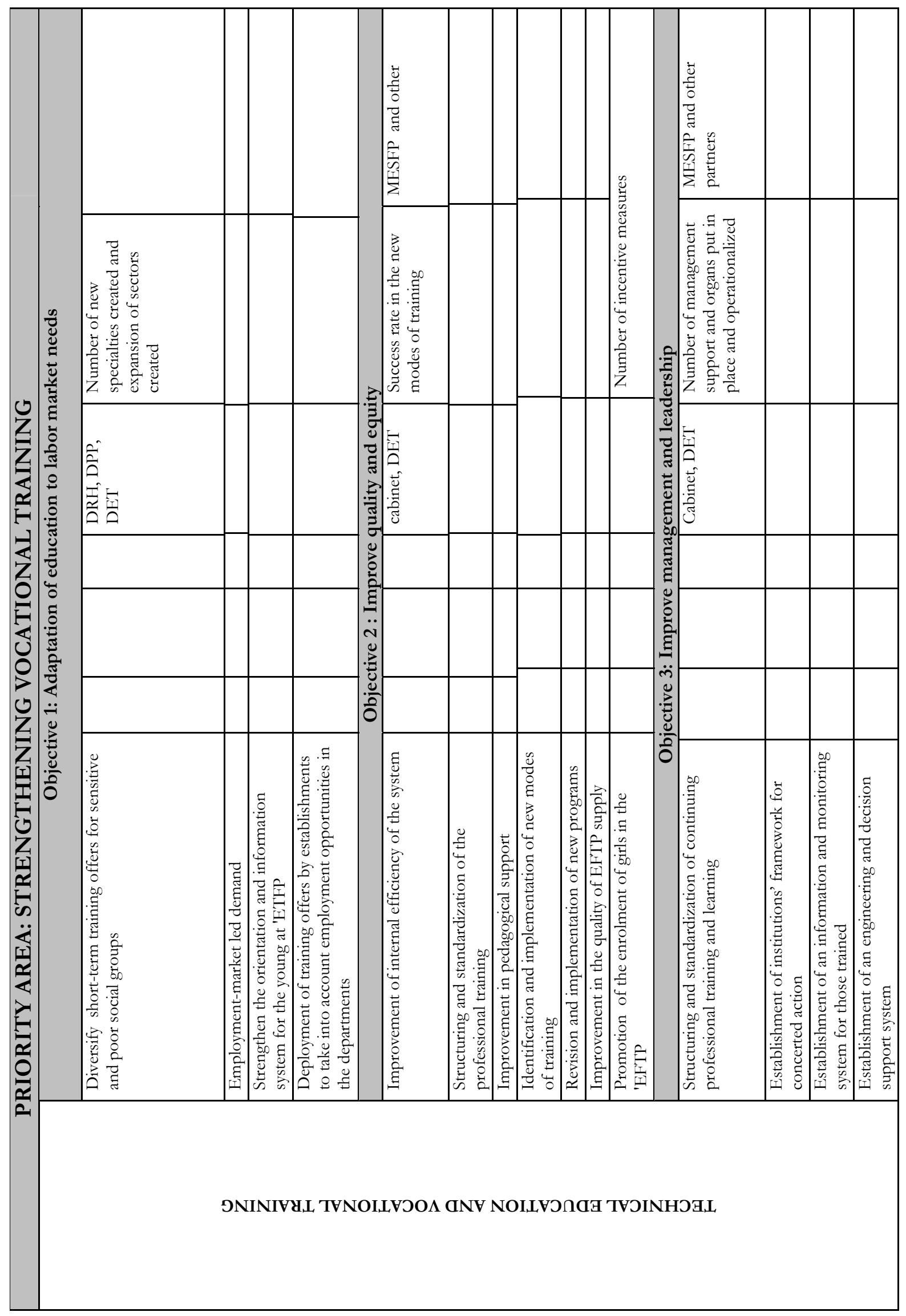




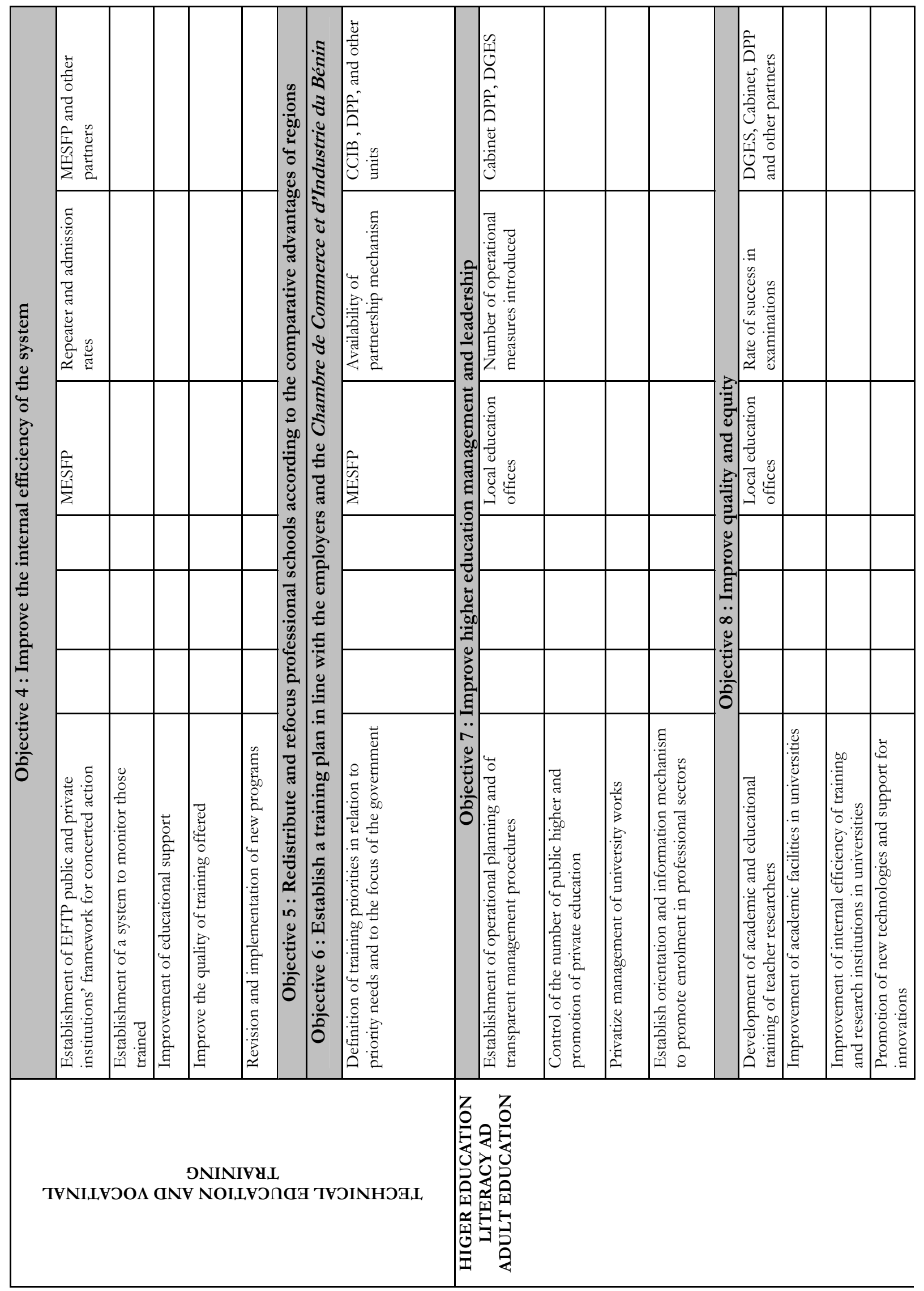




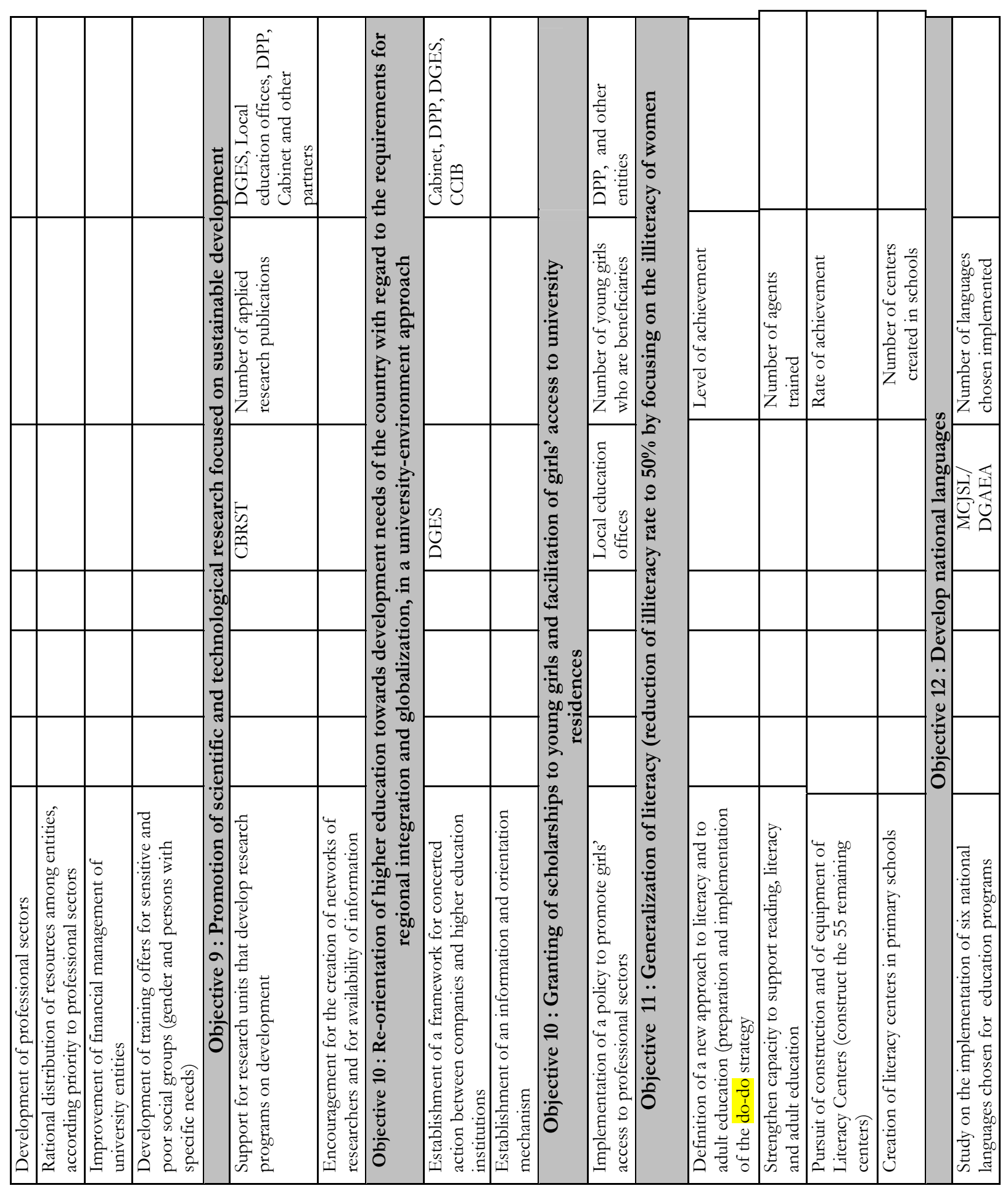




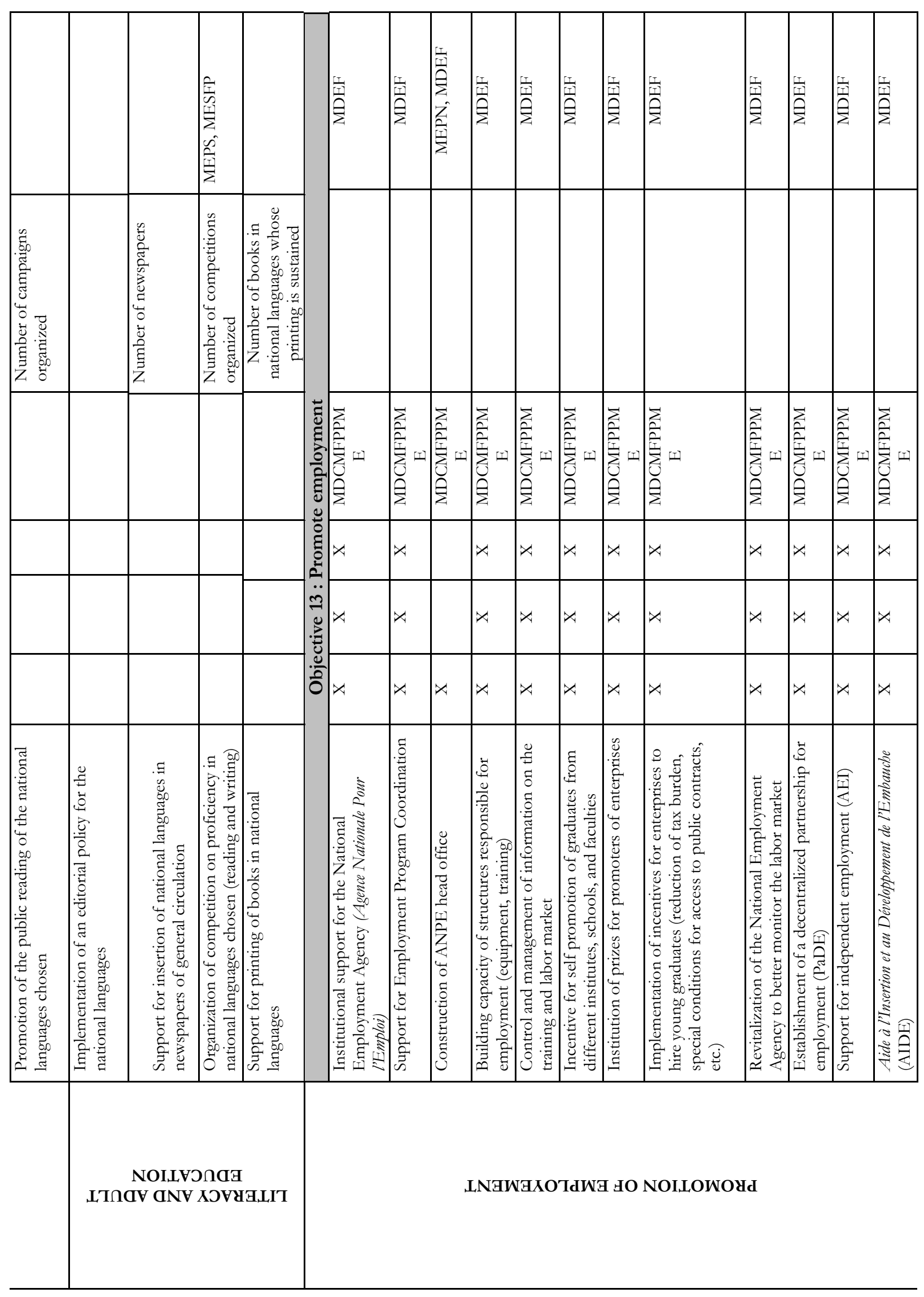




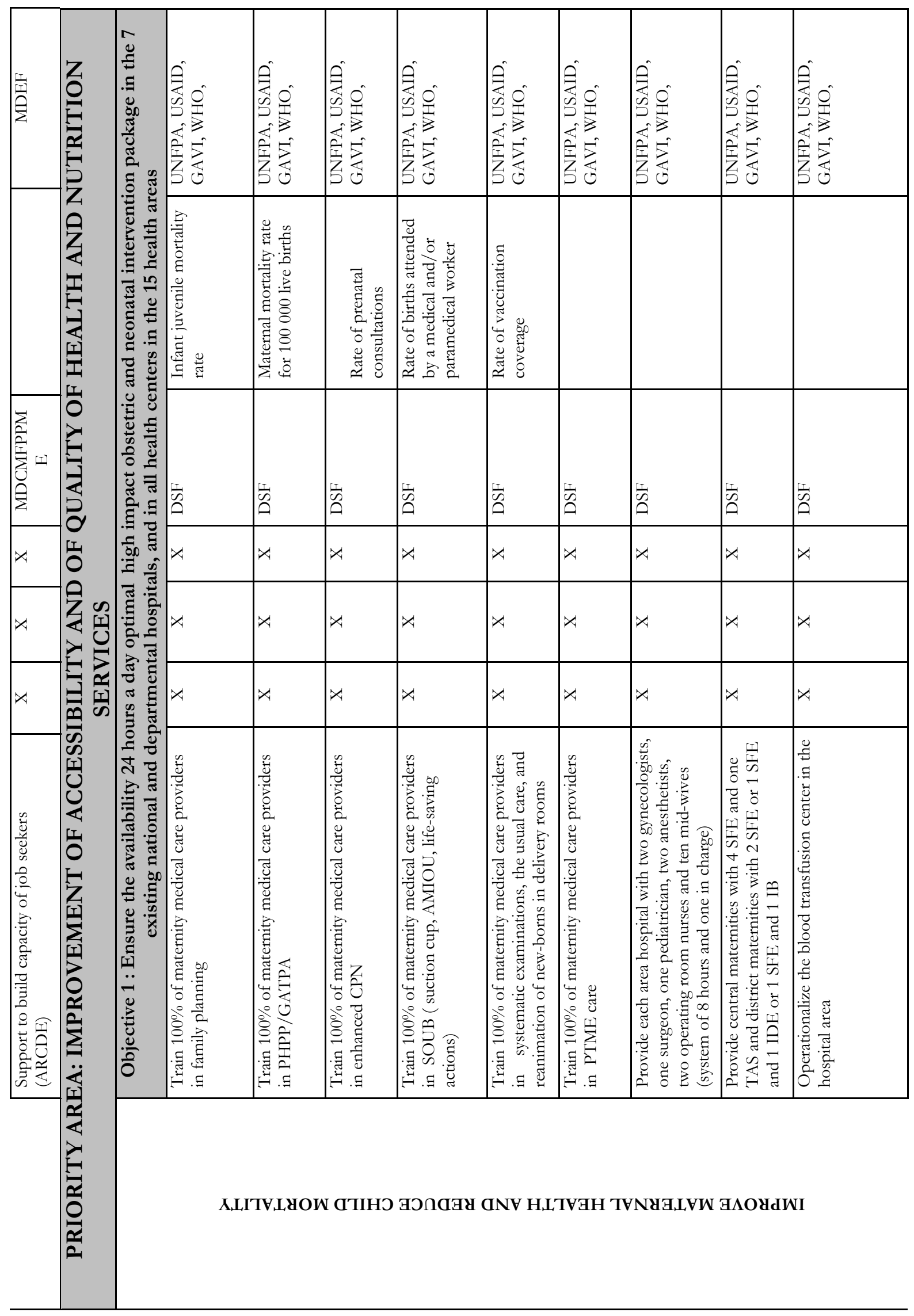




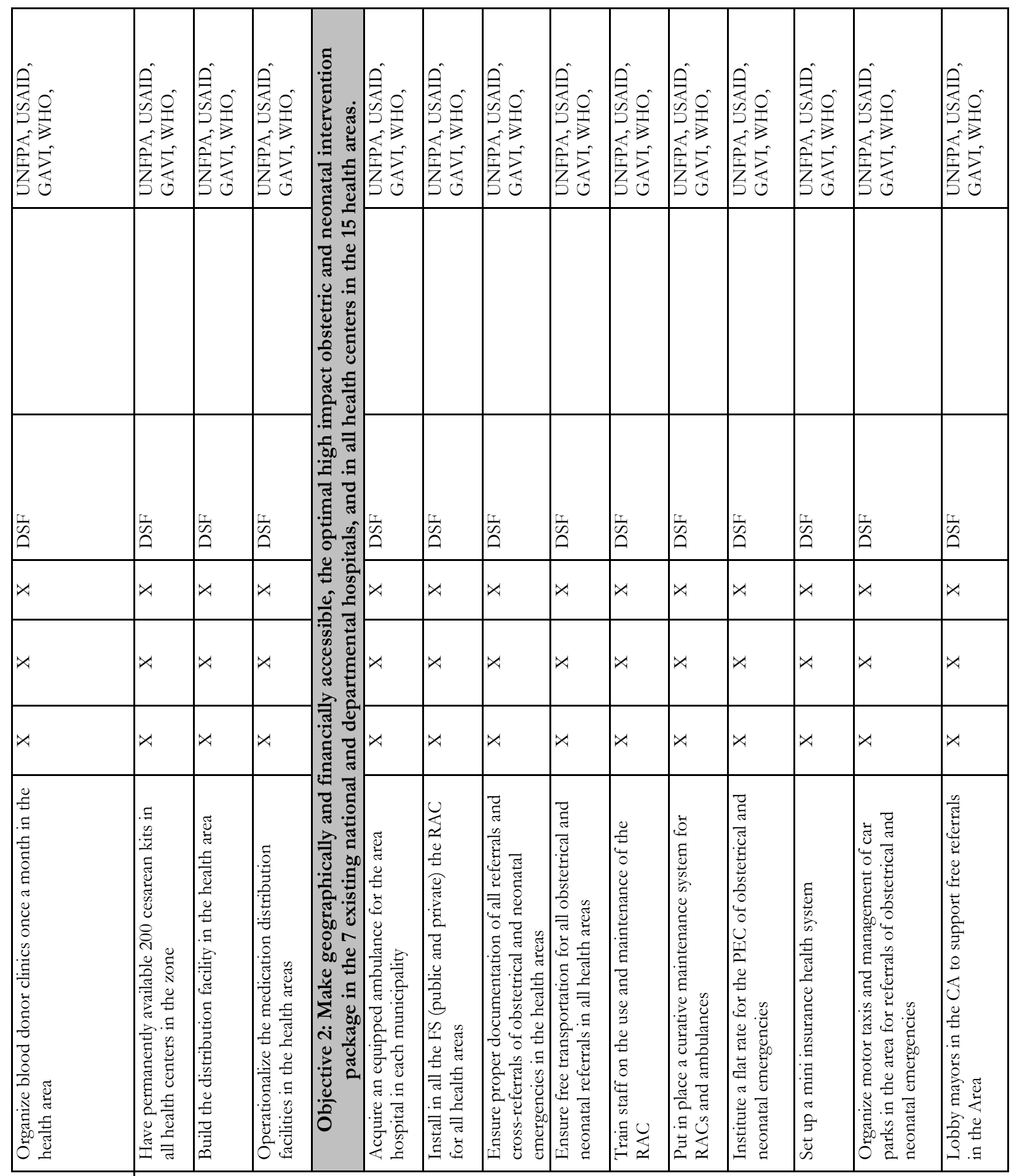




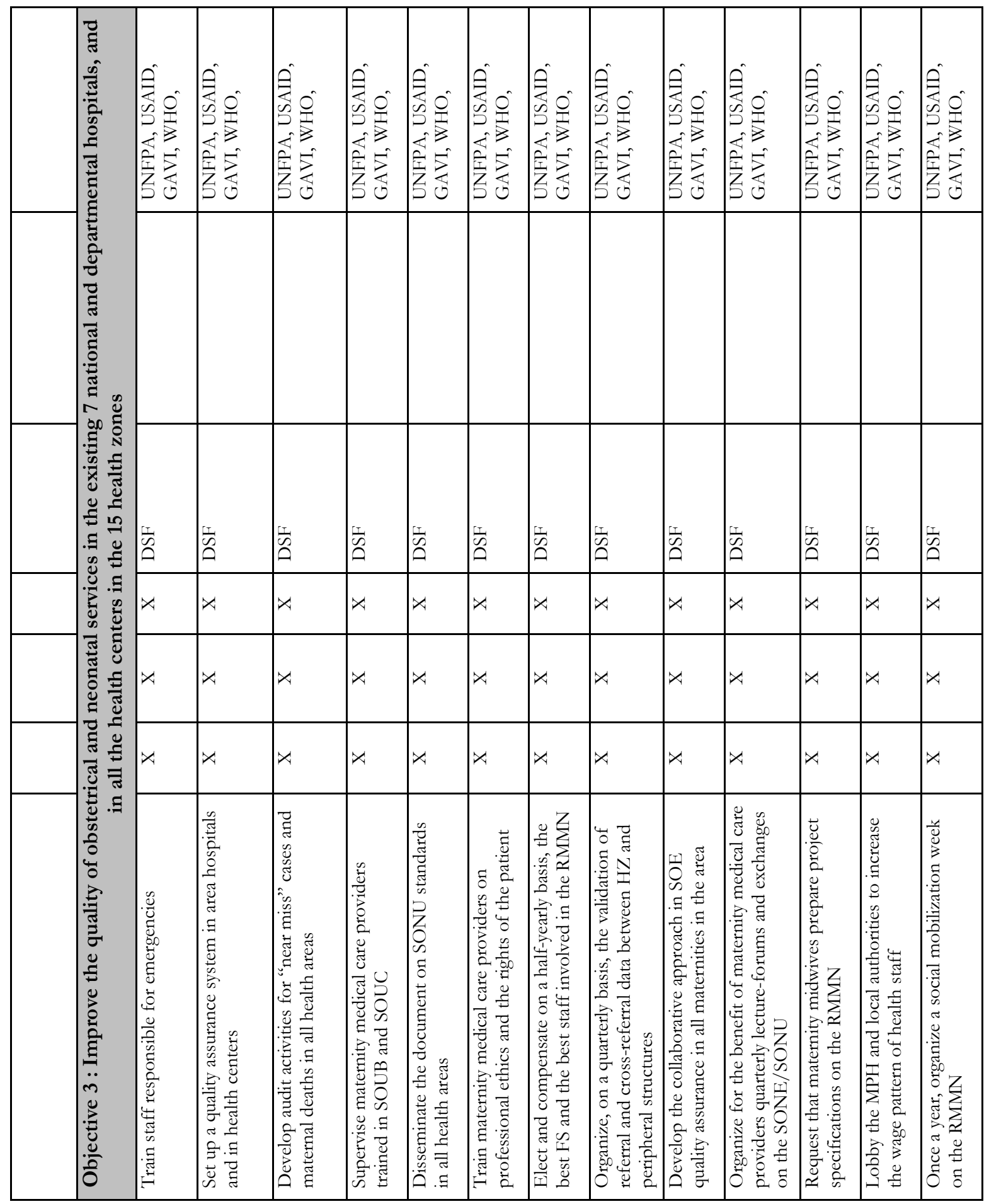




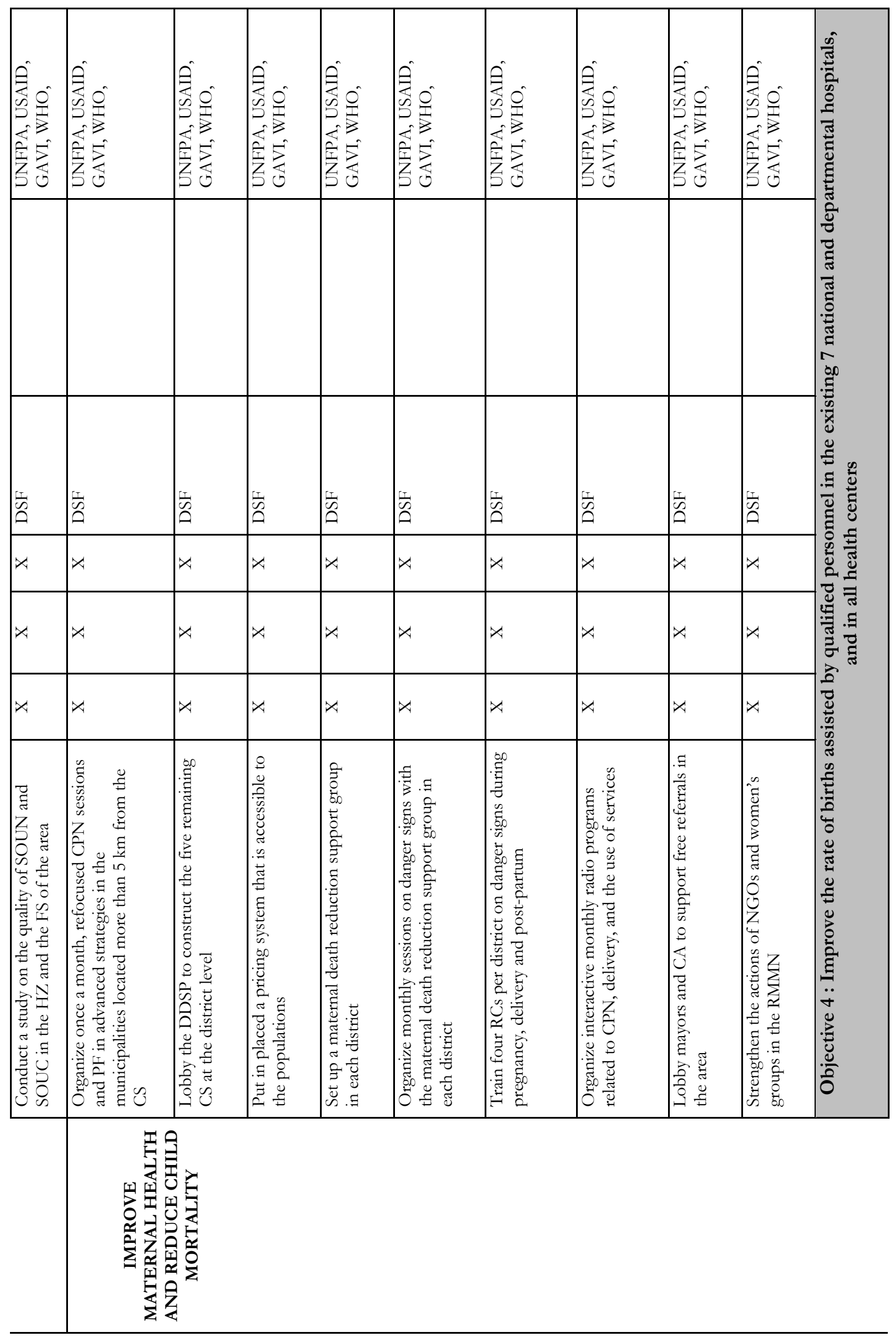




\begin{tabular}{|c|c|c|c|c|c|c|c|c|c|c|}
\hline 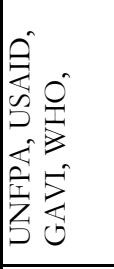 & 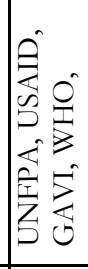 & 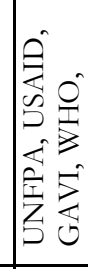 & 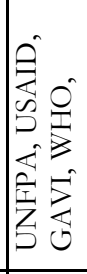 & 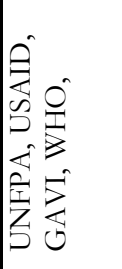 & 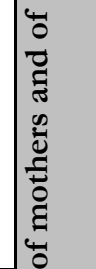 & 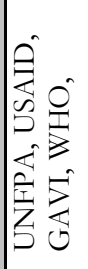 & 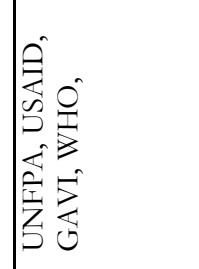 & 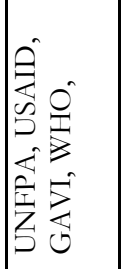 & 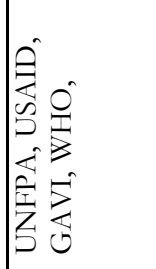 & 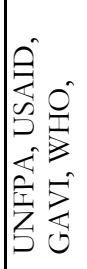 \\
\hline 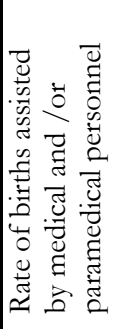 & & & & & 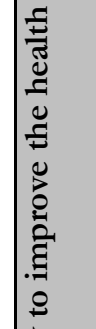 & & 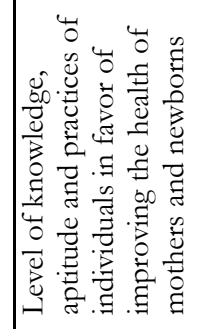 & & & \\
\hline 㟥 & 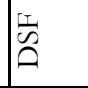 & 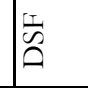 & 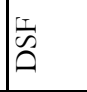 & 㟥 & 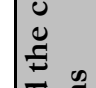 & 㟥 & 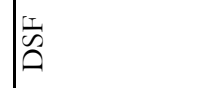 & 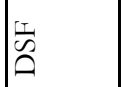 & 㟥 & 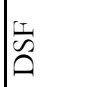 \\
\hline IA & 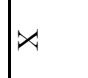 & A & $\nexists$ & $x$ & $\begin{array}{l}5=0 \\
0 \\
s\end{array}$ & $\triangle$ & $x$ & $\not x$ & $\rtimes$ & $x$ \\
\hline$x$ & $\rtimes$ & A & 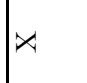 & $x$ & 焉 & $\rtimes$ & $\star A$ & $x$ & $\rtimes$ & $x$ \\
\hline$\rtimes$ & $x$ & $x$ & 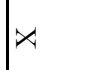 & $\not A$ & 站 & $\rtimes$ & $\rtimes$ & $x$ & $\nexists$ & $\rtimes$ \\
\hline 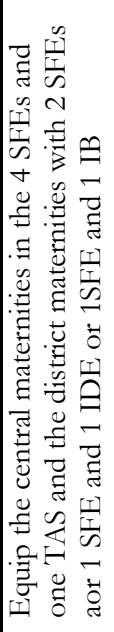 & 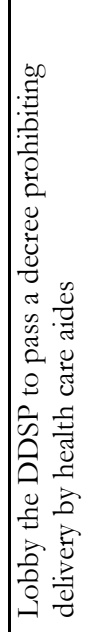 & 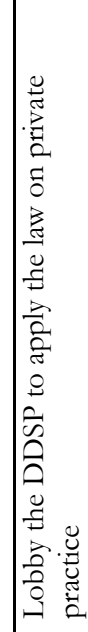 & 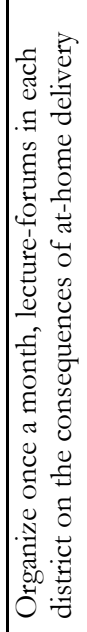 & 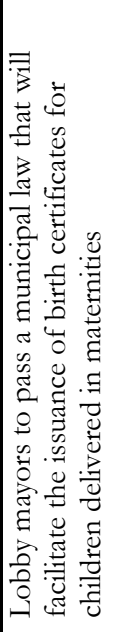 & 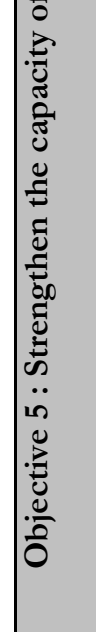 & 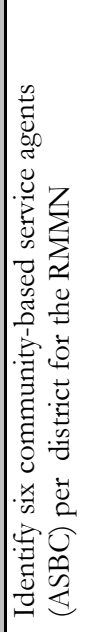 & 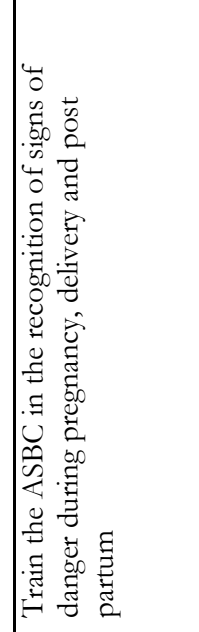 & 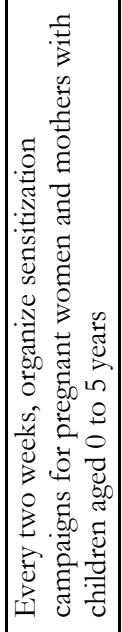 & 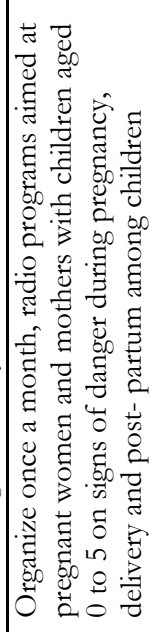 & 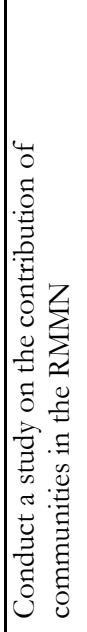 \\
\hline
\end{tabular}




\begin{tabular}{|c|c|c|c|c|c|c|c|c|c|c|c|c|}
\hline 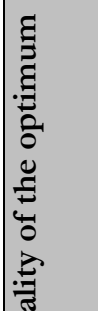 & 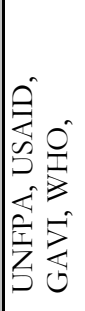 & 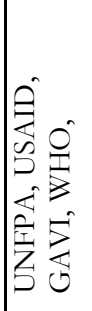 & 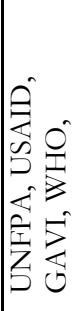 & 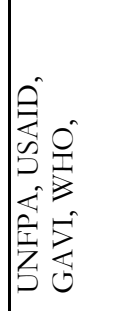 & 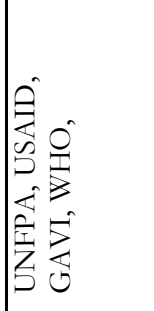 & 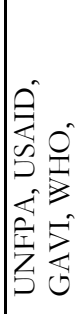 & 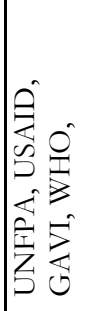 & 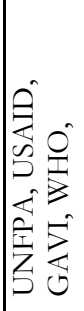 & 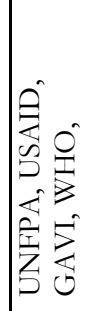 & 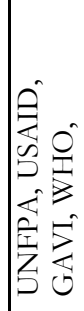 & 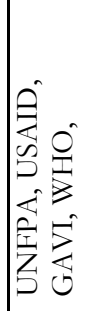 & 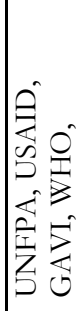 \\
\hline 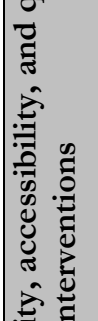 & & & & & & & & & & & & \\
\hline 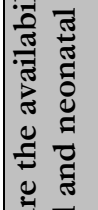 & $\mid \begin{array}{c}\omega \\
\hat{A}\end{array}$ & 嵾 & 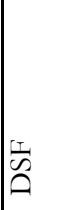 & 梤 & 梯 & 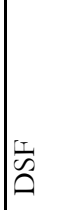 & 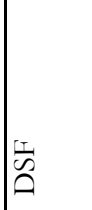 & $\mid \begin{array}{c}\omega \\
\tilde{D}\end{array}$ & 崖 & 崖 & $\mid \begin{array}{c}\omega \\
\hat{A}\end{array}$ & 㟶 \\
\hline 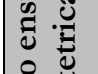 & $x$ & 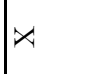 & $x$ & $x$ & $x$ & $x$ & $x$ & $\rtimes$ & 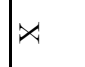 & $x$ & $x$ & $x$ \\
\hline & $x$ & $x$ & $x$ & $x$ & $x$ & $x$ & $x$ & $x$ & $x$ & $x$ & $x$ & $x$ \\
\hline$\frac{1}{0}$ & $\rtimes$ & $x$ & $x$ & $x$ & $x$ & $x$ & $x$ & $x$ & $x$ & $x$ & $\rtimes$ & $x$ \\
\hline 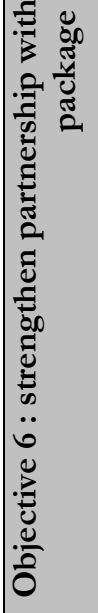 & 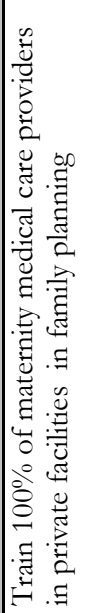 & 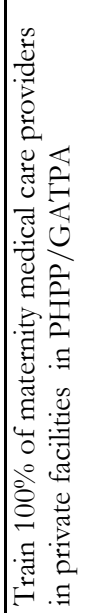 & 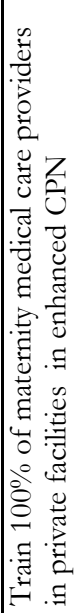 & 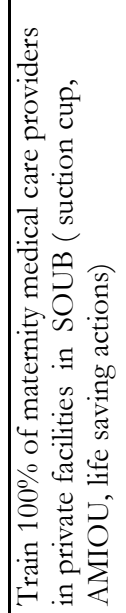 & 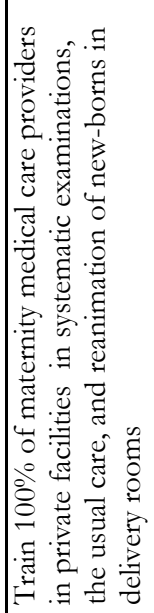 & 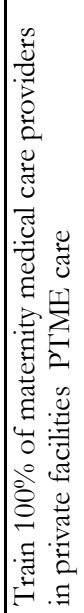 & 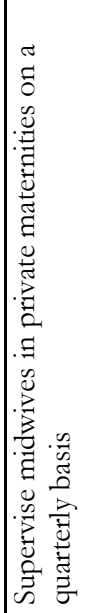 & 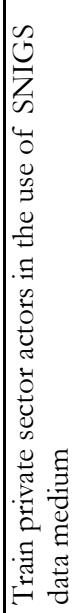 & 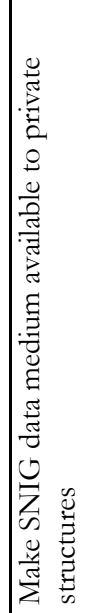 & 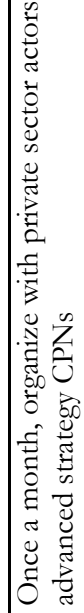 & 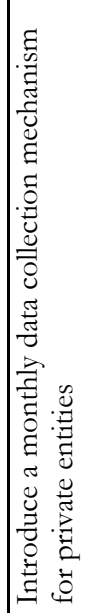 & 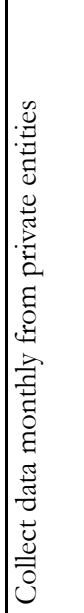 \\
\hline
\end{tabular}




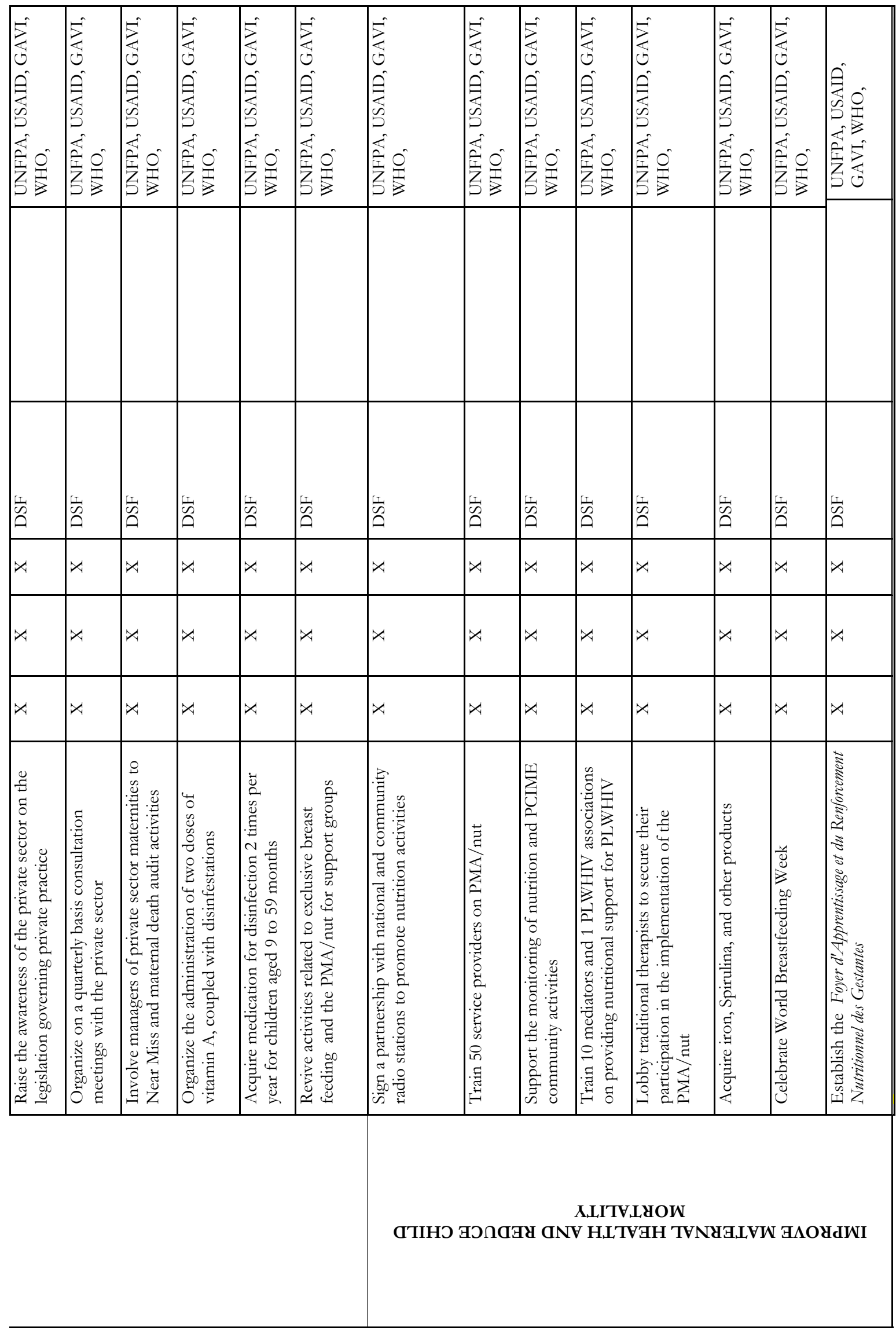




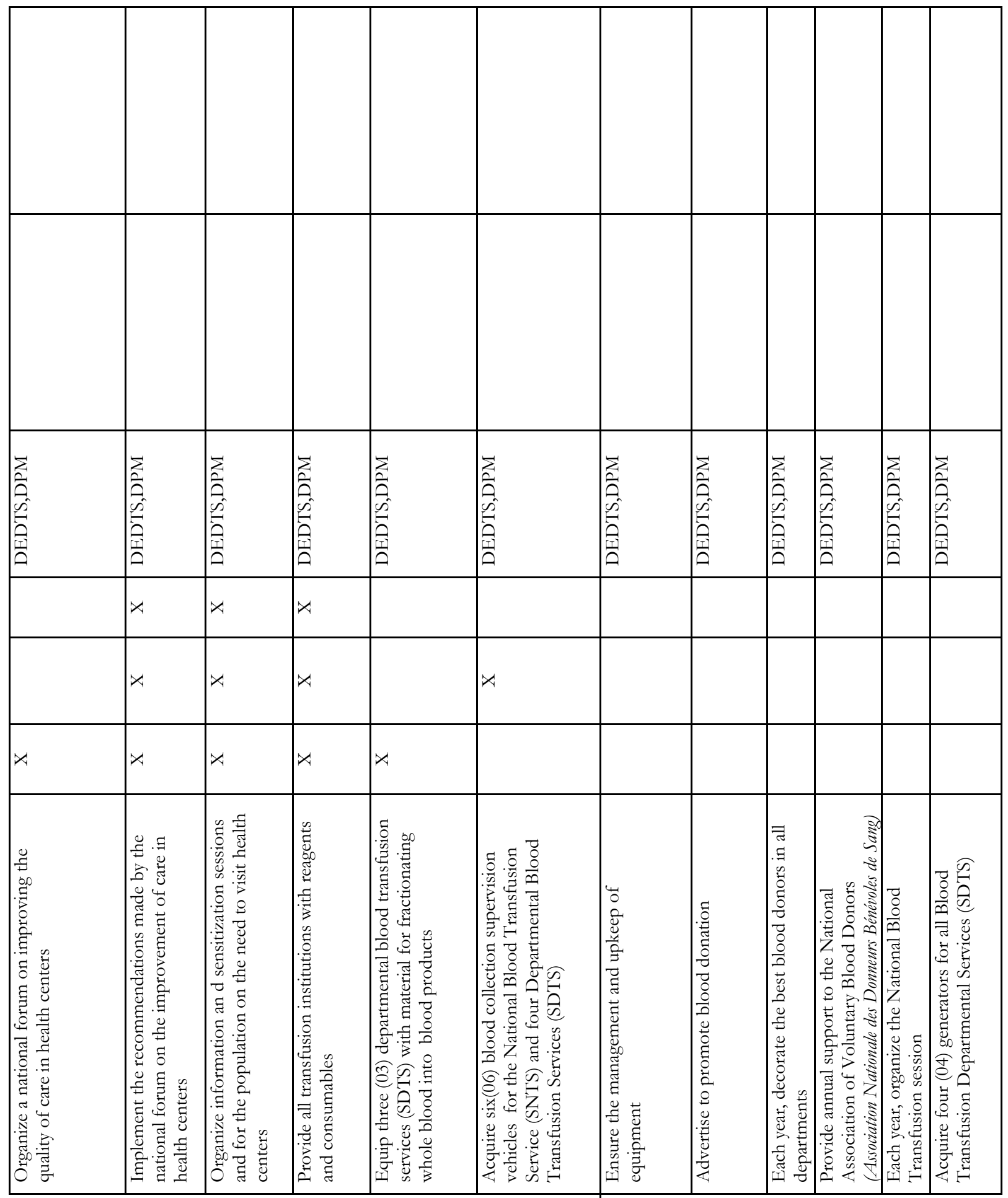

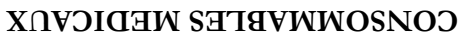




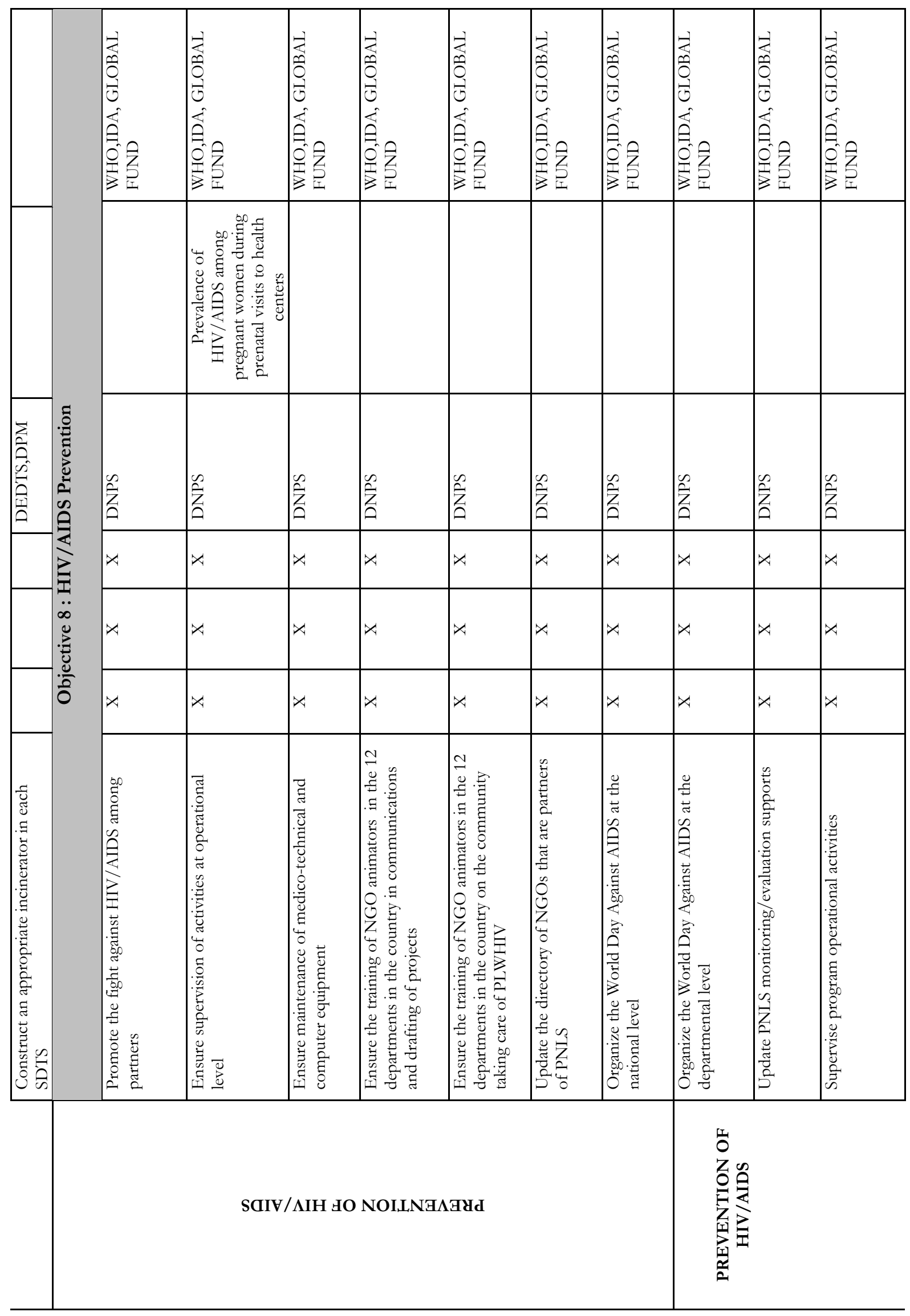




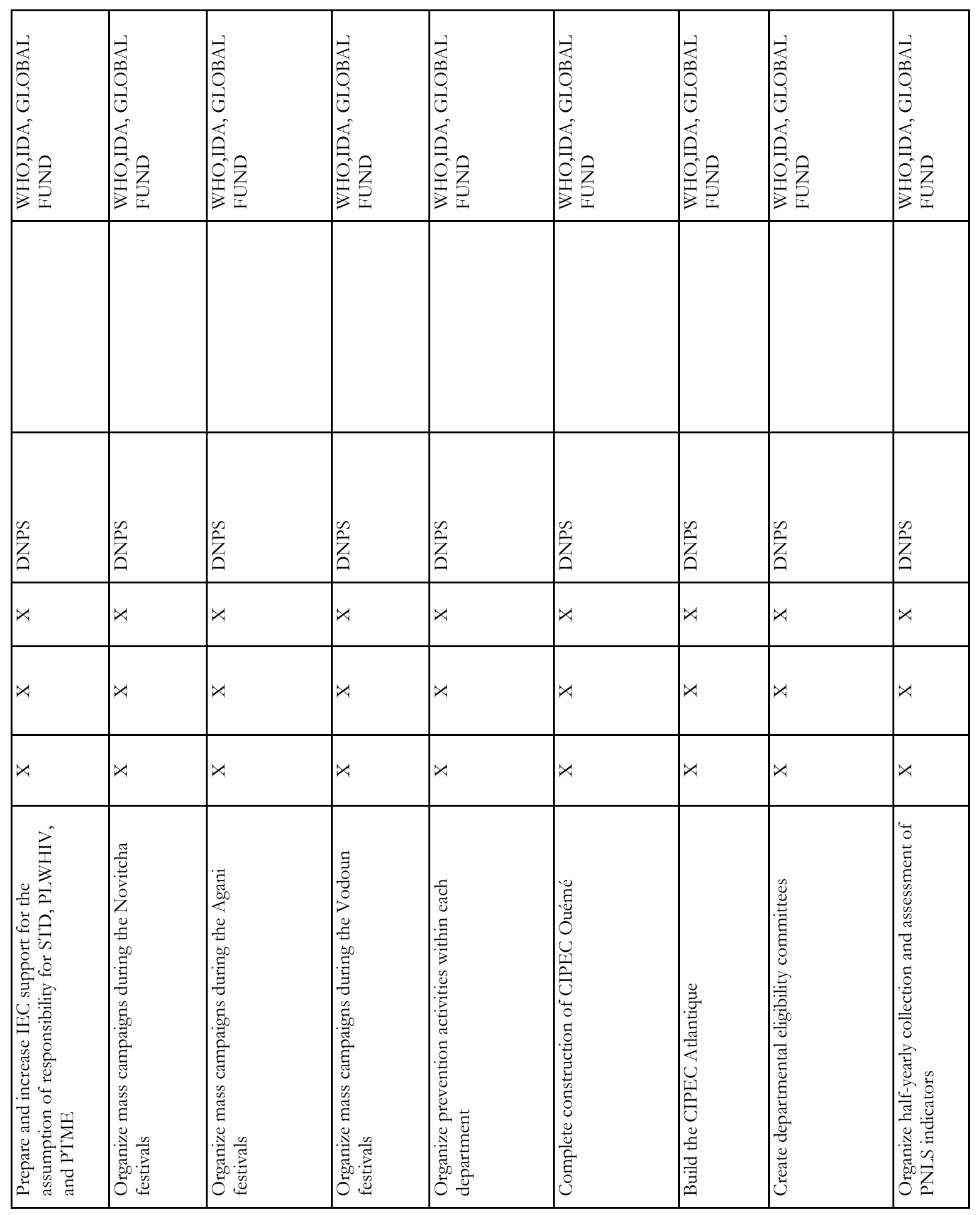




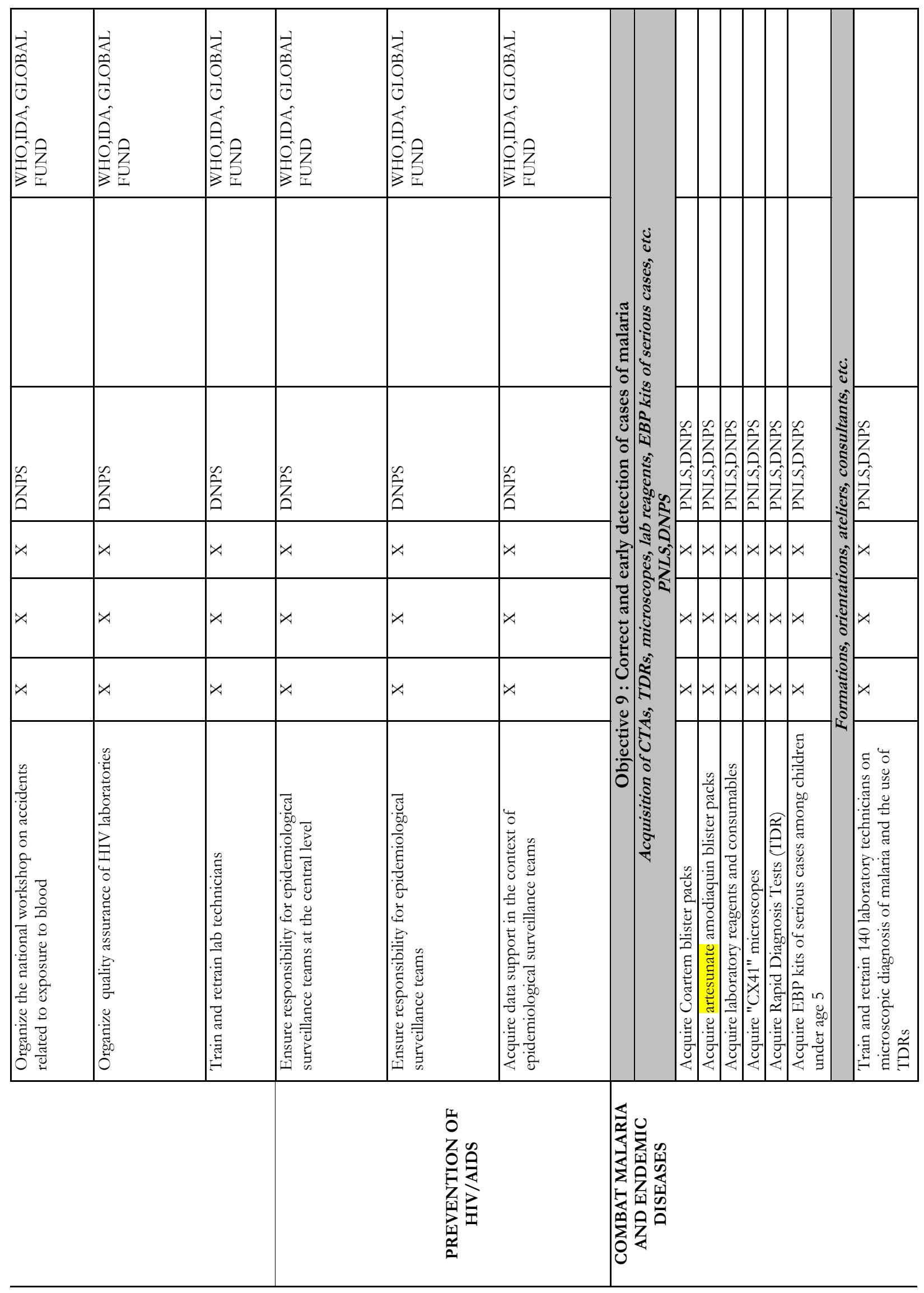




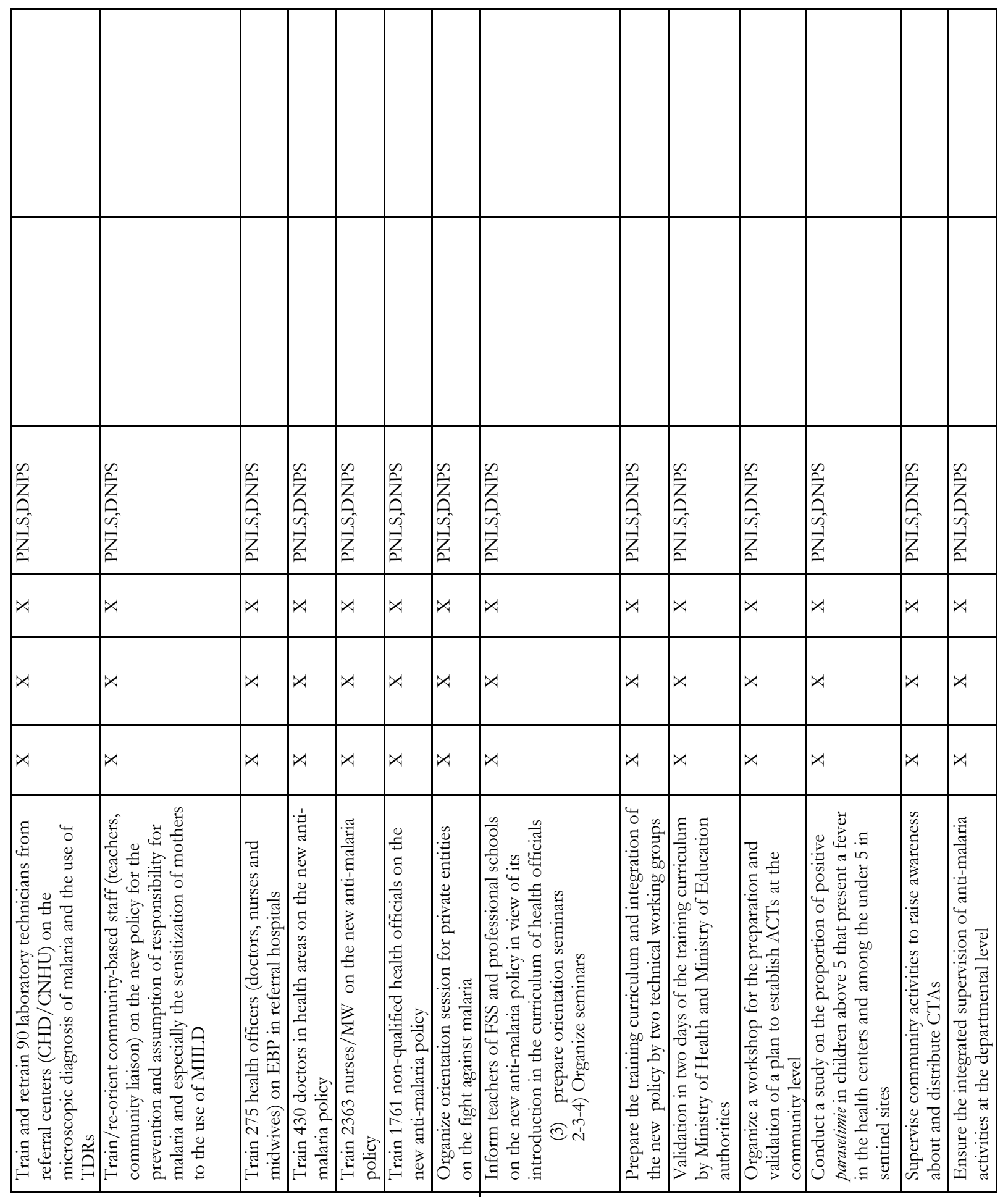

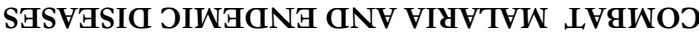




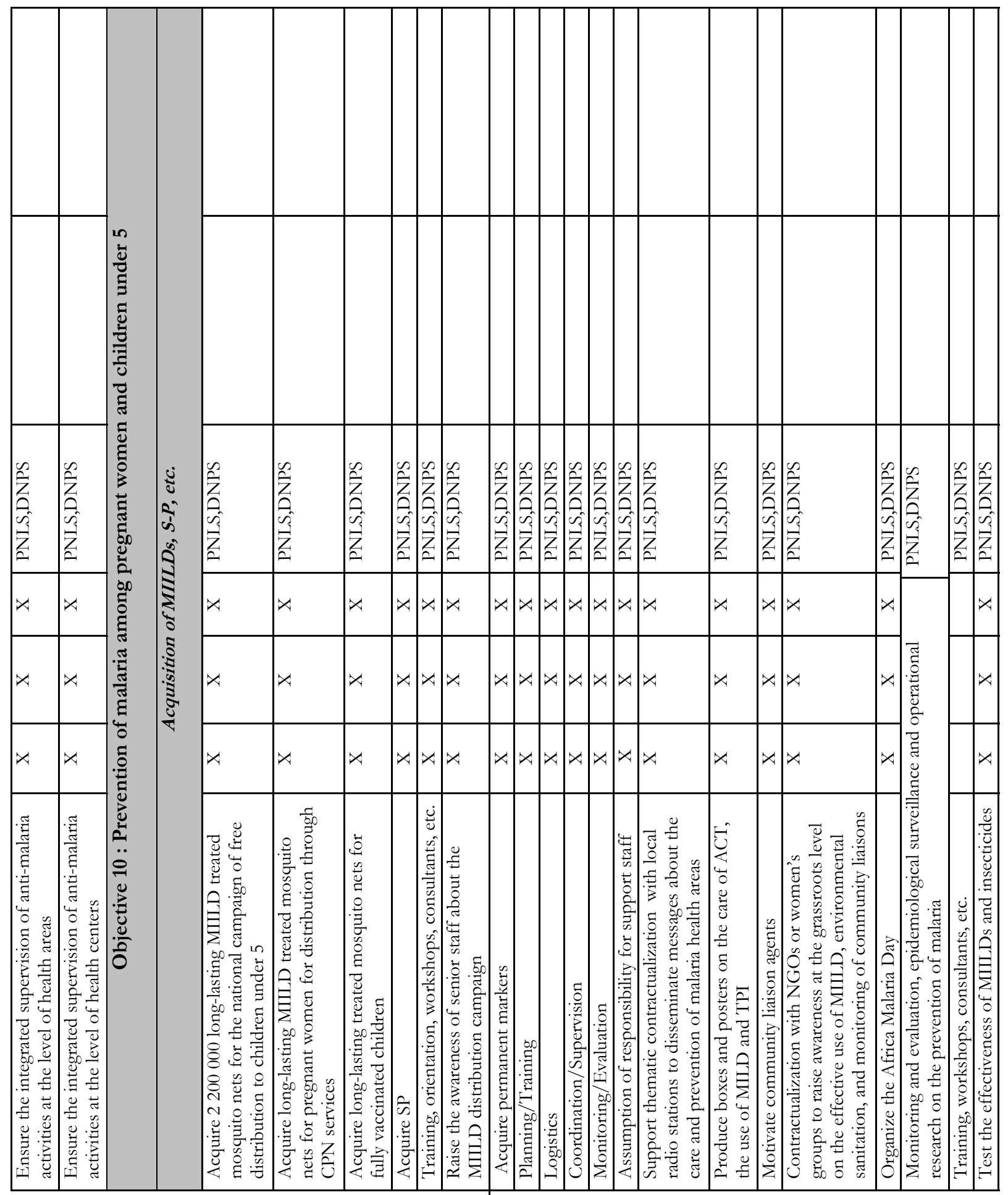

SASV'GSIC JIW'ACN' GNV VIYV'TVW IVGWOJ 


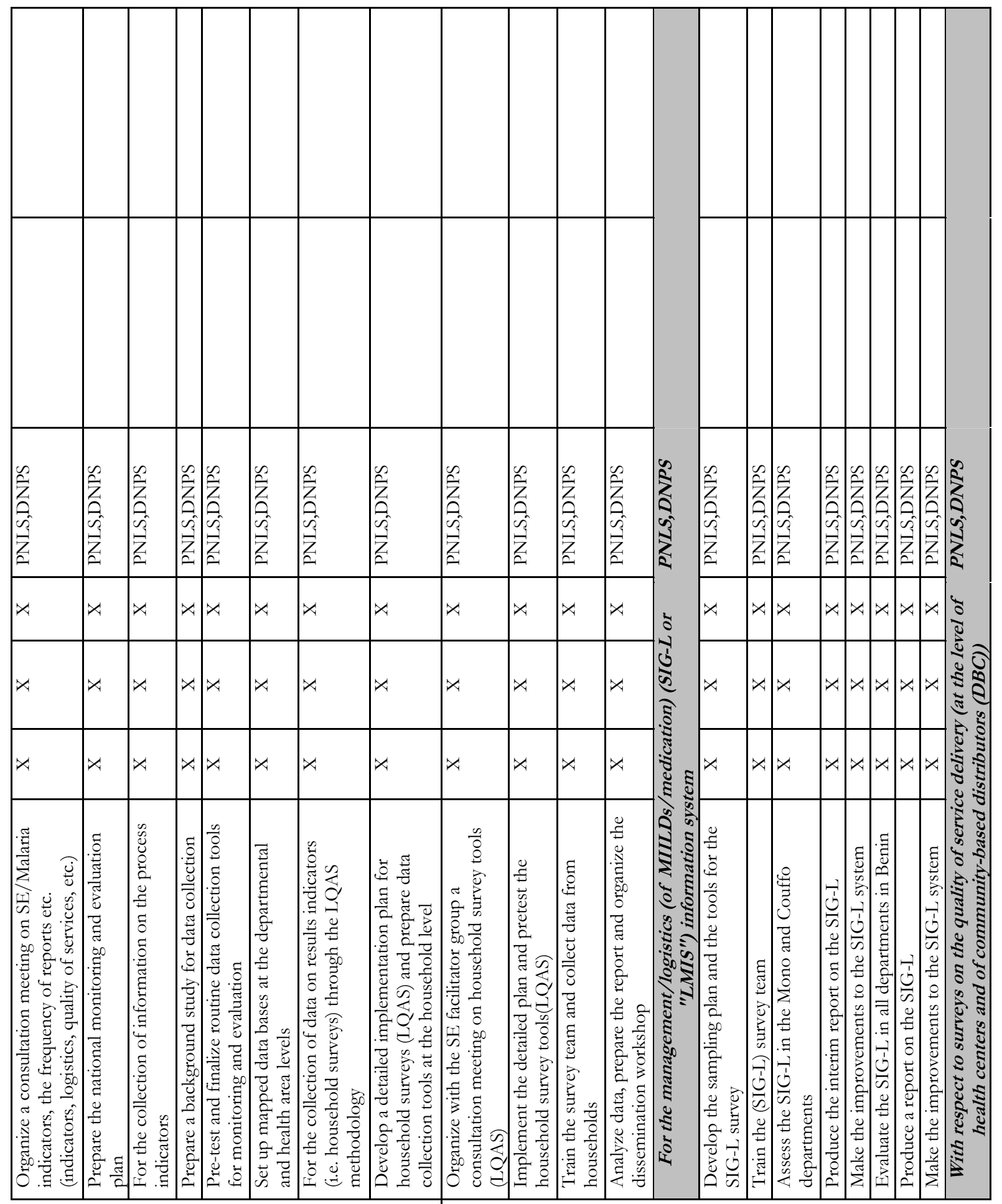

SASVGSIC JIWGANG đNV VIYVTVW LVGWOJ 


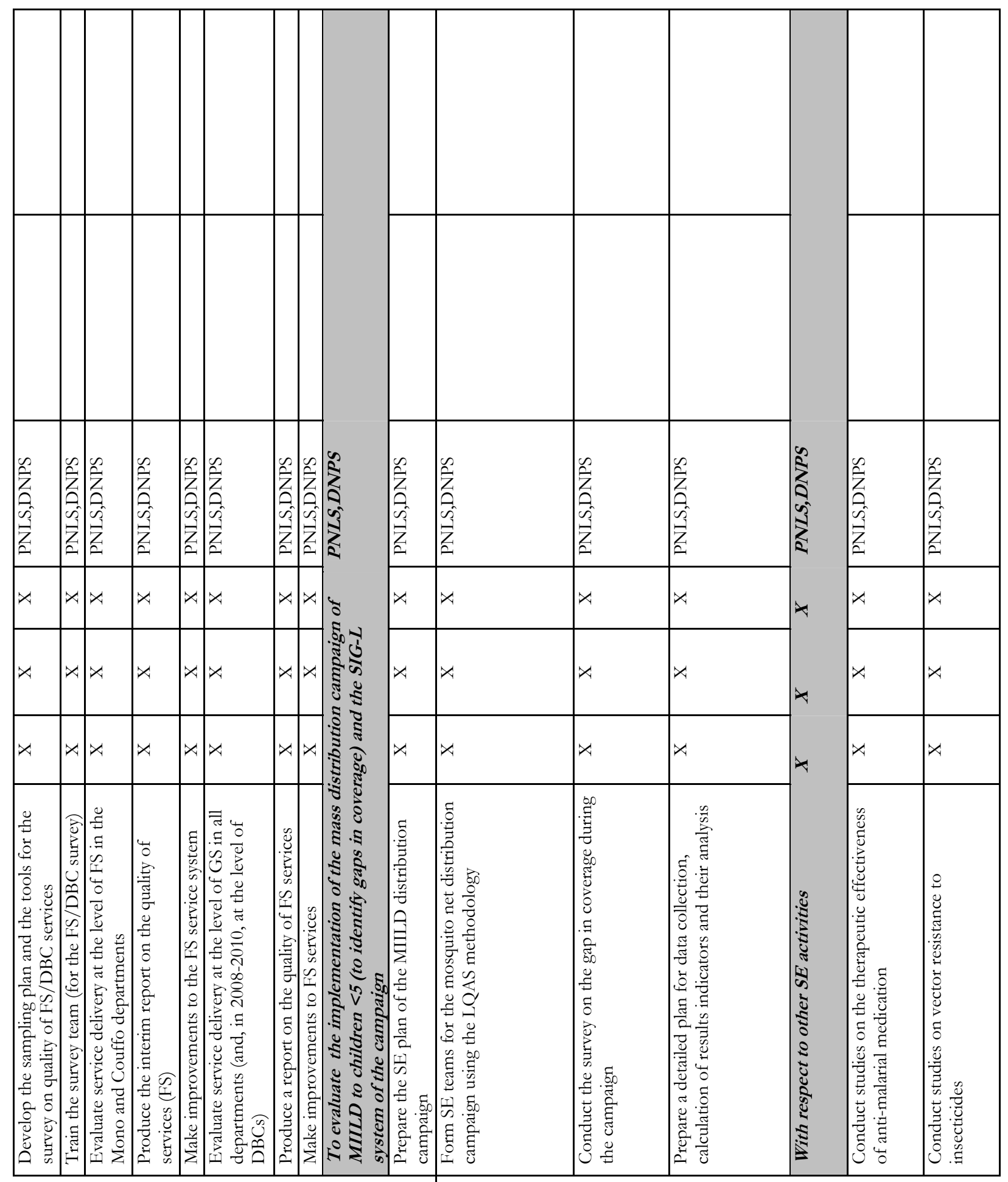




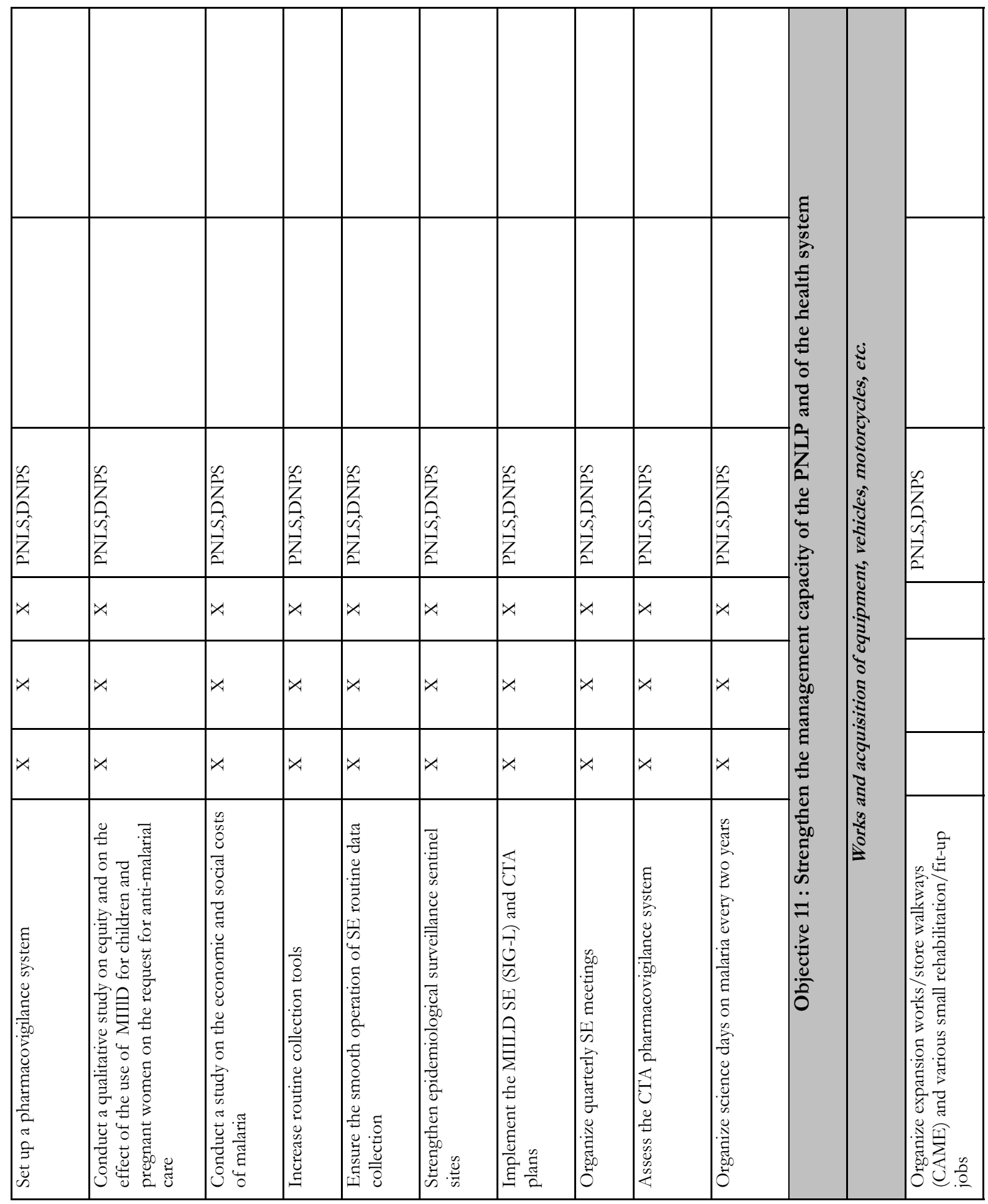




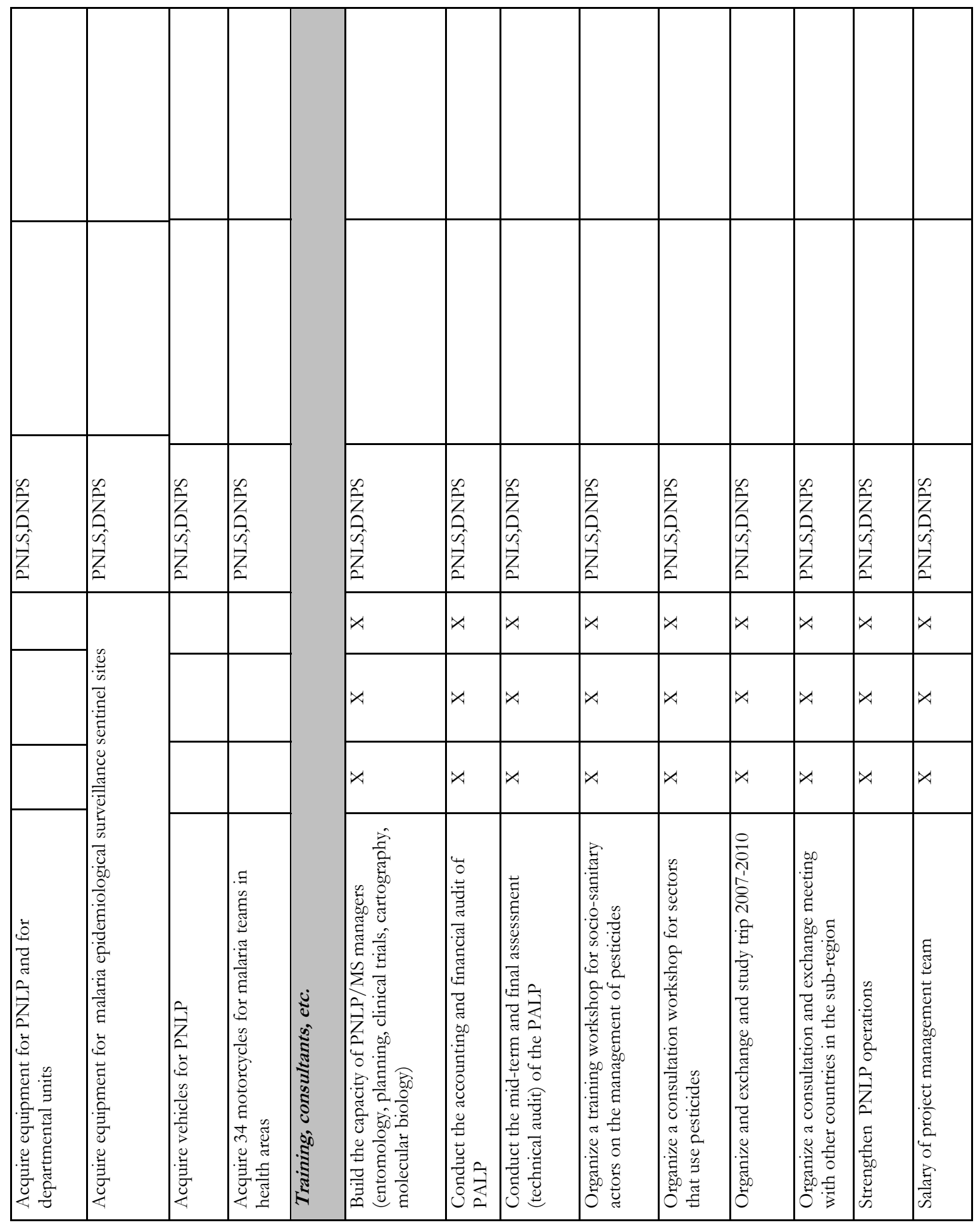




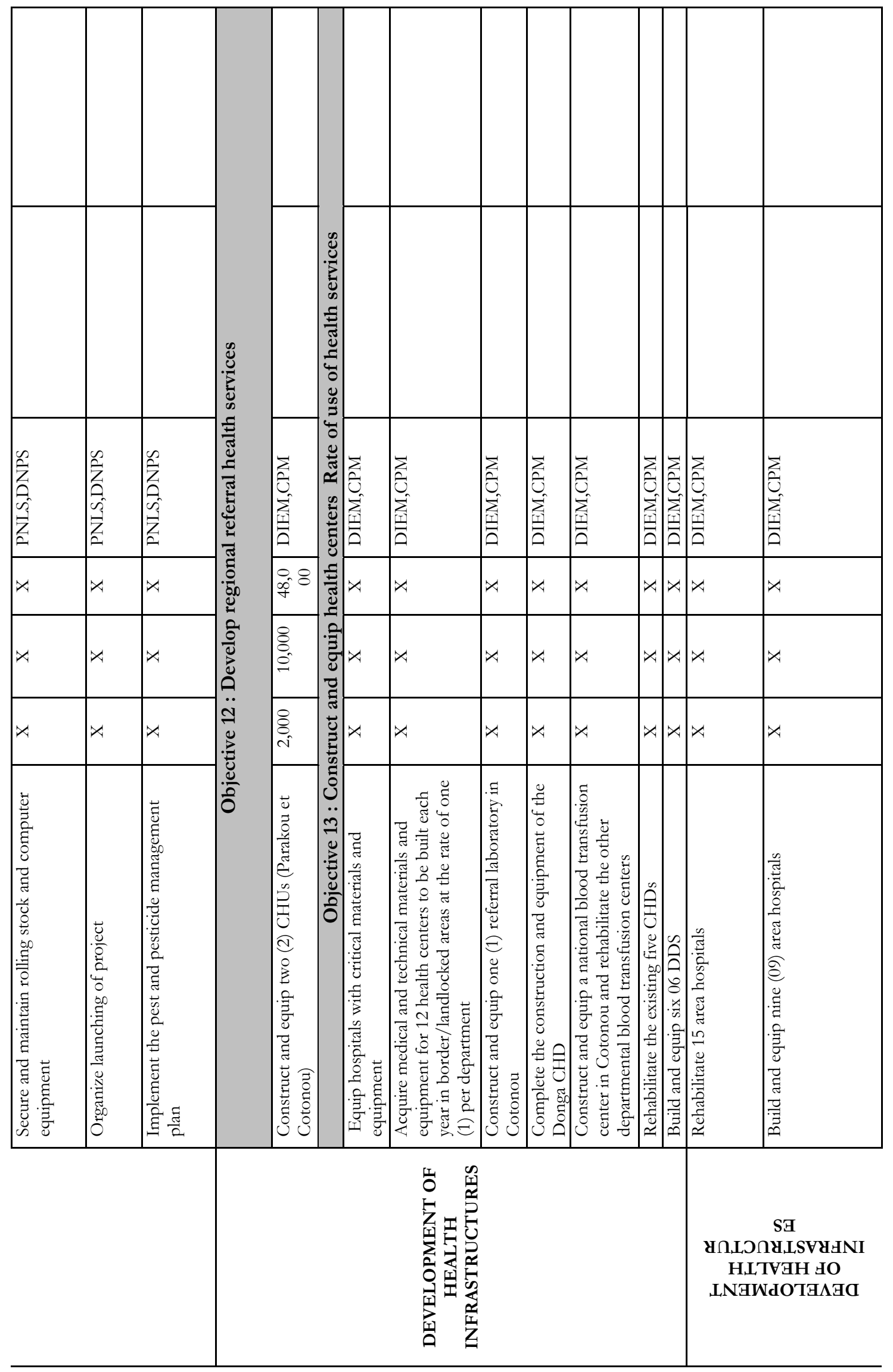




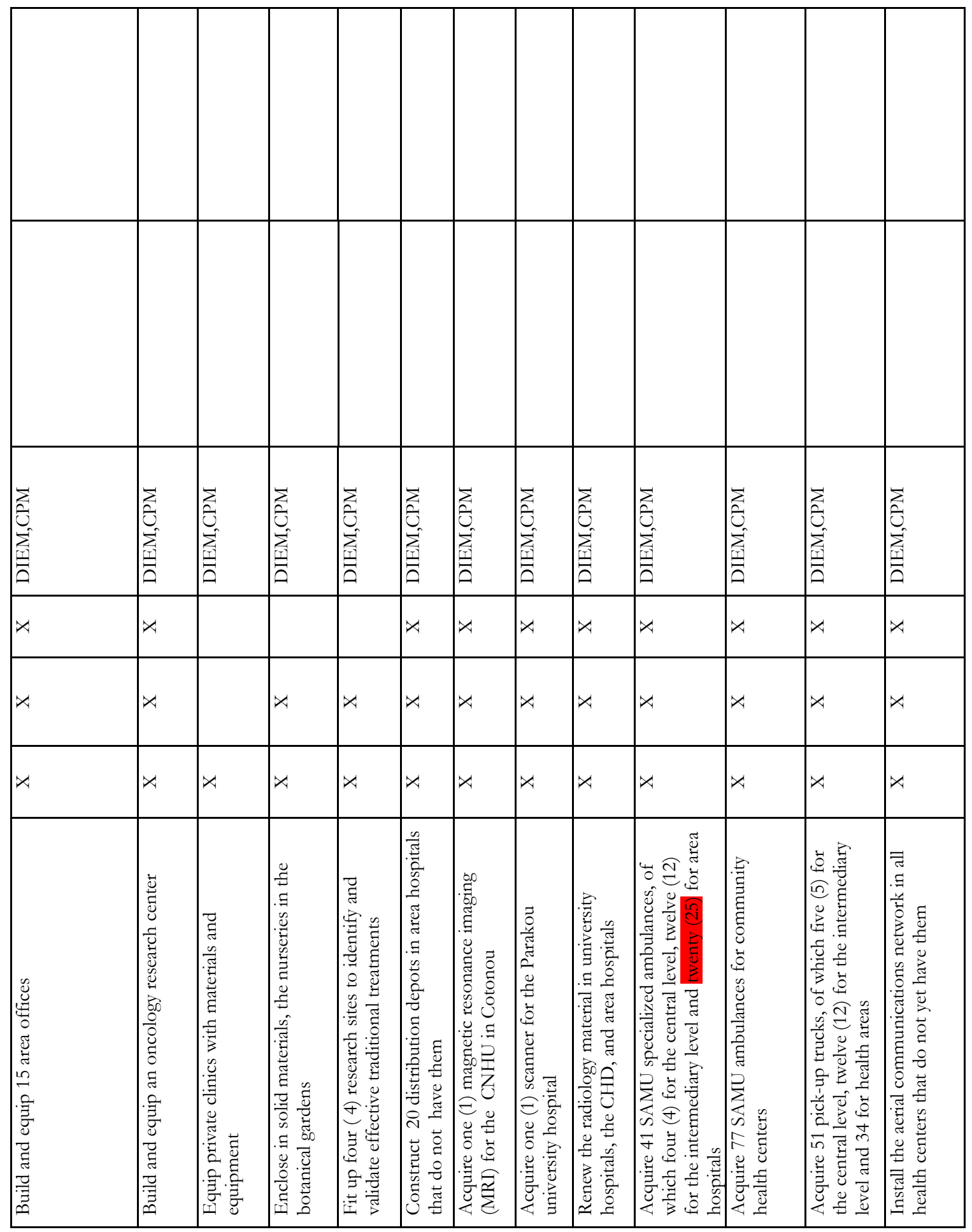




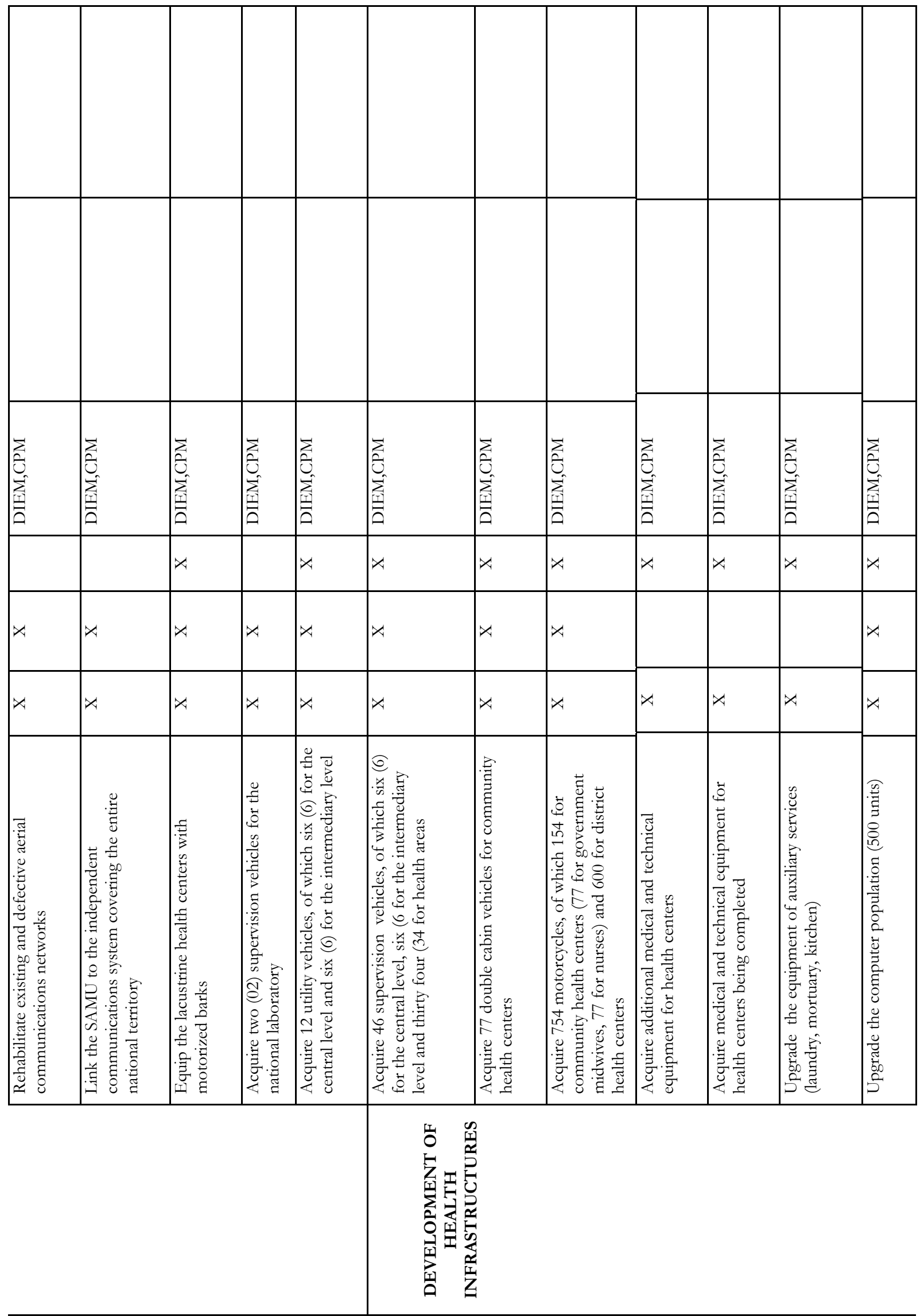




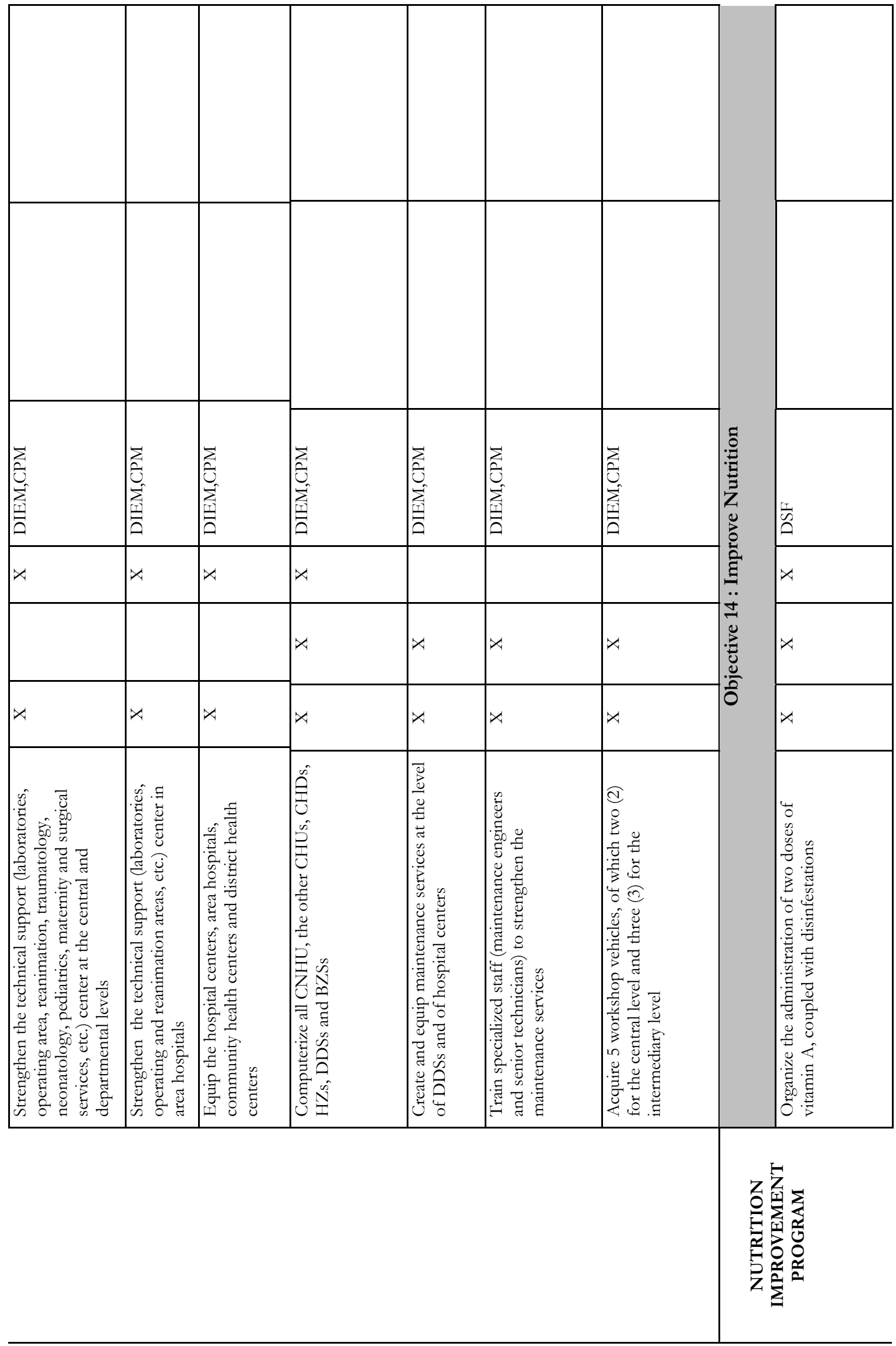




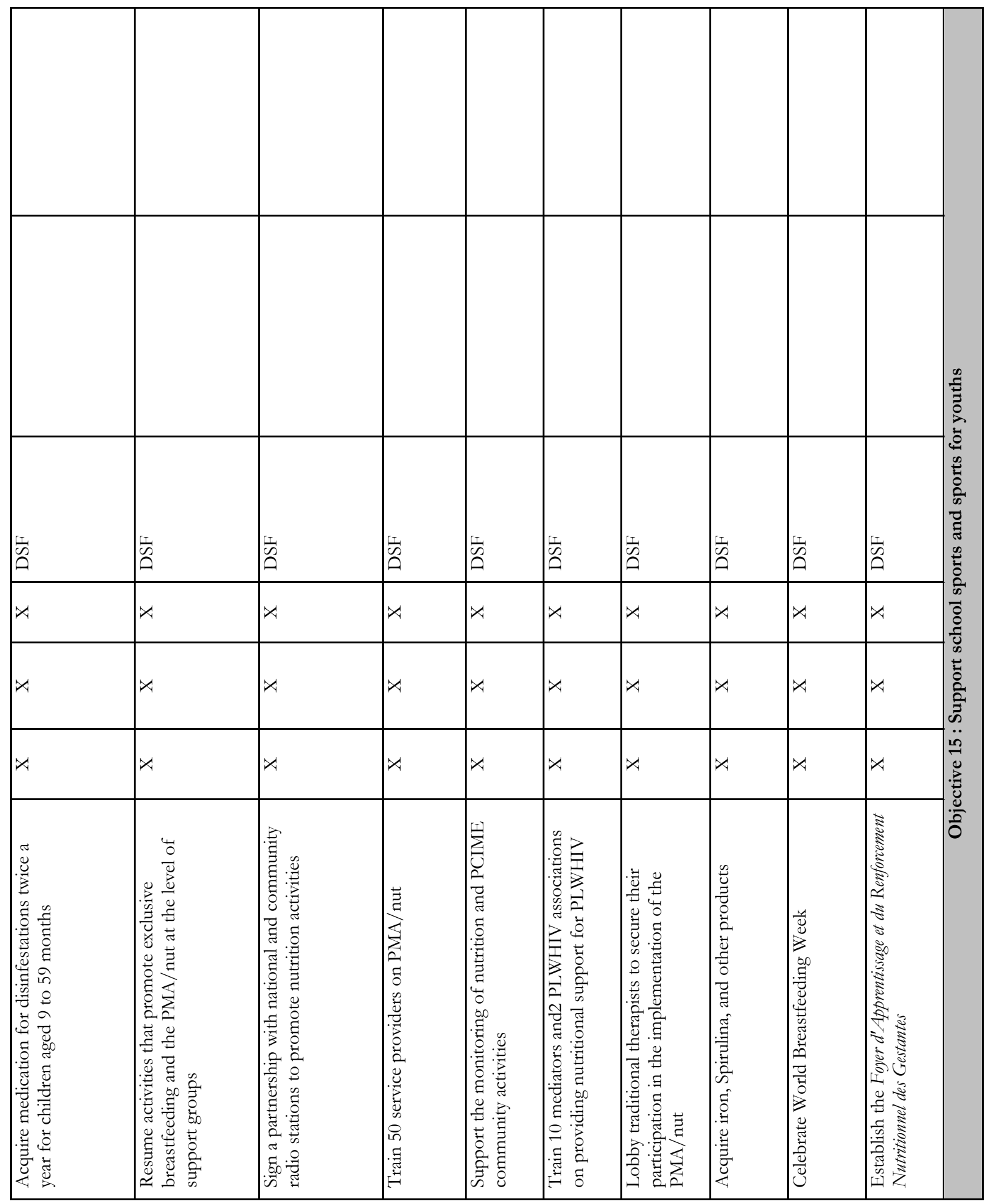




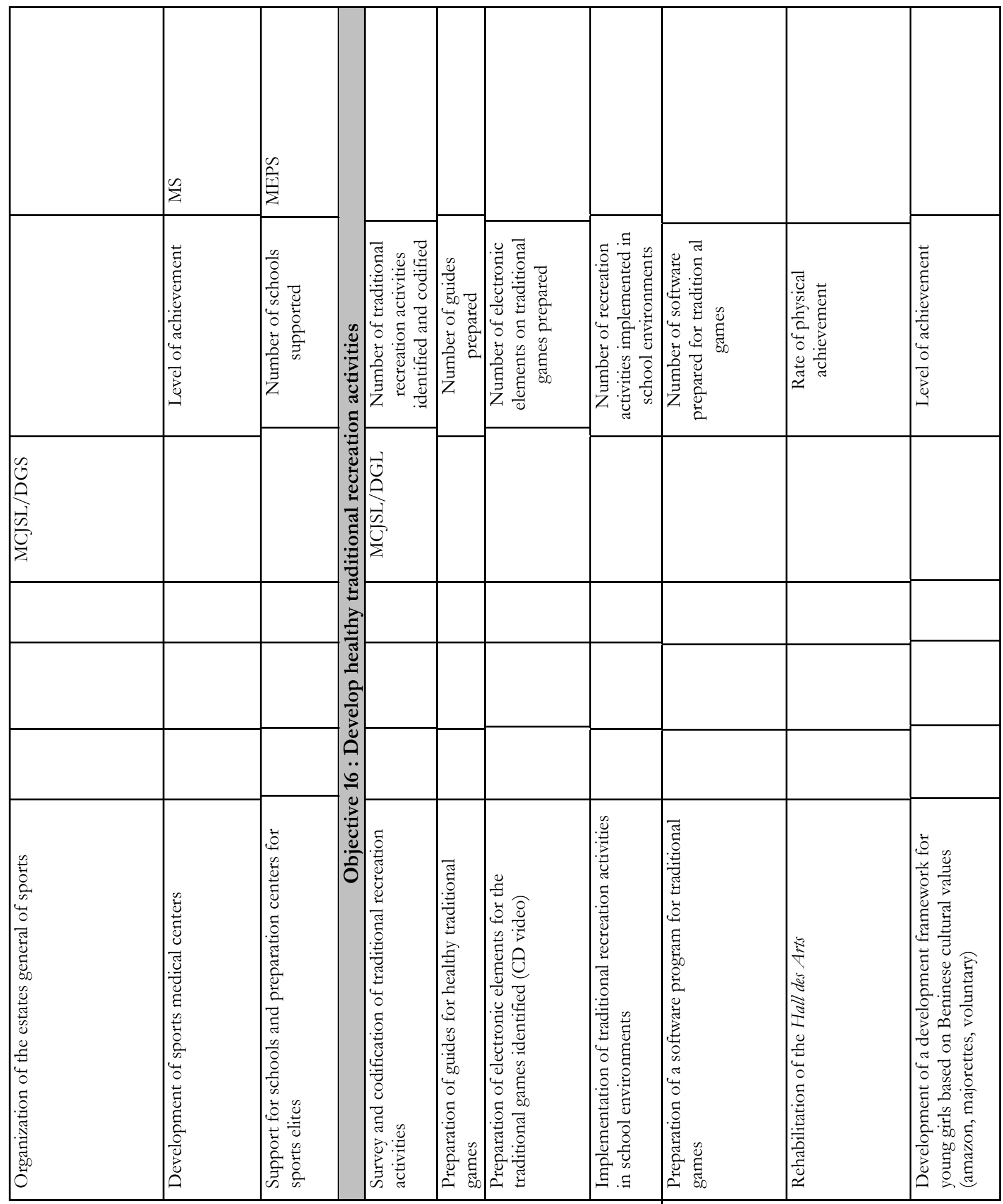

SGกठICกT LA SALILYOdS SGILIAILJV SAG NOILOWOYd 


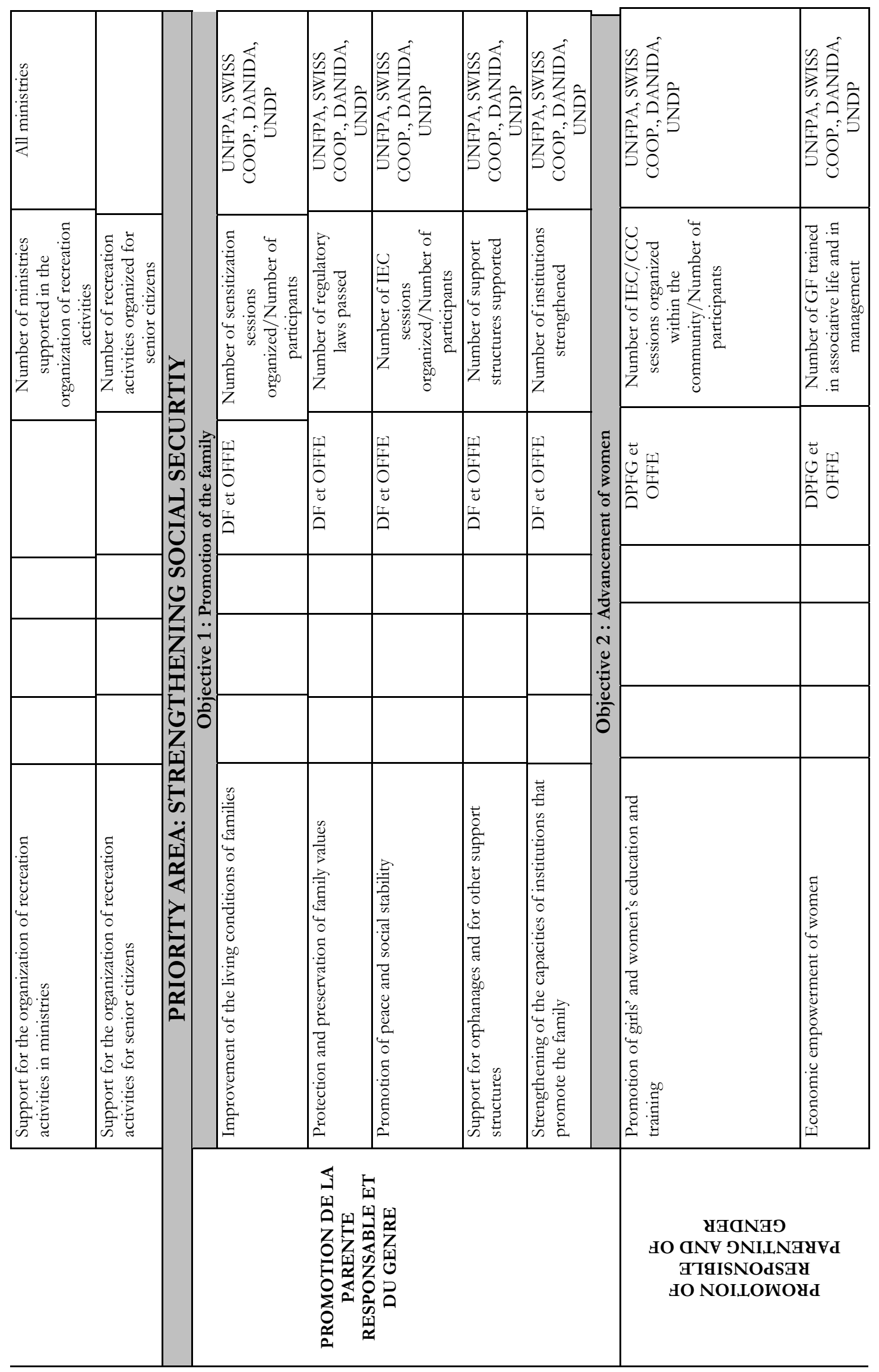




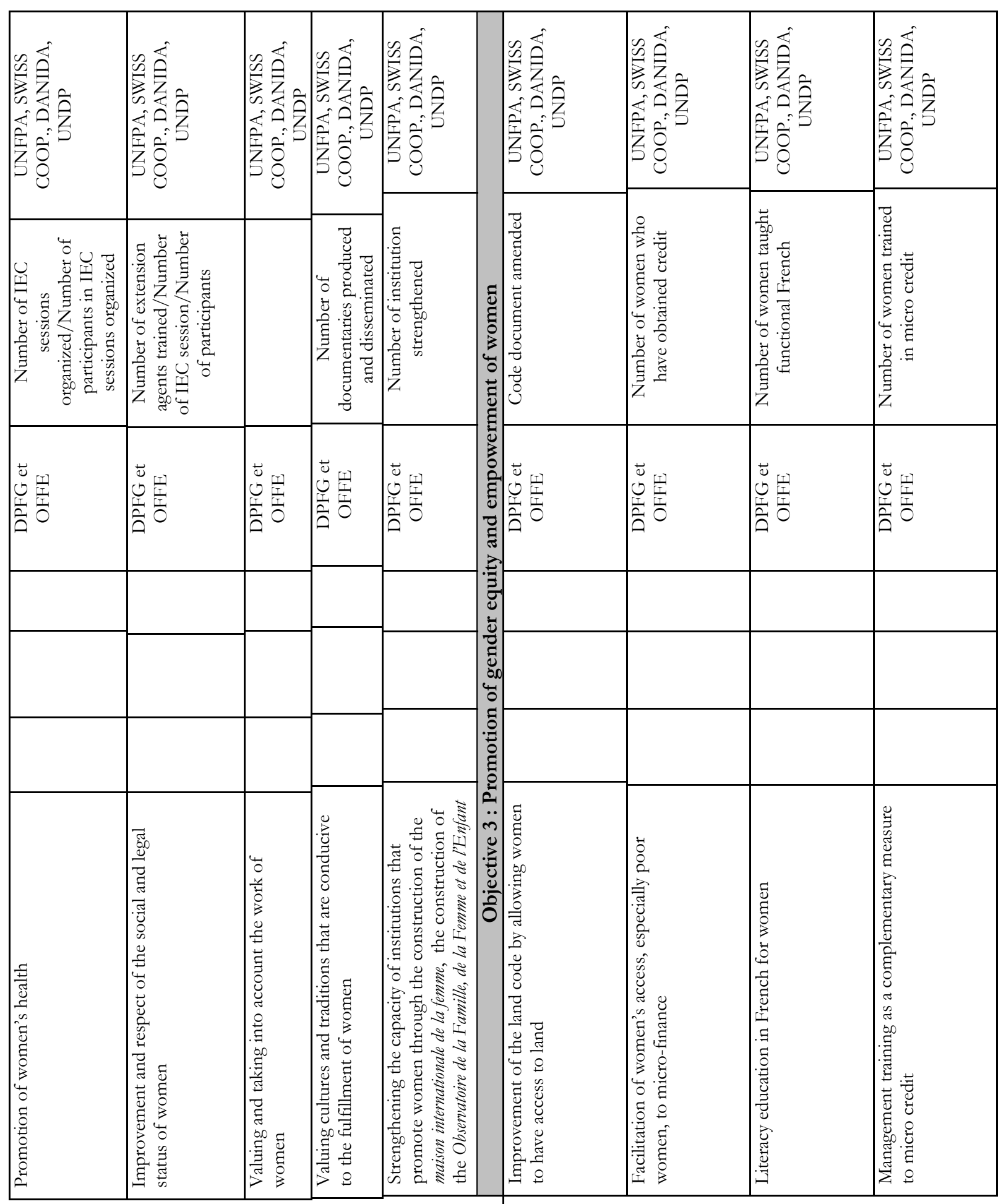




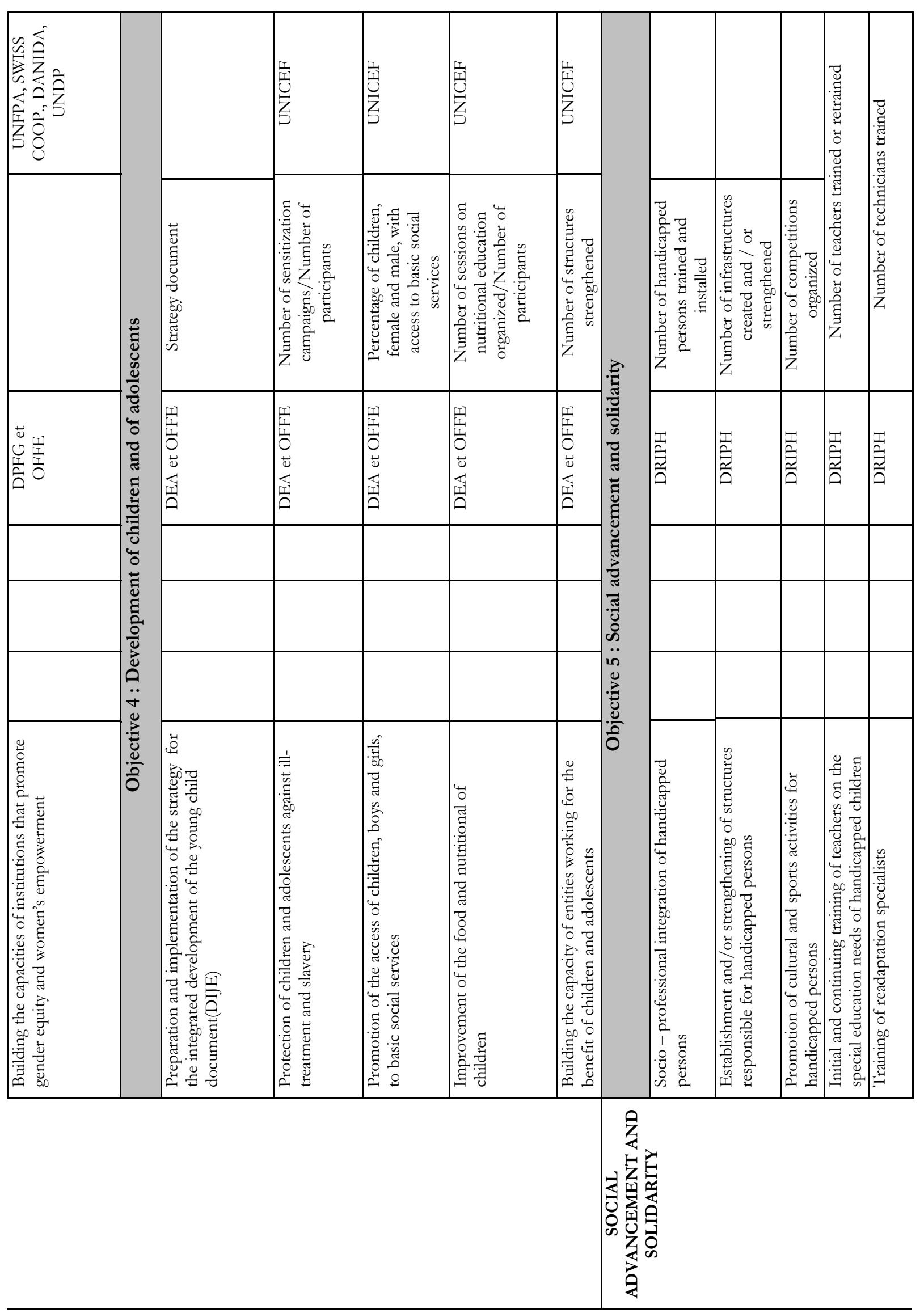




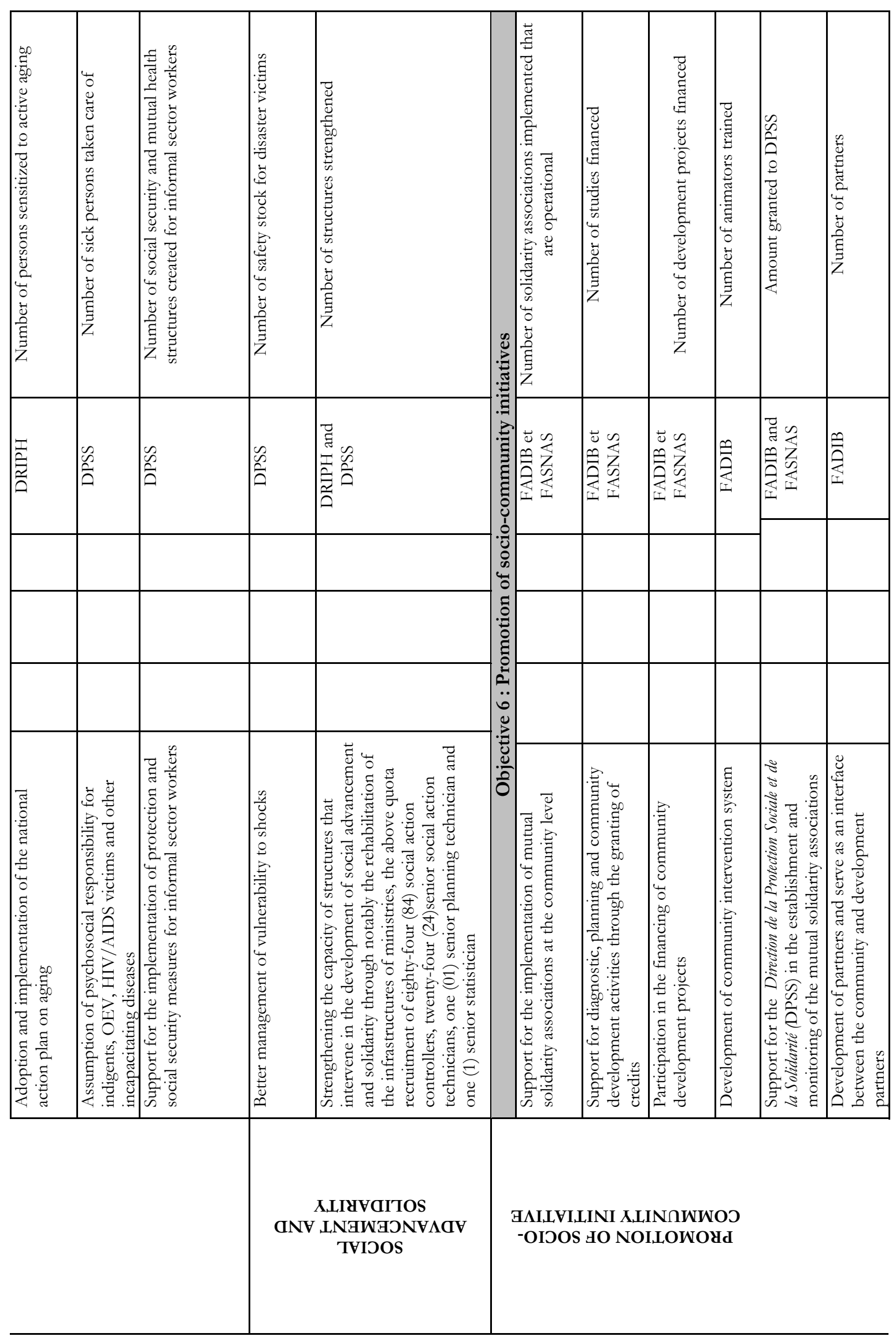




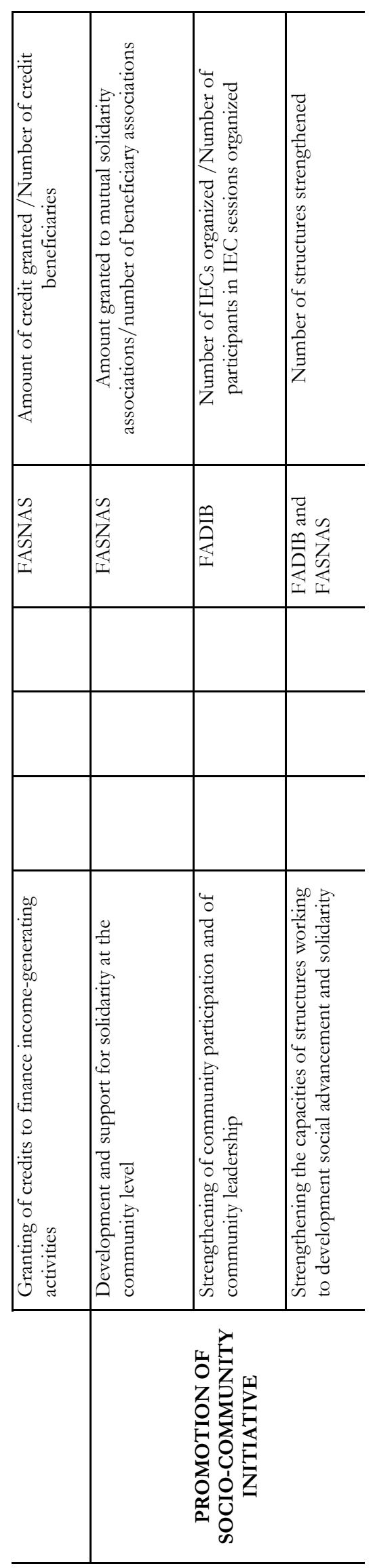


82

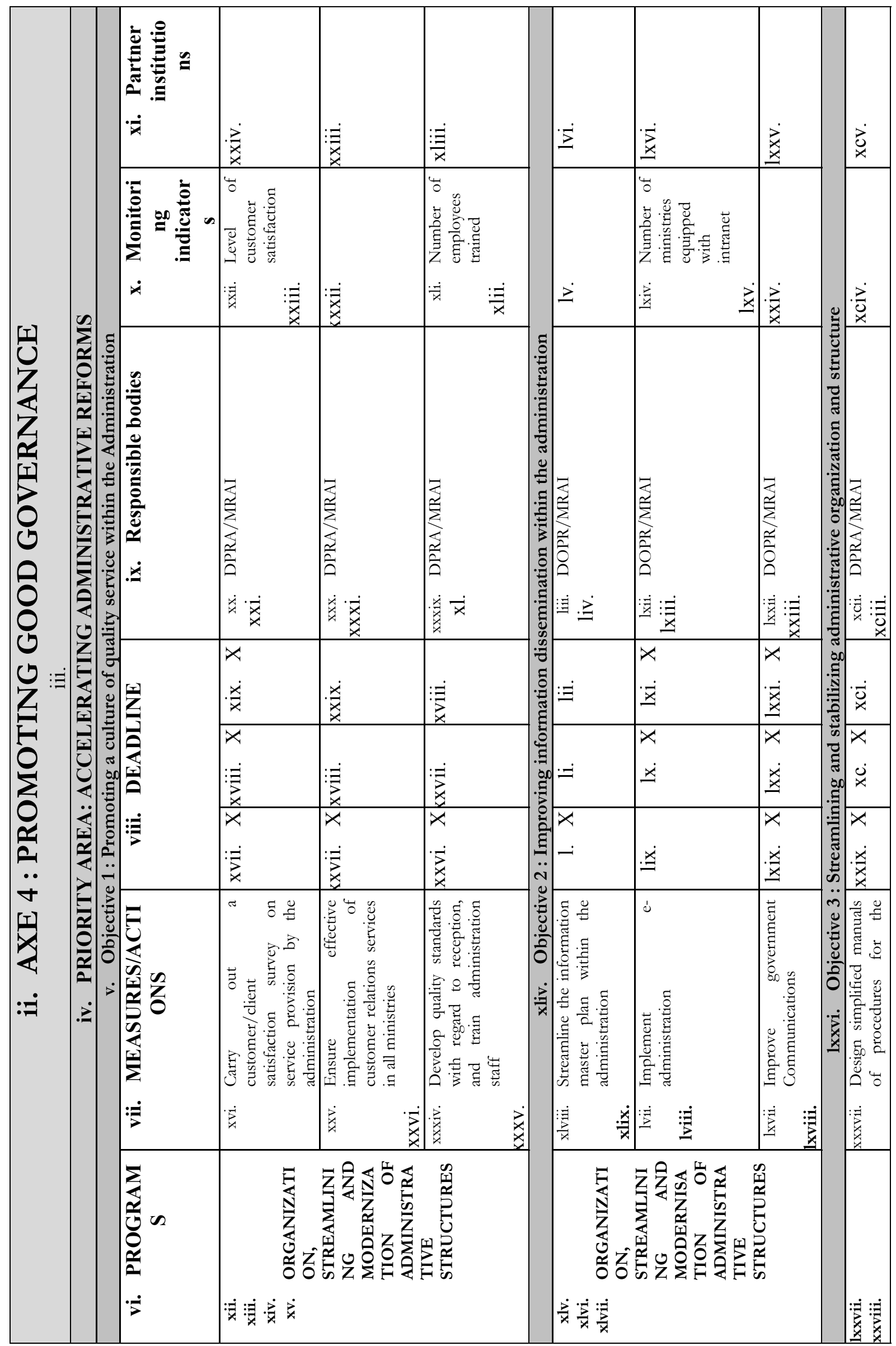


83

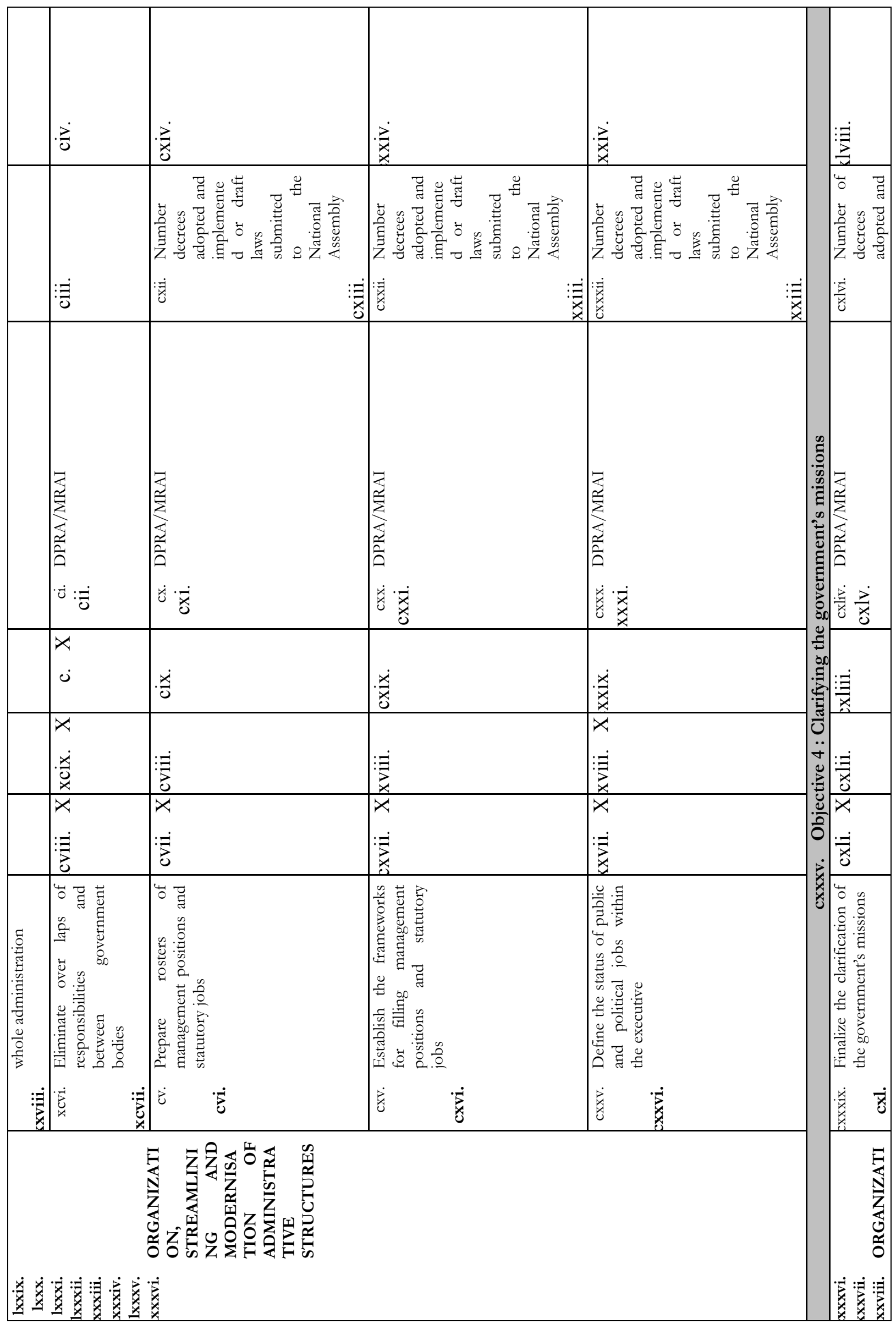




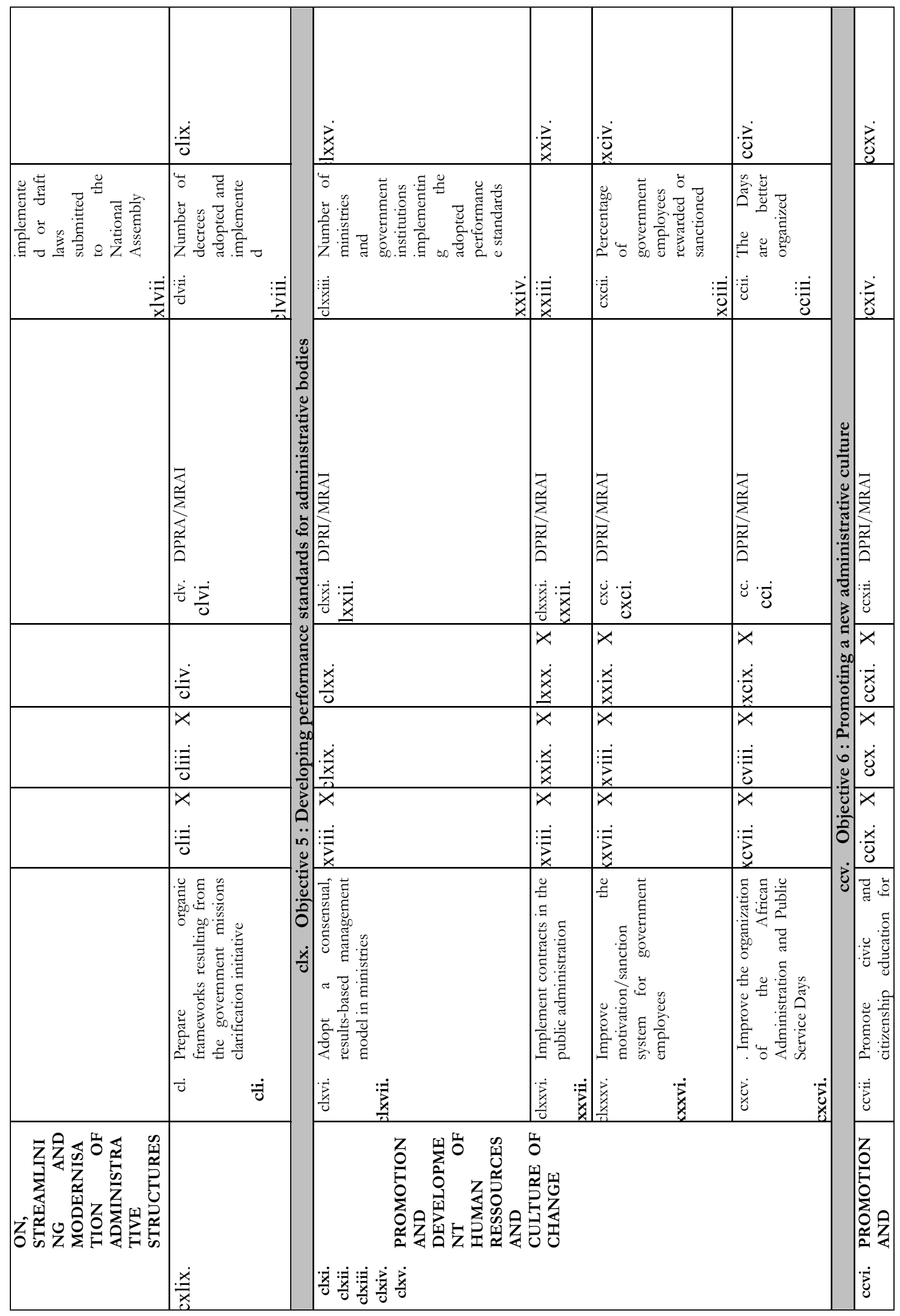




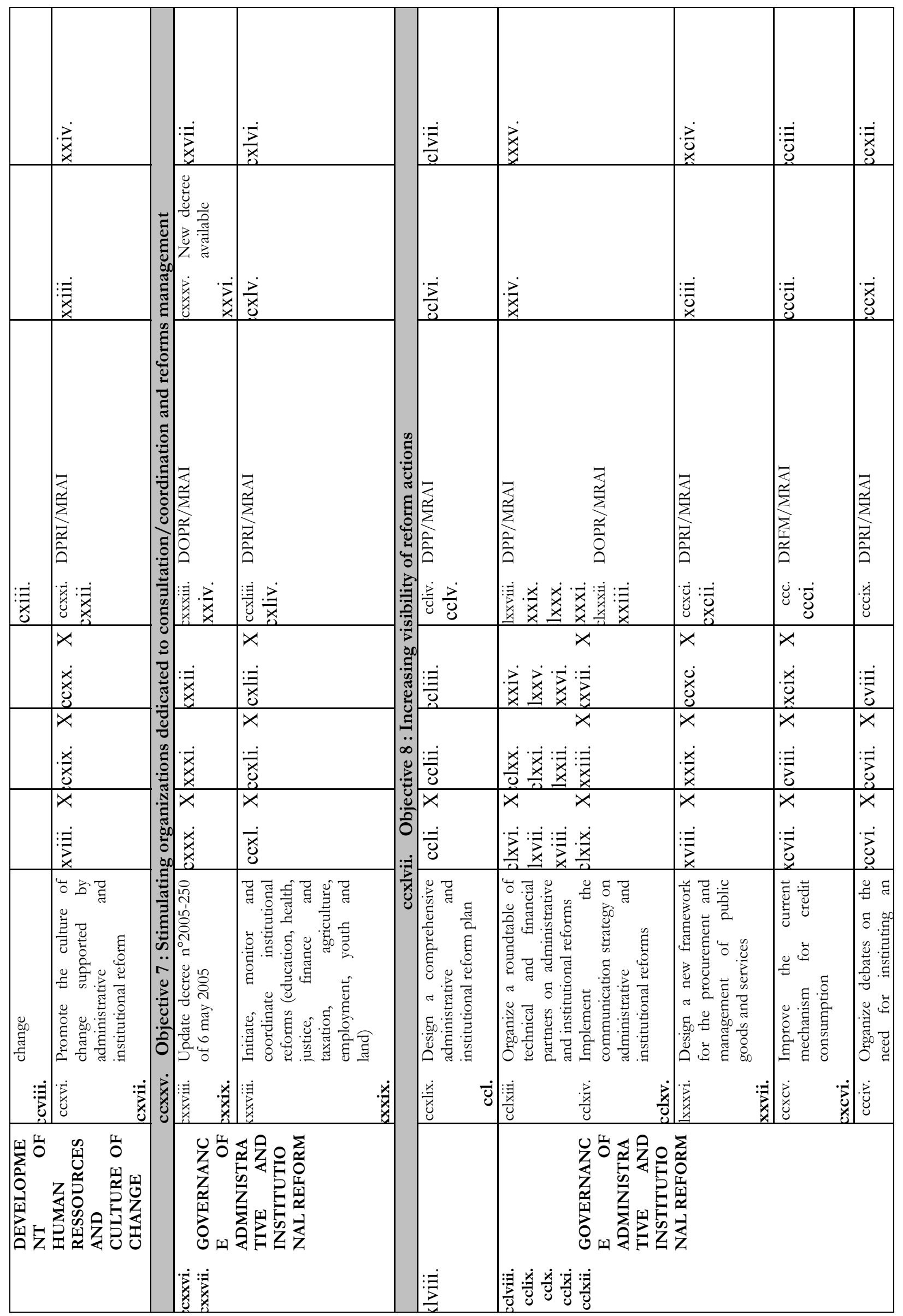




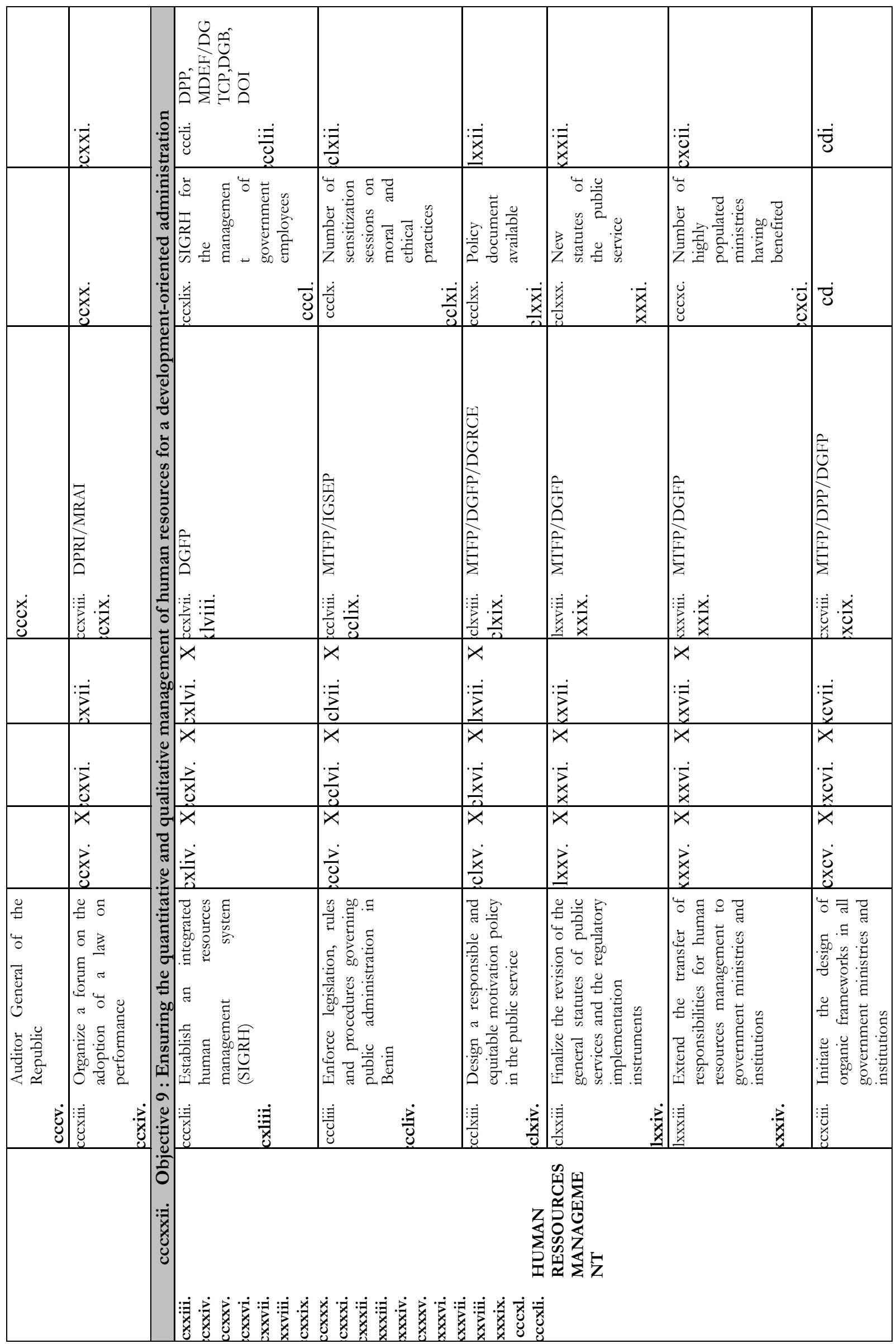




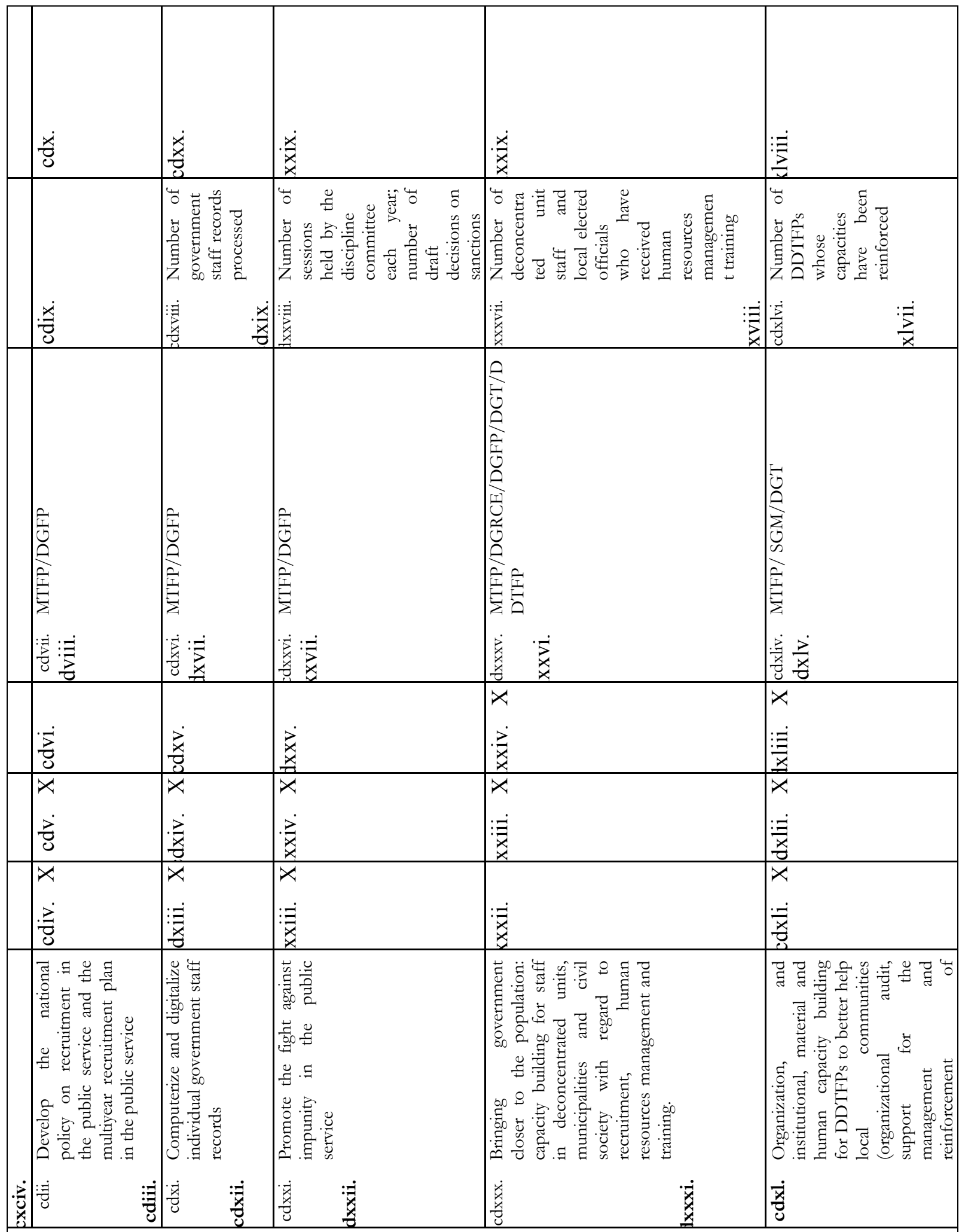


88

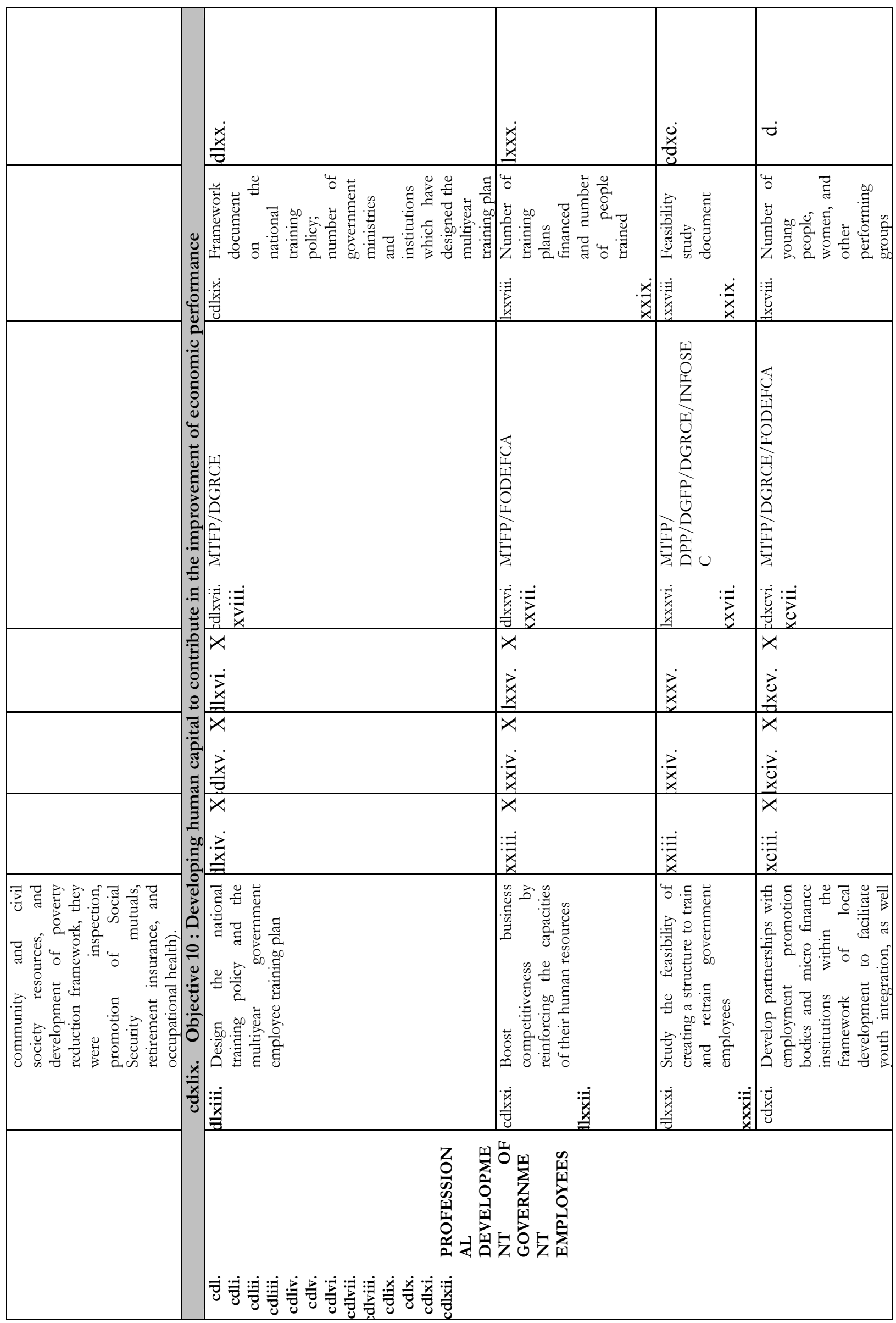


89

\begin{tabular}{|c|c|c|c|c|}
\hline & $\dot{x}$ & 离 & 㐫 & $\dot{x}$ \\
\hline 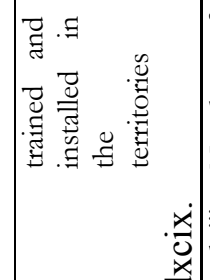 & 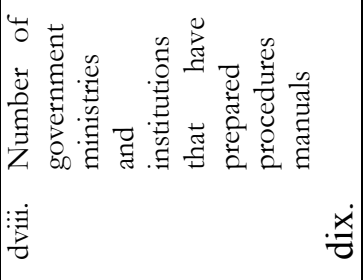 & 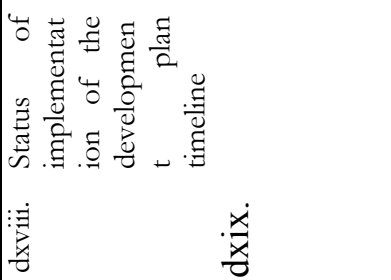 & 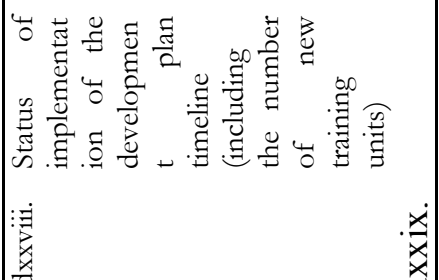 & 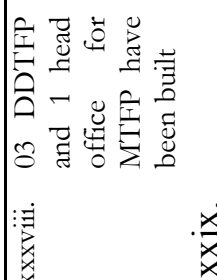 \\
\hline & 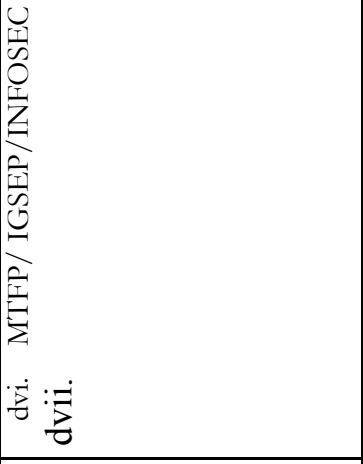 & 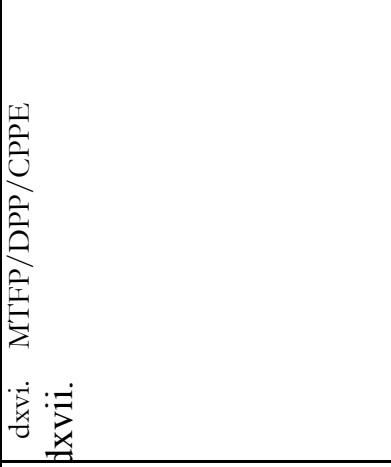 & 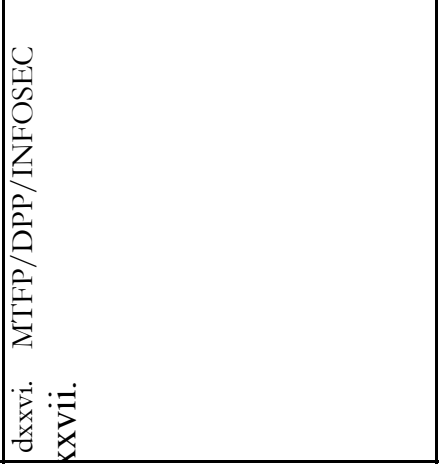 & 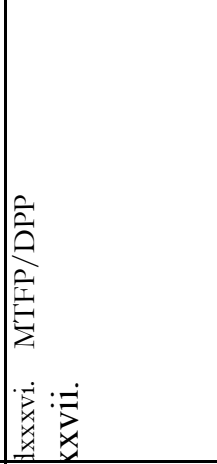 \\
\hline & $\frac{7}{2}$ & $\begin{array}{l}x \\
\dot{x} \\
\dot{x}\end{array}$ & $\begin{array}{l}x \\
\dot{x} \\
\dot{x} \\
a \\
a\end{array}$ & $\begin{array}{l}x \\
\dot{x} \\
\dot{x} \\
\dot{x} \\
x\end{array}$ \\
\hline & $\begin{array}{l}x \\
\dot{x}\end{array}$ & $\begin{array}{l}x \\
\dot{x} \\
\dot{x} \\
\end{array}$ & $\begin{array}{l}x \\
\dot{x} \\
\dot{x} \\
x \\
\end{array}$ & $\begin{array}{l}x \\
x \\
\dot{x} \\
x \\
x\end{array}$ \\
\hline & $\begin{array}{l}x \\
\vdots \\
\vdots\end{array}$ & $\begin{array}{l}x \\
\vdots \vdots \\
\dot{x} \\
\end{array}$ & \begin{tabular}{|l|} 
\\
$\vdots$ \\
$\vdots$ \\
\hdashline \\
$x$
\end{tabular} & \begin{tabular}{l}
$x$ \\
$\vdots \vdots$ \\
\hdashline \\
\hdashline \\
$x$
\end{tabular} \\
\hline 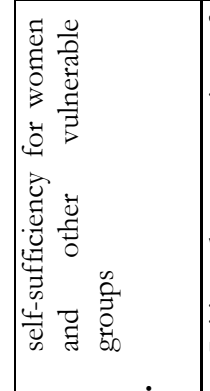 & 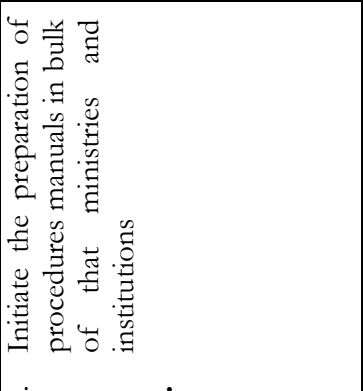 & 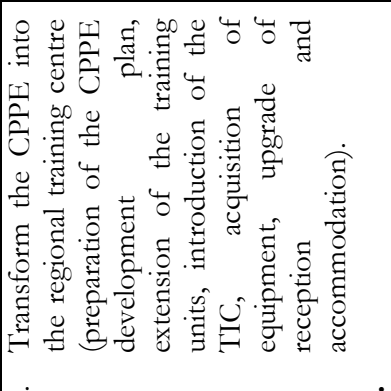 & 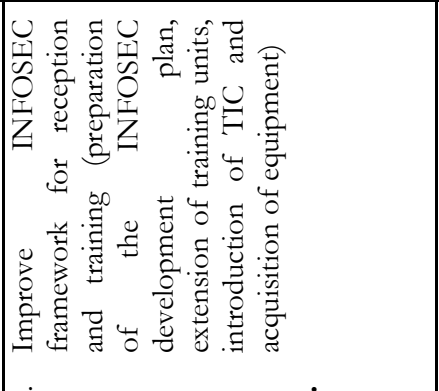 & 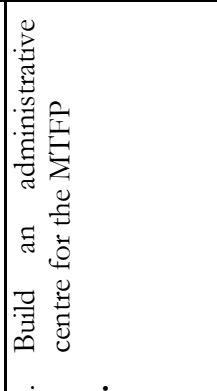 \\
\hline $\begin{array}{l}: \dot{\bar{y}} \\
\text { zy }\end{array}$ & تं $\quad$ : & $\dot{\vec{y}} \quad: \dot{\bar{x}}$ & 莲 & : \\
\hline
\end{tabular}




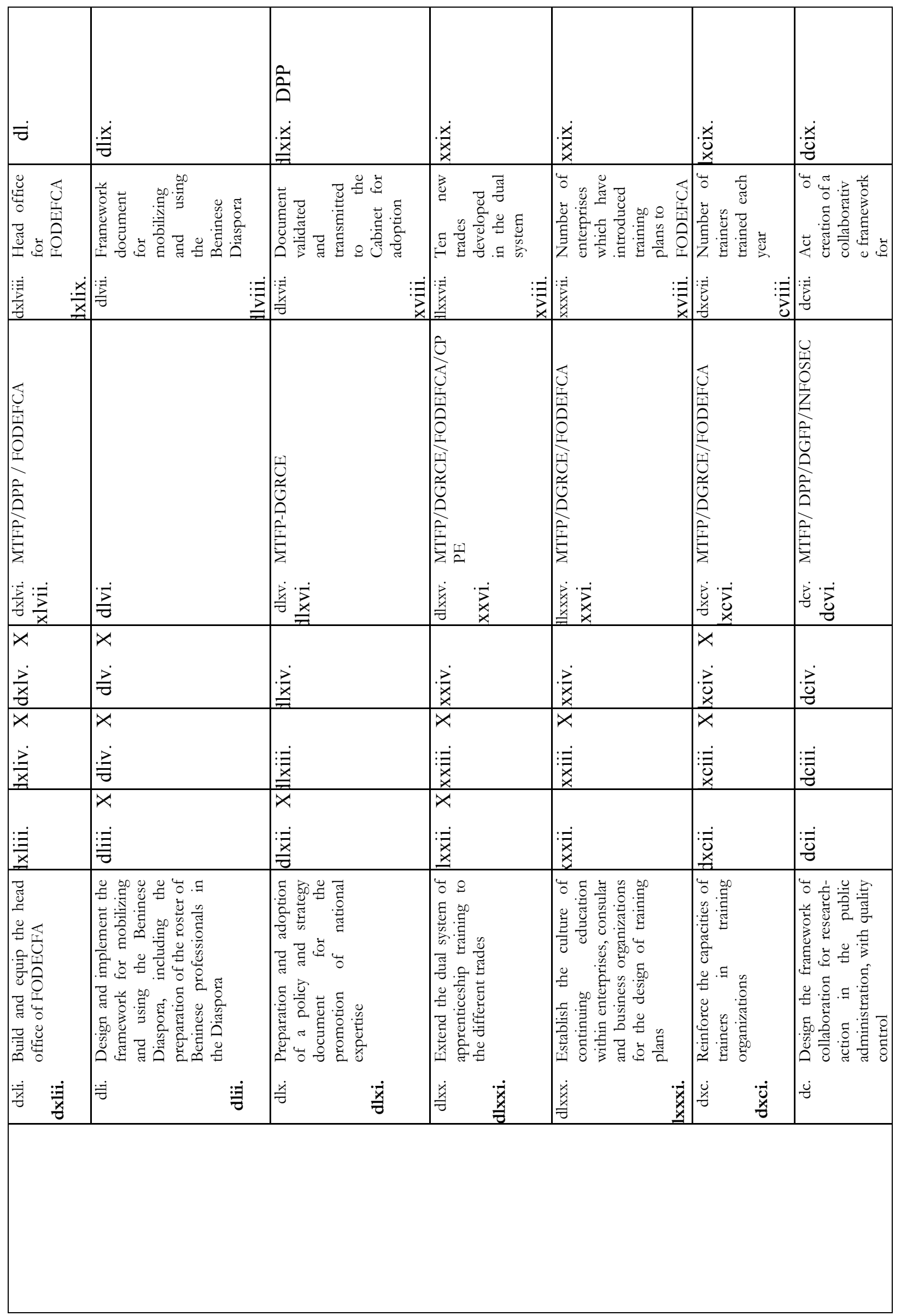


91

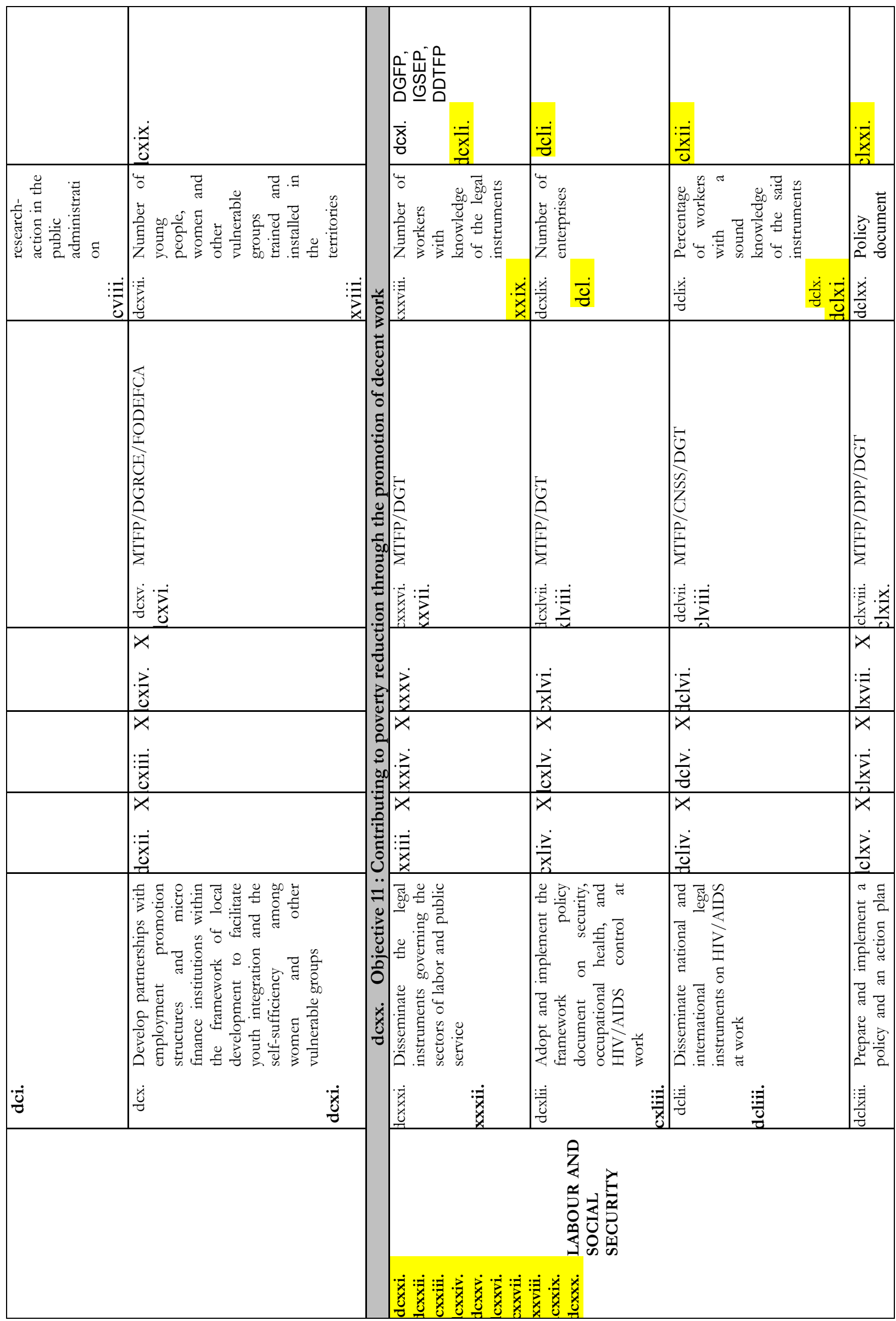


92

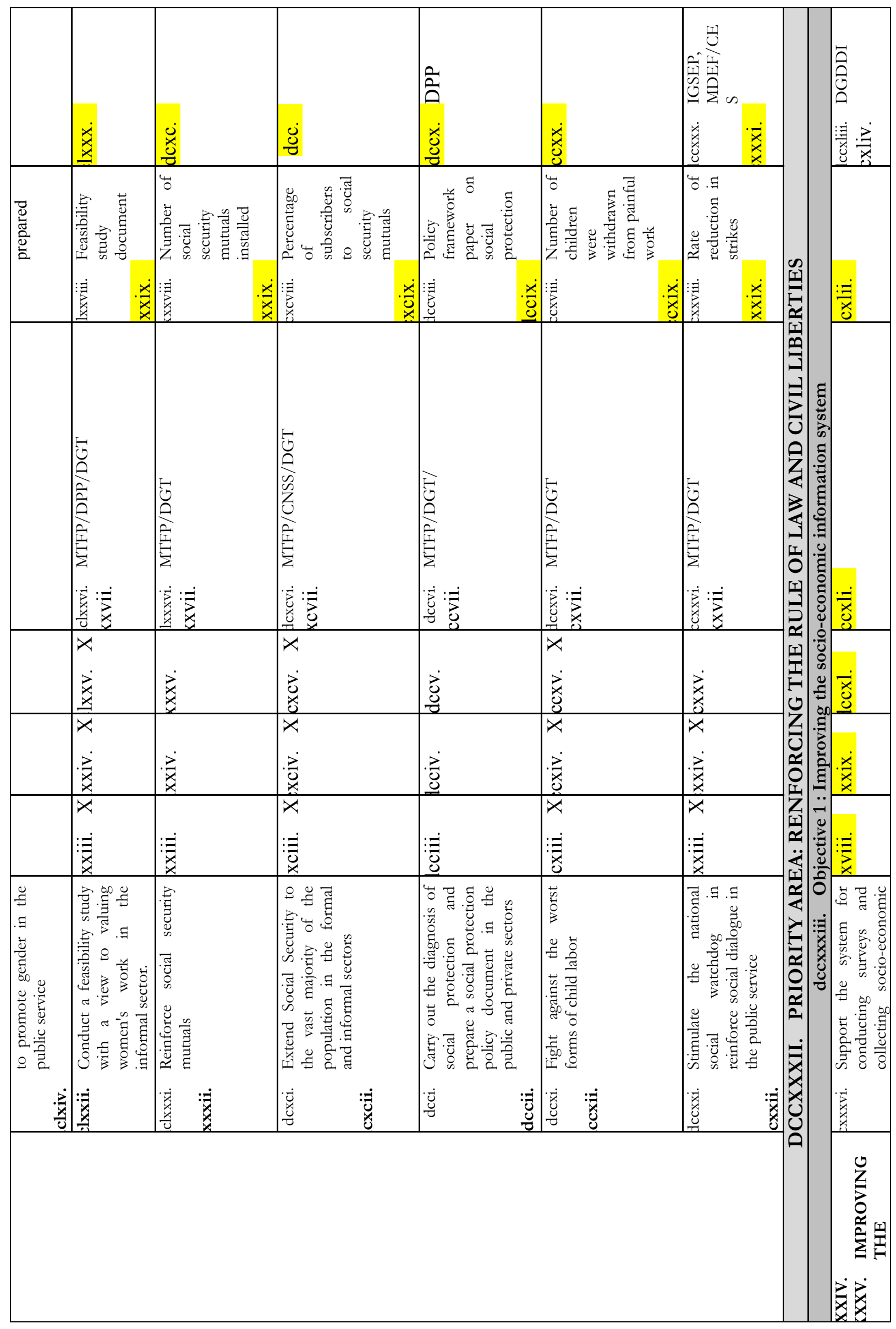


93

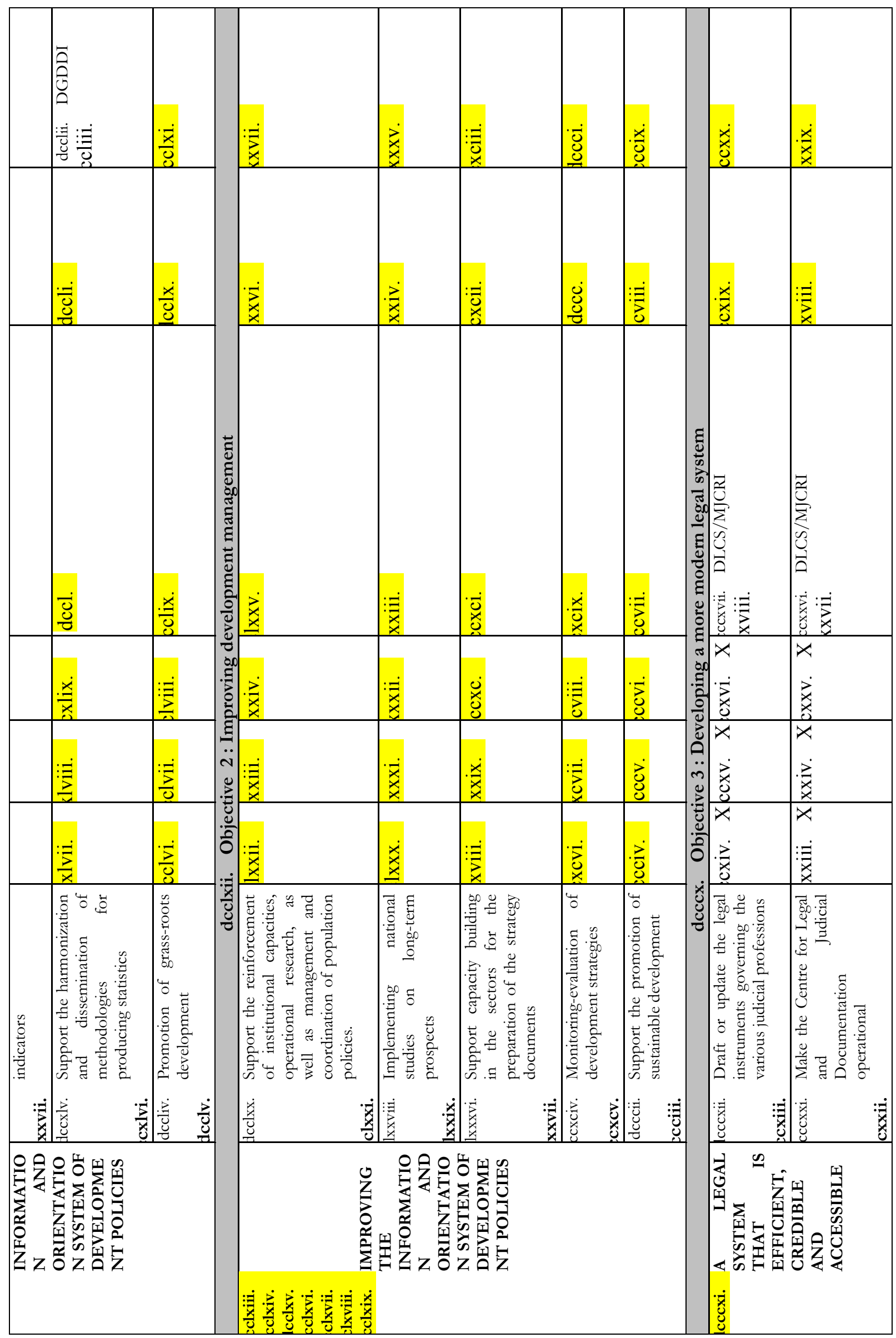




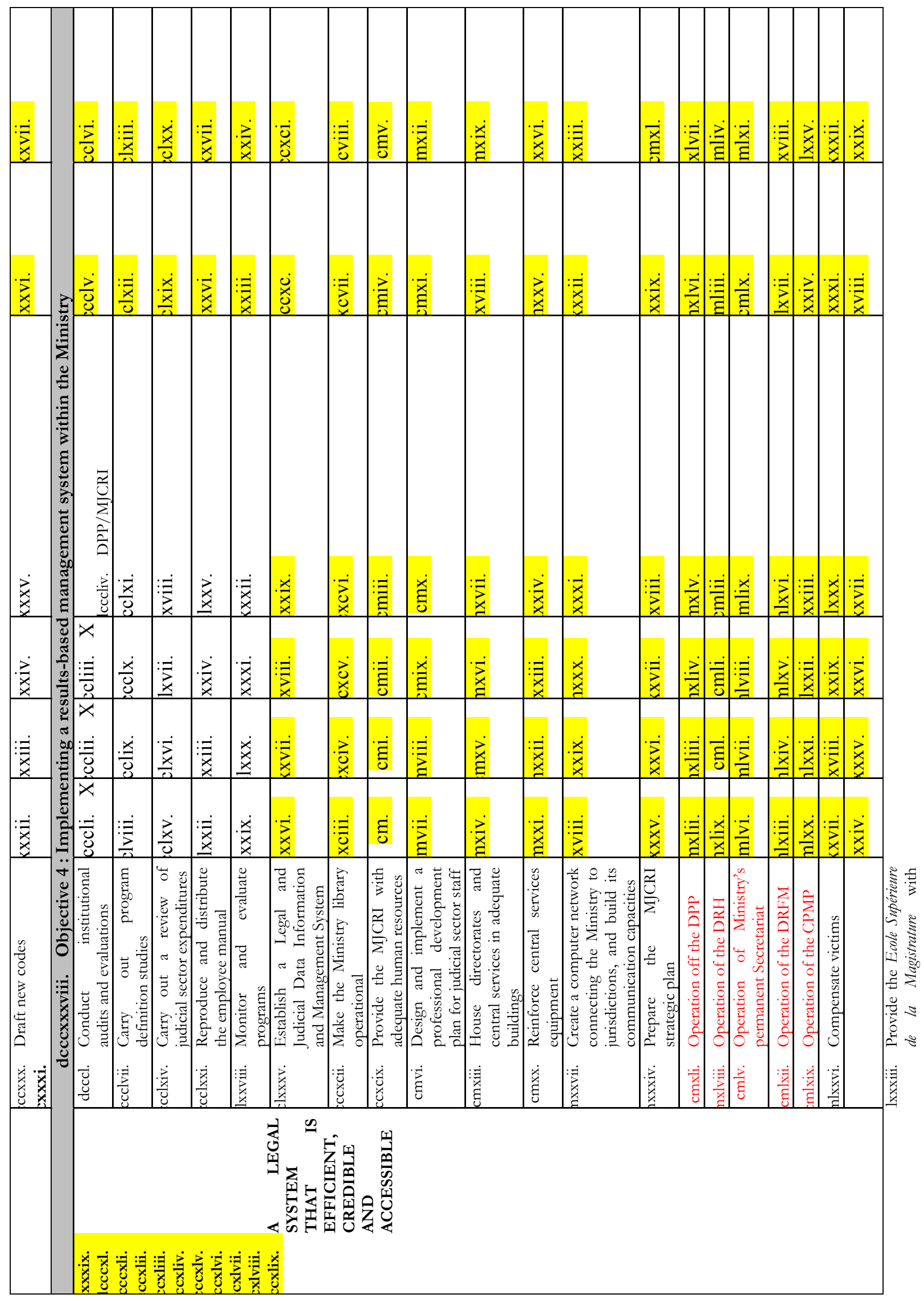




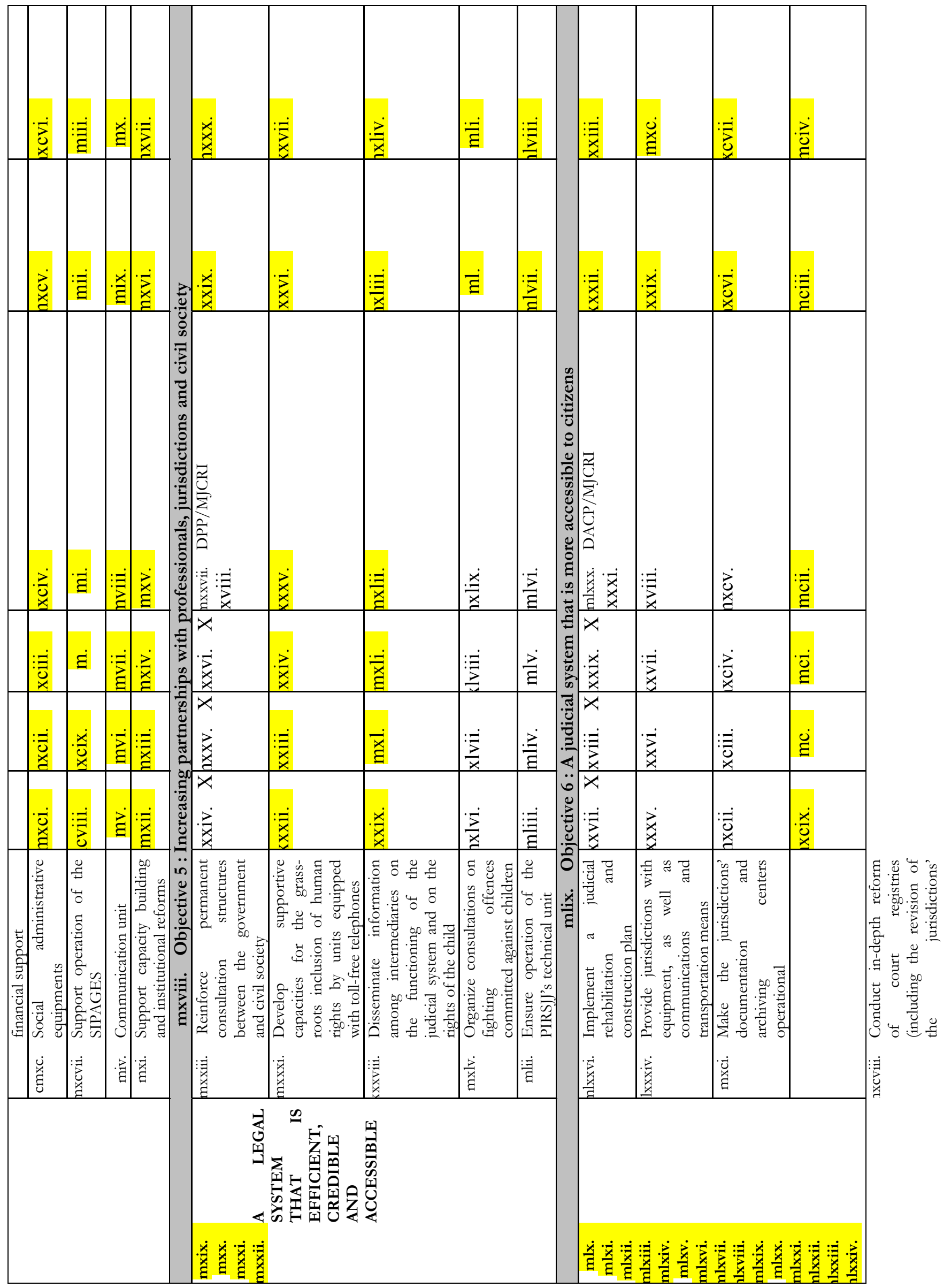




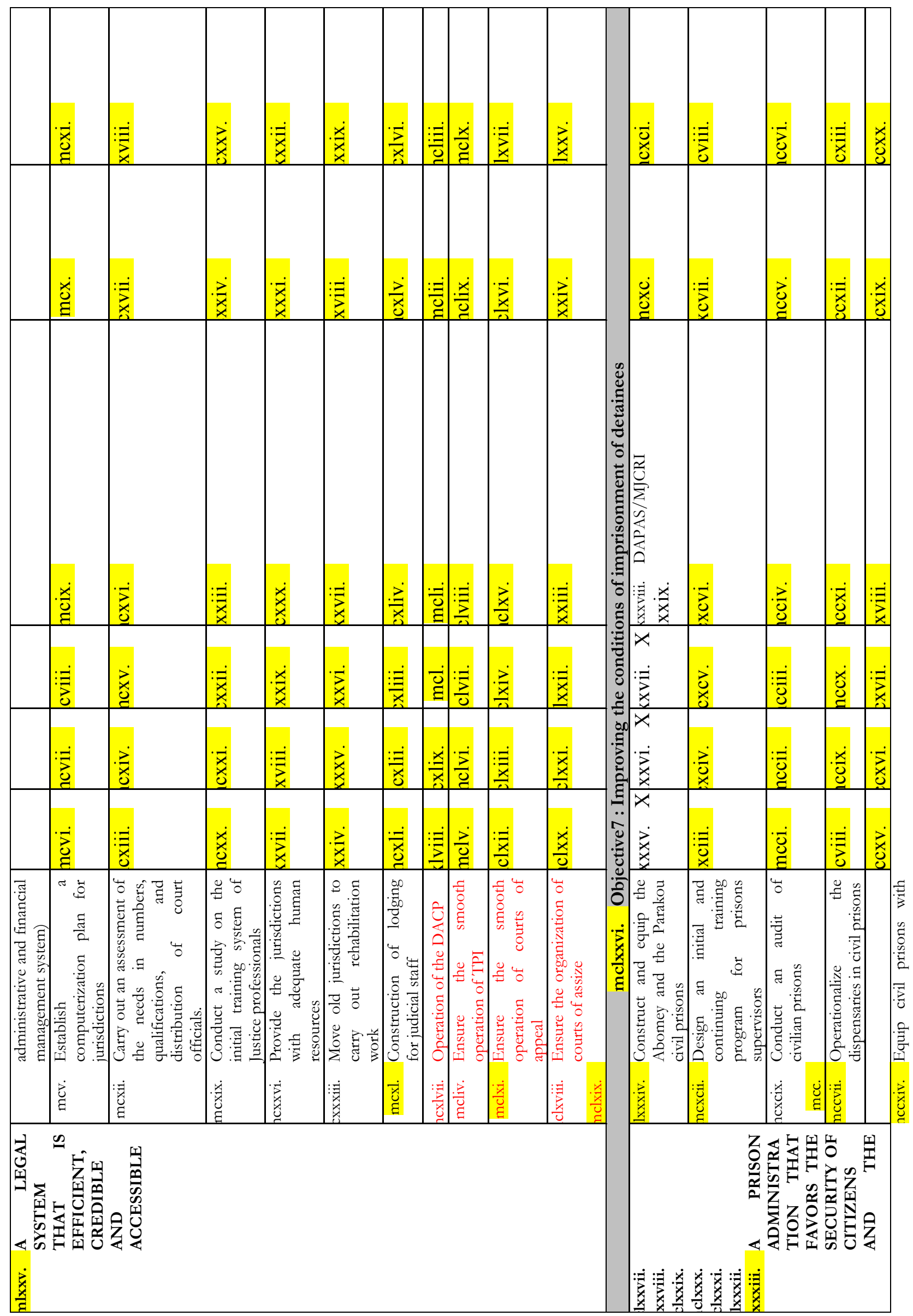




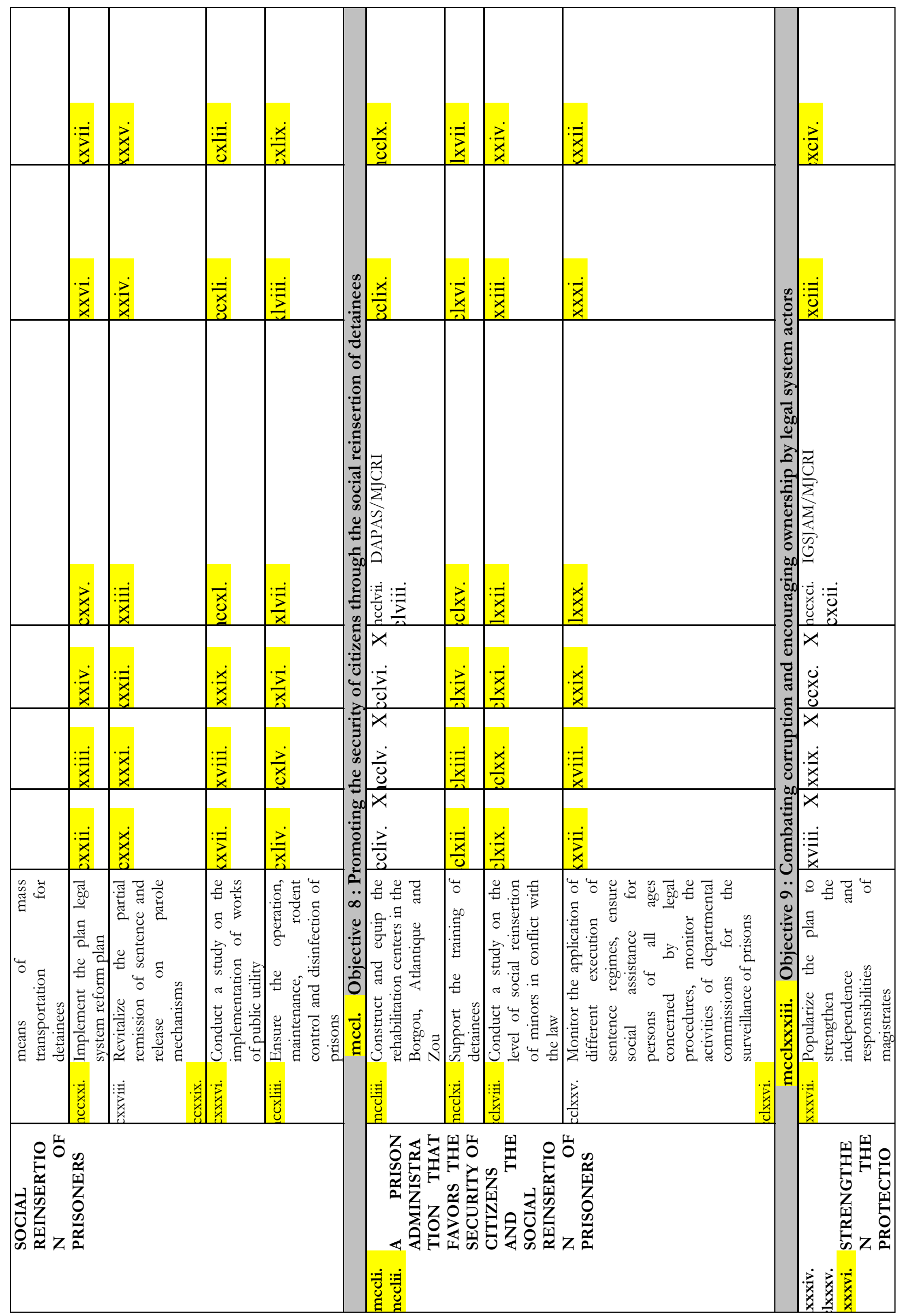




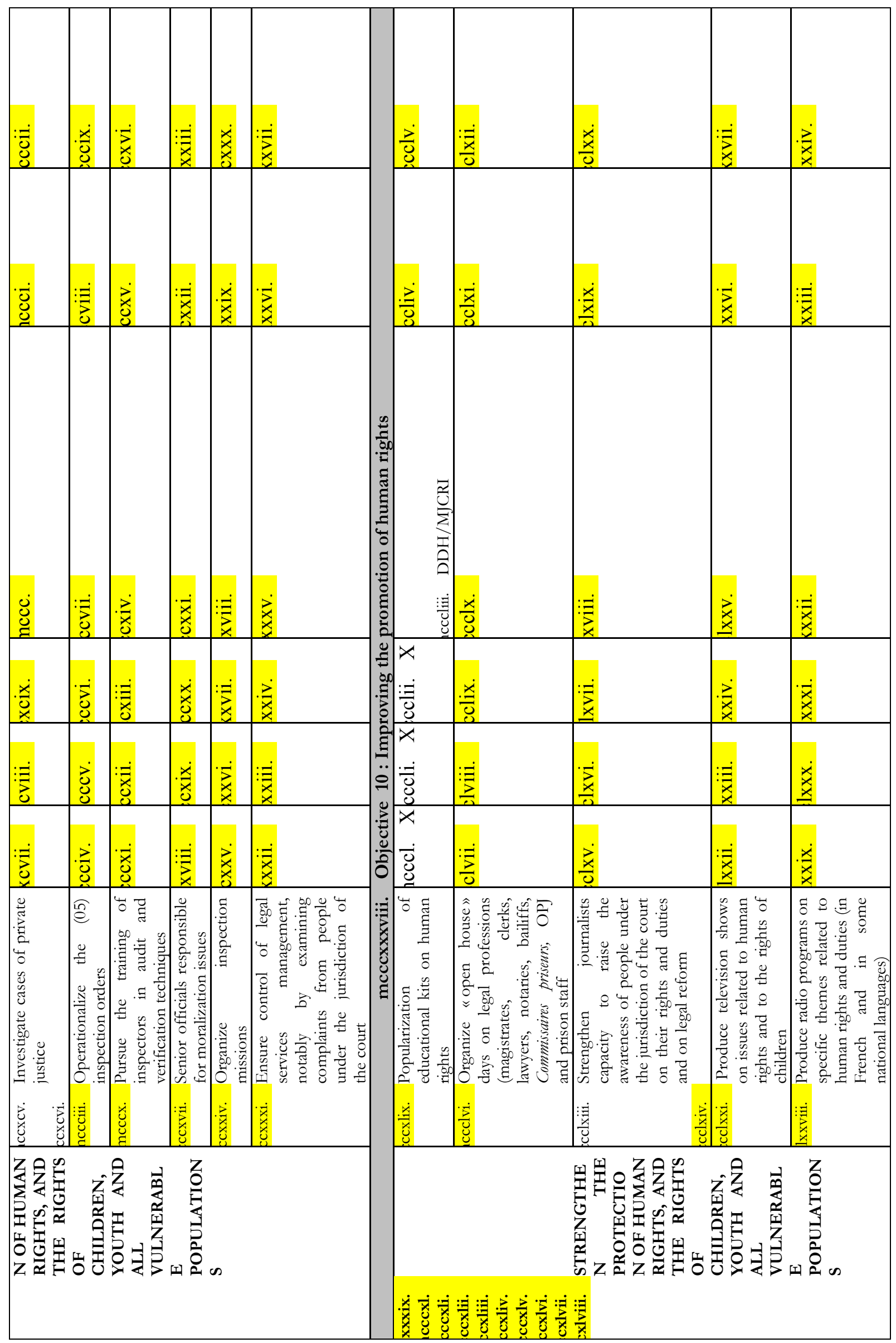




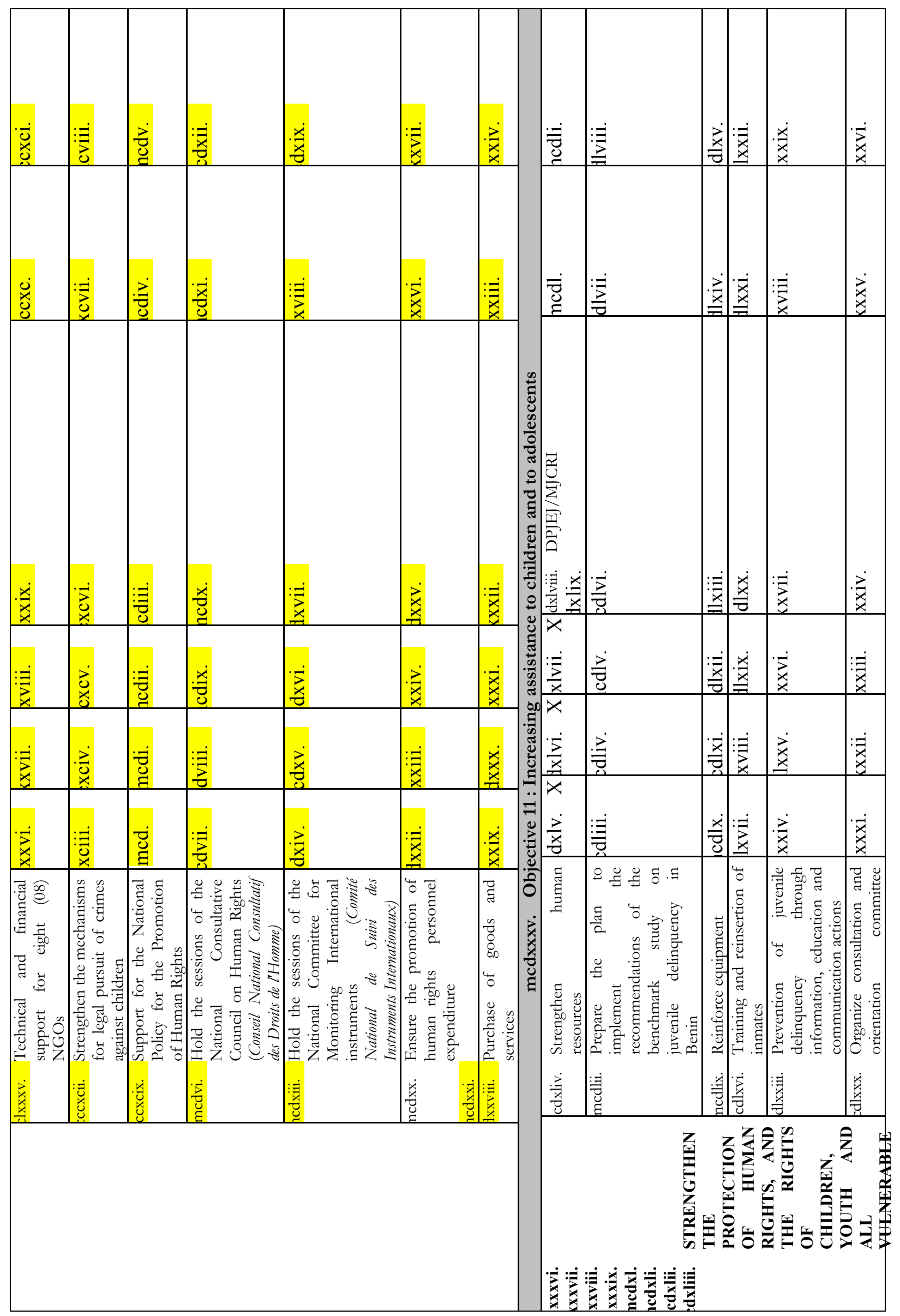




\begin{tabular}{|l|l|l|l|l|l|l|l|l|l|l|l|}
\hline & & & & & & & & \\
\\
\end{tabular}




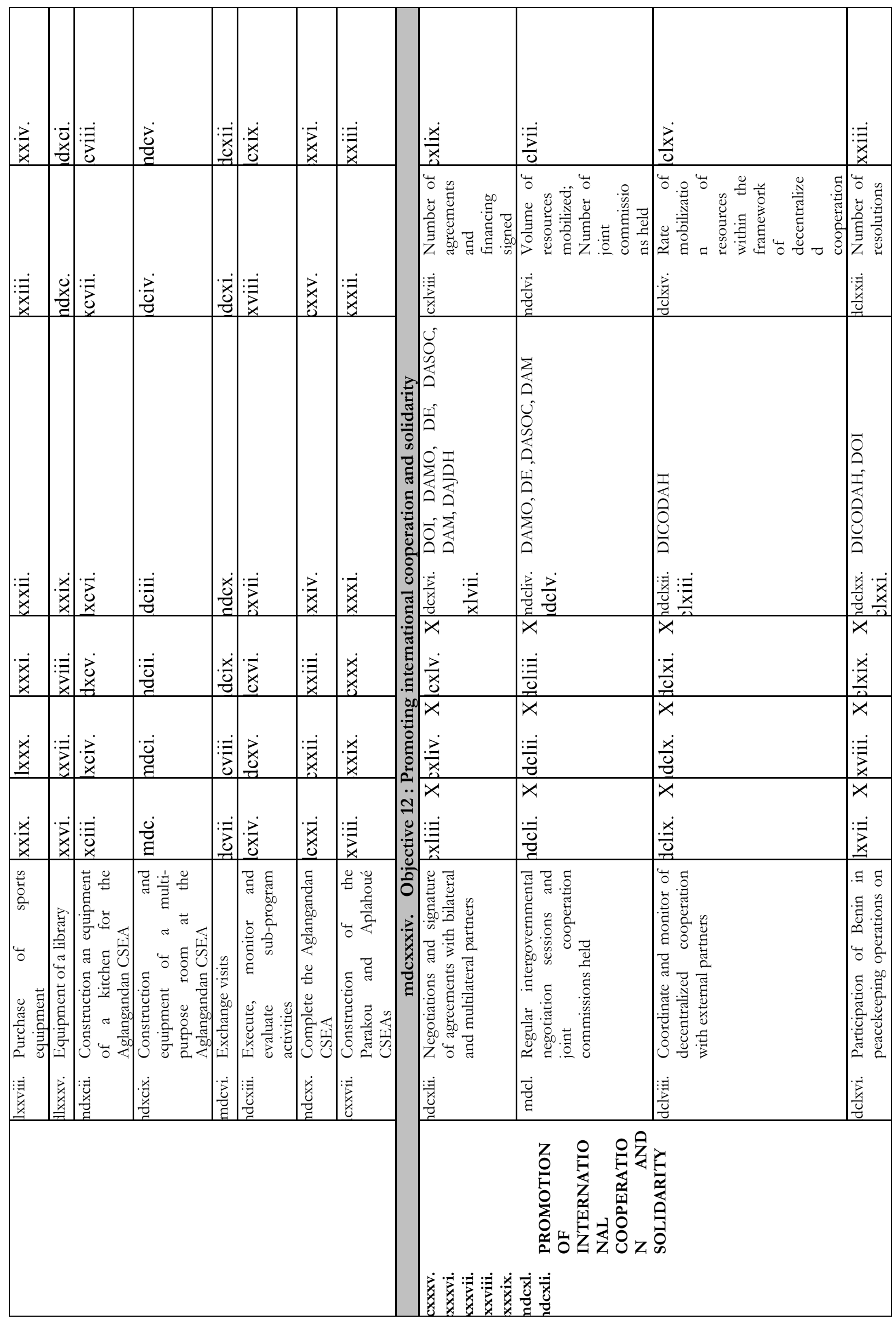


102

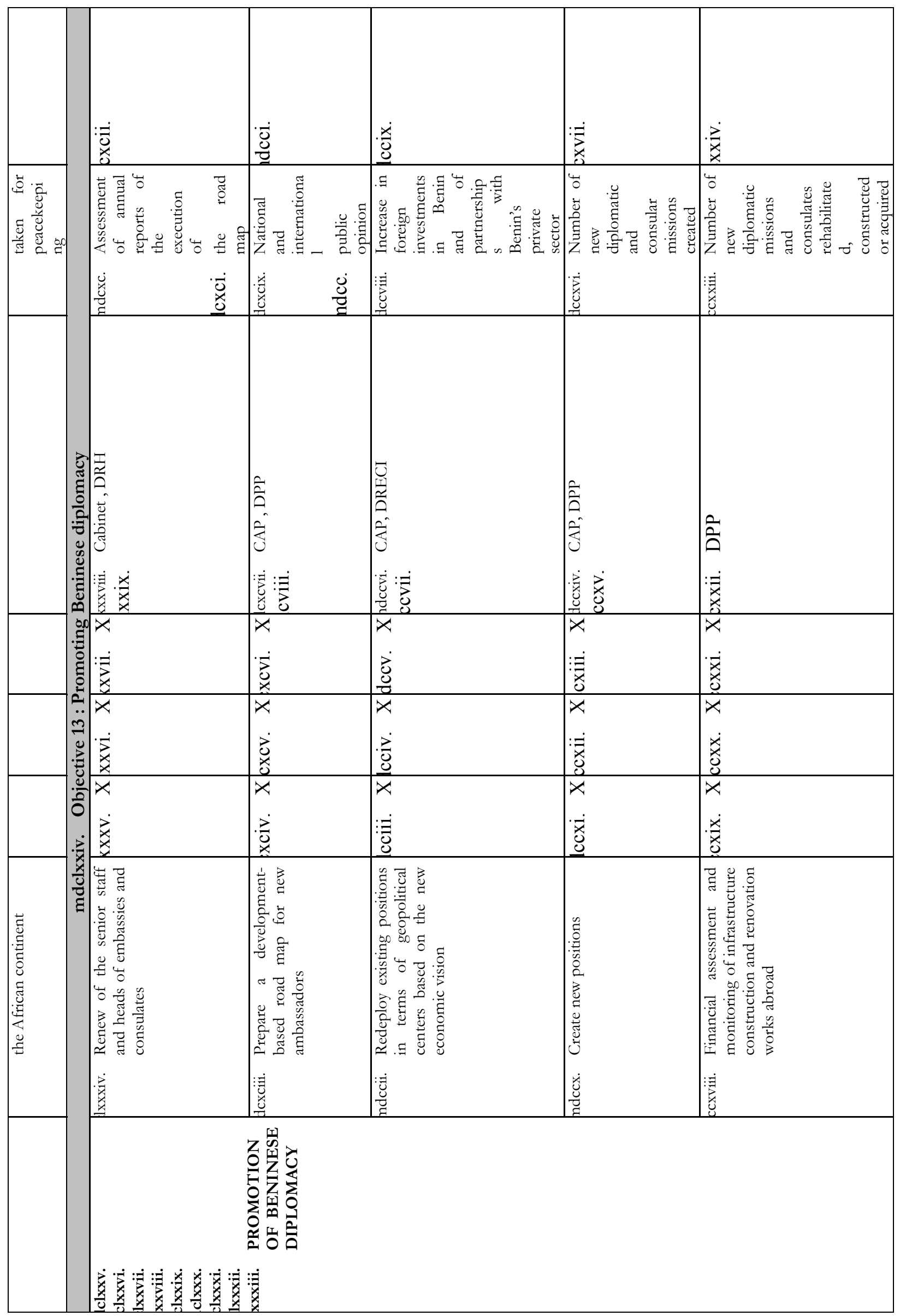


103

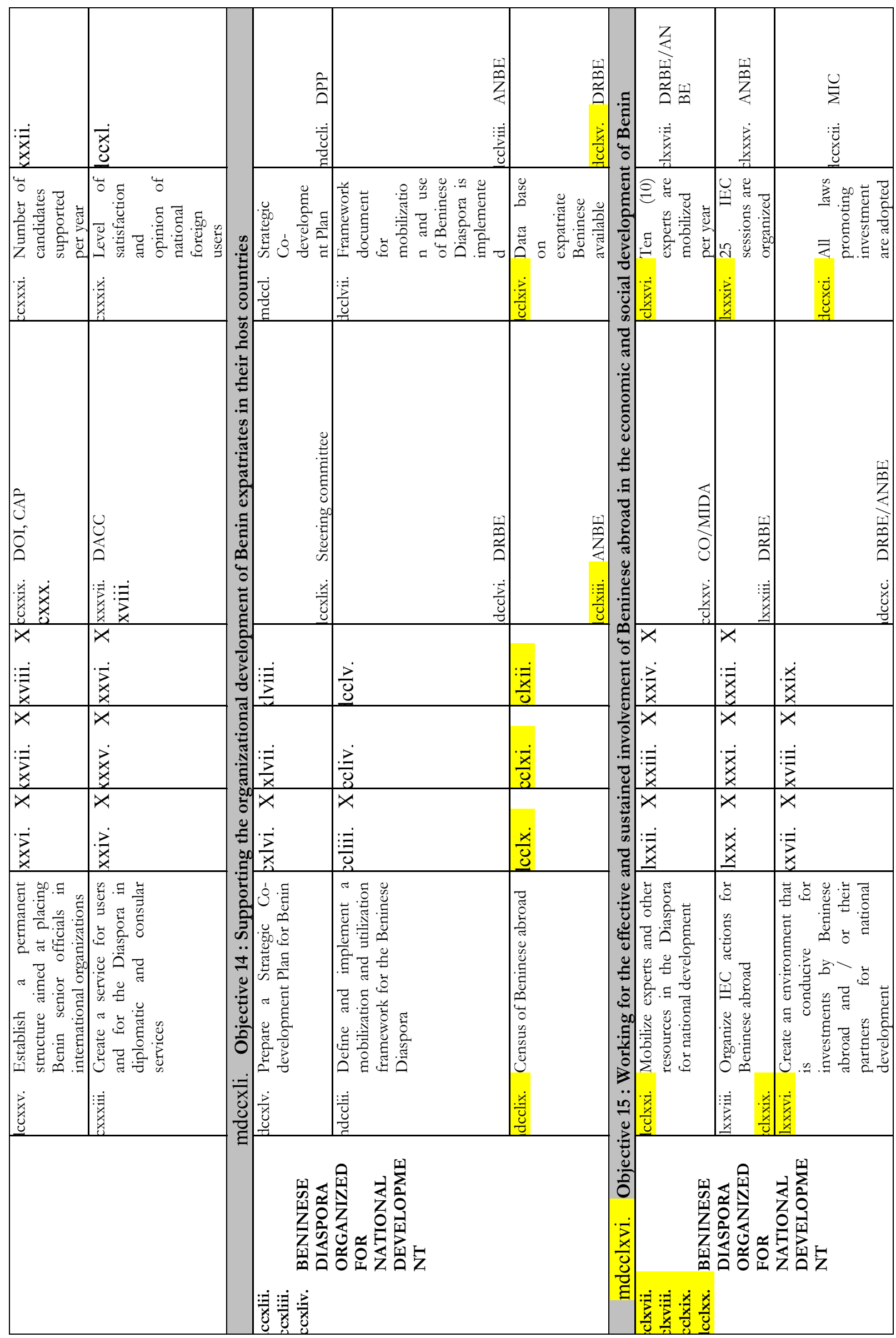


104

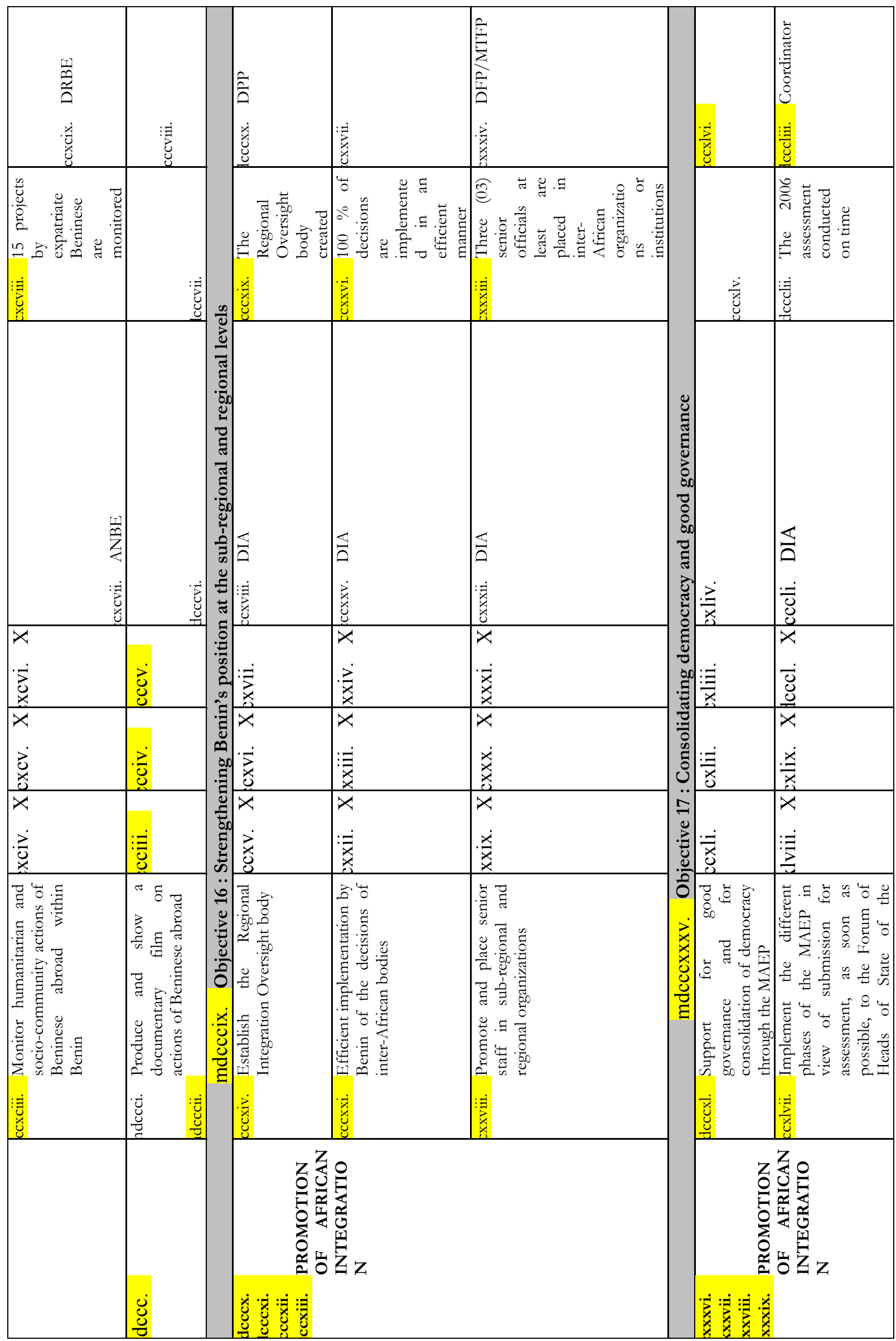




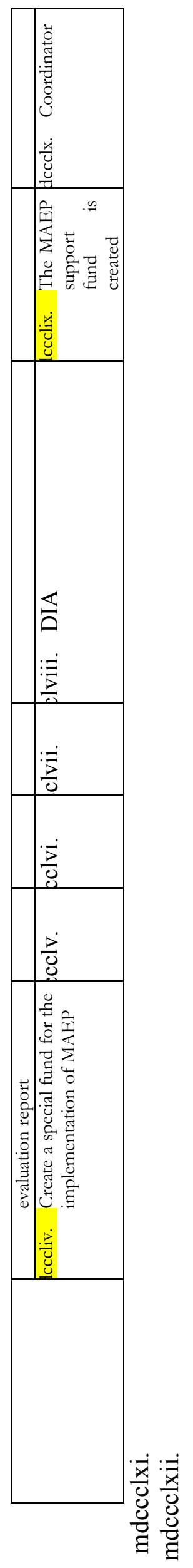




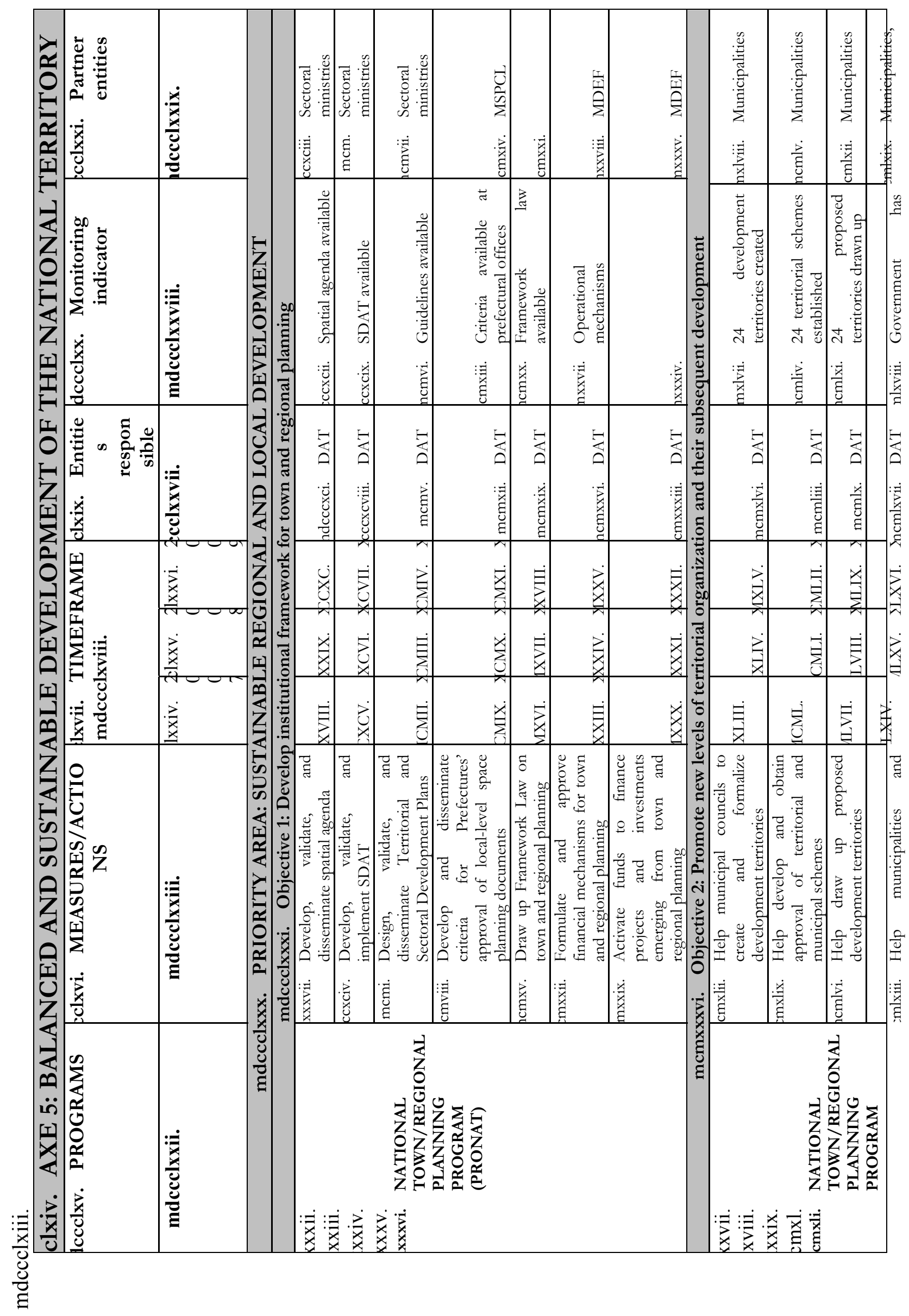




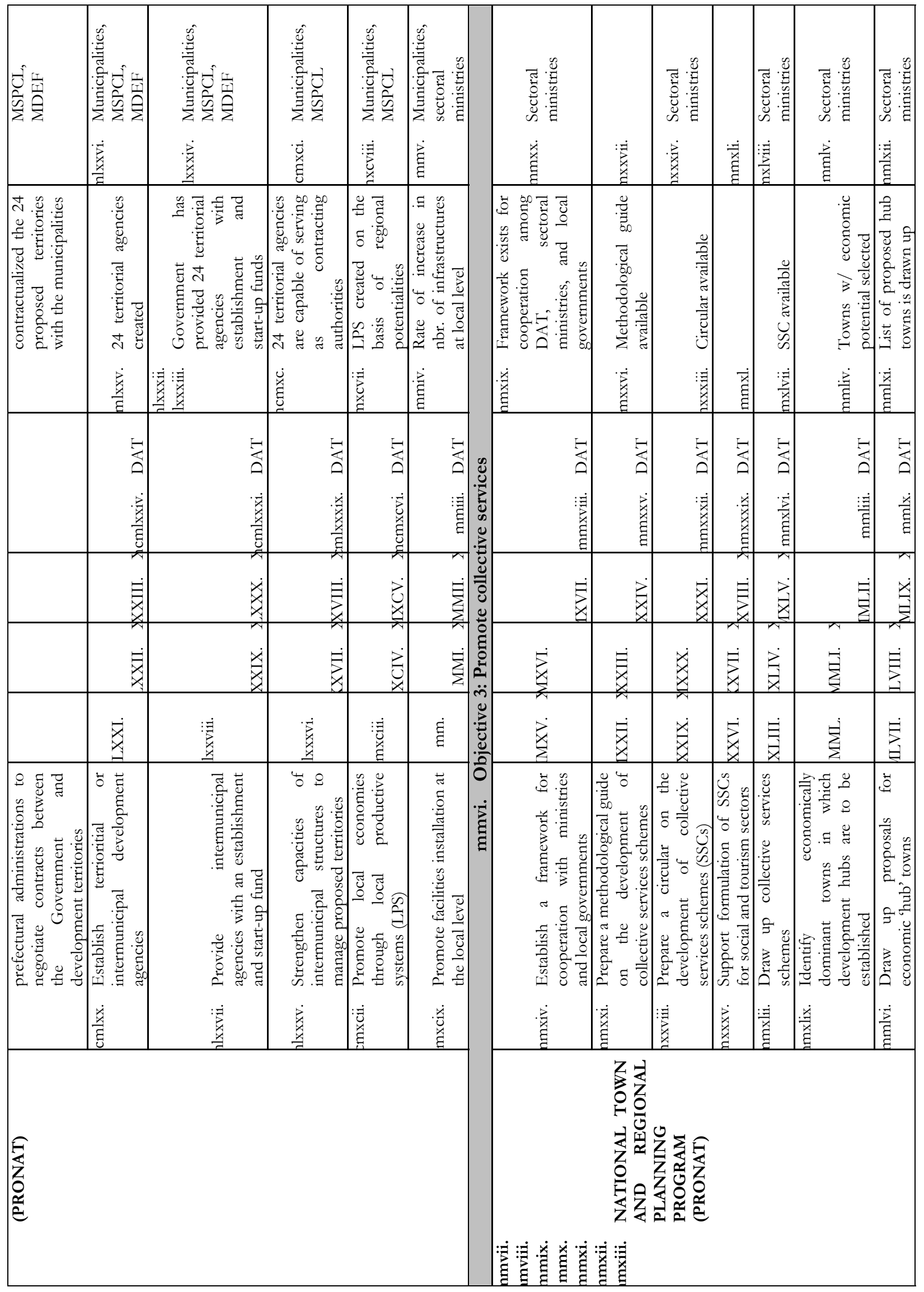




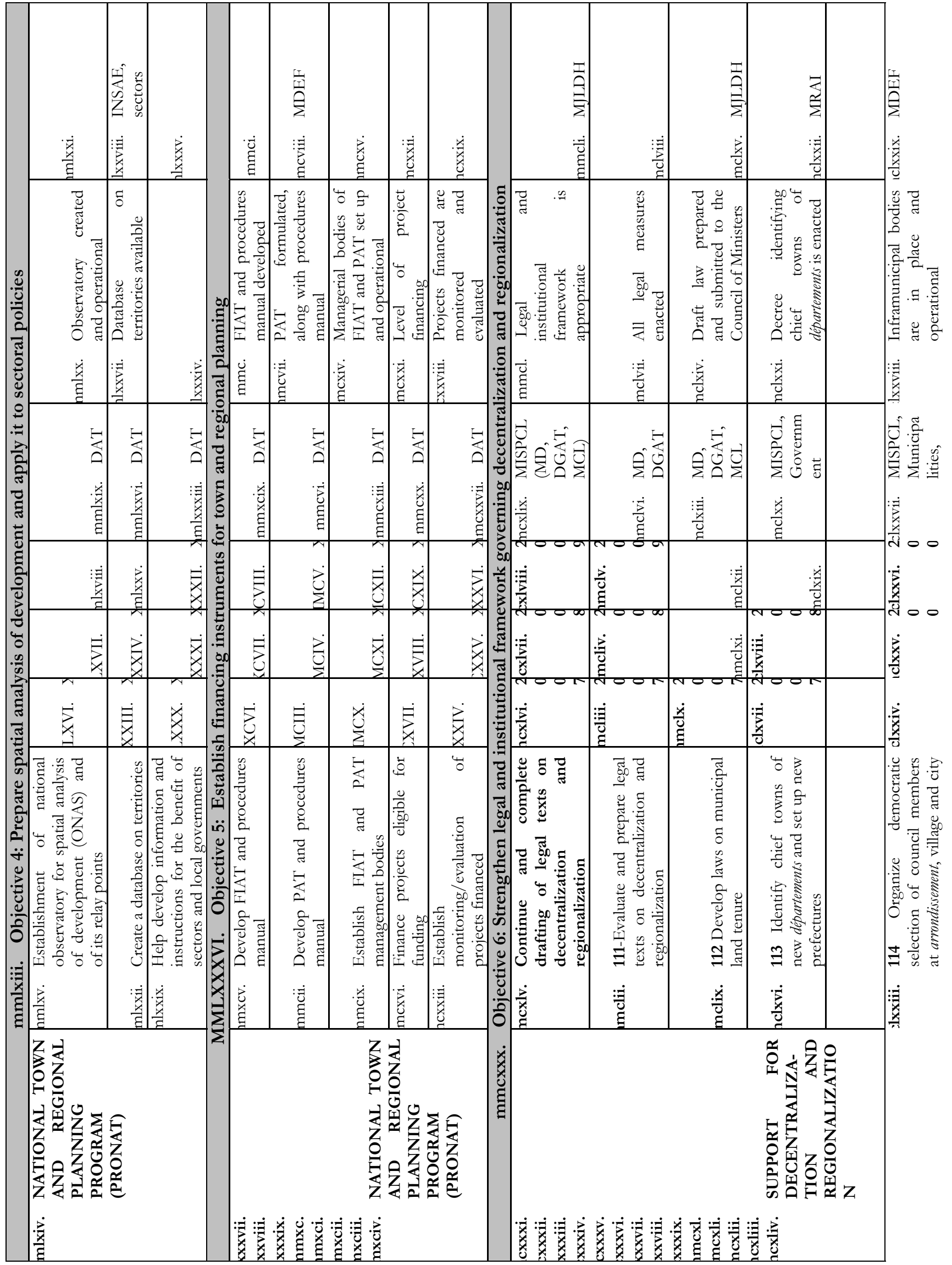




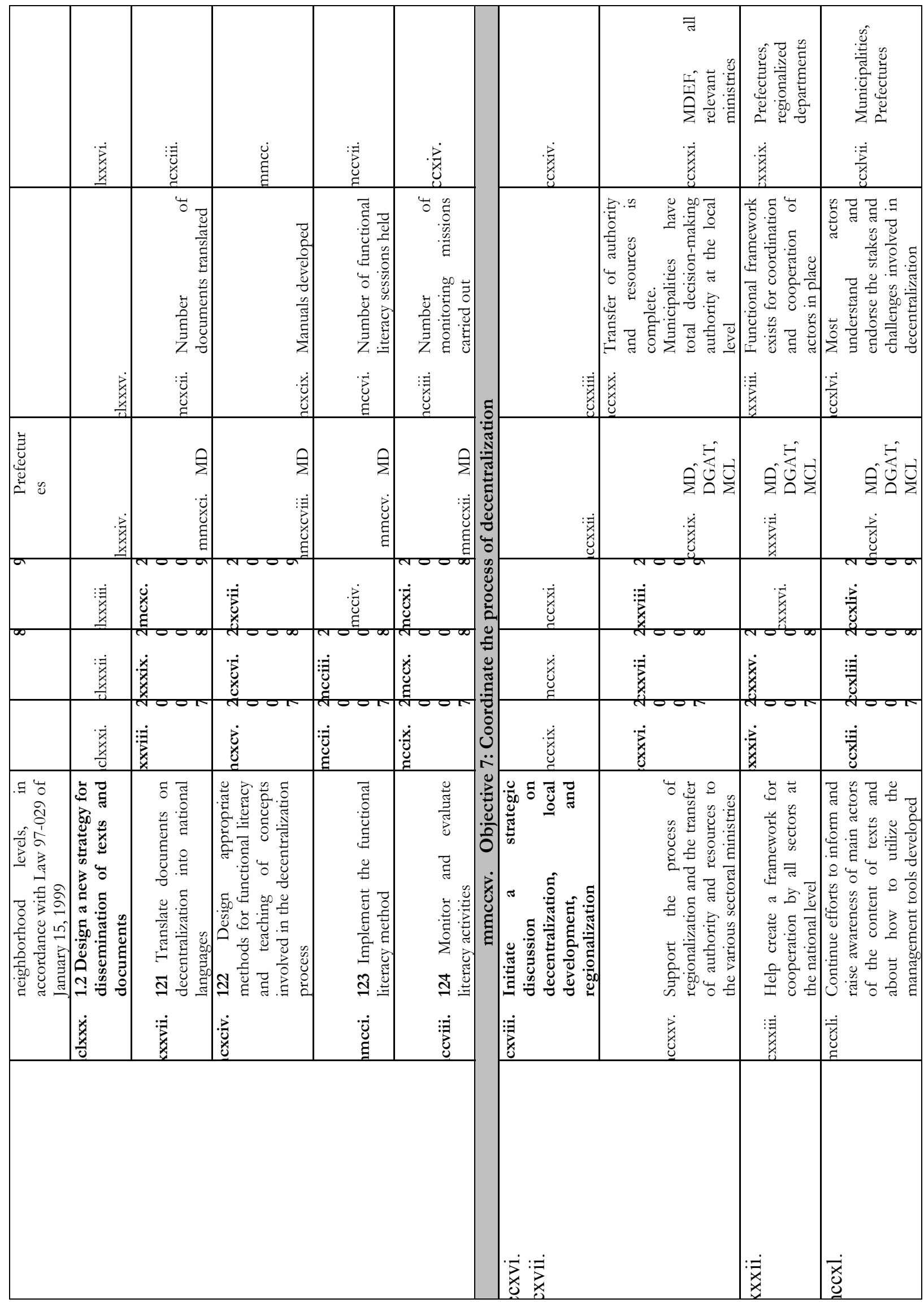




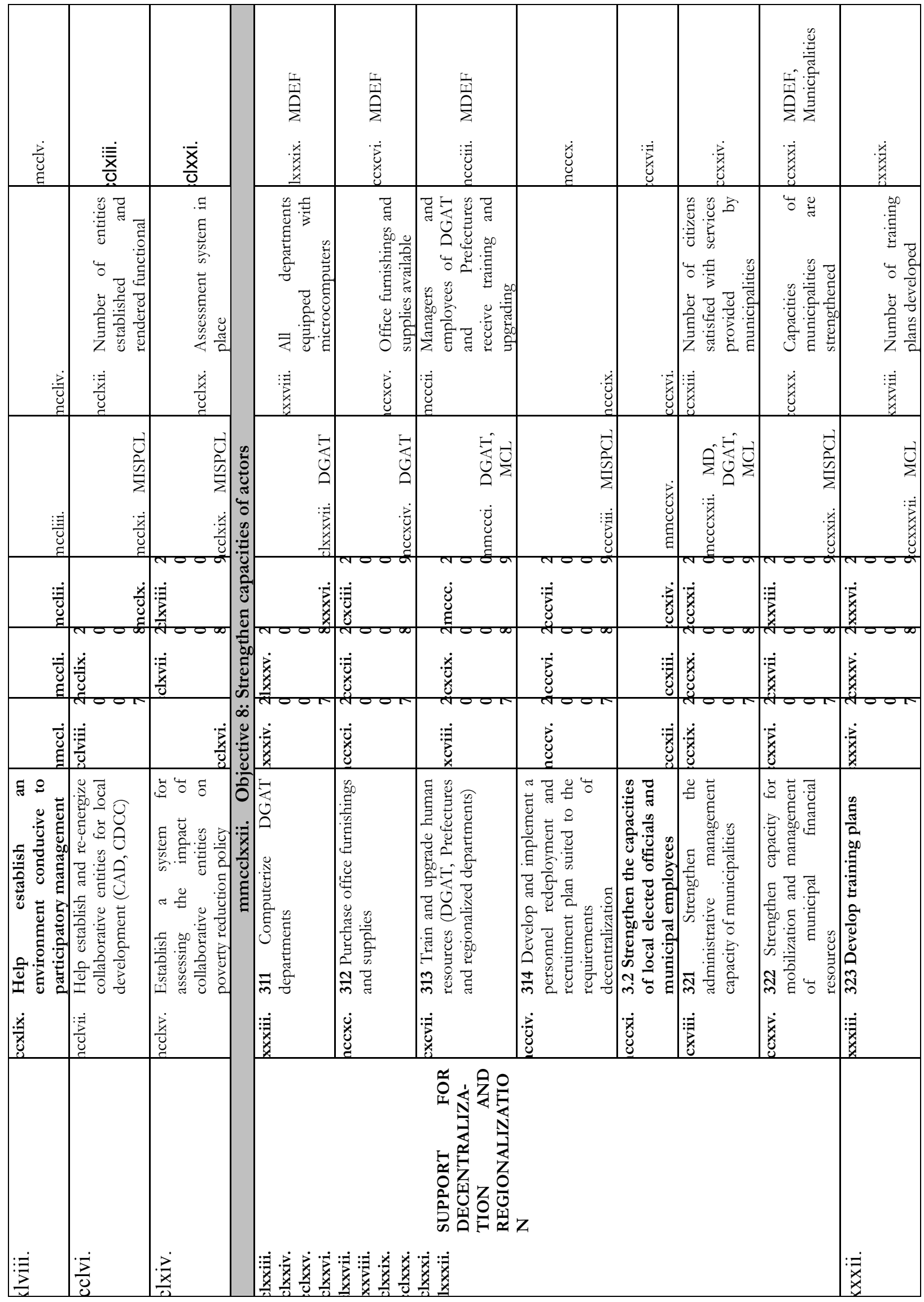




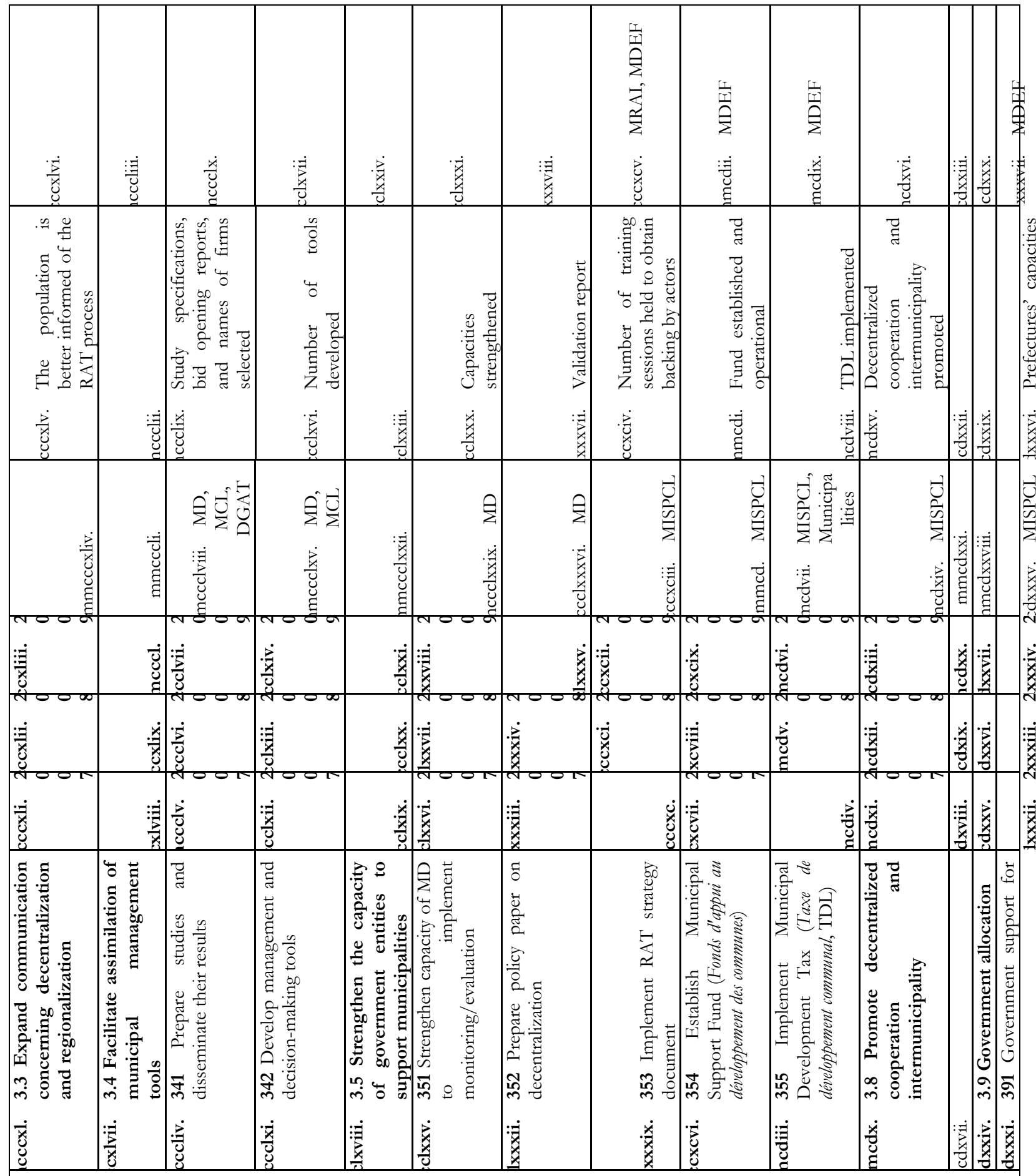




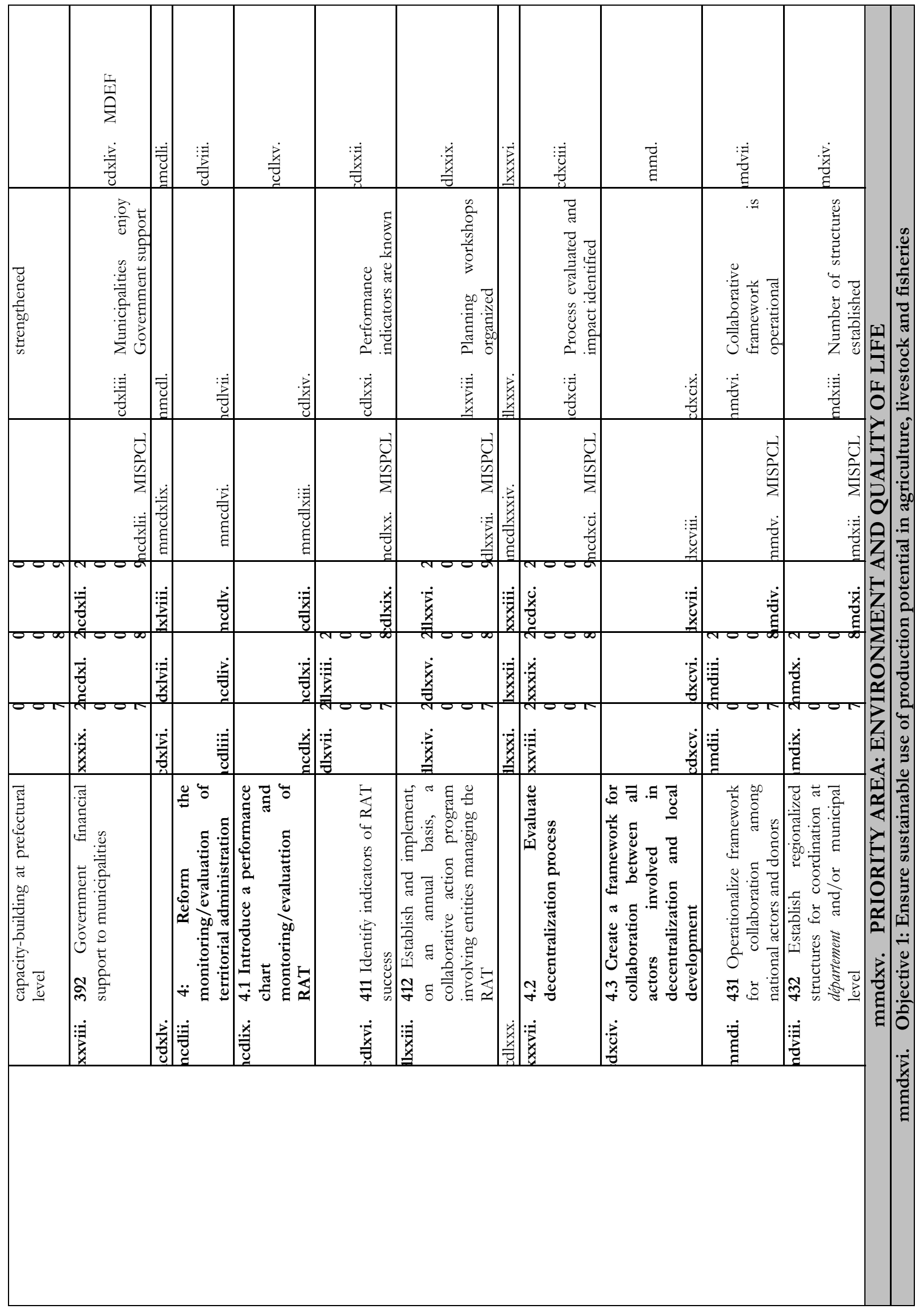




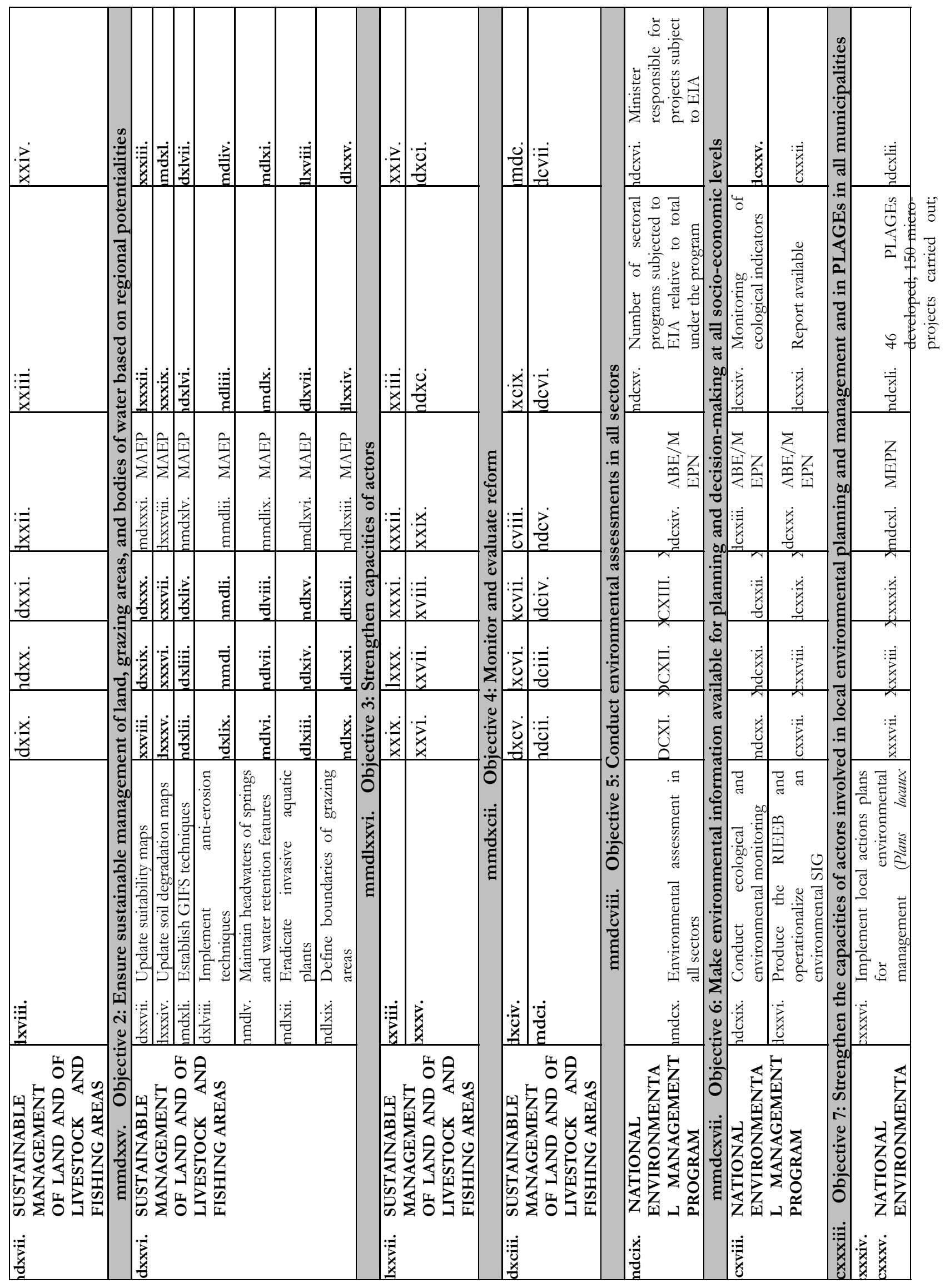




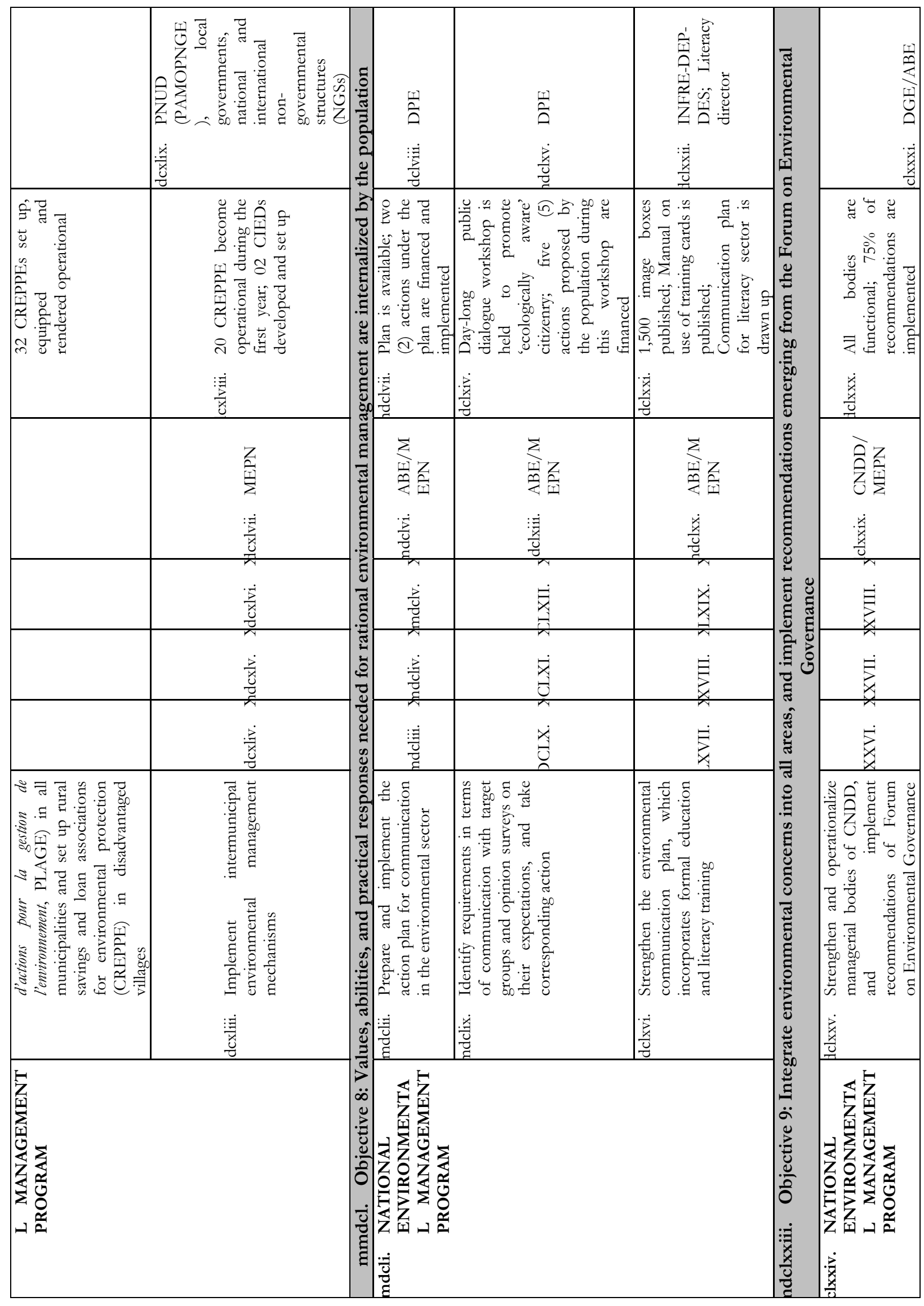




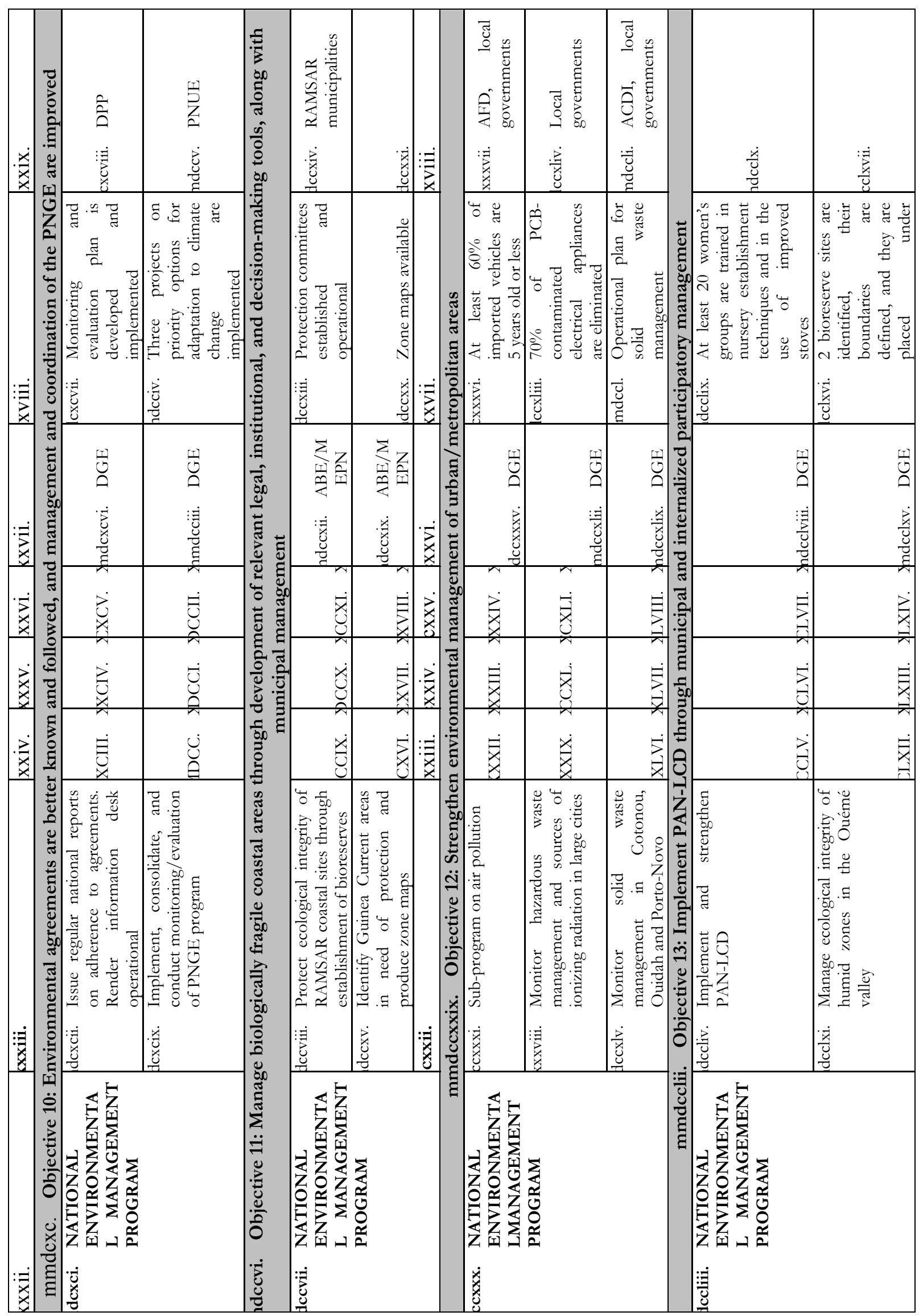




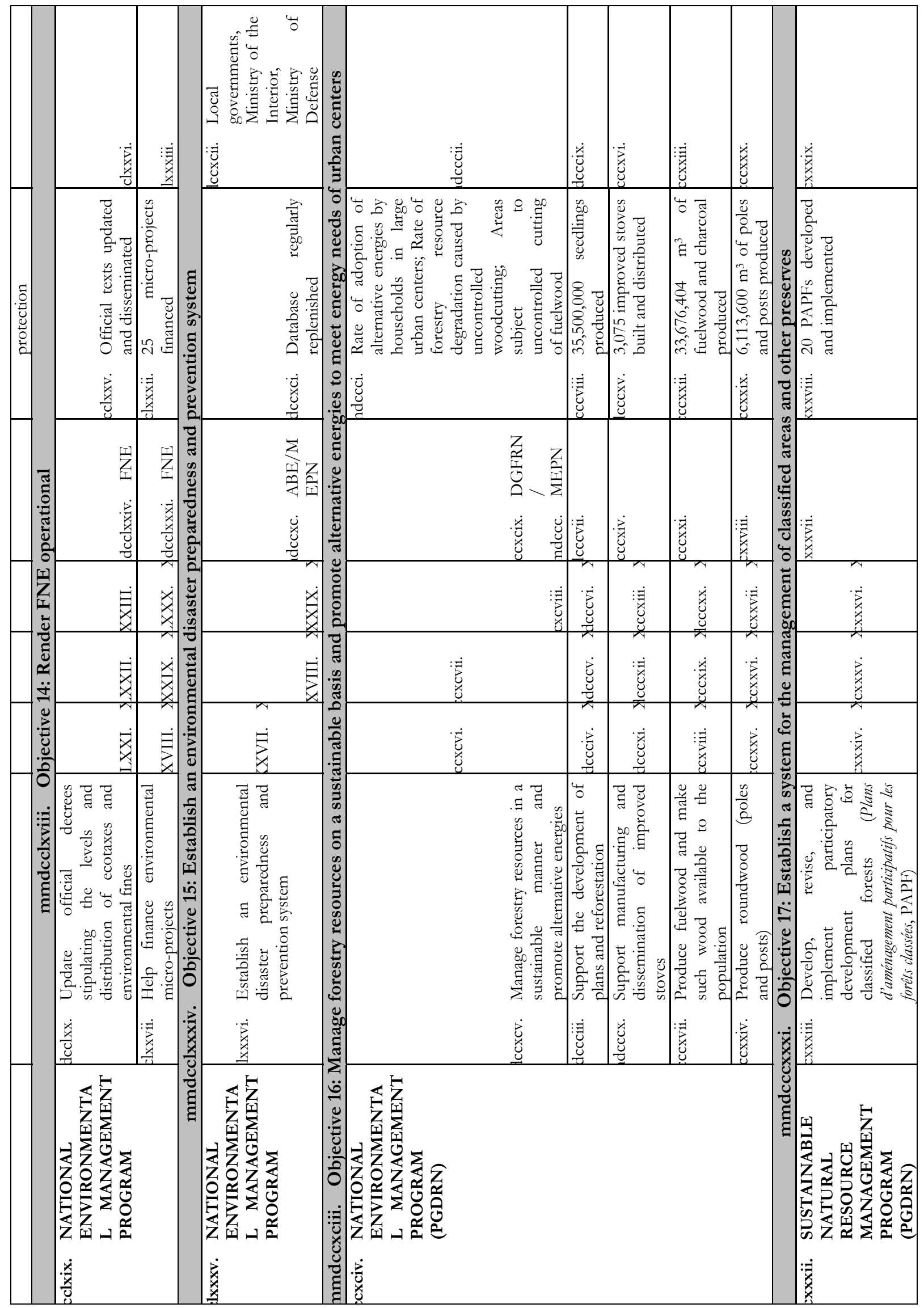




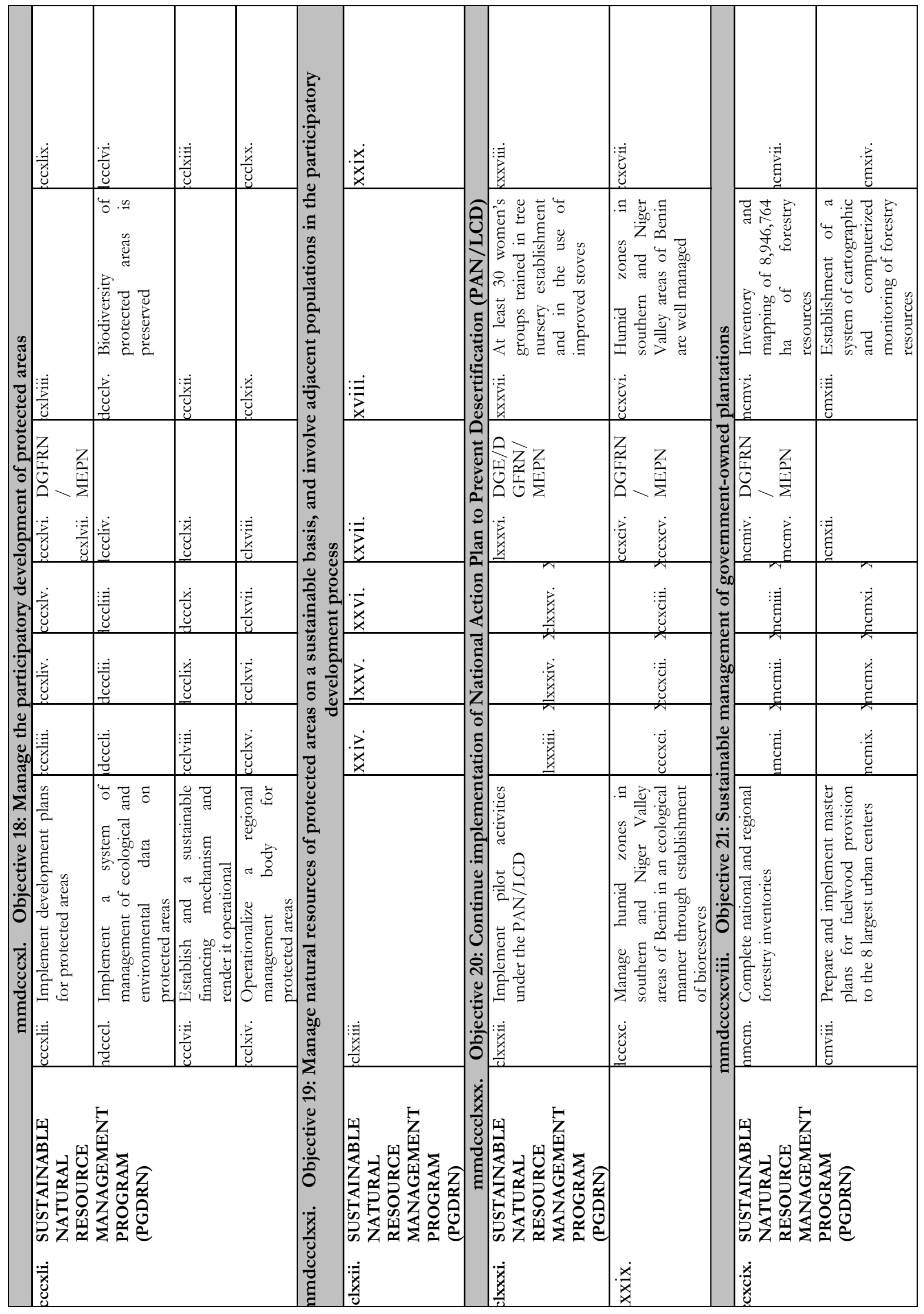




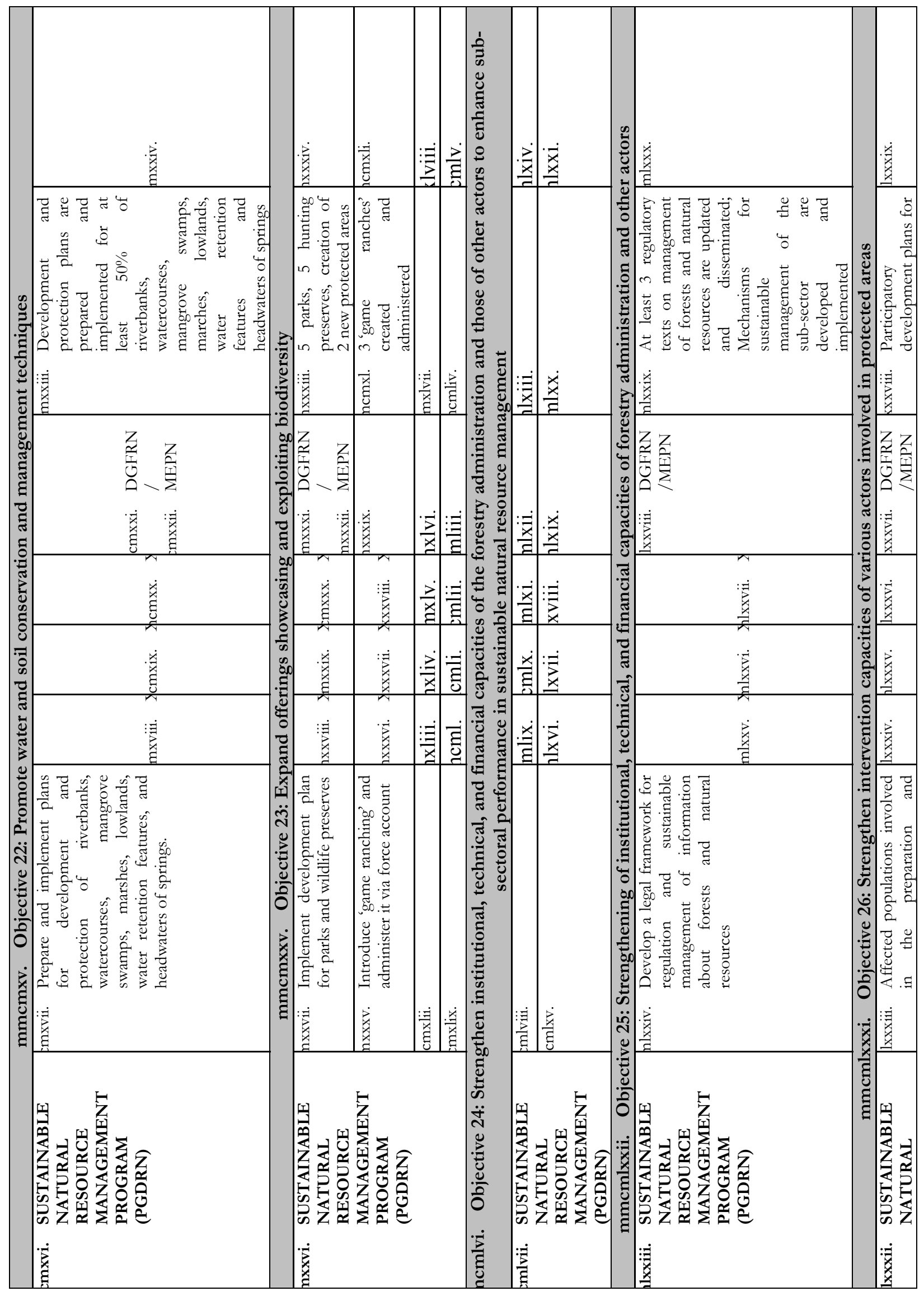




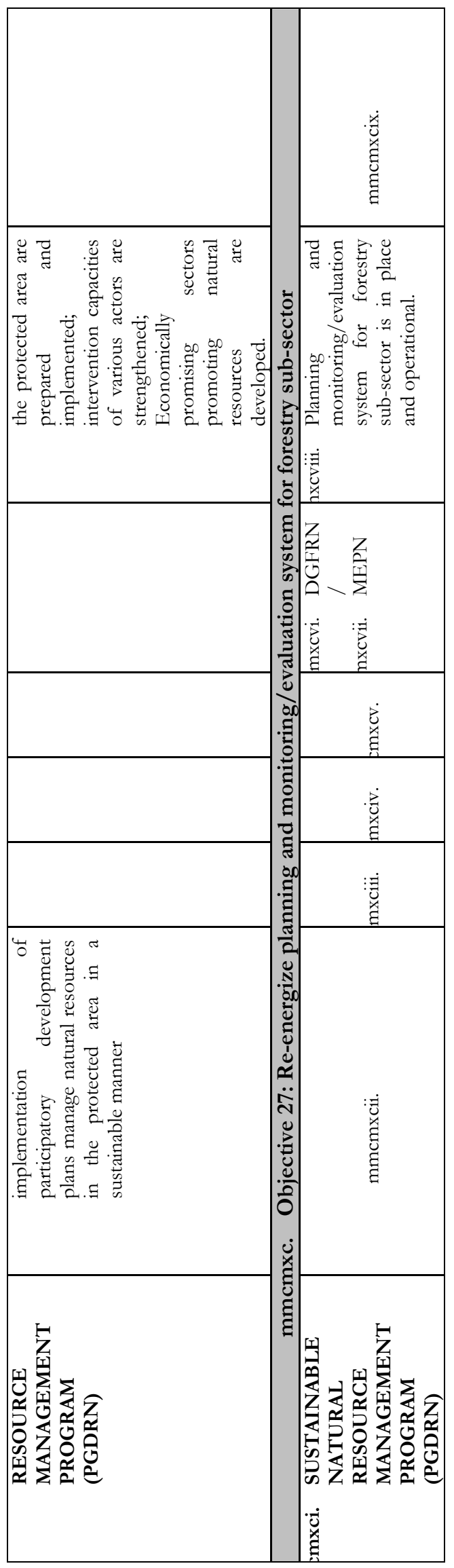

